\title{
Revision of the Neotropical treehopper genus Tolania (Hemiptera, Membracidae)
}

\author{
Jesse L Albertson \& Christopher H. Dietrich
}

Center for Biodiversity, Illinois Natural History Survey, 607 E. Peabody Dr., Champaign, IL 61820, USA. E-mail: dietrich@inhs.uiuc.edu

\begin{abstract}
The treehopper genus Tolania Stål (Hemiptera: Membracidae: Nicomiinae: Nicomiini) and 69 valid species (59 new) are described and illustrated based on adult morphology. Ten informal species groups are recognized based on a previously published phylogenetic analysis: (1) the dira species group comprising $T$. calista sp. nov., T. dira sp. nov., T. inca sp. nov., T. macaria sp. nov., T. secoya sp. nov, and $T$. zaparo sp. nov,; (2) the fasciata species group comprising $T$. fasciata (Walker), T. gracilis sp. nov., and T. laticlava sp. nov.; (3) the femoralis species group comprising T. femoralis Stål, T. fraterna Stål, and $T$. roberti sp. nov.; (4) the furcata species group comprising $T$. furcata sp. nov., T. tryphena sp. nov., and $T$. venezuelensis sp. nov.; (5) the hispida species group comprising $T$. alida sp. nov., T. hispida sp. nov., and T. periculosa sp. nov.; (6) the malefica species group comprising $T$. cactina sp. nov., T. curvata sp. nov., T. grallator sp. nov., T. jocosa sp. nov., T. mackameyi sp. nov., T. malefica sp. nov., T. obliqua (Walker), and T. terencia sp. nov.; (7) the obtusa species group comprising $T$. obtusa Fowler, $T$. obunca sp. nov., and T. torosa sp. nov.; (8) the opponens species group comprising T. alvira sp. nov., T. arcuata sp. nov., T. damia sp. nov., T. insolita sp. nov., T. lunata sp. nov., T. Iurida sp. nov., T. opponens (Walker), T. oriana sp. nov., T. reflexa sp. nov., T. risa sp. nov., T. sinuata sp. nov., T. trilobata sp. nov., T. tumida sp. nov., T. umbella sp. nov., T. vitocensis sp. nov., T. woodi sp. nov., and

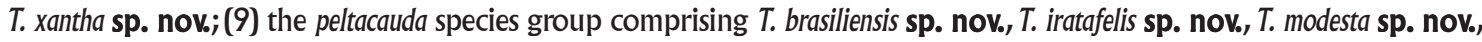
T. peltacauda sp. nov., T. picta sp. nov., and $T$. thyrea sp. nov.; and (10) the semipellucida species group comprising $T$. atrata sp. nov., $T$. fimbriata sp. nov., $T$. nicia sp. nov., and $T$. semipellucida Stål. The following new species are not placed in species groups: T. anomala sp. nov., T. corcula sp. nov, T. hamulata sp. nov, T. histria sp. nov., T. inornata sp. nov., T. laticornis sp. nov., T. melantha sp. nov., T. pogonia sp. nov., T. rideri sp. nov., and T. taura sp. nov. A key to the species groups and unplaced species is provided for Tolania males. The following species, previously placed in Tolania, are considered species incertae sedis: Cicada armata Stoll; Centrotus felinus Germar; Centrotus obscurus Germar; Centrotus fasciatus Walker. One new synonymy is proposed: Tolania humilis (Walker, 1858) = Tolania scutata Stål, 1862 syn. nov. Tolania cristata Lethierry sp. rev., is reinstated from synonymy with $T$. femoralis. Lectotypes are designated for $T$. cristata, $T$. femoralis, $T$. fraterna, and $T$. scutata. KEY WORDS. Biogeography; Homoptera; identification; morphology; taxonomy.
\end{abstract}

RESUMO. O gênero de soldadinhos Tolania Stål (Hemiptera, Membracidae, Nicomiinae, Nicomiini) e 69 espécies válidas (59 novas espécies) são descritos e ilustrados baseado na morfologia de adultos. Dez grupos informais de espécies são reconhecidos baseados em uma análise filogenética previamente publicada: (1) o grupo de espécies dira inclui $T$. calista sp. nov, T. dira sp. nov, T. inca sp. nov., T. macaria sp. nov., T. secoya sp. nov. e T. zaparo sp. nov; (2) grupo fasciata inclui T. fasciata (Walker), T. gracilis sp. nov. e T. laticlava sp. nov.; (3) grupo femoralis inclui T. femoralis Stål, T. fraterna Stål e T. roberti sp. nov.; (4) grupo furcata inclui $T$. furcata sp. nov., T. tryphena sp. nov. e T. venezuelensis sp. nov;; (5) grupo hispida inclui T. alida sp. nov., T. hispida sp. nov. e T. periculosa sp. nov.; (6) grupo malefica inclui T. cactina sp. nov., T. curvata sp. nov., T. grallator sp. nov., T. jocosa sp. nov., T. mackameyi sp. nov., T. malefica sp. nov., T. obliqua (Walker) e $T$. terencia sp. nov.; (7) grupo obtusa inclui T. obtusa Fowler, T. obunca sp. nov. e T. torosa sp. nov.; (8) grupo opponens inclui T. alvira sp. nov., T. arcuata sp. nov., T. damia sp. nov., T. insolita sp. nov., T. Iunata sp. nov., T. Iurida sp. nov., T. opponens (Walker), T. oriana sp. nov., T. reflexa sp. nov., T. risa sp. nov., T. sinuata sp. nov., T. trilobata sp. nov., T. tumida sp. nov., T. umbella sp. nov., T. vitocensis sp. nov., T. woodi sp. nov. e T. xantha sp. nov.; (9) grupo peltacauda inclui $T$. brasiliensis sp. nov, T. iratafelis sp. nov., T. modesta sp. nov., T. peltacauda sp. nov., T. picta sp. nov. e T. thyrea sp. nov.; e o (10) grupo semipellucida inclui $T$. atrata sp. nov., $T$. fimbriata sp. nov., T. nicia sp. nov. e T. semipellucida Stål. As seguintes espécies novas não são incluídas em nenhum dos grupos acima mencionados: T. anomala sp. nov., T. corcula sp. nov., T. hamulata sp. nov., T. histria sp. nov., T. inornata sp. nov., T. laticornis sp. nov, T. melantha sp. nov., T. pogonia sp. nov, , T. rideri sp. nov. e T. taura sp. nov. Uma chave taxonômica para grupos de espécies e espécies não posicionadas é apresentada para machos de Tolania. As seguintes espécies previamente incluídas em Tolania são consideradas de posicionamento incerto (species incertae sedis): Cicada armata Stoll; Centrotus felinus Germar; Centrotus obscurus Germar; Centrotus fasciatus Walker. Uma nova sinonímia é proposta: Tolania humilis (Walker, 1858) = Tolania scutata Stål, 1862 syn. nov. Tolania cristata Lethierry, 1890 sp. rev., previamente considerada sinônimo de $T$. femoralis, é revalidada. Lectótipos são designados para $T$. cristata, $T$. femoralis, $T$. fraternal e $T$. scutata. PALAVRAS-CHAVE. Biogeografia; Homoptera; identificação; morfologia; taxonomia. 


\section{CONTENTS}

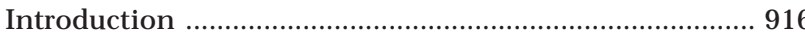

Materials and Methods .................................................... 917

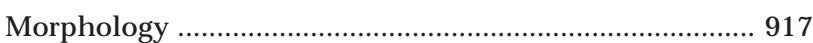

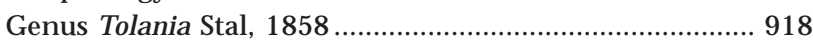

Key to the species of Tolania (males only) .......................... 919

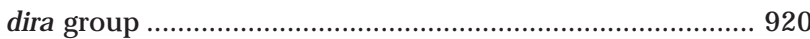

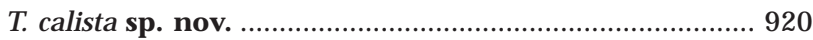

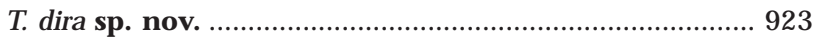

T. inca sp. nov. …………………………………........ 923

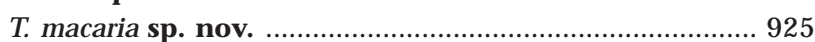

T. secoya sp. nov. …………………………….......... 925

T. zaparo sp. nov.

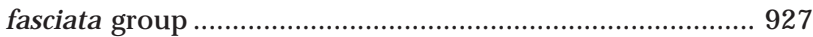

T. fasciata (Walker) ........................................................ 927

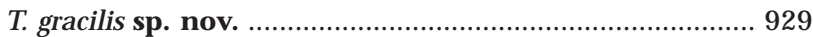

T. laticlava sp. nov.

femoralis group .................................................................... 930

T. femoralis Stål .................................................................. 931

T. fraterna Stål ................................................................ 931

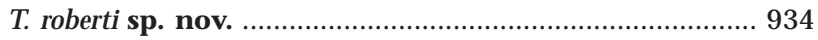

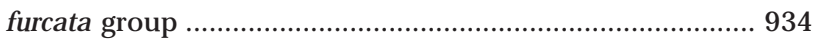

T. furcata sp. nov.

T. tryphena sp. nov. ........................................................ 935

T. venezuelensis sp. nov. .................................................. 935

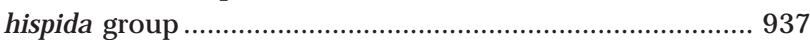

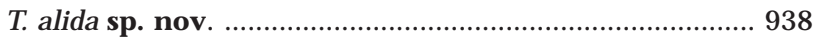

T. hispida \$sp. nov.

T. periculosa \$p. nov.

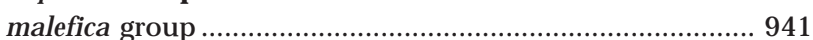

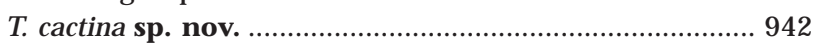

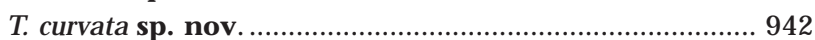

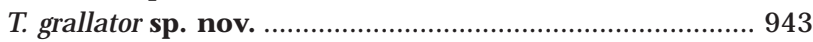

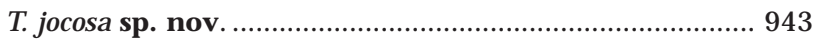

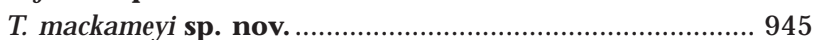

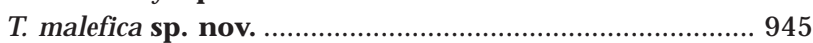

T. obliqua (Walker) ............................................................... 947

T. terencia sp. nov. ............................................................ 948

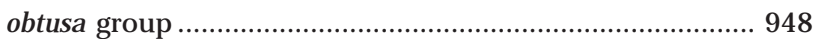

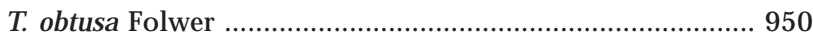

T. obunca sp. nov.

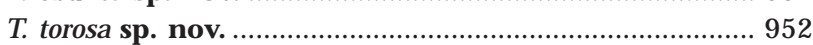

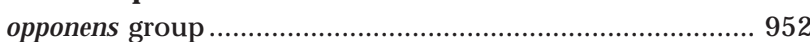

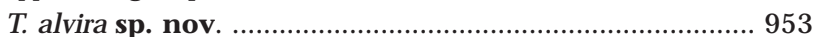

T. arcuata sp. nov. ........................................................... 954

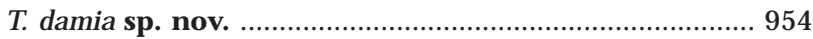

T. insolita sp. nov.

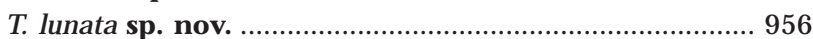

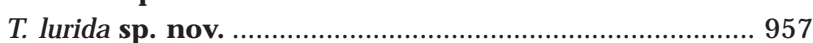

T. opponens (Walker) ......................................................... 957

T. oriana sp. nov.

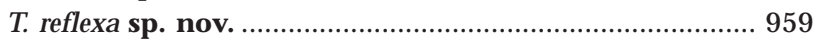

T. risa Sp. nov.
T. sinuata Sp. nov.

T. trilobata sp. nov.

T. tumida sp. nov. …………………………….......... 962

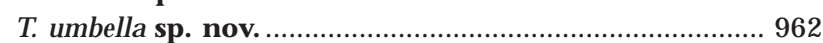

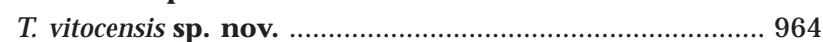

T. woodi sp. nov. ........................................................ 966

T. xantha sp. nov.

peltacauda group ……………………………………...... 966

T. brasiliensis sp. nov. ................................................. 969

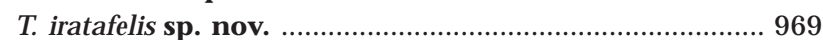

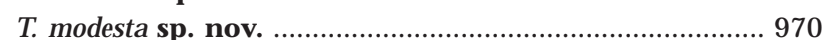

T. peltacauda sp. nov. ………………………………........ 970

T. picta sp. nov. ........................................................... 972

T. thyrea sp. nov. …………………………………...... 972

semipellucida group ………............................................ 972

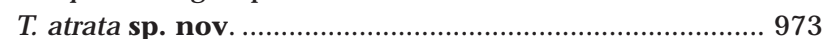

T. fimbriata sp. nov.

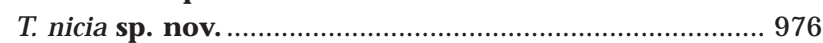

T. semipellucida Stål .............................................................. 976

Unplaced Species ........................................................... 978

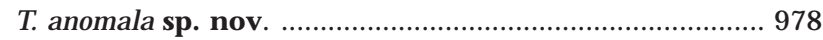

T. corcula sp. nov. ………………………………....... 979

T. cristata Lethierry ............................................................... 980

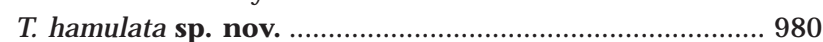

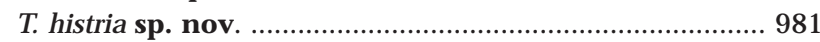

T. humilis (Walker) ........................................................... 981

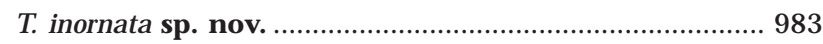

T. laticornis sp. nov.

T. melantha sp. nov. ………………………………........ 985

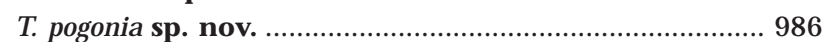

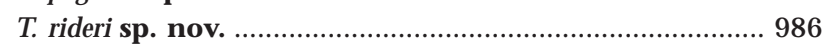

T. stria (Cryan \& Deitz) ........................................................ 988

T. taura sp. nov.

Species of uncertain position …….................................. 992

Concluding Remarks ...................................................... 992

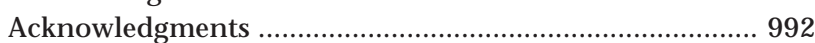

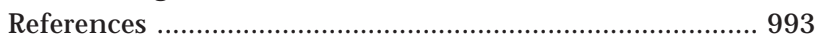

Tolania Stål, 1858 (Membracidae, Nicomiinae, Nicomiini) is a common, widespread, and speciose genus of treehoppers occurring in Neotropical rainforests and savannas from southern Mexico to northern Argentina. Like most members of the subfamily Nicomiinae, species of Tolania lack a posterior pronotal process. The genus differs from other Nicomiinae in having the following combination of features: frontoclypeus produced ventrally, pronotum with suprahumeral horns usually present, metathoracic tibia with three rows of cucullate setae, and forewing usually with one r-m crossvein.

The classification of Nicomiinae was recently revised based on phylogenetic analysis of adult morphological characters (AlBERTSON \& DIETRICH 2005). In that work, the definition of Nicomiinae was expanded to include seven monophyletic genera (Eudonica Albertson, Euwalkeria Goding, Holdgatiella Evans, Nicomia Stål, Nodonica Dietrich, McKamey \& Deitz, Stalomia

Revista Brasileira de Zoologia 23 (4): 915-993, dezembro 2006 
Albertson, and Tolania Stål). These genera were placed in the nominotypical tribe, Nicomiini (equals Tolaniini Haupt), and keys were provided for species of all genera except the largest, Tolania. Phylogenetic analysis consistently recovered Tolania as sister group to a clade comprising the remaining genera of Nicomiinae (Albertson \& Dietrich 2005).

This study builds on the previous work by revising the genus Tolania at the specific level based on adult morphology. The study treats 69 valid species, 59 of which are described as new. The previous phylogenetic analysis (ALBERTSOn \& DIETRICH 2005) recovered several clades within Tolania and many of these are here recognized as informal species groups. Based on examination of the available type specimens ten of the 15 previously described species are considered valid, one is a junior synonym, and four species are of uncertain position. A key is provided for males of species groups and unplaced species. Species within groups may be identified by referring to the illustrations and verbal diagnoses given for each.

\section{MATERIAL AND METHODS}

Nearly 1,000 pinned specimens were borrowed from museum and personal collections in the USA, Europe, and Latin America. Primary types were examined for all previously described species, except Tolania armata Goding - described based on illustrations by SToLl (1788) -, T. walkeri Goding (type apparently lost), Holdgatiella stria Cryan and Deitz (described based on a single female), and two species described by Germar (type specimens not located). The following abbreviations are used in the "Material Examined" section of each species description to refer to the collections from which specimens were borrowed or have been deposited: AMNH - American Museum of Natural History, New York (R. T. Schuh); BMNH - Natural History Museum, London (M. D. Webb); CAS - California Academy of Sciences, San Francisco (N. D. Penny); CNC - Canadian National Collection of Insects, Biosystematics Research Institute, Ottawa (K. G. A. Hamilton); DZUP - Universidade Federal do Paraná, Curitiba (A. M. Sakakibara); DZRJ - Universidade Federal do Rio de Janeiro, Rio de Janeiro (J. L. Nessimian); FSCA - Florida State Collection of Arthropods, Gainesville (F. W. Mead, S. Hal bert); GMNH - Georgia Museum of Natural History, Athens (C. Smith); ICCM - Carnegie Museum of Natural History, Pittsburgh (C. W. Young); INBio - Instituto Nacional de Biodiversidad, Santo Domingo, Costa Rica (M. Zumbado); INHS - Illinois Natural History Survey, Champaign (C. Favret); INPA - Instituto Nacional de Pesquisas da Amazônia, Manaus (A. L. Henriques); MNHN Museum National d'Histoire Naturelle, Paris (M. Boulard); MLUH - Martin-Luther-Universität, Halle (M. Dorn); MZSP - Museu de Zoologia, Universidade de São Paulo, São Paulo (E. Cancello); NCSU - North Carolina State University, Raleigh (L. L. Deitz, R. L. Blinn); NRS - Naturhistorisches Riksmuseet, Stockholm (B. Viklund); SHMC - S.H. McKamey Collection; current address: Systematic Entomology Laboratory, USDA, National Museum of Natural History, Smithsonian Institution, Washington; UCB:
Essig Museum of Entomology, University of California, Berkeley (C. B. Barr); UKY - Department of Entomology, University of Kentucky, Lexington (P. H. Freytag); UMOC - Molecular Ecology Lab tissue storage facility, University of Missouri, Columbia (R. B. Cocroft); USNM - National Museum of Natural History, Washington (D. G. Furth, S. H. M CKamey); ZIMH - Zoologisches Institut und Zoologisches Museum, Universität Hamburg, Hamburg (H. Strümpel).

The methods used for preparing, observing, measuring, and photographing specimens are described in AlBERTSON \& Dietrich (2005). The scale bars included in the lateral habitus photographs indicate one millimeter. Only critical synonymies are included. Complete listings of synonymies can be found in the catalogues of FunKhouser (1927), Metcalf \& W Wde (1965), and MCKameY (1998).

Within the "Material Examined" section of each species description, labels for the primary types are quoted using a virgule (/) to denote line breaks within a label and a semicolon (;) between separate labels. Holotypes are indicated with a red label and paratypes with a blue label. Males were designated as the holotype or lectotype or for all but three species; only females were available for T. alida sp. nov., T. jocosa sp. nov., and T. cristata Lethierry.

Distributions of species were based only on specimen labels, and records from the literature were not included unless they could be verified through examination of specimens.

Host plant records are based on label data and WooD (1984).

For convenience, species groups and species within groups are listed in alphabetical order. New names and other nomenclatural acts should be attributed only to the first author.

\section{MORPHOLOGY}

Morphological characters relevant for the subfamily Nicomiinae, including Tolania, were described and illustrated by AlbeRTSON \& DietRICH (2005). The terminology used follows that of Deitz (1975), Dietrich \& Deitz (1993), and Dietrich ET AL. (2001).

The most useful characters for distinguishing species include features of the male genitalia, forewing venation, and the number of longitudinal cucullate setal rows on the mesothoracic tibia (absent, or with one or two rows).

Species in the genus exhibit two distinct patterns of forewing venation. In the typical Tolania forewing, vein $M$ is initially divided into $M_{1+2}$ and $M_{3+4}$ (Fig. 1); however, in the malefica group the initial division of vein $M$ is $M_{1+2+3}$ and $M_{4}$ (Fig. 2). The number and placement of crossveins is often useful for separating species into groups. The number of crossveins may also vary intraspecifically or between the two forewings of an individual.

Among species of the genus, the male abdomen exhibits one of the following two forms: evenly tapered posteriorly (Fig. 3) or with the lateral margins roundly tapered between segments III-VII and segments VII and VIII attenuate (Fig. 4). 

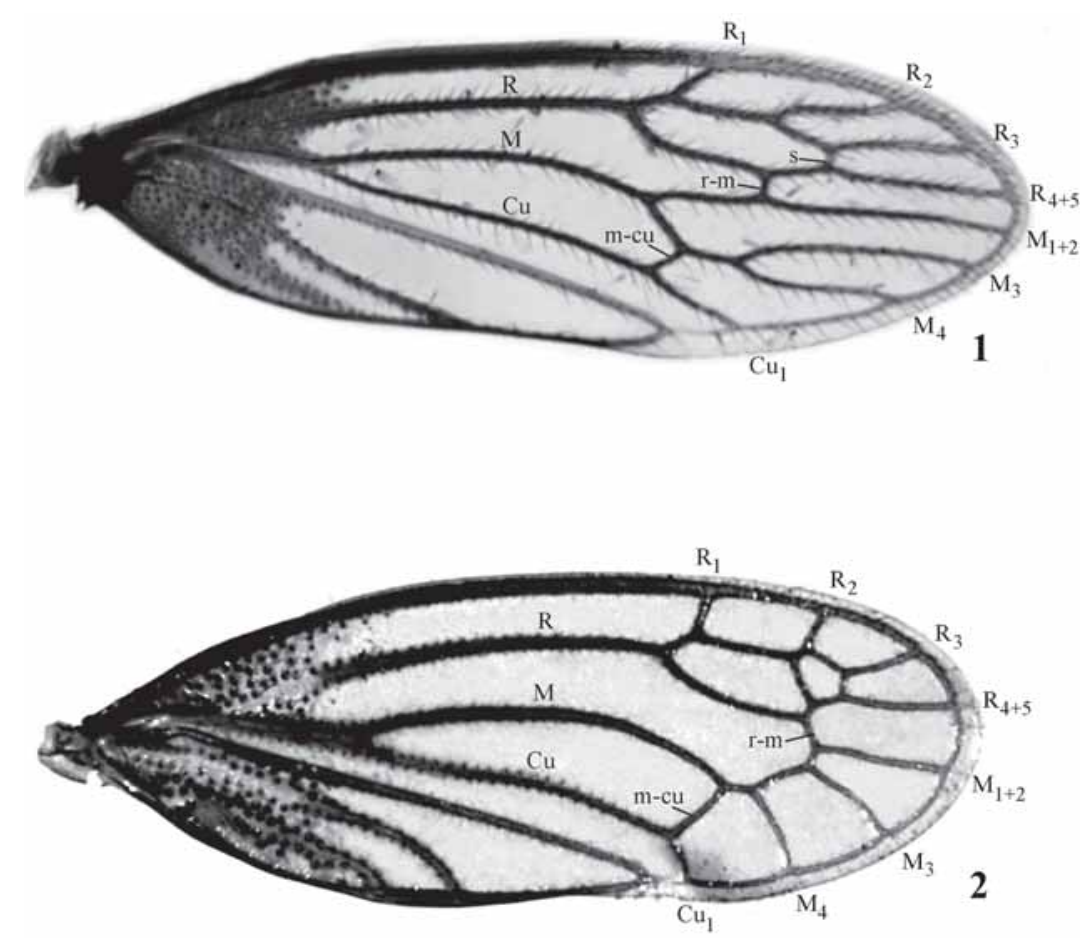
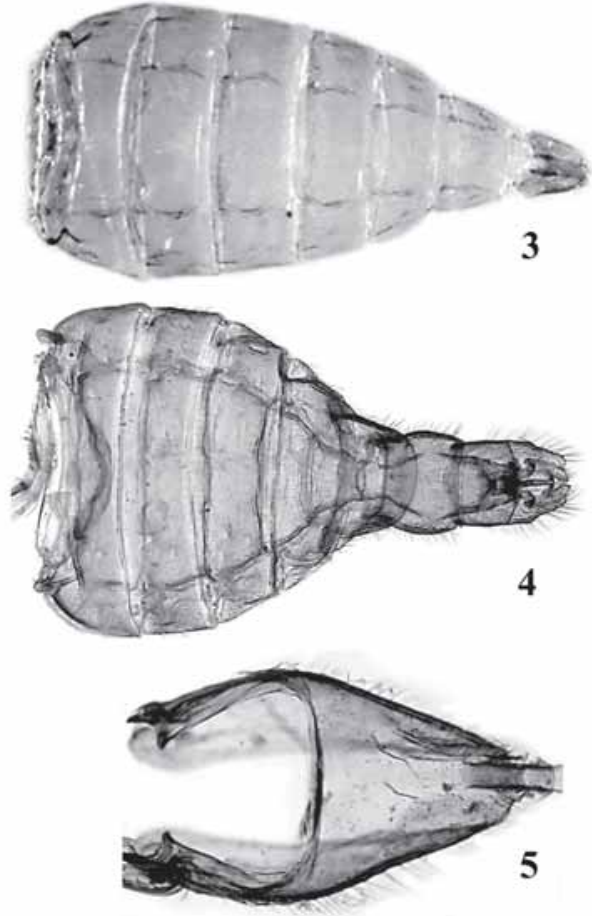

Figures 1-5. (1-2) Forewings: (1) Tolania sp.; (2) T. malefica; (3-4) abdomen, dorsal view: (3) Tolania sp.; (4) T. obtusa Fowler; (5) T. inca female, pygofer, dorsal view.

The most useful characters at the specific level in Tolania, as in other nicomiine genera, are features of the male genitalia, including the pygofer, lateral plate, subgenital plate, style, connective, and in particular, the aedeagus. The aedeagus varies greatly among species, exhibiting a number of different shapes and processes.

The females of many Tolania species can only be identified by association with males. The female pygofer (Fig. 5) is nearly identical among all species. The second valvulae width varies from uniform throughout to broadened near midlength with the dorsal margin distinctly angulate.

\section{Tolania Stål, 1858}

Tolania Stål, 1858: 248.

Type species: Tolania semipellucida Stål, 1858, by original monotypy.

Diagnosis. Species of Tolania have the frontoclypeus produced ventrally; suprahumeral horns usually present (but reduced or absent in some individuals or species); posterior pronotal process absent, scutellum exposed; forewing usually with 1 r-m crossvein (rarely 2) present; and metathoracic tibia with cucullate setal rows I, II, and III.

Description. Head. Vertex width between eyes more or less than twice height; dorsal processes closer to eyes than to midline; ventrolateral margins carinate or foliaceous; ocelli sessile or stalked. Frontoclypeus produced ventrally. Thorax. Pronotum punctation sparse to dense; pubescence sparse or dense; metopidium weakly to strongly elevated; median longitudinal carina slightly el evated, (rarely weakly keel ed); suprahumeral horn development varying from absent to weakly developed and tubercleliketo well developed; posterior margin straight, angulate laterally, with posterolateral projections well developed, posterior projection absent. Scutellum with base slightly inflated, evenly convex or acutely produced dorsally; apex narrow and rounded or acute, longitudinal median groove distinct or indistinct. Forewing opaquely sclerotized and punctate in basal third, except area between claval suture and $\mathrm{Cu}$ (exception: Tolania anomala, with sclerotization covering basal two-thirds of forewing); vein $M$ initial division $M_{1+2}$ and $M_{3+4}$ (Fig. 1) (exception: malefica group, vein $M$ initial division $M_{1+2+3}$ and $M_{4}$, Fig. 2); 1 or 2 scrossveins present, distad of $r-m_{2} ; 1$ or $2 \mathrm{r}$-m crossveins present, if $2 \mathrm{r}-\mathrm{m}$ crossveins then either both distad of vein $R_{1}$ or with $r-m_{1}$ basad of $R_{1}$ and slanted, nearly parallel with vein $R ; m$ crossvein absent or present; $1 \mathrm{~m}$-cu crossvein present, connected between first and second vein $M$ fork (Fig. 1), or basad of first $M$ fork (Fig.2); supranumerary crossveins present in $\mathrm{T}$. anomala; clavus apex acuminate; first and second anal veins free, second Anal vein usually well developed. Legs: pro- and mesothoracic tibiae slender; mesothoracic femur with dorsal preapical cucullate se tae (exception: T. anomala, only distal pair present), tibia with 0 ,

Revista Brasileira de Zoologia 23 (4): 915-993, dezembro 2006 
1 , or 2 cucullate setal rows; metathoracic femur with row of preapical cucullate setae dorsally, tibia with cucullate setal rows I, II, and III. Male. Lateral plate length and shape variable; setose; extending posteriorly (exceptions: peltacauda group and $\mathrm{T}$. inornata, lateral plate extending laterally with medial margins divergent). Subgenital plates incompletely fused; uniformly sclerotized or with densely sclerotized lateral ridge and median basal fenestra. Aedeagus shapevariable; tubular, or broad in lateral view and strongly compressed in ventral view; with or without processes; apex narrow to broad and massive. Style with shank and apex variable; apical hook usually oriented laterally. Female. Second valvulae width more or less uniform throughout or abruptly broadened near midlength with dorsal margin distinctly angulate.

Nymph. See Albertson \& Dietrich (2005).

Distribution. Argentina, Belize, Bolivia, Brazil, Colombia, Costa Rica, Ecuador, El Salvador, French Guiana, Guatemala, Guyana, Honduras, Mexico, Paraguay, Panama, Peru, Suriname, and Venezuela. The record from Belize is based on unidentified female specimens. More detailed locality information is included in the species treatments below.

Host Plants. Tolania lurida sp. nov., is recorded from Annona muricata (Annonaceae); T. obtusa Fowler is recorded from Luhea seemanni (Tiliaceae). Wood (1984) listed Sapium sp. (Euphorbiaceae) as a host plant of Tolania.

Notes. The number of branches of veins $R$ and $M$ in the forewing are consistent among species (exception: Tolania thyrea forewing vein $\mathrm{R}$ with five branches), as well as the presence of three cucullate setal rows on the metathoracic tibia.

Groups of species are defined by differences in the number and placement of forewing crossveins, the forewing with a distinct venation (malefica group, Fig. 2), the number of cucullate setal rows on the mesothoracic tibia, and features of the male genitalia. The male genitalia of Tolania are highly variable and provide the most useful characters for distinguishing species.

Comprising 69 species distributed throughout the Neotropical region from southern Mexico to northern Argentina, Tolania is by far the most widespread and speciose genus of Nicomiinae. A previous morphology-based phylogenetic analysis (ALBERTSON \& DIETRICH 2005) incorporated all but two species (T. curvata and T. histria) of the genus for which males were known, most of them undescribed. The undescribed species were referenced by letters (e.g., Tolania A, B, C, etc.) in the data matrix and cladogram presented by ALBERTSON \& DIETRICH (2005). Formal descriptions of these taxa are presented here, and table $I$ indicates the name and letter code of each species.

Based on the phylogeny of AlberTson \& Dietrich (2005) we recognize ten informal species groups, each comprising three or more species. These groups were all monophyletic on at least some of the most parsimonious trees recovered by cladistic analysis of morphological data. Diagnostic characters separating males of these groups, as well as unplaced species, are provided in the following key. Species within each species group may be distinguished by the illustrations and descriptions provided.

\section{Key to the species of Tolania (males only)}

1. Mesothoracic tibia with cucullate setal rows absent; width of vertex less than $2 x$ height (Figs 86-87) .................... 2

1 '. Mesothoracic tibia with cucullate setal row I or rows I and II, weakly or well developed; width of vertex variable, often more than $2 x$ height.....

2. Forewing with supranumerary crossveins (Fig. 363); frontoclypeus with transverse fold (Fig. 388)...T. anomala sp. nov.

2 '. Forewing without supranumerary crossveins; frontoclypeus without fold (Figs 86-87) ............................................... 3

3. Forewing with $2 \mathrm{r}$-m crossveins, both distad of vein $\mathrm{R}_{1}$; subgenital plate with dense group of elongate setae laterally (Figs 431-432) T. pogonia sp. nov.

3'. Forewing with $1 \mathrm{r}-\mathrm{m}$ crossvein; subgenital plate without dense group of elongate setae.....

4. Suprahumeral horns well developed and extending laterad of humeral angles, acuminate (exception: T. tumida) ....... opponens group

4'. Suprahumeral horns weakly developed and not extending laterad of humeral angles, or reduced to carinae.....

furcata group

5. Vertex width between eyes greater than 2x height (Figs 178180); male abdomen in dorsal view with lateral margins roundly tapered between segments III-VI, segments VII and VIII attenuate (Fig. 4) .............................................. 6

5'. Vertex width between eyes less than 2x height (Figs 18-23); male abdomen as above or evenly tapered (Fig. 3) ......... 9

6. Lateral plate extending laterally, medial margin divergent from midline (Figs 330, 430) ....................................... 7

6 '. Lateral plate extending posteriorly (Figs 188, 426) ......... 8

7. Suprahumeral horns present or absent; pygofer with median posterior process well developed (Figs 329-331) or with posteromedian dorsal lobe weakly produced (Fig. 332); aedeagus with 2 pairs of apical processes (Figs 323-328) .. peltacauda group

7'. Suprahumeral horns absent; pygofer without median posterior process (Figs 429-430); aedeagus with pair of apical processes present or absent (Figs 411-412)...T. inornata sp. nov.

8. Forewing with $2 \mathrm{r}-\mathrm{m}$ crossveins, both distad of vein $\mathrm{R}_{1}$; aedeagus slender with pair of apical processes (Figs 419420); style apex bladelike ....................... T. rideri $\mathbf{s p . ~ n o v . ~}$

8'. Forewing with $1 \mathrm{r}-\mathrm{m}$ crossvein; aedeagus broad in lateral view (Figs 181, 183); style apex notched (Figs 183, 185).. .. obtusa group

9(5'). Forewing (Fig. 1) vein $M$ initial division $M_{1+2}$ and $M_{3+4}$, $\mathrm{m}$-cu crossvein connected distad of first $M$ fork ........... 10

9'. Forewing (Fig. 2) vein $M$ initial division $M_{1+2+3}$ and $M_{4}, m-c u$ crossvein connected basad of first $M$ fork . malefica group

10. Mesothoracic tibia with cucullate setal rows I and II well developed; suprahumeral horns spatulate in dorsal view (Fig. 377) T. laticornis $\mathbf{s p}$. nov.

10'. Mesothoracic tibia with cucullate setal row I well developed, row II absent or weakly developed; suprahumeral horns

Revista Brasileira de Zoologia 23 (4): 915-993, dezembro 2006 
variable, usually not spatulate ................................... 11

11. Forewing with $2 \mathrm{r}$-m crossveins ................................ 12

$11^{\prime}$. Forewing with $1 \mathrm{r}-\mathrm{m}$ crossvein .................................... 14

12. Forewing with crossvein $r-m_{1}$ basad of vein $R_{1}$ and slanted, nearly parallel with vein $\mathrm{R}$......................... fasciata group

12 '. Forewing with both $r-m$ crossveins distad of vein $R_{1}$,

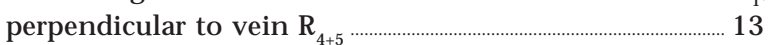

13. Male abdomen in dorsal view evenly tapered (Fig. 3); aedeagus, in dorsal view, distinctly compressed medially (Fig. 408) ............................................. T. histria sp. nov.

13'. Male abdomen in dorsal view with lateral margins roundly tapered between segments III - VI, segments VII and VIII attenuate (Fig. 4); aedeagus, in dorsal view, not compressed (Fig. 25) dira group

14. Lateral plate with apex produced into barblike process (Fig. 424) T. hamulata sp. nov.

14'. Lateral plate not as above ............................................ 15

15. Aedeagus apex broadly expanded, surrounded by serrate flange (Fig. 349); lateral plate with ventral lobe (Fig. 356) semipellucida group

15'. Aedeagus apex broad or narrow, if flange present, extending lengthwise al ong shaft apically; lateral plate without ventral lobe (exception: T. taura) ........................................... 16

16. Aedeagus compressed, broad in lateral view (Figs 69-74, 409410) 17

16'. Aedeagus not compressed, slender in lateral view ....... 18

17. Mesothoracic tibia without cucullate setae in row II; lateral plate with dorsal and ventral margins parallel, apex truncate (Fig. 75) femoralis group

17'. Mesothoracic tibia with row II weakly developed, with 1-5 widely spaced cucullate setae; lateral plate tapered, apex rounded T. humilis (Walker)

18. Pronotum with dorsal setae long and erect, surface shiny; vertex dorsal processes large and conical (Fig. 108)

hispida group

18'. Pronotum with dorsal setae recumbent, surface dull; vertex dorsal processes small, not distinctly conical ................ 19

19. Lateral plate with ventral process; subgenital plate bent abruptly dorsad in apical third, with distinct ventral preapical process (Fig. 433); aedeagus with irregularly serrate lateral preapical flange (Fig. 423)

T. taura sp. nov.

19'. Lateral plate without ventral process; subgenital plate without abrupt bend or processes; aedeagus without lateral flange, apical processes present .................................. 20

20(19'). Forewing with crossvein m present; male abdomen in dorsal view evenly tapered (Fig. 3); aedeagus (Fig. 404) with apical processes simple, dorsal processes present.

T. corcula sp. nov.

20 . Forewing with crossvein m absent; male abdomen in dorsal view with lateral margins roundly tapered between segments III-VI, segments VII and VIII attenuate (Fig. 4); aedeagus (Fig. 415) with apical processes bifurcate, dorsal processes absent T. melantha sp. nov.

\section{dira group}

Figs $5-42$

Diagnosis. This species group differs from other Tolania in having the following combination of features: vertex less than twice as wide as high; forewing with $2 \mathrm{r}$-m crossveins, both distad of vein $R_{1}$, and $1 \mathrm{~m}$ crossvein present; and mesothoracic tibia with cucullate setal row I present.

Description. Head. Vertex width between eyes less than twice height; dorsomedial surface flat; ventrolateral margin foliaceous; ocelli sessile. Frontoclypeus with apex directed ventrally in lateral view. Thorax. Pronotum punctation dense; densely covered with short setae; metopidium high, nearly vertical; suprahumeral horns well developed. Scutellum with base slightly inflated, evenly convex; apex punctate, with distinct median longitudinal groove. Legs: mesothoracic tibia with cucullate setal row I well developed. Tymbals large and conspicuous, extending beyond posterior margin of metathorax. Forewing with 1 or $2 \mathrm{~s}$ crossveins present; 2 r-m crossveins present, both distad of vein $R_{1}$; $1 \mathrm{~m}$ crossvein present; $\mathrm{m}$-cu crossvein connected between first and second vein $M$ fork. Male. Abdomen in dorsal view with lateral margins roundly tapered between segments III-VI, segments VII and VIII attenuate. Lateral plate more than half length of subgenital plate; slender, tapered. Subgenital plate (Fig. 39) without constriction, tapered; uniformly sclerotized without distinct fenestra. Aedeagus slender, processes variable. Connective with anterior margin strongly emarginate, apices divergent; posteriorly produced into short or long (Figs $29,33)$ arm. Style with shank and apex variable. Female. Second valvulae (Figs 40-41) broadened near midlength and dorsal margin distinctly angulate; uniformly dentate dorsally.

Notes. In the phylogenetic analysis (Albertson \& Dietrich 2005), the monophyly of the dira group was supported by the presence of $2 \mathrm{r}-\mathrm{m}$ crossveins in the forewing, both distad of vein $\mathrm{R}_{1}, 1 \mathrm{~m}$ crossvein, and the connective posteriorly produced into a short or long arm.

Species in this group have been collected in Peru, Ecuador, Colombia, Venezuela, French Guiana, and Guyana (Fig. 42).

\section{Tolania calista Albertson sp. nov.}

$$
\text { Figs 6-7, 18, 24-25 }
$$

Type locality. 1 km S Onkonegare Camp, Reserva Etnica Waorani, Napo, Ecuador [USNM].

Diagnosis. This species differs from other species in the group in having the aedeagus with a pair of short, straight preapical processes laterally.

Description. Color. Head, pronotum and forewing basal sclerotization mottled yellow, brown, and red overall; suprahumeral horns black; scutellum yellow with basolateral margins reddish brown; thoracic venter black; femora black, tibiae and tarsi yellow to orange. Forewing membrane hyaline to brown hyaline. Head. Frontoclypeus ventral lobe with lateral margins broadly expanding ventrally. Thorax. Pronotum with

Revista Brasileira de Zoologia 23 (4): 915-993, dezembro 2006 
Table I. Alphabetical list of valid species of Tolania indicating current species group placements and letter codes used for species included on the previously published cladogram (ALBERTSON \& DIETRICH 2005: fig. 134).

\begin{tabular}{|c|c|c|c|c|c|}
\hline Species & Group & Code & Species & Group & Code \\
\hline T. alida & hispida & & T. malefica & malefica & $\mathrm{HH}$ \\
\hline T. alvira & opponens & $P$ & T. melantha & unplaced & $\mathrm{FF}$ \\
\hline T. anomala & unplaced & $\mathrm{CCC}$ & T. modesta & peltacauda & $\mathrm{RR}$ \\
\hline T. arcuata & opponens & G & T. nicia & semipellucida & $\mathrm{ZZ}$ \\
\hline T. atrata & semipellucida & AAA & T. obliqua & malefica & \\
\hline T. brasiliensis & peltacauda & $\mathrm{PP}$ & T. obtusa & obtusa & \\
\hline T. cactina & malefica & KK & T. obunca & obtusa & UU \\
\hline T. calista & dira & $\mathrm{CC}$ & T. opponens & opponens & \\
\hline T. corcula & unplaced & $\mathrm{Q}$ & T. oriana & opponens & $\mathrm{C}$ \\
\hline T. cristata & unplaced & & T. peltacauda & peltacauda & NN \\
\hline T. curvata & malefica & & T. periculosa & hispida & LL \\
\hline T. damia & opponens & $\mathrm{D}$ & T. picta & peltacauda & $\mathrm{OO}$ \\
\hline T. dira & dira & $x$ & T. pogonia & unplaced & W \\
\hline T. fasciata & fasciata & & T. reflexa & opponens & $\mathrm{O}$ \\
\hline T. femoralis & femoralis & & T. rideri & unplaced & WW \\
\hline T. fimbriata & semipellucida & YY & T. risa & opponens & $E$ \\
\hline T. fraterna & femoralis & & T. roberti & femoralis & V \\
\hline T. furcata & furcata & $\mathrm{T}$ & T. secoya & dira & Z \\
\hline T. gracilis & fasciata & DD & T. semipellucida & semipellucida & \\
\hline T. grallator & malefica & J & T. sinuata & opponens & B \\
\hline T. hamulata & unplaced & $\mathrm{U}$ & T. stria & unplaced & \\
\hline T. hispida & hispida & MM & T. taura & unplaced & $X X$ \\
\hline T. histria & unplaced & & T. terencia & malefica & II \\
\hline T. humilis & unplaced & & T. thyrea & peltacauda & SS \\
\hline T. inca & dira & BB & T. torosa & obtusa & W \\
\hline T. inornata & unplaced & $\pi$ & T. trilobata & opponens & $J$ \\
\hline T. insolita & opponens & $\mathrm{H}$ & T. tryphena & furcata & $\mathrm{S}$ \\
\hline T. iratafelis & peltacauda & QQ & T. tumida & opponens & $\mathrm{L}$ \\
\hline T. jocosa & malefica & & T. umbella & opponens & K \\
\hline T. laticlava & fasciata & EE & T. venezuelensis & furcata & $\mathrm{R}$ \\
\hline T. laticornis & unplaced & BBB & T. vitocensis & opponens & $A$ \\
\hline T. lunata & opponens & 1 & T. woodi & opponens & $\mathrm{N}$ \\
\hline T. lurida & opponens & $M$ & T. xantha & opponens & $\mathrm{F}$ \\
\hline T. macaria & dira & $\mathrm{Y}$ & T. zaparo & dira & $A A$ \\
\hline T. mackameyi & malefica & GG & & & \\
\hline
\end{tabular}




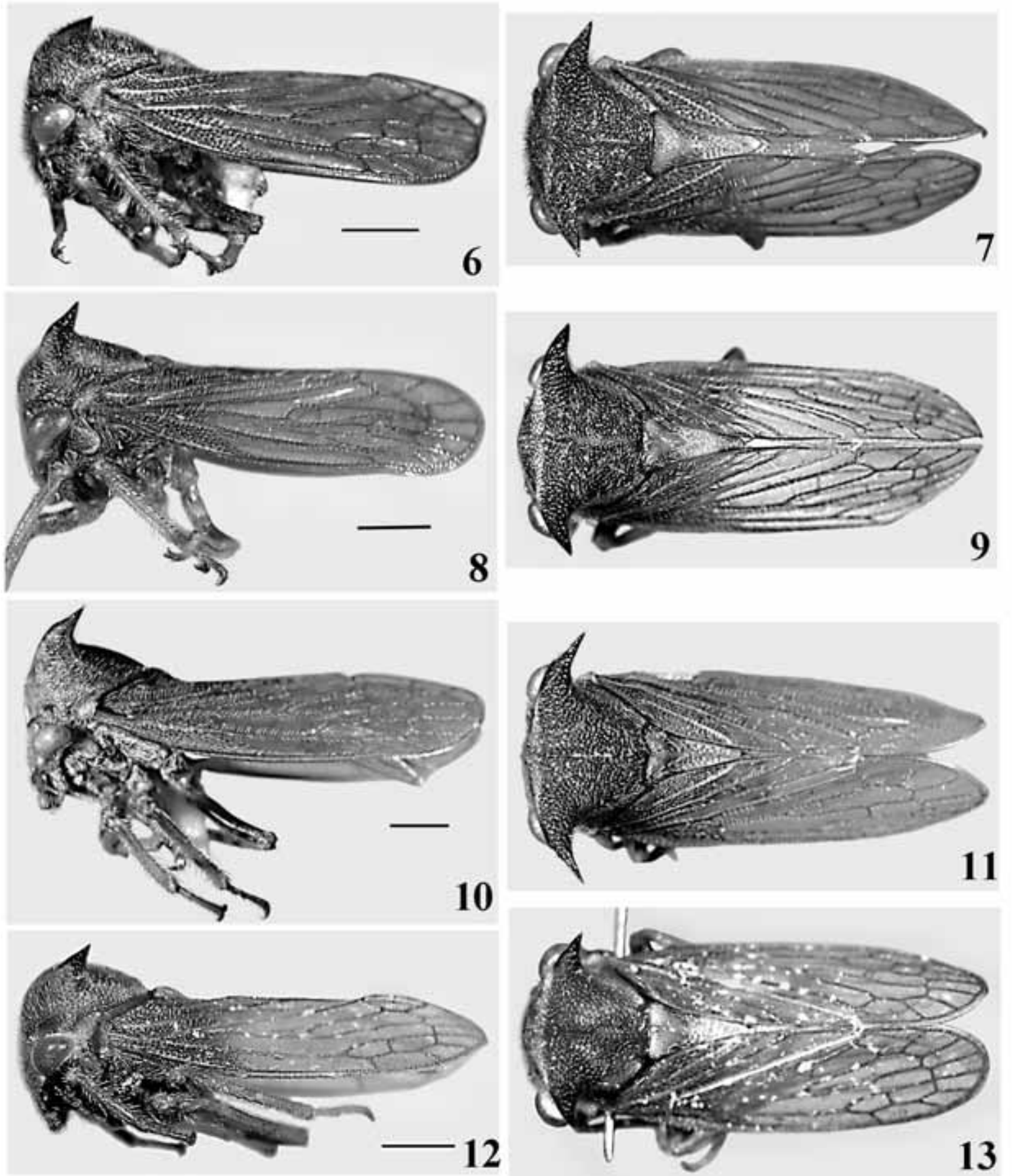

Figures 6-13. Dira group adult lateral and dorsal habitus. (6-7) Tolania calista holotype male; (8-9) T. dira holotype male; (10-11) T. inca holotype male; (12-13) T. macaria holotype male.

suprahumeral horn elevation polymorphic (dorsal surface even with dorsal midline to erect); in dorsal view acuminate, extending laterally (Fig. 7); with anterior and posterior carinae. Legs: metathoracic tibia with 5-12 supranumerary cucullate setae present between rows II and III. Forewing with $1 \mathrm{~s}$ crossvein present. Male. Lateral plate with ventral margin convex medi-

Revista Brasileira de Zoologia 23 (4): 915-993, dezembro 2006 
ally and abruptly narrowing apically. Aedeagus (Figs 24-25) with pair of short, straight preapical processes laterally; gonopore on ventral preapical surface. Connective (Fig. 25) posteriorly produced into short arm. Style (Figs 24-25), in lateral view, with shank abruptly curved dorsad basally and descending gradually toward apex; apex abruptly bent laterally, acute.

Measurements (mm). Male/female. Body length 6.4-6.5/ 6.8-7.5; head width 2.8/2.8-3.1; width across pronotal humeri 2.5/2.5-2.8; width across tips of horns 3.4-3.5/3.5-4.0; forewing length 5.4-5.5/5.8-6.3.

Material examined. Holotype male: “ECUADOR: Napo, Tran-/ sect Ent. 1km S Onkonegare/ Camp. Reserva Etnica Waorani/ 0039'10"S, 07626'00"W; 29-Jun-1994, T.L. Erwin,/ et al., fogging, terre [sic] firme/ forest, lot \#753; Albertson Research/ TOL-0143 o'0", Holotype/ Tolania/ calista/ Albertson" [USNM]. Paratypes: 3 females, same locality [USNM]. Other material: 1 male, 5 females [CAS, USNM].

Distribution. Ecuador: Napo; Peru: Madre de Dios. Collection dates: June, August, October, and November.

Notes. The specific name 'calista' translates from Greek as "beautiful".

\section{Tolania dira Albertson sp. nov.}

Figs 8-9, 19, 26-27 [USNM].

Type locality. Kartabo Point, Cuyuni-Mazaruni, Guyana

Diagnosis. This species differs from other species in the group in having the aedeagus with a pair of concavely curved lateral processes apically.

Description. Color. Head and pronotum yellow overall with red punctures and variable red and black markings; suprahumeral horns black; scutellum yellow with basolateral margins red; thoracic venter red to black; femora red to black, tibiae yellow, tarsi yellow to brown. Forewing basal sclerotization red with veins yellow; membrane brown hyaline. Head. Frontoclypeus ventral lobe with lateral margins convex. Thorax. Pronotum with suprahumeral horns erect; in dorsal view acuminate, extending laterally (Fig. 9); with anterior and posterior carinae. Legs: metathoracic tibia with 7-9 supranumerary cucullate setae present between rows II and III. Forewing with $1 \mathrm{~s}$ crossvein present. Male. Aedeagus (Figs 26-27) with pair of concavely curved lateral processes apically; gonopore on ventral preapical surface. Connective (Fig. 27) posteriorly produced into short arm. Style (Figs 26-27), in lateral view, with shank abruptly curved dorsad basally and descending gradually toward apex; apex abruptly bent laterally, acute.

Measurements (mm). Male/female. Body length 6.3/7.6; head width 2.6/3.1; width across pronotal humeri 2.3/2.8; width across tips of horns 3.4/4.9; forewing length 5.4/6.5.

Material examined. Holotype male: “GUYANA: Mazaruni-/ Potaro District/ Kartabo Point/ 27 December 1983; Malaise trap at edge/ of secondary forest/ and farmed field; EARTHWATCH Research/ Expedition:/ W. Steiner, J. Byrd,/ J.
Hill \& F. Holtzclaw/ collectors; Albertson Research/ TOL-0035 o', Holotype/ Tolania/ dira/ Albertson" [USNM]. Paratype: 1 female, Maroni, Guyane [ZIMH].

Distribution. French Guiana: Saint-Laurent du Maroni; Guyana: Cuyuni-Mazaruni. Collection date: December.

Notes. The specific name 'dira' is derived from the Latin word dirus meaning "fierce, ominous" and refers to the appearance of the long, erect suprahumeral horns in anterior view.

\section{Tolania inca Albertson, sp. nov. Figs 5, 10-11, 20, 28-29, 38, 40}

Typelocality. 30 km SW Puerto Maldonado, Río Tambopata Reserve, Madre de Dios, Peru [USNM].

Diagnosis. This species differs from other species in the group in having the aedeagus with a pair of raised preapical processes dorsally and with a pair of elongate apical processes.

Description. Color. Head and pronotum yellow overall with red punctures and variable black and red markings; pronotum reddish brown mottled with yellow dorsally; suprahumeral horns reddish brown, black apically; scutellum yellow with median longitudinal reddish brown stripe basally; thoracic venter black; femora black, tibiae and tarsi reddish brown to yellow. Forewing basal sclerotization red with veins yellow; membrane brown hyaline. Head. Frontoclypeus ventral lobe with lateral margins convex. Thorax. Pronotum with suprahumeral horns erect; in dorsal view slender, acuminate, extending posterolaterally (Fig. 11); with anterior, posterior, and dorsal carinae. Legs: metathoracic tibia with 14 supranumerary cucullate setae present between rows II and III. Forewing with $1 \mathrm{~s}$ crossvein present. Male. Lateral plate (Fig. 38) with ventral margin convex, apex narrow and curved dorsally. Aedeagus (Figs 28-29) with pair of raised preapical processes dorsally, directed anteriorly; with pair of elongate apical processes, directed ventrally; gonopore apical. Connective (Fig. 29) posteriorly produced into short arm. Style (Figs 28-29), in lateral view, with shank straight; apex abruptly bent laterally, acute.

Measurements (mm). Male/female. Body length 7.1-7.6/ 7.1-8.0; head width 2.8-2.9/2.8-3.1; width across pronotal humeri 2.5-2.7/2.7-2.8; width across tips of horns 3.8-4.7/4.2-4.6; forewing length 6.1-6.5/6.0-6.8.

Material examined. Holotype male: “PERU: Madre de Dios/ Rio Tambopata Res./ 30km (air) SW Pto./ Maldonado, 290m./ 1250'S, 06917'W; Smithsonian Institution/ Canopy Fogging Project/ T.L. Erwin, et al., colls./ 07 Nov 1983 01/03112; Albertson Research/ TOL-0064 o; Holotype/ Tolania/ inca/ Albertson" [USNM]. Paratypes: 1 male, 4 females, same locality [USNM]. Other material: 2 males [CAS, USNM].

Distribution. Peru: Madre de Dios. Collection dates: April and November.

Notes. This species is named for the Inca civilization which inhabited Peru from 1438 AD to 1533 AD.

Revista Brasileira de Zoologia 23 (4): 915-993, dezembro 2006 

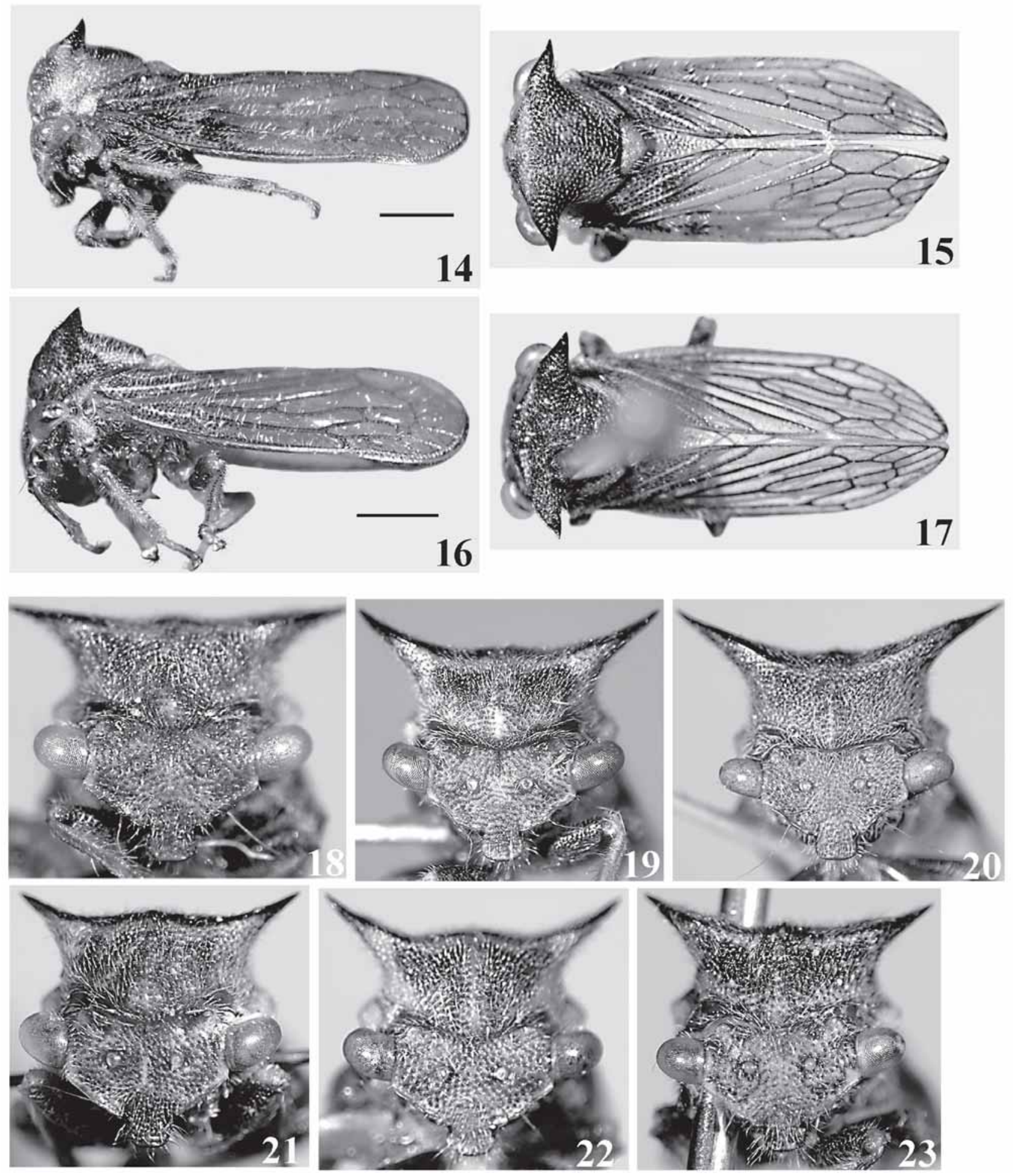

Figures 14-23. Dira group adult lateral and dorsal habitus. (14-15) Tolania secoya holotype male: (14) lateral view; (15) dorsal view; (1617) T. zaparo holotype male: (16) lateral view; (17) dorsal view; (18-23) anterior view: (18) T. calista holotype male; (19) T. dira holotype male; (20) T. inca holotype male; (21) T. macaria holotype male; (22) T. secoya holotype male; (23) T. zaparo holotype male.

Revista Brasileira de Zoologia 23 (4): 915-993, dezembro 2006 


\section{Tolania macaria Albertson, sp. nov. Figs 12-13, 21, 30-31, 39, 41}

Type locality. Macarena, Meta, Colombia [ZIMH].

Diagnosis. This species differs from others in the group in having the forewing with two s crossveins and the aedeagus with a pair of acute preapical processes dorsally and a pair of truncate processes apically.

Description. Color. Head and pronotum yellow overall with brown punctures and variable reddish brown markings; suprahumeral horns black; scutellum yellow with basolateral margins reddish brown; thoracic venter black; femora black, tibiae reddish brown, yellow with reddish brown bands, or yellow, tarsi yellow. Forewing basal sclerotization reddish brown with veins yellow; membrane hyaline. Head. Frontoclypeus ventral lobe with lateral margins parallel. Thorax. Pronotum with suprahumeral horns erect; shape in dorsal view polymorphic (triangular or acuminate, Fig. 13); with anterior and posterior carinae. Legs: metathoracic tibia with 5-8 supranumerary cucullate setae present between rows II and III. Forewing with 2 scrossveins present. Male. Aedeagus (Figs 30-31) with pair of acute preapical processes dorsally; with pair of truncate processes apically; gonopore on ventral preapical surface. Connective (Fig. 31) posteriorly produced into short arm. Style (Figs 30-31), in lateral view, with shank more or less straight; apex curved laterally, acute.

Measurements (mm). Male/female. Body length 5.3-6.8/ 6.0-7.1; head width 2.4-2.9/2.4-3.0; width across pronotal humeri 2.1-2.5/2.0-2.7; width across tips of horns 2.5-3.0/2.4-3.6; forewing length 4.5-5.7/4.8-6.2.

Material examined. Holotypemale: “Columbien/ Macarena/ 500-650m/ Jan.-Feb. 1950; leg. L. Richter/ Eing.-Nr 18/1958/ 02186; Albertson Research/ TOL-0540 o; Holotype/ Tolania/ macaria/ Albertson" [ZIMH]. Paratypes: 1 male, 5 females, same locality [ZIMH]. Other material: 1 male, 12 females [MZSP, USNM, ZIMH].

Distribution. Colombia: Amazonas-Vaupes; Choco; Meta; Santander; Venezuela: Amazonas; Carabobo. Collection dates: January to February, May to June, September, and November to December.

Notes. The pronotum varies in coloration, as described above or entirely reddish brown.

The specific name 'macaria' is derived from the Greek word makarios meaning "happiness".

\section{Tolania secoya Albertson, sp. nov. Figs 14-15, 22, 32-33, 36-37}

Type locality. 1 km S Onkonegare Camp, Reserva Etnica Waorani, Napo, Ecuador [USNM].

Diagnosis. This species differs from other species in the group in having the aedeagus with a pair of straight processes apically and the connective posteriorly produced into a long arm extending ventrad of the aedeagus.

Description. Color. Head, pronotum, and forewing basal sclerotization yellow overall with red punctures and variable black and red markings; pronotum with reddish brown transverse macula dorsally; suprahumeral horns black apically; scutellum yellow with basolateral margins reddish brown; thoracic venter reddish brown to black; femora reddish brown to black with venter yellow, tibiae yellow with 2-3 reddish brown bands, tarsi yellow to brown. Forewing membranehyaline. Head. Frontoclypeus ventral lobe with lateral margins broadly expanding ventrally. Thorax. Pronotum with suprahumeral horns erect; in dorsal view acuminate, extending laterally (Fig. 15); with anterior and posterior carinae. Legs: metathoracic tibia with six supranumerary cucullate setae present between rows II and III. Forewing with 1 s crossvein present. Male. Pygofer (Figs 36-37) with posterior margin distinctly produced over anal tube. Aedeagus (Figs 3233) with pair of straight processes apically; gonopore on ventral preapical surface. Connective (Fig. 33) posteriorly produced into long arm extending ventrad of aedeagus. Style (Figs 32-33), in lateral view, with shank abruptly curved dorsad basally and descending gradually toward apex; apex hooked laterally, abruptly narrowed and acute. Female. Unknown.

Measurements (mm). Male. Body length 5.9; head width 2.5; width across pronotal humeri 2.2; width across tips of horns 2.9; forewing length 4.9.

Material examined. Holotype male: “ECUADOR: Napo, Tran-/ sect Ent. 1km S Onkonegare/ Camp. Reserva Etnica Waorani/ 0039'10"S, 07626'00"W; 20-Jun-1994, T.L. Erwin,/ et al., fogging, terre [sic] firme/ forest, lot\#684; Albertson Research/ TOL-0028 o', Holotype/ Tolania/ secoya/ Albertson" [USNM].

Distribution. Ecuador: Napo. Collection date: June.

Notes. The species name is based on the name of an indigenous people of Ecuador.

\section{Tolania zaparo Albertson, sp. nov.}

Figs 16-17, 23, 34-35

Type locality. 1 km S Onkonegare Camp, Reserva Etnica Waorani, Napo, Ecuador [USNM].

Diagnosis. This species differs from other species in this group in having the aedeagus with the apex cupulate and with a pair of subtruncate processes, and the connective posteriorly produced into a long arm extending ventrad of the aedeagus.

Description. Color. Vertex dark yellow with brown punctures and variable black markings; frontoclypeus orange, black posteriorly; pronotum black with yellow transverse maculae on metopidium and laterally; scutellum yellow with basolateral margins reddish brown; thoracic venter black; femora black, tibiae yellow with brown markings, tarsi yellow. Forewing basal sclerotization dark yellow with black punctures; membrane brown hyaline. Head. Frontoclypeus ventral lobe with lateral margins parallel. Thorax. Pronotum with suprahumeral horns erect; in dorsal view acuminate, extending laterally (Fig. 17); with anterior and posterior carinae. Legs: metathoracic tibia with 6-9 supranumerary cucullate setae present between rows II and III. Forewing with one s crossvein present. Male. Aedeagus (Figs 34-35) with apex cupulate; with pair of subtruncate processes

Revista Brasileira de Zoologia 23 (4): 915-993, dezembro 2006 


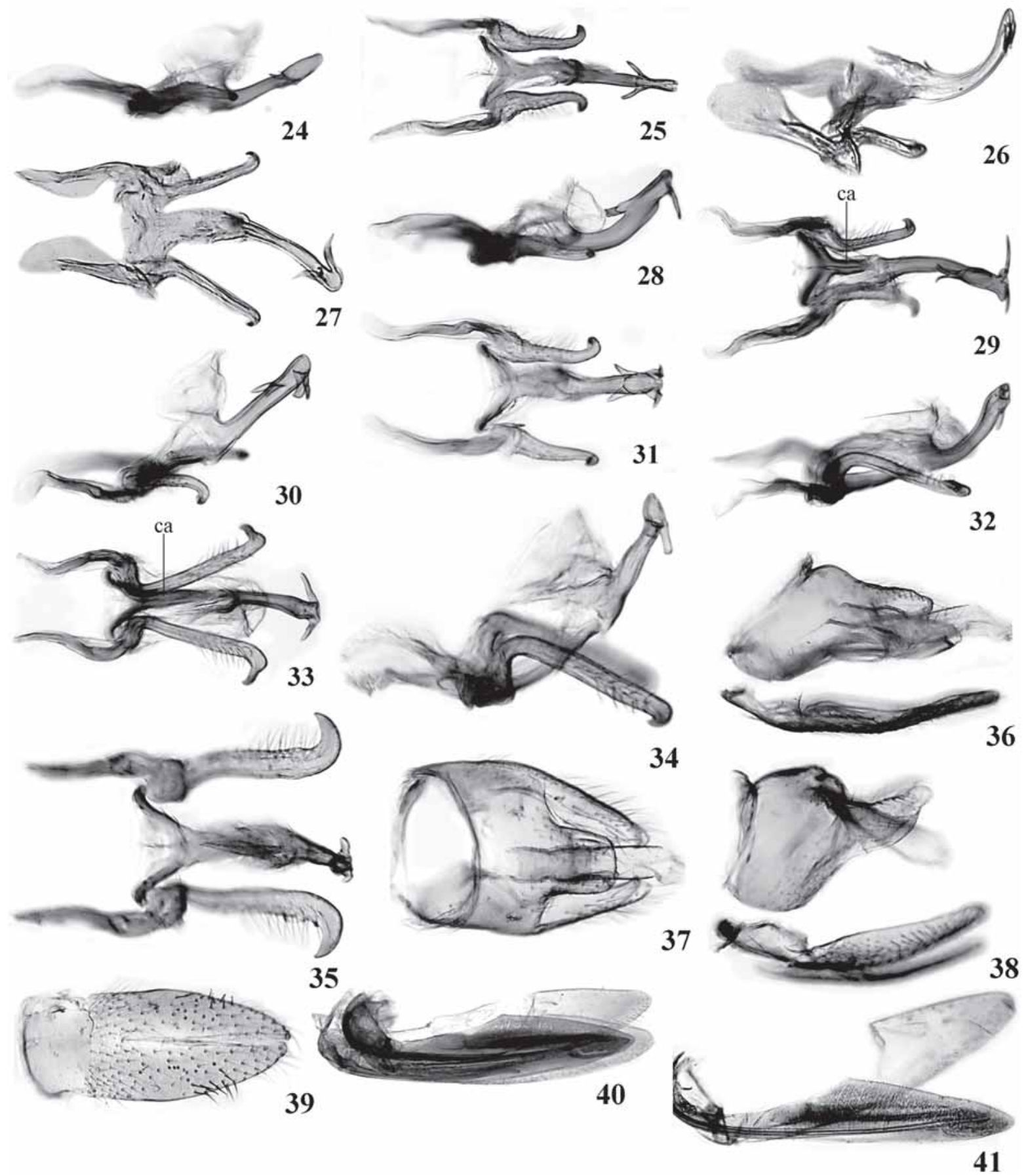

Figures 24-33. Dira group. (24-39) Males: (24-25) Tolania calista holotype: (24) genitalia, lateral view; (25) same, dorsal view; (26-27) T. dira holotype: (26) genitalia, lateral view; (27) same, ventral view; (28-29) T. inca paratype: (28) genitalia, lateral view; (29) same, dorsal view; (30-31) T. macaria holotype: (30) genitalia, lateral view; (31) same, dorsal view; (32-33) T. secoya holotype: (32) genitalia, lateral view; (33) same, dorsal view. ca: Connective posterior arm; (34-35) Tolania zaparo holotype: (34) genitalia, lateral view; (35) same, dorsal view; (36-37) T. secoya holotype: (36) pygofer, lateral view; (37) same, dorsal view; (38) T. inca paratype, pygofer, right lateral view, inverted; (39) T. macaria holotype, subgenital plate; (40-41) females: (40) T. inca paratype, second and third valvulae; (41) T. macaria paratype, second and third valvulae.

Revista Brasileira de Zoologia 23 (4): 915-993, dezembro 2006 


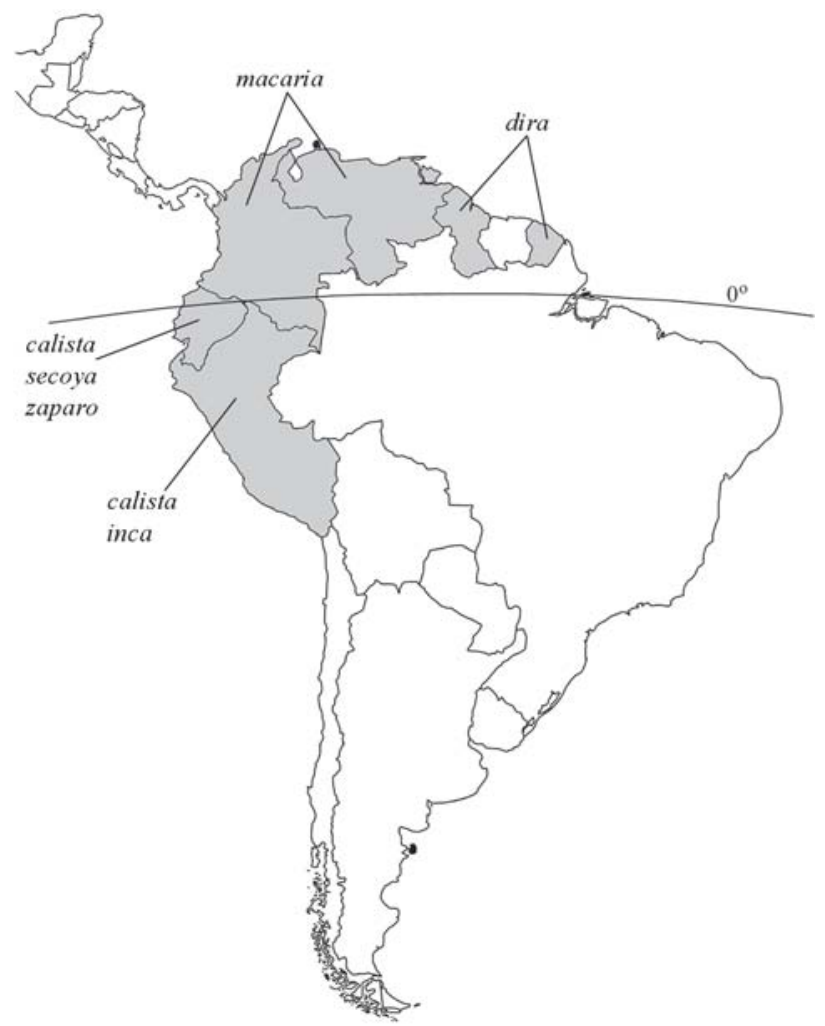

Figure 42. Known distributions of the dira group species.

apically; gonopore on ventral preapical surface. Connective (Fig. 35) posteriorly produced into long arm extending ventrad of aedeagus. Style (Figs 34-35), in lateral view, with shank abruptly curved dorsad basally and descending gradually toward apex; apex broadly curved laterally, acuminate. Female. Unknown.

Measurements (mm). Male. Body length 5.6-5.7; width of head 2.3; width across pronotal humeri 2.2; width across tips of horns 2.7-2.8; forewing length 4.9-5.0.

Material examined. Holotype male: “ECUADOR: Napo, Tran-/ sect Ent. $1 \mathrm{~km}$ S Onkonegare/ Camp. Reserva Etnica Waorani/ 0039'10"S, 07626'00"W; 9-Oct-1994, T.L. Erwin,/ et al., fogging, terre [sic] firme/ forest, lot\#927; Albertson Research/ TOL-0040 o', Holotype/ Tolania/ zaparo/ Albertson" [USNM]. Paratype: 1 male, same data [USNM].

Distribution. Ecuador: Napo. Collection date: October.

Notes. This species name is based on that of an indigenous people of Ecuador.

\section{fasciata group \\ Figs 43-59}

Diagnosis. Species in this group differ from other Tolania in having the following combination of features: vertex less than twice as wide as high; forewing with $2 \mathrm{r}$-m crossveins, $\mathrm{r}$ $m_{1}$ basad of vein $R_{1}$ and slanted, nearly parallel with vein $R$; mesothoracic tibia with cucullate setal row I present.

Description. Head. Vertex width between eyes less than twice height; dorsomedial surface flat; ventrolateral margin carinate; ocelli sessile. Frontoclypeus with apex directed ventrally in lateral view. Thorax. Pronotum pubescence short and dense; suprahumeral horns well developed. Scutellum with base slightly inflated, evenly convex; apex without punctures, with distinct median longitudinal groove. Legs: mesothoracic tibia with cucullate setal row I well developed. Tymbals large and conspicuous, extending beyond posterior margin of metathorax. Forewing with $1 \mathrm{~s}$ crossvein present; $2 \mathrm{r}-\mathrm{m}$ crossveins present, $r-m_{1}$ basad of vein $R_{1}$ and slanted, nearly parallel with vein $\mathrm{R}$; $\mathrm{m}$ crossvein absent; $\mathrm{m}$-cu crossvein connected between first and second vein $M$ fork. Male. Abdomen in dorsal view with lateral margins roundly tapered between segments III VI, segments VII and VIII attenuate. Lateral plate (Figs 55-56) more than half length of subgenital plate, extending dorsomedially, abruptly bent posterad in lateral and dorsal views. Subgenital plates (Fig. 57) narrow, with lateral margins parallel basally, broad and rounded apically; uniformly sclerotized without distinct fenestra. Aedeagus (Figs 51-54) broad in lateral view, slender in ventral view; apex broad and massive; gonopore apical. Connective with anterior margin strongly emarginate, apices divergent; acuminate posteriorly. Style with shank and apex variable; with apical scales. Female. Second valvulae (Fig. 58) uniformly dentate dorsally.

Notes. In the phylogenetic analysis (AlberTson \& Dietrich 2005), Tolania gracilis and T. Iaticlava formed a monophyletic group with moderate support $(\mathrm{DI}=3$ ) and were united by the presence of $2 \mathrm{r}$-m crossveins in the forewing, with $r-m_{1}$ basad of vein $R_{1}$ and slanted, and by characters of the male genitalia. Tolania fasciata, which shares these diagnostic characters, was not included in the phylogenetic analysis because only the female is known.

Species in this group are known only from Brazil (Fig. 59).

\section{Tolania fasciata (Walker, 1852) Figs 43-44}

Centrotus fasciatus Walker, 1852: 1147

[Tolania] fasciata; Funkhouser, 1927: 494.

Type locality. Brazil [BMNH].

Diagnosis. This species differs from others in the group in having the forewing with a black transverse macula basally and the abdomen with a black transverse band dorsally.

Description. Color. Head, pronotum, and forewing basal sclerotization dark yellow to orange overall with variable black markings; scutellum base red to brown laterally, yellow medially with basolateral corners black, apex yellow; legs yellow with black markings; abdomen with broad black transverse band beneath forewing macula. Forewing membrane brown hyaline with black transverse macula basally. Head. Frontoclypeus ventral lobe with lateral margins parallel, slightly converging ventrally. Thorax. Pronotum punctation dense; 

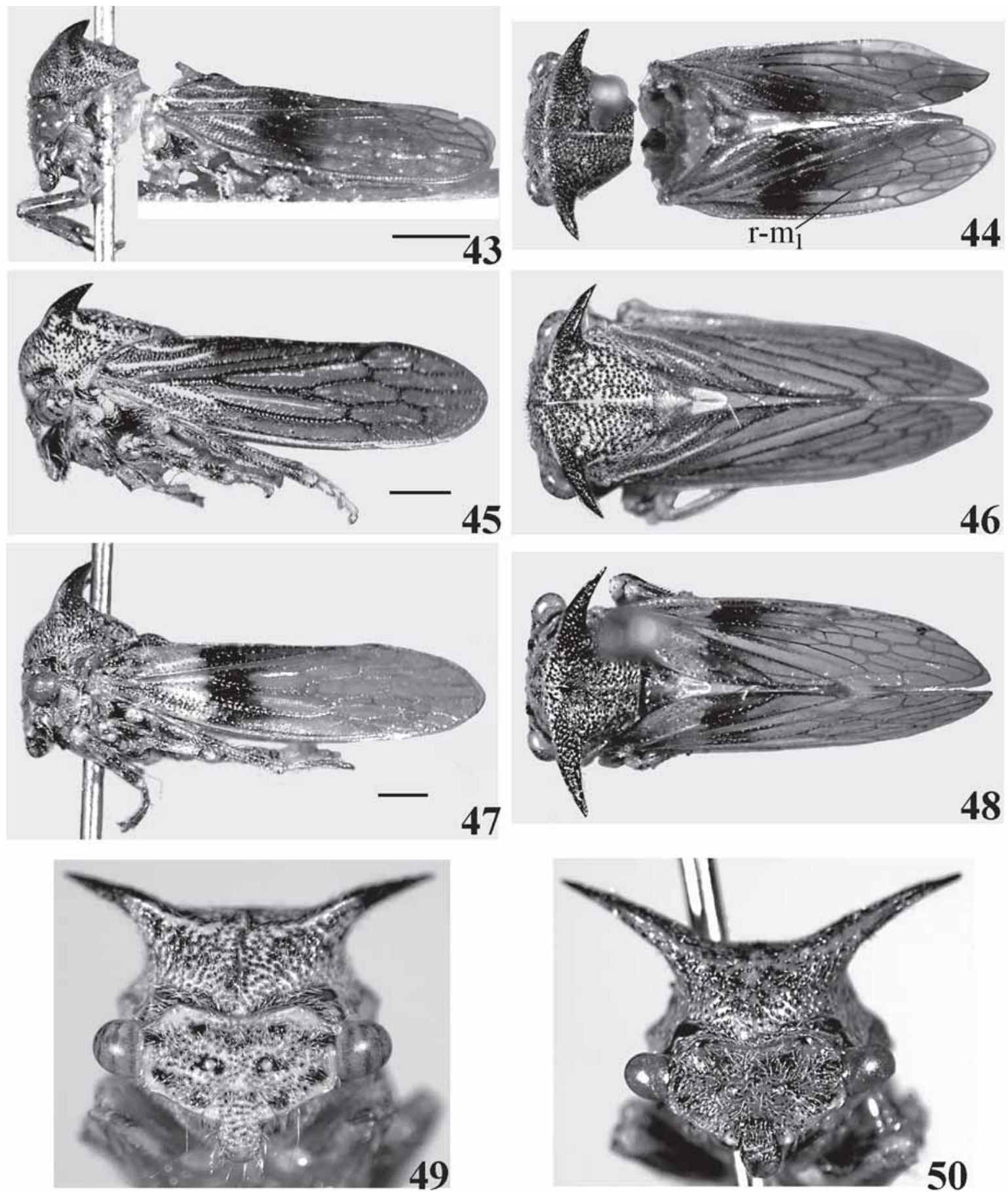

Figures 43-50. Fasciata group adult habitus. (43-44) Centrotus fasciatus Walker holotype female: (43) lateral view; (44) dorsal view; (4546) Tolania gracilis holotype male: (45) lateral view; (46) dorsal view; (47-48) T. laticlava paratype female: (47) lateral view; (48) dorsal view; (49-50) anterior view: (49) T. gracilis holotype male; (50) T. laticlava paratype female.

metopidium high, nearly vertical; suprahumeral horns erect, in dorsal view slender, acuminate, extending posterolaterally

Revista Brasileira de Zoologia 23 (4): 915-993, dezembro 2006
(Fig. 44), with anterior and posterior carinae. Female. [not dissected]. Male. Unknown. 
Measurements. Female. Body length [broken]; head width 1.9; width across pronotal humeri 1.8; width across tips of horns 2.7; forewing length 4.2.

Material examined. Holotype female: "Type; Brazil; CENTROTUS FASCIATUS; Albertson Research/ TOL-1012 ㅇ " [BMNH].

Distribution. BrazIL.

Notes. Walker apparently described two separate species (1852, 1858a) using the name Centrotus fasciatus for both. Goding (1931) renamed the homonym C. fasciatus Walker, 1858, with the replacement name Tolania walkeri. Examination of the only $\mathrm{C}$. fasciatus type specimen found in $\mathrm{BMNH}$ reveals that the specimen agrees more closely with Walker's 1852 description. Also, the "Centrotus fasciatus" label on the specimen was apparently cut from the 1852 manuscript (the words on the back of the label match those on the reverse side of the page in the original publication). The type specimen is in poor condition with the head and pronotum on one pin and the thorax and abdomen mounted on a separate pin. Most of the legs are missing or cannot be seen.

This species is similar to T. laticlava and can be distinguished by differences in suprahumeral horn length, width, and degree of elevation and the presence of a broad black band on the abdomen.

\section{Tolania gracilis Albertson, sp. nov. Figs 45-46, 49, 51-52, 55-56, 58}

Type locality. Corcovado, Rio de Janeiro, Brazil [UFPC].

Diagnosis. This species differs from others in the group in lacking a forewing macula, the subgenital plate with setae of equal length throughout, and the apex of the aedeagus weakly expanded in lateral view.

Description. Color. Head, pronotum, and forewing basal sclerotization yellow overall with black punctures and variable black markings; scutellum yellow with basolateral margins orange; thoracic venter yellow with longitudinal black stripe laterally; femora yellow with black markings or entirely black (some females), tibiae yellow with black bands, tarsi yellow; female abdomen orangeto red. Forewing membrane brown hyalinewith dark veins; costal margin yellow, commisural margin dark brown. Head. Frontoclypeus ventral lobe with lateral margins parallel, slightly converging ventrally. Thorax. Pronotum punctation dense; metopidium sloping, low; suprahumeral horns erect, in dorsal view slender, acuminate, extending posterolaterally (Fig. 46), with anterior, posterior, dorsal, and ventral carinae. Legs: metathoracic tibia with 6-20 supranumerary cucullate setae between rows II and III. Male. Lateral plate (Figs 55-56) with distal half slender. Subgenital plates with lateral margins parallel basally, gradually broadening near midlength toward apex, lateral margins rounded distally; setae of equal length throughout. Aedeagus (Figs 51-52) with apex, in lateral view, weakly expanded; in dorsal view, produced laterally into a pair of large convexly curved foliaceous processes. Style (Figs 51-52), in lat- eral view, with shank convexly curved; apex curving ventrolaterally, rounded. Female. Second valvulae (Fig. 58) slightly broadened near midlength, dorsal margin angulate.

Measurements (mm). Male/female. Body length 7.1-7.4/ 7.5-8.3; head width 2.9-3.0/3.0-3.3; width across pronotal humeri 2.5-2.6/2.6-2.9; width across tips of horns 3.6-3.8/3.8-4.6; forewing length 6.2-6.3/6.3-7.1.

Material examined. Holotypemale: "Brasil Rio de Janeiro/ D.F. CORCOVADO/ XI.1957/ Seabra e Alvarenga; Albertson Research/ TOL-0835 ơ, Holotype/ Tolania/ gracilis/ Albertson" [UFPC]. Paratypes: 2 males, 3 females, same locality [UFPC]. Other material: 2 females [MNHN, ZIMH].

Distribution. BrazlL: Minas Gerais; Rio de Janeiro. Collection dates: March, October to November.

Notes. The specific name 'gracilis' translates from Latin as "slender," referring to the shape of the suprahumeral horns.

\section{Tolania laticlava Albertson, sp. nov. Figs 47-48, 50, 53-54, 57}

Type locality. Itatiaia, Rio de Janeiro, Brazil [UFPC].

Diagnosis. This species differs from others in the group in having the forewing with a black transverse macula basally, the abdomen without a black transverse band, the subgenital plate with setae distinctly longer on distal half, and the apex of the aedeagus with the ventral margin protuberant in lateral view.

Description. Color. Head and pronotum yellow overall with black punctures and various black and red markings; scutellum base black with median yellow longitudinal stripe, or entirely black, apex yellow; thoracic venter black; femora black with yellow markings, prothoracic tibia black, meso- and meta-thoracic tibiae yellow with broad black bands. Forewing basal sclerotization black basally, pale yellow apically; membrane hyaline with broad black transverse macula basally. Head. Frontoclypeus ventral lobe with lateral margins parallel, slightly converging ventrally. Thorax. Pronotum punctation sparse, scattered; metopidium high, nearly vertical; suprahumeral horns erect, in dorsal view long and slender throughout, acuminate, extending posterolaterally (Fig. 48), with anterior, posterior, dorsal, and ventral carinae. Legs: metathoracic tibia with 6-12 supranumerary cucullate setae between rows II and III. Forewing with second anal vein weak. Male. Lateral plate with distal half slender. Subgenital plates (Fig. 57) with lateral margins parallel basally, abruptly broadened near midlength, lateral margins rounded distally; setae on distal half distinctly longer than basal setae, especially along lateral margins. Aedeagus (Figs 53-54), in lateral view, with ventral margin protuberant apically, apex strongly expanded; apex, in dorsal view, with pair of convexly curved foliaceous lateral processes. Style (Figs 53-54), in lateral view, with shank straight, abruptly narrowing preapically in dorsal view; apex hooked laterally, rounded. Female. Second valvulae broadened near midlength, dorsal margin distinctly angulate.

Measurements (mm). Male/female. Body length 8.1/8.38.5; head width 3.2/3.1-3.3; width across pronotal humeri 2.8/

Revista Brasileira de Zoologia 23 (4): 915-993, dezembro 2006 


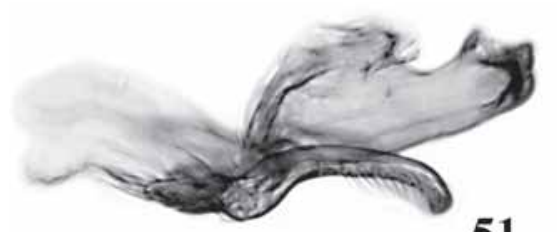

51

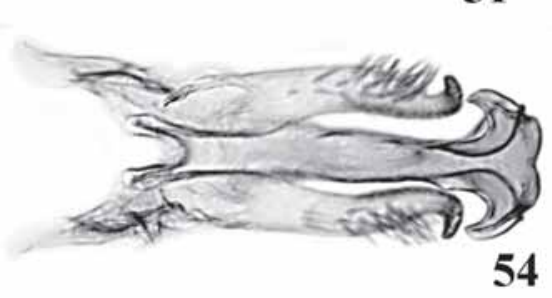

54

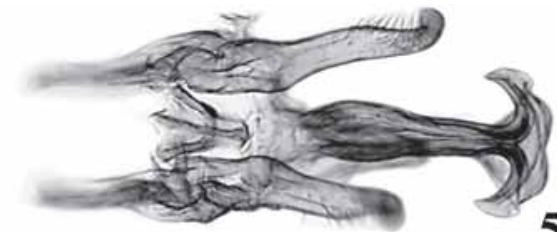

52

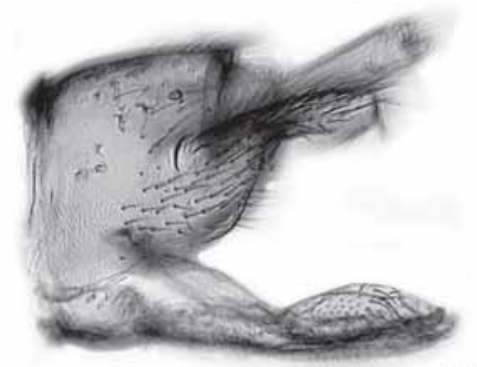

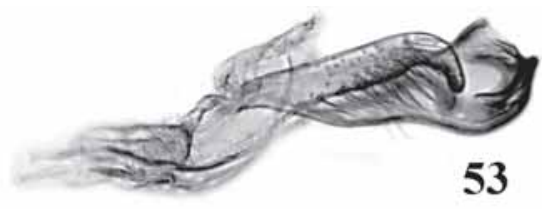

53

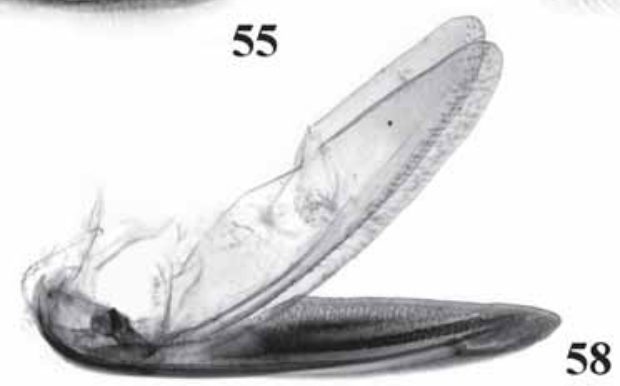

57

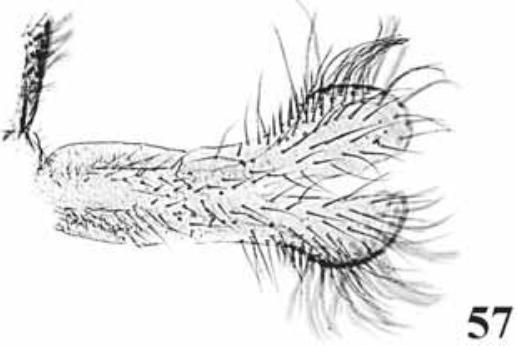

Figures 51-58. Fasciata group. (51-57) Males: (51-52) Tolania gracilis paratype: (51) genitalia, lateral view; (52) same, ventral view; (5354) T. laticlava holotype: (53) genitalia, lateral view; (54) same, ventral view; (55-56) T. gracilis paratype: (55) pygofer, lateral view; (56) same, dorsal view; (57) T. laticlava holotype, subgenital plate; (58) T. gracilis paratype female, second and third valvulae.

2.8-2.9; width across tips of horns [broken]/4.6-4.8; forewing length 6.9/7.0-7.1.

Material examined. Holotype male: “DPTo ZOOL/ UF PARANA; P.N. ITATIAIA - RJ/ BRASIL - 8/9/1967/ M. Alvarenga leg; Albertson Research/ TOL-0832 o; Holotype/ Tolania/ laticlava/ Albertson" [UFPC]. Paratypes: 2 females, "Sa. BOCAINA - SP./ Brasil" [UFPC]; 1 female, "Passa Quatro/ M. Geraes Brazil" [NCSU].

Distribution. Brazıl: Minas Gerais; Rio de Janeiro; São Paulo. Collection dates: September and November.

Notes. Tolania laticlava resembles T. fasciata, differing in the shape and elevation of the suprahumeral horns and the absence of a black abdominal band. The male holotype is in poor condition with the suprahumeral horns broken, the pronotum nearly separated from the thorax, and a forewing torn.

The name 'laticlava' is a combination of the Latin words latus and clavus meaning "broad" and "stripe" respectively, and refers to the macula of the forewing.

\section{femoralis group}

Figs 60-79

Diagnosis. This species group differs from other Tolania in having the following combination of features: vertex less than twice as wide as high; mesothoracic tibia with cucullate setal row I present; lateral plate parallel-sided in lateral view; and aedeagus broad in lateral view, strongly compressed.

Description. Head. Vertex width between eyes less than twice height; dorsomedial surface flat; ventrolateral margin carinate; ocelli sessile. Frontoclypeus with apex directed ventrally in lateral view. Thorax. Pronotum punctation dense; densely covered with short pubescence; metopidium high, nearly vertical; suprahumeral horns variable. Scutellum with base slightly inflated, evenly convex; apex with distinct median Iongitudinal groove. Legs: mesothoracic tibia with cucullate setal row I well developed. Tymbals large and conspicuous, extending beyond posterior margin of metathorax. Forewing with $1 \mathrm{~s}$ crossvein present; $1 \mathrm{r}$-m crossvein present; $\mathrm{m}$ crossvein absent; $m$-cu crossvein connected between first and second vein $M$ fork. Male. Abdomen in dorsal view evenly tapered. Lateral plate (Fig. 75) more than half length of subgenital plate; in lateral view parallel-sided, truncate or rounded apically. Subgenital plates (Fig. 76) with subbasal constriction, apical two-thirds tapered (except T. roberti); uniformly sclerotized without distinct fenestra. Aedeagus (Figs 69-74) broad in lateral view, strongly compressed in ventral view; gonopore on ventral preapical surface. Style with shank and apex variable. Female. Second valvulae variable. 


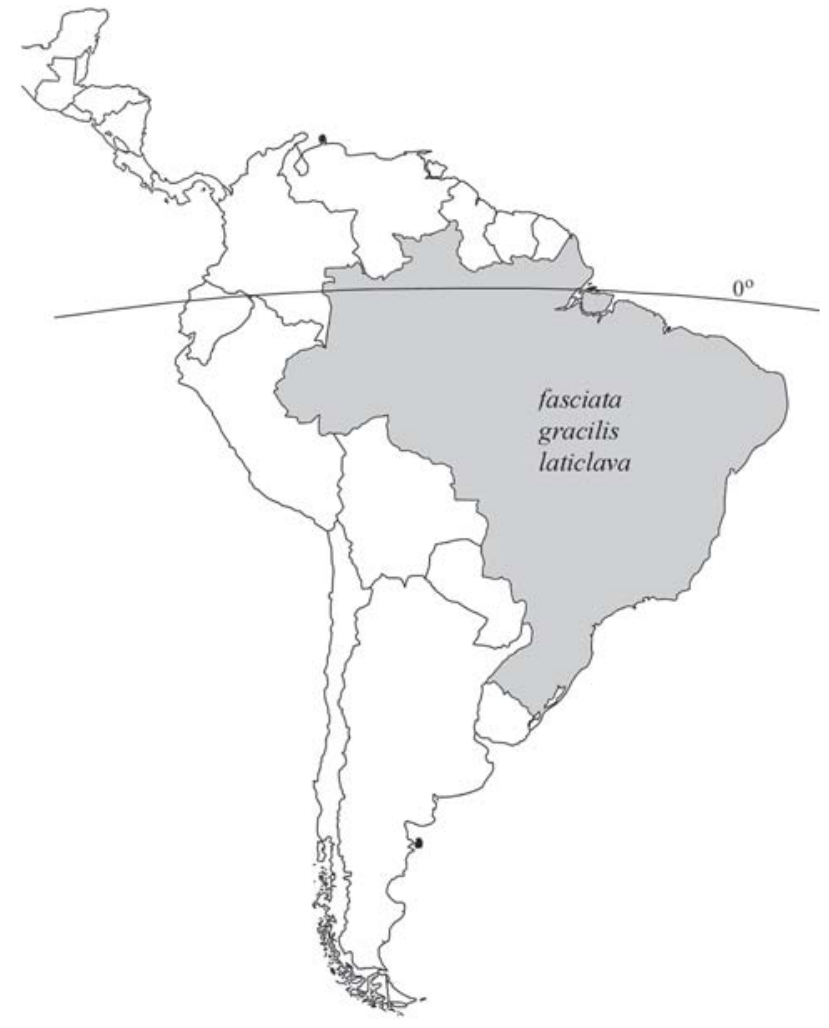

Figure 59. Known distributions of the fasciata group species.

Notes. In the phylogenetic analysis (AlberTson \& Dietrich 2005), the species in the femoralis group were united by the following characters: the vertex with ventral margins carinate; the aedeagus shaft broad in lateral view, strongly compressed in ventral view, with dorsal processes; and the connective posteriorly produced into a short arm. (Fig. 79).

The species in this group are recorded only from Brazil

\section{Tolania femoralis Stål, 1862 \\ Figs 60-61, 66, 69-70, 75}

T[olania] femoralis Stål, 1862b: 37.

Type locality. Rio de Janeiro, Brazil [NRS].

Diagnosis. This species differs from others in the group in having the face red or reddish yellow and the aedeagus with a broad serrate apical flange.

Description. Color. Head and forewing basal sclerotization yellow or dark yellow overall with variable red and black markings; face and ventral margin of metopidium dark red, or reddish yellow; pronotum yellow, red dorsally; scutellum yellow with reddish orange basolaterally; thoracic venter black; femora black with yellow basally and apically, tibiae and tarsi yellow. Forewing membrane orange hyaline. Head. Frontoclypeus ventral lobe with lateral margins convex. Thorax. Pro- notum densely covered with long white setae, dark setae on suprahumeral horn dorsally; median longitudinal carina with dorsal acute process absent or present; suprahumeral horns well developed, dorsal surface even with dorsal midline, in dorsal view triangular (Fig. 61), with anterior carina. Scutellum apex with punctures absent. Legs: metathoracic tibia with 7-9 supranumerary cucullate setae betweens rows II and III. Male. Subgenital plateroundly tapered in apical two-thirds. Aedeagus (Figs 69-70) with pair of acute dorsal projections preapically; apex expanded into broad flange, serrate laterally. Style (Fig. 70) with shank distinctly narrowed preapically; apex oriented ventrally, notched. Female. Second valvulae abruptly broadened near midlength, dorsal margin distinctly angulate; uniformly dentate dorsally.

Measurements (mm). Male/female. Body length 6.1/6.88.2; head width 2.5/2.5-2.9; width across pronotal humeri 2.3/ 2.3-2.7; width across tips of horns 2.6/3.1-3.6; forewing length 5.1/5.8-6.9.

Material examined. Lectotype female, here designated: “Rio Jan; Stål; Typus; Albertson Research/ TOL-0990 ㅇ” [NRS]. Paralectotype: "Brasil; Paratypus; Albertson Research/ TOL-0988 o " [NRS]. Other material: 1 male, 8 females [MZSP, UFPC, USNM].

Distribution. Brazıl: Rio de Janeiro; São Paulo. Collection dates: September to November.

Notes. Stål (1862) apparently examined two female specimens, which are currently in the NRS and labeled "Typus" and "Paratypus", respectively. According to ICZN Art. 72.4.7 the labels cannot be construed as an indication that the specimen labeled "Typus" is the holotype. Because Stål did not make explicit type designations in his publication, in accordance with ICZN Art. 74.7, we designate the specimen labeled "Typus" as the lectotype of T. femoralis to fix the identity of the species. The specimen labeled "Paratypus" thus becomesa paralectotype. The color description above is based on the type series. The coloration varies as follows: vertex mottled red and yellow with black markings, or black and orange; frontoclypeus black; pronotum yellow overall with black ventral margin, suprahumeral horns red dorsally, black ventrally; scutellum yellow with basolateral margins red; femora black with red venter and yellow apically.

\section{Tolania fraterna Stål, 1862}

Figs 62-63, 67, 71-72, 76-77

T[olania] fraterna Stål, 1862b: 37.

Type locality. Rio de Janeiro, Brazil [NRS].

Diagnosis. This species differs from others in the group in having the overall coloration yellow with black punctures and the aedeagus with the apex weakly produced laterally, serrate.

Description. Color. Head, pronotum, and forewing basal sclerotization yellow overall with black punctures and variable reddish orange markings; scutellum yellow with two reddish orange maculae basally; thoracic venter reddish orange to black; legs yellow, femora with longitudinal black stripe present or 

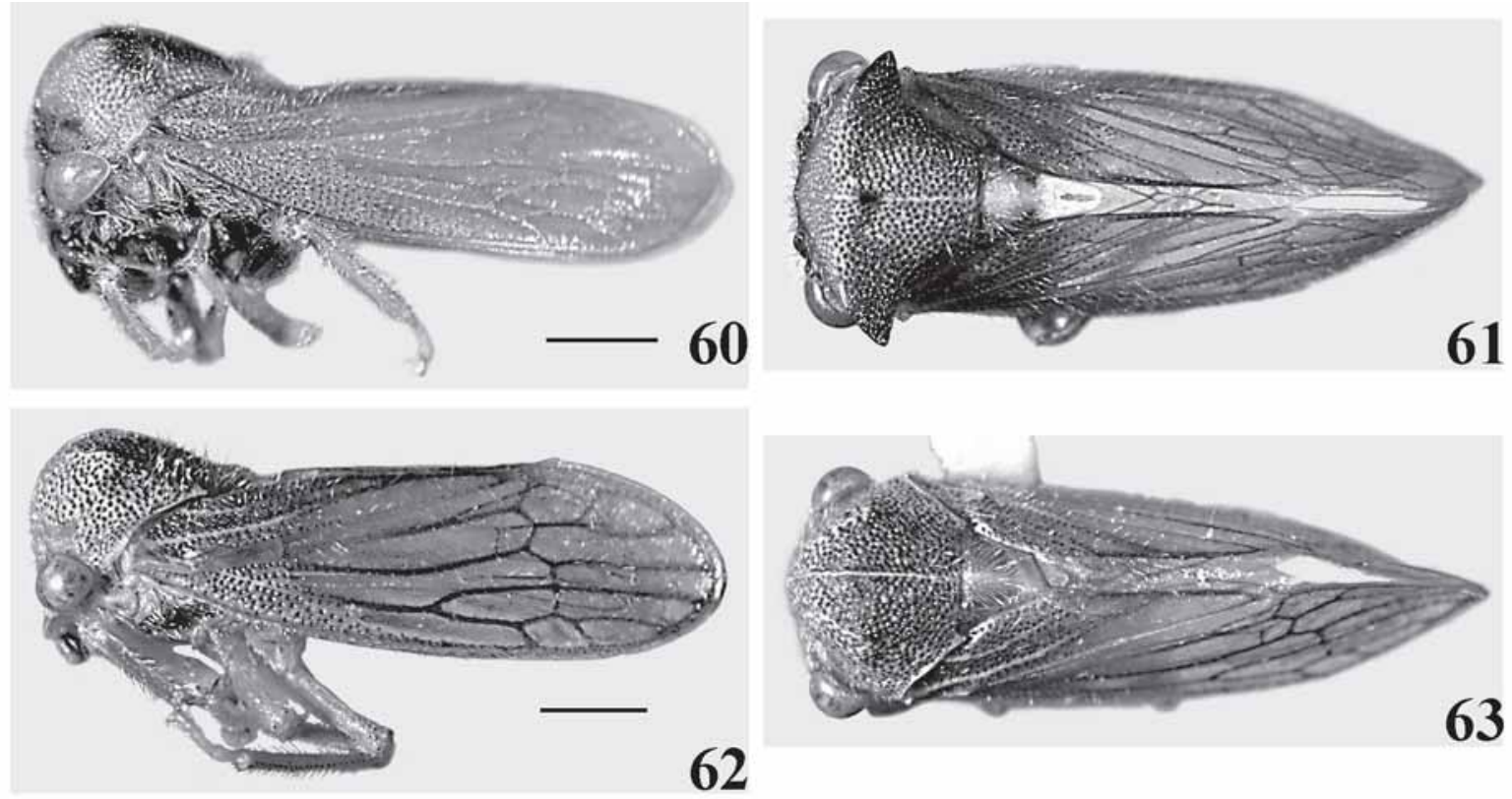

62
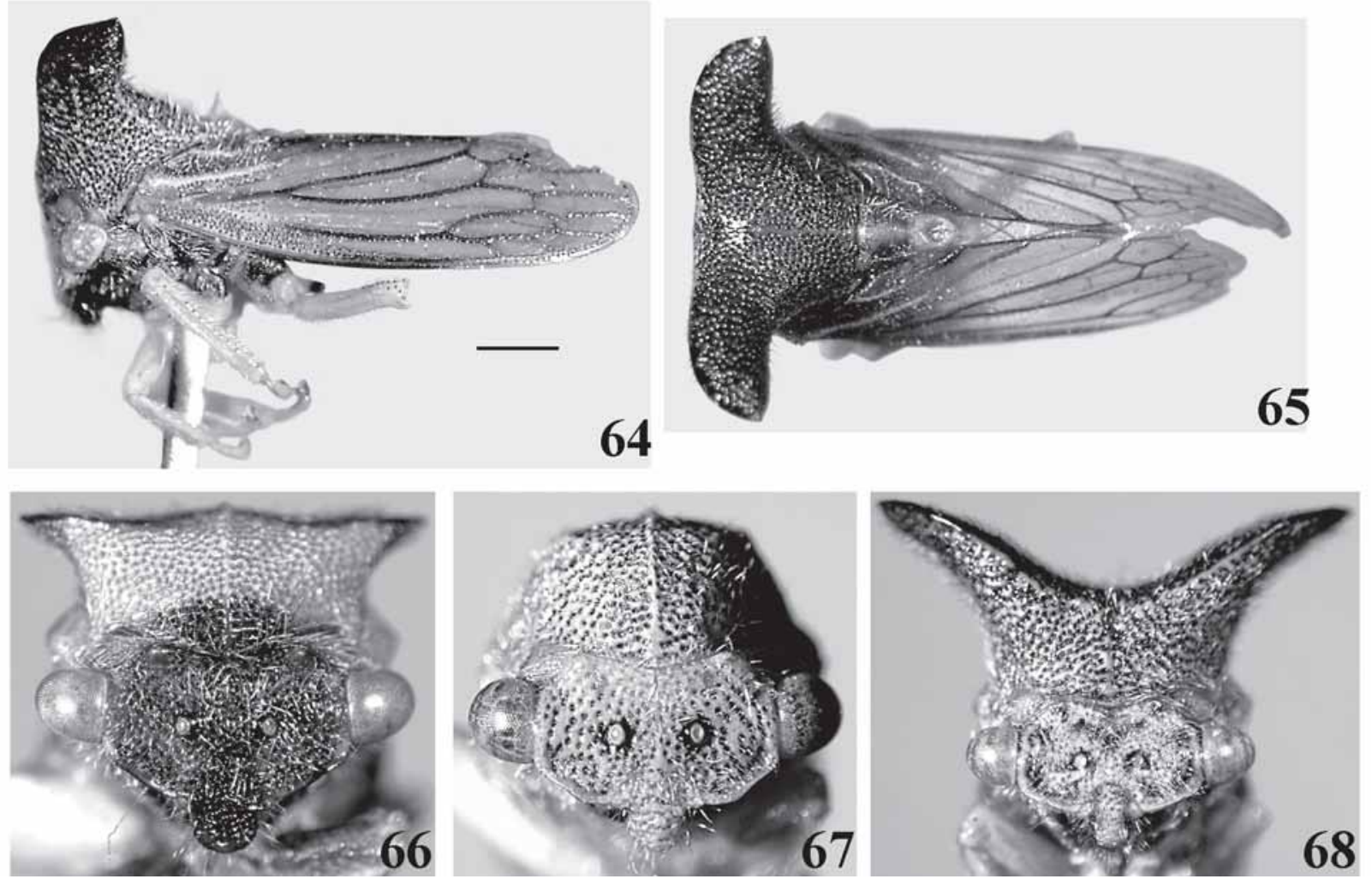

Figures 60-68. Femoralis group adult habitus. (60-61) Tolania femoralis Stål male: (60) lateral view; (61) dorsal view; (62-63) T. fraterna Stål male: (62) lateral view; (63) dorsal view; (64-65) T. roberti holotype male: (64) right lateral view, inverted; (65) dorsal view; (66-68) anterior view: (66) T. femoralis Stål male; (67) T. fraterna Stål male; (68) T. roberti holotype male.

Revista Brasileira de Zoologia 23 (4): 915-993, dezembro 2006 


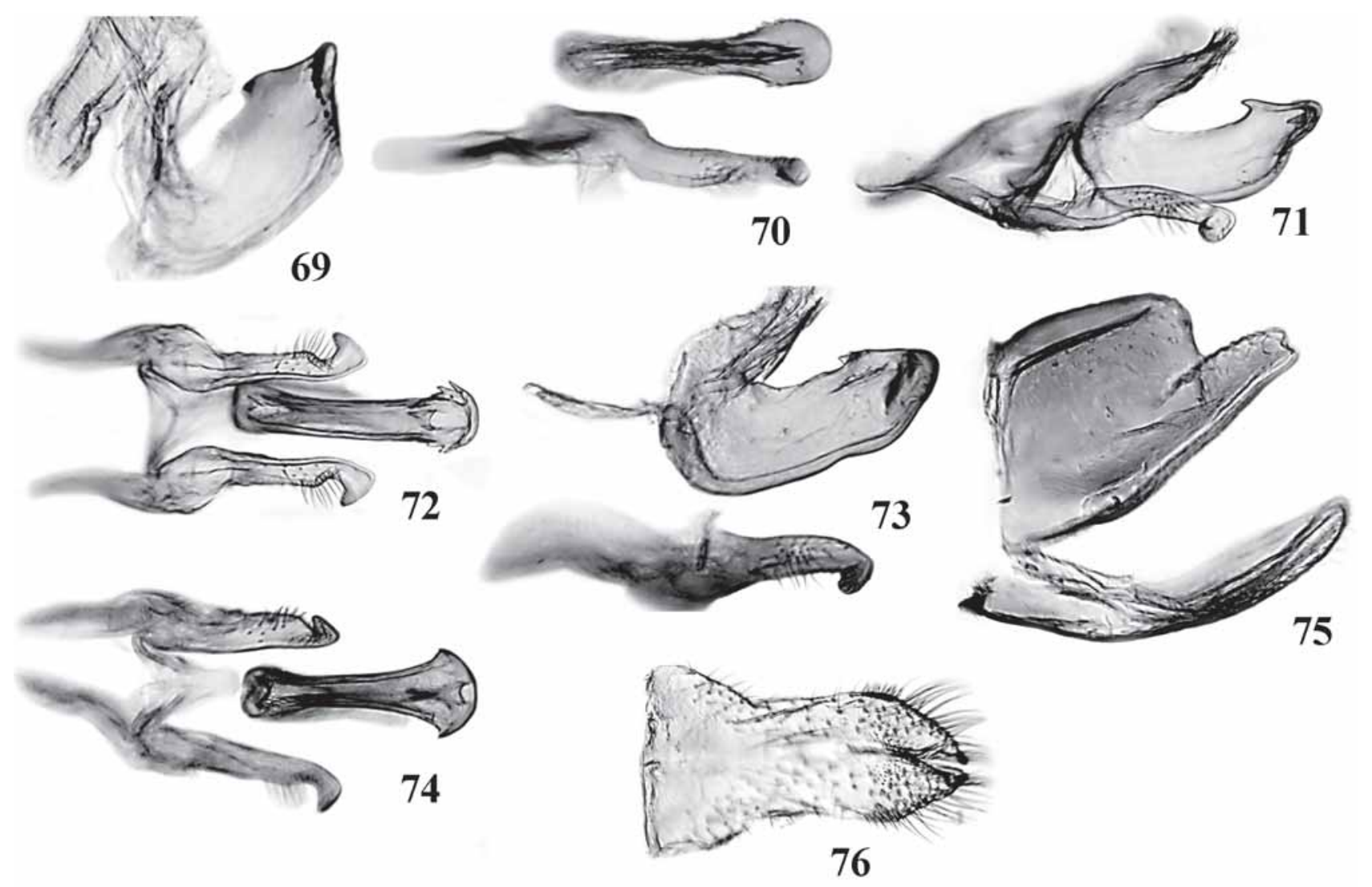

\section{7}

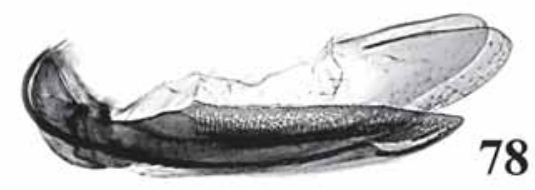

Figures 69-78. Femoralis group. (69-76) Males: (69-70) Tolania femoralis Stål: (69) genitalia, lateral view; (70) same, ventral view; (7172) T. fraterna Stål: (71) genitalia, lateral view; (72) same, ventral view; (73-74) T. roberti holotype: (73) genitalia, lateral view; (74) same, ventral view; (75) T. femoralis Stål, pygofer, lateral view; (76) T. fraterna Stål, subgenital plate; (77-78) females: (77) T. fraterna Stål, second valvulae; (78) T. roberti paratype, second and third valvulae.

absent. Forewing membrane orange to brown hyaline; veins black, pale apically; commisural margin black. Head. Frontoclypeus lateral lobes distinct; ventral lobe with lateral margins convex. Thorax. Pronotum densely covered with long white setae; median longitudinal carina weakly elevated anteriorly, acutely produced dorsally; suprahumeral horn development polymorphic (weakly developed, tuberclelike (Fig. 67) or well developed), well developed horns erect, in dorsal view triangular or acuminate, with anterior and posterior carinae. Scutellum with apex punctate. Legs: metathoracic tibia with 78 supranumerary cucullate setae between rows II and III. Male. Aedeagus (Figs 71-72) with pair of acute dorsal projections preapically; apex weakly produced laterally, serrate. Style (Figs 71-72) with shank distinctly narrowed preapically; apex bent laterally, rounded. Female. Second valvulae (Fig. 77) abruptly broadened near midlength, dorsal margin distinctly angulate; uniformly dentate dorsally.

Measurements (mm). Male/female. Body length 4.9-5.9/ 5.5-6.0; width of head 2.1-2.2/2.3-2.4; width across pronotal humeri 1.9-2.1/2.2-2.3; forewing length 4.2-5.0/4.6-5.0.

Material examined. Lectotype male: "Rio Jan; F. Sahlb.; Allotypus; Albertson Research/ TOL-0987 o" [NRS]. Paralectotype female: "Rio Jan; Stål; Typus; Albertson Research/ TOL-0989 " [NRS]. Other material: 7 males, 34 females [BM NH, MZSP, NCSU, UFPC, USNM].

Distribution. Brazıl: Minas Gerais; Paraná; Rio de Janeiro; Rio Grande do Sul; Santa Catarina; São Paulo. Collection dates: January, September to November.

Revista Brasileira de Zoologia 23 (4): 915-993, dezembro 2006 


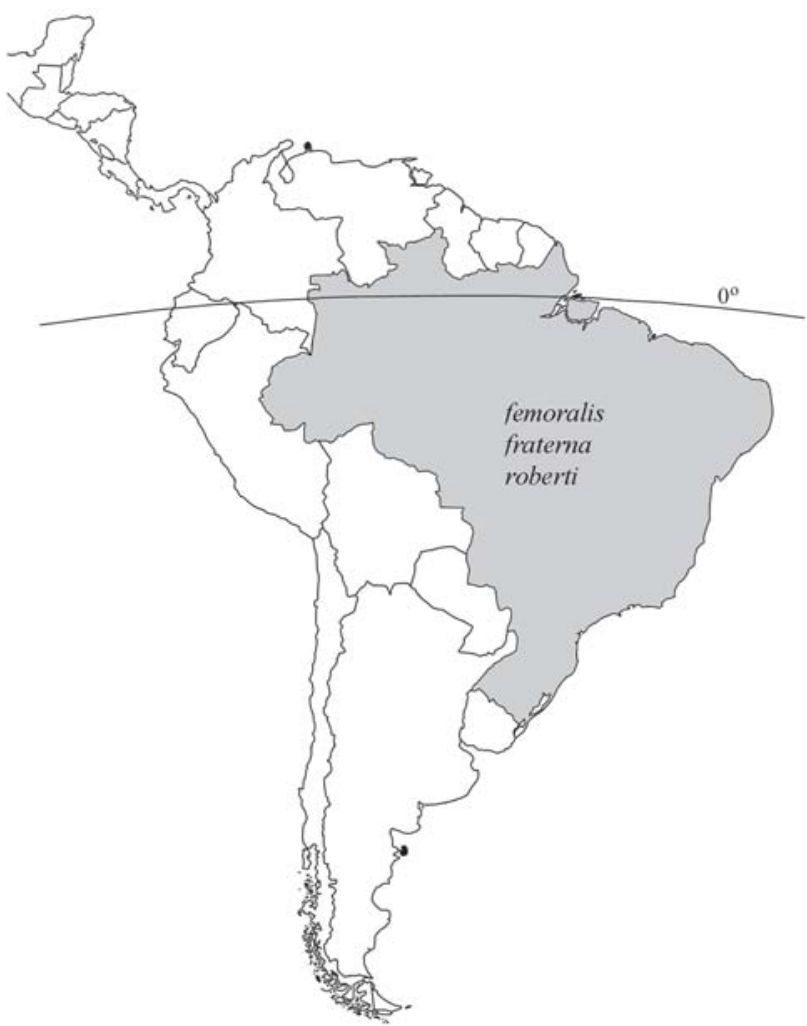

Figure 79. Known distributions of the femoralis group species.

Notes. Two specimens apparently examined by Stål in NRS are labeled "Typus" and "Allotypus", but as noted for T. femoralis, under ICZN Art. 72.4.7 this label evidence does not suffice to establish that the specimen labeled "Typus" is the holotype. The two specimens should therefore be considered syntypes. To fix the identity of T. fraterna, we designate the male specimen labeled "Allotypus" as lectotype because the male genitalia provide the most reliable characters for species identification. The color description above is based on the type specimens. Other specimens vary as follows: vertex mottled black and red; pronotum yellow or dark orange or mottled black and yellow; scutellum yellow with basolateral margins red; forewing veins yellow; thoracic venter black with yellow stripe laterally; femora black, tibiaeyellow with dark transverse bands.

\section{Tolania roberti Albertson, sp. nov. Figs $64-65,68,73-74,78$}

Typelocality. Nova Teutonia, Santa Catarina, Brazil [UFPC].

Diagnosis. This species differs from others in the group in the large size, the broad suprahumeral horns, the scutellum with a distinct depression apically, and the aedeagus with the apex produced laterally into short acute projections.

Description. Color. Head and metopidium mottled yellow and reddish brown; pronotum reddish brown dorsally; scutellum yellow with basolateral margins brown; thoracic venter black; legs yellow. Forewing basal sclerotization brown with yellow veins, membrane hyaline. Head. Frontoclypeus lateral lobes distinct; ventral lobe with lateral margins slightly convex. Thorax. Pronotum with suprahumeral horns well developed, erect; in dorsal view broad, nearly foliaceous or spatulate (Fig. 65), extending laterally; with anterior and posterior carinae. Scutellum apex with punctures absent; median Iongitudinal groove absent, with distinct circular depression posteriorly. Legs: metathoracic tibia with 6-8 supranumerary cucullate setae between rows II and III. Male. Subgenital plates with lateral margins parallel basally, constricted near midlength, apical half tapered. Aedeagus (Figs 73-74) with pair of acute dorsal processes preapically; apex broad and convex, produced laterally into acute projections. Style (Figs 73-74) with shank distinctly narrowed preapically; apex bent laterally, rounded. Female. Second valvulae (Fig. 78) width more or less uniform throughout, irregularly dentate dorsally.

Measurements (mm). Male/female. Body length 6.6/7.37.9; head width 2.5/2.8-2.9; width across pronotal humeri 2.4/ 2.7-2.8; width across tips of horns 4.2/5.4-5.7; forewing length 5.4/6.0-6.5

Material examined. Holotype male: "Brasilien/ Nova Teutonia/ 27일'B, 52은'L/ Fritz Plaumann/ XI 1976/ 300500m; Albertson Research/ TOL-0837 o; Holotype/ Tolania/ roberti/ Albertson" [UFPC]. Paratypes: 3 females, same locality [NCSU, UFPC]

Distribution. BrazIL: Santa Catarina. Collection dates: January and November.

Notes. Tolania roberti is named for the first author's husband, Robert Padgett.

\section{furcata group \\ Figs 80-97}

Diagnosis. This species group differs from other Tolania in having the following combination of features: vertex less than twice as wide as high, suprahumeral horns weakly developed or small, and mesothoracic tibia without cucullate setal rows.

Description. Head. Vertex width between eyes less than twice height; ventrolateral margin foliaceous; ocelli sessile. Frontoclypeus with apex directed ventrally in lateral view; median Iongitudinal carina absent. Thorax. Pronotum punctation dense; densely covered with short setae; metopidium high, nearly vertical; suprahumeral horns weakly developed, not extending beyond humeral angles, or carinate. Scutellum with base slightly inflated, evenly convex; apex punctate, with distinct median longitudinal groove. Legs: mesothoracic tibia without cucullate setal rows; metathoracic tibia with supranumerary cucullate setae present between rows II and III. Tymbals large and conspicuous, extending beyond posterior margin of metathorax. Forewing with $1 \mathrm{~s}$ crossvein present; 1 r-m crossvein present; $\mathrm{m}$ crossvein absent; $\mathrm{m}$-cu crossvein con- 
nected between first and second vein $M$ fork. Male. Abdomen in dorsal view with lateral margins roundly tapered between segments III-VI, segments VII and VIII attenuate. Lateral plate length more than half length of subgenital plate. Subgenital plate without constriction, tapered (except T. venezuelensis, weakly constricted basally); uniformly sclerotized without distinct fenestra. Aedeagus with pair of bifurcate apical processes (except T. tryphena). Connective with anterior margin strongly emarginate, apices divergent; posterior apex variable. Style with shank and apex variable. Female. Second valvulae (Figs 95-96) broadened near midlength, dorsal margin distinctly angulate; uniformly dentate dorsally.

Notes. These species formed a monophyletic group with low support (DI =1) in the phylogenetic analysis (ALBERTSON \& DIETRICH 2005), united by the bifurcate apical aedeagal processes of two of the three species.

The species in this group have been collected in Bolivia, Peru, and Venezuela (Fig. 97).

\section{Tolania furcata Albertson, sp. nov. Figs $80-81,86,88-89$, 94-95}

Type locality. Villa Tunari, Cochabamba, Bolivia [INHS].

Diagnosis. This species differs from others in the group in having the aedeagus with a dorsal bifurcate process basally and the shaft distinctly tapered with a pair of slender bifurcate processes apically.

Description. Color. Coloration yellow overall. Forewing membrane hyaline. Head. Vertex (Fig. 86) with dorsomedial surface flat. Frontoclypeus ventral lobe with lateral margins convex. Thorax. Pronotum with suprahumeral horns carinate (Fig. 81). Legs: metathoracic tibia with 7-9 supranumerary cucullate setae between rows II and III. Male. Lateral plate (Fig. 94), in lateral view, robust; strongly curved mesad apically. Aedeagus (Figs 88-89) with dorsal bifurcate process basally; shaft distinctly tapered, apex thin; with pair of slender apical processes, each with small projection subbasally; gonopore on ventral preapical surface. Connective (Fig. 89) posteriorly produced into short arm. Style (Figs 88-89) with shank broad basally, abruptly narrowing subbasally; apex hooked laterally. Female. Second valvulae (Fig. 95) broadened near midlength, dorsal margin distinctly angulate; uniformly dentate dorsally.

Measurements (mm). Male/female. Body length 5.0/5.55.9; head width 2.4/2.6-2.7; width across pronotal humeri 2.1/ 2.3-2.5; forewing length 4.3/4.7-5.0.

Material examined. Holotype male: "BOLIVIA: Cochabamba Prov./ Villa Tunari 08.XI.2001/ tropical forest, malaise trap/ 1654'55"S, 65²2'06"W/ leg. Helmut Heider; Albertson Research/ TOL-1001 o", Holotype/ Tolania/ furcata/ Albertson" [INHS]. Paratypes: 7 females, same locality [INHS].

Distribution. BolıviA: Cochabamba. Collection dates: January, July, and October to November.

Notes. The specific name 'furcata' is derived from the Latin word furcatus and translates as "forked, two-pronged", referring to the process at the base of the aedeagus.

\section{Tolania tryphena Albertson, sp. nov.}

Figs 82-83, 90-91

Type locality. Panguana, Amazonas, Peru [ZIMH].

Diagnosis. This species differs from others in the group in having the median Iongitudinal carina of the pronotum weakly keeled and acute dorsally; and the aedeagus, in lateral view, with the shaft broad basally, narrow and weakly curved apically, with a pair of acute dorsal projections medially.

Description. Color. Coloration yellow to orange overall with variable brown markings. Forewing membrane hyaline. Head. Vertex with dorsomedial surface distinctly concave. Frontoclypeus ventral lobe with lateral margins convex. Thorax. Pronotum with median Iongitudinal carina weakly keeled and acute dorsally; suprahumeral horns weakly developed, erect, triangular (Fig. 83), with anterior and posterior carina. Legs: metathoracic tibia with 9 supranumerary cucullate setae between rows II and III. Male. Lateral plate robust. Aedeagus (Figs 90-91), in lateral view, with shaft broad basally, apical half narrow and weakly curved; with pair of acute dorsal projections medially; gonopore on ventral preapical surface. Connective (Fig. 91) broadly rounded posteriorly. Style (Figs 90-91) with shank broad, abruptly narrowing preapically, in dorsal view, acute distally; apex hooked laterally, oriented ventrally with ventral projection in lateral view. Female. [not dissected].

Measurements (mm). Male/female. Body length 5.8/6.3; head width 2.4/2.5; width across pronotal humeri 2.2/2.2; width across tips of horns 1.6/2.1; forewing length 4.9/5.3.

Material examined. Holotype male: "Peru/ Panguana/ 15.7.1978/ Dubosg-Brasil; Z.I.M. Hamburg/ Eing.Nr. 3/1982/ leg. W. Fick; Albertson Research/ TOL-0665 o', Holotype/ Tolania/ tryphena/ Albertson" [ZIMH]. Paratype: 1 female, same data [ZIMH].

Distribution. Peru: Amazonas. Collection date: July

Notes. The name 'tryphena' is from the Greek word trypheros meaning "dainty, delicate".

\section{Tolania venezuelensis Albertson, sp. nov.}

Figs 84-85, 87, 92-93, 96

Type locality. San Esteban, Carabobo, Venezuela [USNM].

Diagnosis. This species differs from others in the group in having the aedeagus with a pair of stout lateral processes apically, each with a small acute subbasal projection.

Description. Color. Vertex yellow with brown to black markings; frontoclypeus yellow, black posteriorly; pronotum mottled black, brown, and yellow, median Iongitudinal carina yellow; scutellum yellow with basolateral margins orange; thoracic venter black; femora black with venter yellow, tibiae yellow with black markings, tarsi yellow. Forewing basal scleroti-

Revista Brasileira de Zoologia 23 (4): 915-993, dezembro 2006 

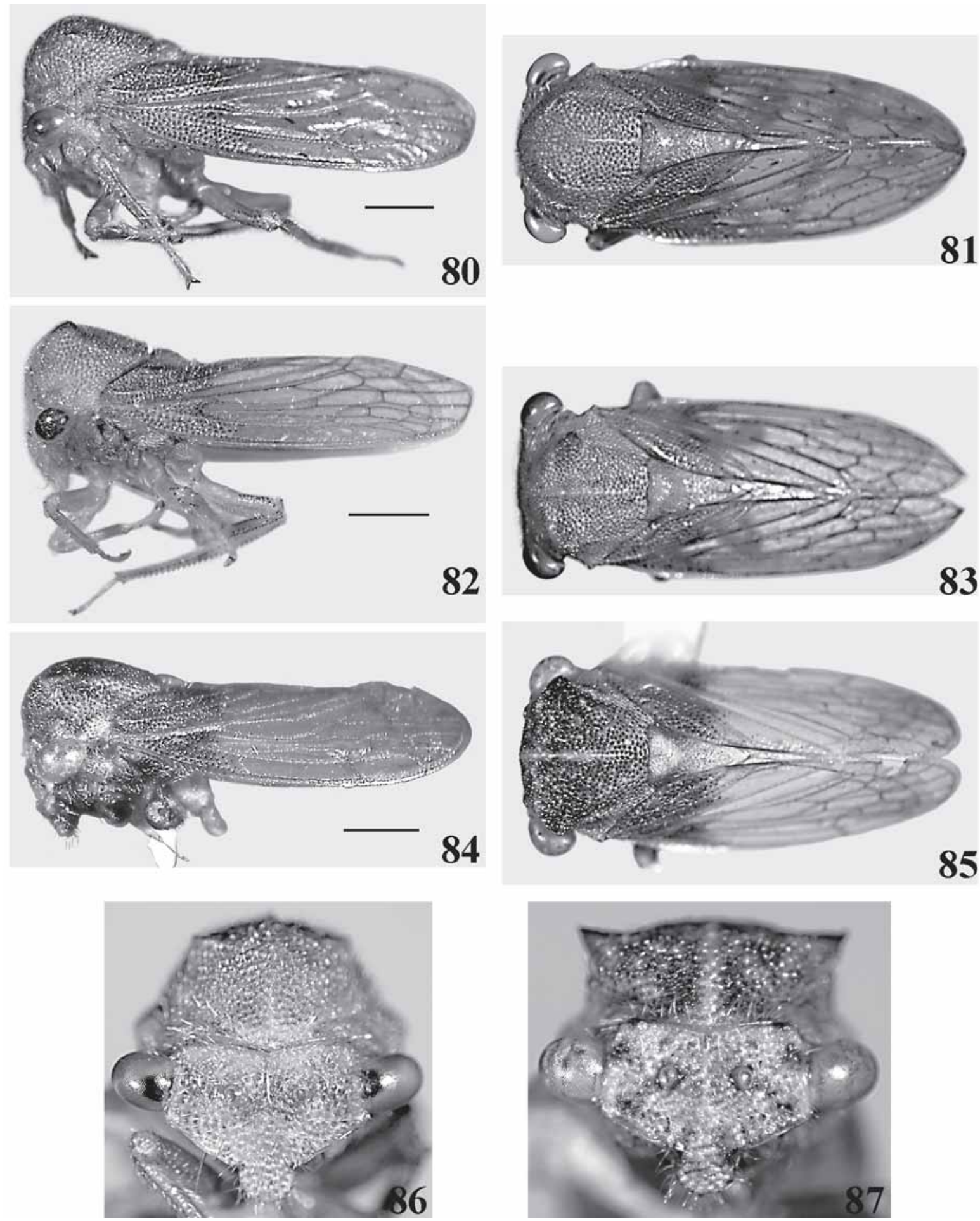

Figures 80-87. Furcata group adult habitus. (80-81) Tolania furcata holotype male: (80) lateral view; (81) dorsal view; (82-83) T. tryphena holotype male: (82) lateral view; (83) dorsal view; (84-85) T. venezuelensis holotype male: (84) lateral view; (85) dorsal view; (86-87) anterior view: (86) T. furcata holotype male; (87) T. venezuelensis holotype male.

Revista Brasileira de Zoologia 23 (4): 915-993, dezembro 2006 


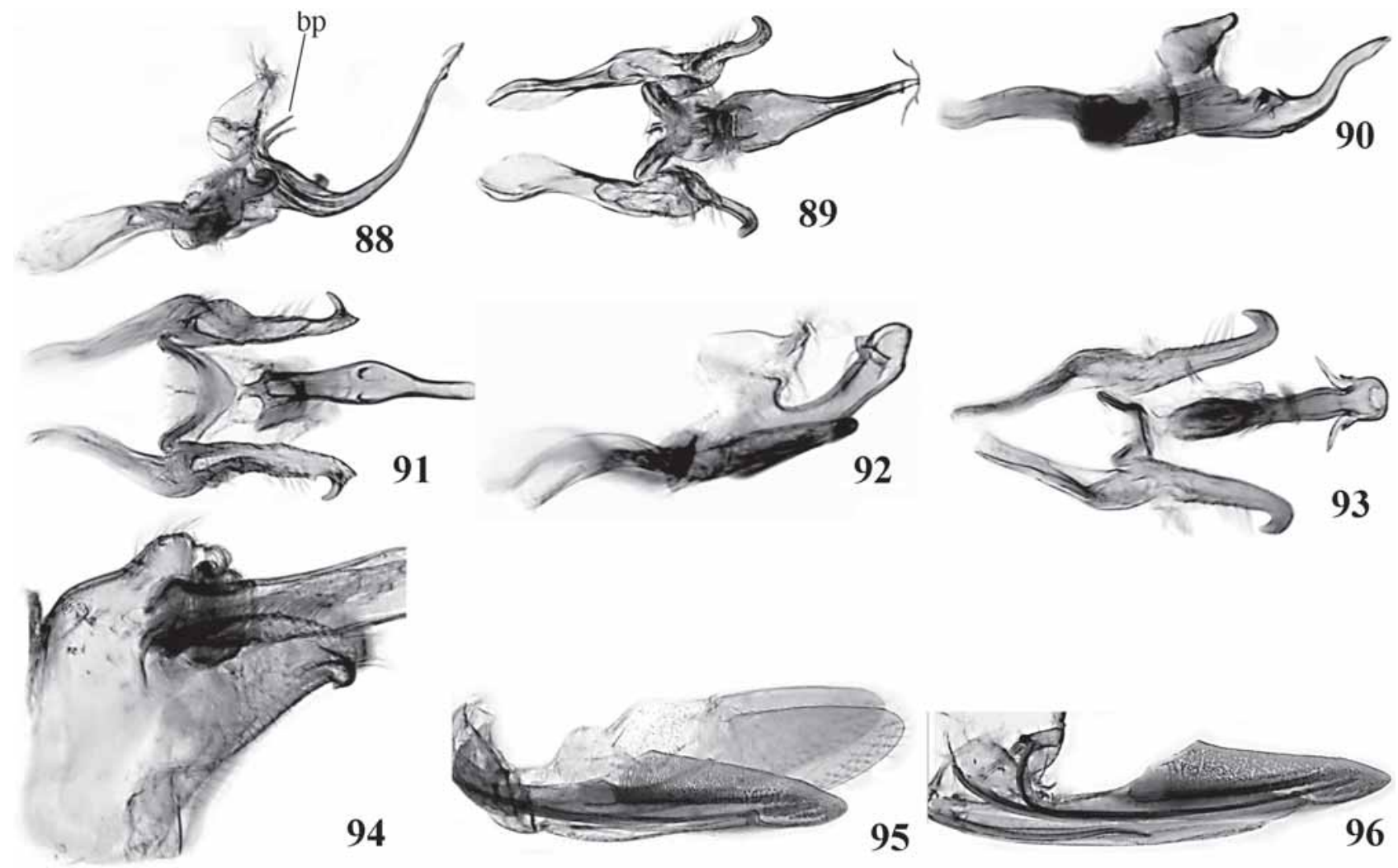

Figures 88-96. Furcata group. (88-94) Males: (88-89) Tolania furcata holotype: (88) genitalia, lateral view; (89) same, dorsal view; (9091) T. tryphena holotype: (90) genitalia, lateral view; (91) same, ventral view; (92-93) T. venezuelensis holotype: (92) genitalia, lateral view; (93) same, dorsal view; (94) T. furcata holotype, pygofer, lateral view; (95-96) females: (95) T. furcata paratype, second and third valvulae; (96) T. venezuelensis paratype, second valvulae. bp: Bifurcate process.

zation mottled brown and yellow with black punctures; membrane hyaline. Head. Vertex (Fig. 87) with dorsomedial surface flat. Frontoclypeus ventral lobe with lateral margins convex. Thorax. Pronotum with metopidium appearing pinched along ventral margin and inflated dorsad of supraocular callosity; suprahumeral horns weakly developed, dorsal surface of horn even with dorsal midline, in dorsal view short, nearly trianguIar (Fig. 85), with anterior carina. Legs: metathoracic tibia with 9 supranumerary cucullate setae between rows II and III. Male. Lateral plate slender, evenly tapered. Subgenital plate weakly constricted basally, apical two-thirds tapered. Aedeagus (Figs 92-93) with pair of stout lateral processes apically, each with small acute subbasal projection; gonopore on ventral preapical surface. Connective (Fig. 93) truncate posteriorly. Style (Figs 92-93) slender throughout with apex hooked laterally and acute. Female. Second valvulae (Fig. 96) broadened near midlength, dorsal margin distinctly angulate; uniformly dentate dorsally.

Measurements (mm). Male/female. Body length 4.6/6.0; head width 2.2-2.4/2.6; width across pronotal humeri 2.0-2.1/2.3; width across tips of horns 1.8-2.1/2.8; forewing length 3.6/4.7.
Material examined. Holotype male: "San Esteban/ Venezuela/ 22-XI-39; Tolania/ opponens [misidentification]/ (Walk.)/ det. Funkh. 1940; Albertson Research/ TOL-0041 ơ, Holotype/ Tolania/ venezuelensis/ Albertson" [USNM]. Paratypes: 2 females, same data [USNM].

Distribution. Venezuela: Carabobo. Collection date: November.

Notes. The female may vary in color, with the metopidium and lateral margins of the pronotum yellow to orange and the femora and tibiae entirely yellow. The specific name 'venezuelensis' refers to the country in which the type specimen was collected.

\section{hispida group}

Figs $98-120$

Diagnosis. This species group differs from other Tolania in having the following combination of features: head and pronotum with erect setae and highly polished in appearance, vertex less than twice as wide as high, mesothoracic tibia with cucullate setal row I present.

Revista Brasileira de Zoologia 23 (4): 915-993, dezembro 2006 


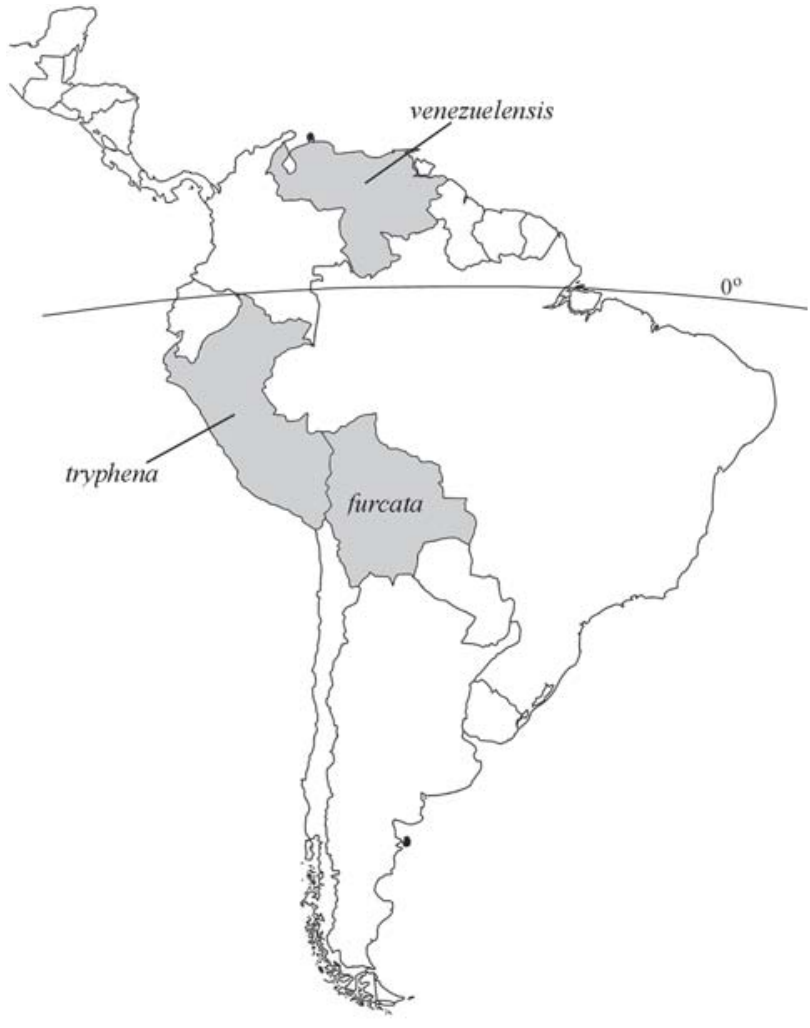

Figure 97. Known distributions of the furcata group species.

Description. Head. Vertex width between eyes less than twice height; dorsomedial surfaceflat (variablein T. hispida); ventrolateral margin foliaceous; ocelli stalked or sessile. Frontoclypeus with apex directed ventrally in lateral view. Thorax. Pronotum appearing polished, densely punctate, sparsely to densely covered with long erect setae; metopidium high, nearly vertical; suprahumeral horns weakly developed and tuberclelike or well developed. Scutellum apex with distinct median Iongitudinal groove. Legs: mesothoracic tibia with cucullate setal row I well developed. Tymbals small, not extending beyond posterior margin of metathorax. Forewing with $1 \mathrm{~s}$ crossvein present; $1 \mathrm{r}-\mathrm{m}$ crossvein present; $\mathrm{m}$ crossvein absent; $\mathrm{m}$-cu crossvein connected between first and second vein $M$ fork. Male. Abdomen in dorsal view evenly tapered. Lateral plate (Fig. 115) morethan half length of subgenital plate. Subgenital plate (Fig. 116) uniformly sclerotized without distinct fenestra. Aedeagus variable; with gonopore on ventral preapical surface. Connective (Fig. 110, 114) with anterior margin strongly emarginate, apices divergent; acuminate to broadly rounded posteriorly. Style with shank and apex variable. Female. Second valvulae uniformly dentate dorsally.

Notes. In the phylogenetic analysis (AlberTson \& Dietrich 2005), Tolania hispida and T. periculosa formed a monophyletic group with low support ( $\mathrm{DI}=2$ ), supported by the conical dorsal processes of the vertex and by features of the dorsal and apical processes of the aedeagus. Tolania alida was not included in the analysis because only the female in known.

The species of this group have been collected in Costa Rica, Colombia, Ecuador, and Panama (Fig. 120).

\section{Tolania alida Albertson, sp. nov. Figs 98-99, 106, 117}

Typelocality. El Llano-Carti Road km. 9, Panama, Panama [GMNH].

Diagnosis. This species differs from others in the group in having distinct black and yellow coloration on the pronotum and the forewing black with a hyaline fenestra medially.

Description. Color. Coloration yellow and black. Head: vertex black with yellow markings on ventrolateral margin and midline; frontoclypeus black. Pronotum with metopidium yellow, black macula extending from median longitudinal carina to ventral margin; black dorsally; suprahumeral horns black dorsally, yellow with black apex ventrally. Scutellum base yellow with basolateral margins and apex black. Thoracic venter black. Legs: femora black with yellow apically; tibiae yellow with black apically; tarsi yellow, third tarsomere black apically. Forewing basal sclerotization black, clavus with yellow macula basally; membrane opaque black with hyaline fenestra from first anal vein to costal margin medially. Abdomen yellow with red transverse stripe on distal margin of sternites. Head. Vertex (Fig. 106) with dorsomedial surface flat; ocelli stalked. Frontoclypeus with dorsal plate slightly depressed; ventral lobe with lateral margins parallel, slightly converging ventrally. Thorax. Pronotum covered in long white setae; median longitudinal carina weakly keeled and acute dorsally; suprahumeral horns well developed, erect, in dorsal view broad, acuminate apically (Fig. 99), extending posterolaterally, with posteroventral carina, anterior carina present on distal half. Scutellum with base inflated, produced dorsally; apex punctate. Legs: metathoracic tibia with 8 supranumerary cucullate setae between rows II and III. Forewing with second anal vein weak. Female. Second valvulae (Fig. 117) width more or less uniform throughout. Male. Unknown.

Measurements (mm). Female. Body length 6.9; head width 2.5; width across pronotal humeri 2.4; width across tips of horns 3.8; forewing length 6.2.

Material examined. Holotype female: "PANAMA: Panama/ El Llano-Carti Rd. km. 9/ mv + bl, 10 May 1996/ R. Turnbow; Albertson Research/ TOL-0425 ; Holotype/ Tolania/ alida/ Albertson" [GMNH].

Distribution. Panama: Panama. Collection date: May.

Notes. This species was not included in the phylogenetic analysis because only the female is known. Tolania alida was placed in the hispida group based on the presence of erect setae on the pronotum, the polished appearance, and similarities in the vertex, legs, and forewing venation.

The specific name 'alida' translates from Latin as "little winged one" and is also named for the first author's grandmother, Alida Albertson. 


\section{Tolania hispida Albertson, sp. nov. Figs 100-101, 107, 109-110, 115-116, 118} [USNM ].

Type locality. Zurqui de Moravia, San José, Costa Rica

Diagnosis. This species differs from others in the group in the reddish brown to black coloration; the aedeagus with the apex convex, produced into acute lateral projections; and the style broadest apically in lateral view.

Description. Color. Head and pronotum reddish brown to glossy black overall with variable yellow markings; pronotum with median longitudinal carina pale; scutellum paleyellow with basolateral margins black; thoracic venter black; femora black with yellow apically, tibiae and tarsi yellow. Forewing basal sclerotization yellow with black punctures and black near commisural margin, membrane hyaline to brown hyaline. Head. Vertex (Fig. 107) covered with long silvery and golden setae; dorsal processes distinctly produced dorsally and conical in shape; dorsomedial surface flat to slightly concave; ocelli stalked. Frontoclypeus ventral lobe short, lateral margins slightly converging ventrally. Thorax. Pronotum with median longitudinal carina varying from weakly elevated to weakly keeled and acutedorsally; suprahumeral horns well developed, erect, in dorsal view slender, acuminate, extending posterolaterally (Fig. 101), with anterior carina. Scutellum with base slightly inflated, evenly convex; apex without punctures. Legs: metathoracic tibia with 3-5 supranumerary cucullate setae between rows II and III. Forewing with second anal vein weak. Male. Pygofer (Fig. 115), in lateral view, with dorsal margin evenly rounded, convex. Lateral plate (Fig. 115) slender, evenly tapered. Subgenital plate (Fig. 116) evenly tapered. Aedeagus (Figs 111-112) with pair of slender dorsal processes preapically; with pair of elongate laterally curved processes apically; apex convex, produced into pair of acute lateral projections; gonopore on ventral preapical surface. Style (Figs 111-112), in lateral view, with shank slender, weakly concave preapically; apex bent laterally, expanded dorsoventrally in lateral view, bladelike. Female. Second valvulae (Fig. 118) broadened near midlength, dorsal margin distinctly angulate, weakly convex.

Measurements (mm). Male/female. Body length 5.6-6.2/ 6.0-6.5; head width 2.1-2.3/2.2-2.4; width across pronotal humeri 2.0-2.1/2.0-2.3; width across tips of horns 2.5-2.9/2.9-3.5; forewing length 4.6-5.1/5.1-5.4.

Material examined. Holotype male: "COSTA RICA, San Josél Zurqui de Moravia/ 1600m, IV. 1992/ col. Godoy, Hanson; Albertson Research/ TOL-0060 ot, Holotype/ Tolania/ hispida/ Albertson" [USNM]. Paratypes: 3 males, 2 females, same data [USNM]. Other material: 12 males, 22 females [CNC, GMNH, INBio, SHMC, UFPC, USNM].

Distribution. Colombia: Valle; Costa Rica: Cartago, Guanacaste, Heredia, Puntarenas, San José; Panama: Boca del Toro, Chiriqui, Cocle. Collection dates: March to July, September.

Notes. The female coloration is usually more pale, often nearly yellow, with black markings. Other color variations in- clude: frontoclypeus entirely black; lateral and posterior margins of pronotum yellow.

The specific name 'hispida' is from the Latin word hispidus meaning "bristly" and refers to the erect setae on the pronotum.

\section{Tolania periculosa Albertson, sp. nov. Figs 102-105, 108, 111-114, 119}

Type locality. Gatun Lake, Panama, Panama [CAS].

Diagnosis. This species is distinguished from others in the group by the overall yellow coloration with red and black markings; the aedeagus with preapical denticuli, apex narrow with 1 or more pairs of processes; and the style broader preapically than at apex in lateral view.

Description. Color. Head, pronotum, and forewing basal sclerotization yellow overall with variable red and black markings; scutellum yellow with basolateral margins red; thoracic venter black; femora black with yellow apically; tibiae and tarsi yellow to reddish yellow. Forewing membrane hyaline. Head. Vertex (Fig. 108) covered with long white setae; dorsal processes distinctly produced dorsally and conical in shape; dorsomedial surface flat; ocelli sessile. Frontoclypeus ventral lobe with lateral margins parallel, slightly converging ventrally. Thorax. Pronotum with median longitudinal carina weakly elevated to acutely produced dorsally; suprahumeral horn (Figs 102-105) development polymorphic (small and tuberclelike or well developed), elevation and shape in dorsal view polymorphic, with anterior and posterior carinae. Scutellum with base slightly inflated, evenly convex; apex sparsely punctate basally. Legs: metathoracic tibia with 3-6 supranumerary cucullate setae between rows II and III. Forewing with second anal vein well developed. Male. Pygofer, in lateral view, with dorsal margin weakly concave medially. Lateral plate slender, tapered, dorsal margin convex, slightly curved ventrad apically. Subgenital plate weakly constricted subbasally, tapered. Aedeagus (Figs 111-114) with preapical denticuli ventrally; with pair of short rounded processes preapically; apical processes variable in number (with 1, 2, or 3 pairs, or with 1 or more pairs incomplete), short and straight (Fig. 112) or more elongate and curved (Fig. 114); gonopore on ventral preapical surface. Style (Figs 111-114), in lateral view, with shank broad, narrowing and curving laterad apically, apex oriented ventrally, rounded or acute. Female. Second valvulae (Fig. 119) broadened near midlength, dorsal margin distinctly angulate.

Measurements $(\mathrm{mm})$. Male/female. Body length 5.1-6.0/ 6.0-6.7; head width 2.0-2.2/2.3-2.4; width across pronotal humeri 1.7-2.0/2.0-2.1; width across tips of horns 1.6-2.9/2.7-3.3; forewing length 4.1-5.3/5.1-5.7.

Material examined. Holotype male: "Gatun Lake/ Panama/ IX-10-31; Tres Rios/ Plantation; TO Zschokke/ Collector; EP VanDuzee/ Collection; Albertson Research/ TOL-0086 o; Holotype/ Tolania/ periculosa/ Albertson" [CAS]. Paratypes: 1 male, 1 female, same data; 1 male, 4 females, same locality [CAS]. Other material: 19 males, 49 females [BMNH, CAS, FSCA, INBio, NCSU, SHMC, USNM, ZIMH].

Revista Brasileira de Zoologia 23 (4): 915-993, dezembro 2006 

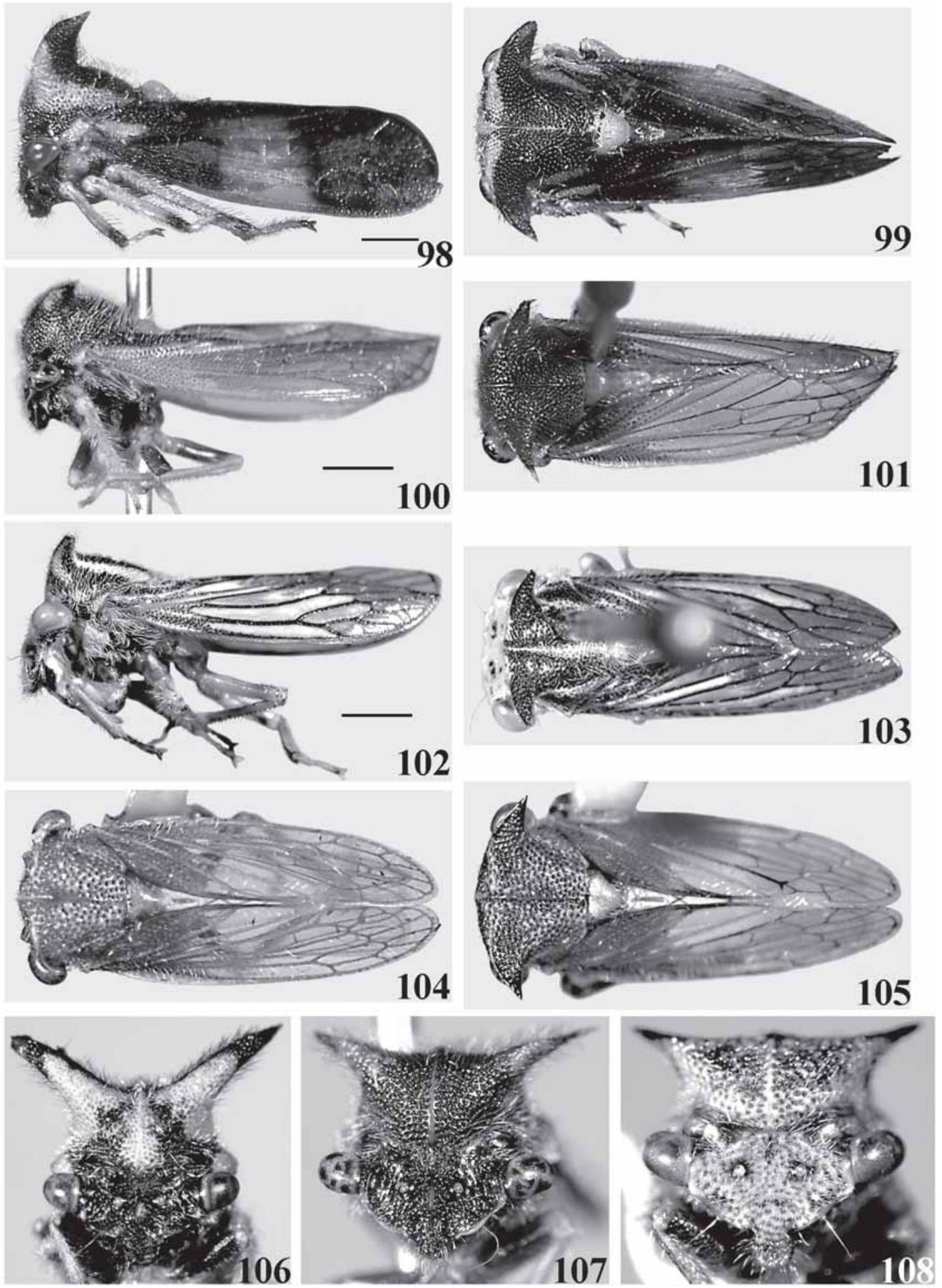

Figures 98-108. Hispida group adult habitus. (98-99) Tolania alida holotype female: (98) lateral view; (99) dorsal view; (100-101) T. hispida holotype male: (100) lateral view; (101) dorsal view; (102-103) T. periculosa male: (102) lateral view; (103) dorsal view; (104) T. periculosa holotype male, dorsal view; (105) T. periculosa male, dorsal view; (106-108) anterior view: (106) T. alida holotype female; (107) T. hispida holotype male; (108) T. periculosa male.

Revista Brasileira de Zoologia 23 (4): 915-993, dezembro 2006 


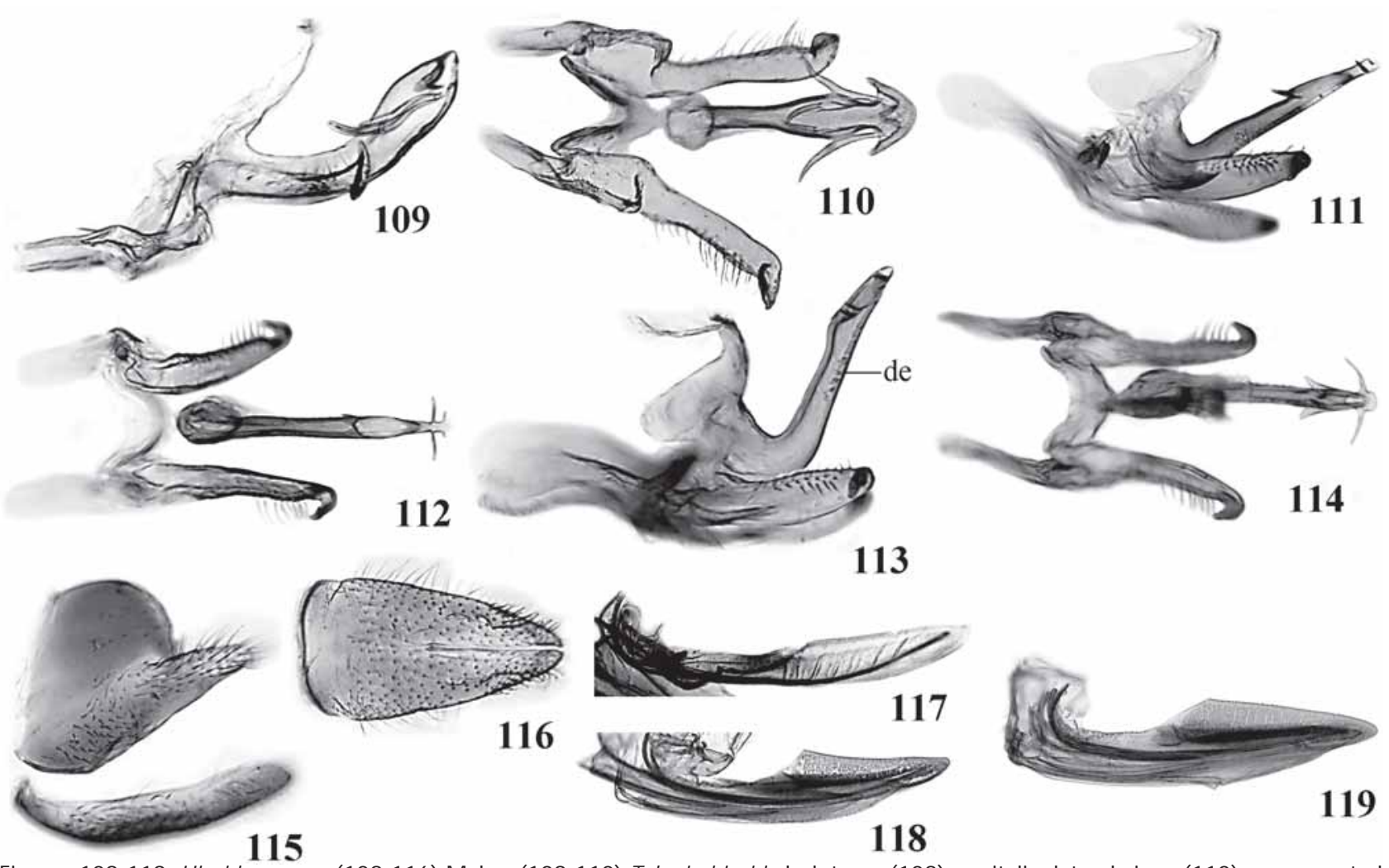

Figures 109-119. Hispida group. (109-116) Males: (109-110) Tolania hispida holotype: (109) genitalia, lateral view; (110) same, ventral view; (111-112) T. periculosa holotype: (111) genitalia, lateral view; (112) same, ventral view; (113-114) T. periculosa: (113) genitalia, lateral view; (114) same, dorsal view; (115-116) T. hispida: (115) pygofer, lateral view; (116) subgenital plate; (117-119) females: (117) T. alida holotype, second valvulae; (118) T. hispida, second valvulae; (119) T. periculosa, second valvulae. de: Denticuli.

Distribution. Colombia: Narino; Santander. Costa Rica: Limon; Puntarenas; San Jose. Ecuador: Los Rios; Napo; Pichincha. Panama: Bocas del Toro; Chiriqui; Cocle; Colon; Darien; Herrera; Panama. Collection dates: April, June to July, and September to December.

Notes. The coloration may vary as follows: bright yellow overall; pronotum with yellow and black stripes laterally, black dorsally with yellow median longitudinal carina (Figs 102-103).

The specific name 'periculosa' is Latin for "dangerous, threatening" and refers to the somewhat fierce appearance of many specimens due to the coloration of the pronotum and shape of the suprahumeral horns.

\section{malefica group}

\section{Figs 2, 121-169}

Diagnosis. This species group differs from other Tolania in having the following combination of features: vertex width less than twice height; pronotum often polished in appearance, sparsely covered with erect setae; mesothoracic tibia with cucullate setal row I, or rows I and II present; forewing with vein
$M$ initial division $M_{1+2+3}$ and $M_{4}$, and $m$-cu crossvein connected basad of first $M$ fork.

Description. Head. Vertex width between eyes less than twice height; ventrolateral margin foliaceous; ocelli elevated. Frontoclypeus with apex directed ventrally in lateral view (except T. obliqua). Thorax. Pronotum often appearing highly polished; punctation sparse, scattered (with exceptions); pubescence long and erect, sparse; metopidium high, nearly vertical (except T. obliqua). Scutellum apex with distinct median longitudinal groove. Legs: mesothoracic tibia with cucullate setal row I or rows I and II well developed. Tymbals small, not extending beyond posterior margin of metathorax. Forewing (Fig. 2) with vein $M$ initial division $M_{1+2+3}$ and $M_{4} ; 1 \mathrm{~s}$ crossvein present; $1 \mathrm{r}-\mathrm{m}$ crossvein present; $\mathrm{m}$ crossvein absent; $\mathrm{m}$-cu crossvein connected basad of first vein $M$ fork; second anal vein weakly developed. Male. Abdomen in dorsal view tapered. Lateral plate length and shape variable. Subgenital plate uniformly sclerotized without distinct fenestra. Aedeagus variable. Connective with anterior margin strongly emarginate, apices divergent; posterior apex variable. Style with shank and apex variable. Female. Second valvulae variable.

Revista Brasileira de Zoologia 23 (4): 915-993, dezembro 2006 


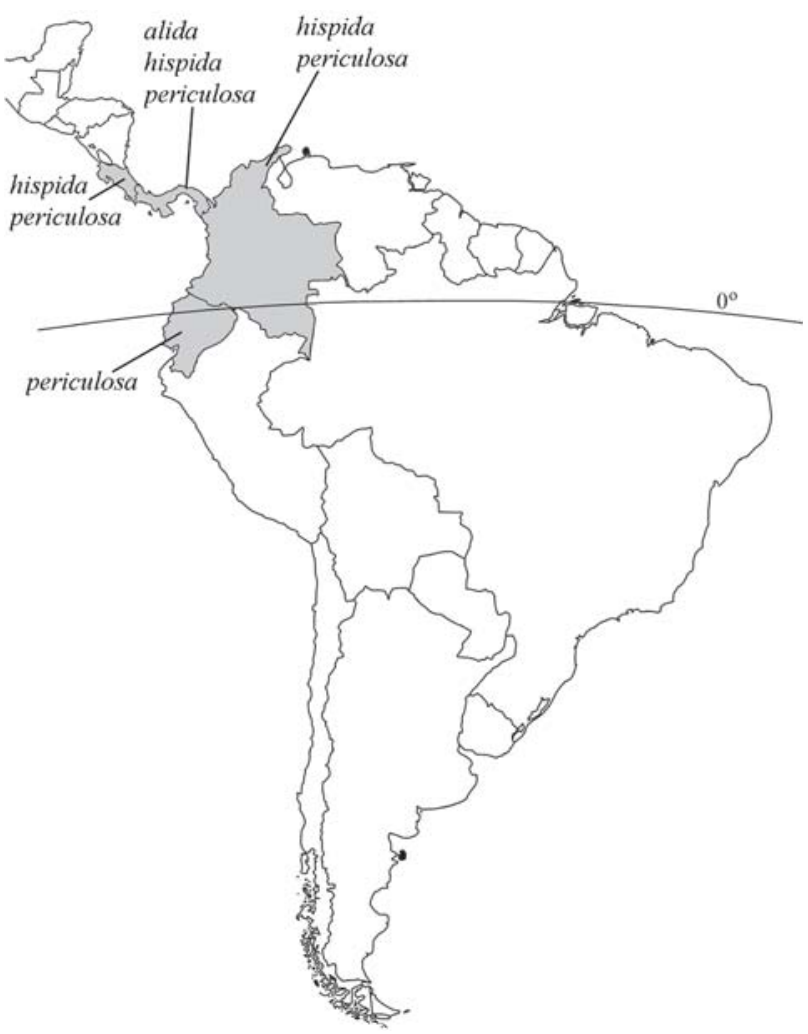

Figure 120. Known distributions of the hispida group species.

Notes. In the phylogenetic analysis (Albertson \& Dietrich 2005), these species formed a monophyletic group with low support ( $\mathrm{DI}=1$ ) and were united by features of the pronotum and the male genitalia. The species also share two synapomorphies unique among Tolania: the forewing vein $M$ initially divided into $M_{1+2+3}$ and $M_{4}$ and the $m-c u$ crossvein connected basad of the first $M$ fork. Tolania jocosa was not included in the analysis as only the female is known.

The species in the malefica group have been collected in Costa Rica, Colombia, Mexico, Panama, and Venezuela (Fig. 169).

\section{Tolania cactina Albertson, sp. nov. Figs 121-122, 137, 145-146, 163, 166}

Typelocality. Rancho Grande, Aragua, Venezuela [USNM].

Diagnosis. This species is distinguished from others in the group by the following characteristics: pronotum unpolished in appearance, densely punctate; the lateral plate small, nearly digitiform; and the aedeagus and style with denticuli.

Description. Color. Head and pronotum yellow overall with variable black markings; pronotum with black macula extending from ventral suprahumeral horn to lateral margin; scutellum yellow with basolateral margins black; thoracic venter yellow with black markings; legs yellow. Forewing basal sclerotization dark brown with black punctures, with yellow macula an- teriorly; membrane hyaline; with dark brown maculae: broad transverse macula basally, extending from costal margin to commisural margin, nearly covering entire clavus; surrounding vein $\mathrm{R}_{1}$; surrounding $\mathrm{m}$-cu crossvein and extending across vein $\mathrm{Cu}_{1}$. Head. Vertex (Fig. 137) with dorsal processes distinctly produced dorsally and conical in shape; dorsomedial surface flat. Frontoclypeus with dorsal plate depressed; ventral lobe with lateral margins parallel. Thorax. Pronotum appearing unpolished; punctation dense; metopidium high, nearly vertical; median longitudinal carina weakly keeled and acute dorsally; suprahumeral horns well developed, erect, in dorsal view acuminate, extending laterally (Fig. 122). Scutellum with base slightly inflated, evenly convex; apex without punctures. Legs: mesothoracic tibia with cucullate setal row I well developed; metathoracic tibia with 5-6 supranumerary cucullate setae between rows II and III. Male. Pygofer, in dorsal view, quadrate; with acute posterolateral angles. Lateral plate (Fig. 163) small, less than half length of subgenital plate; digitiform in lateral view; positioned posterodorsally on pygofer. Subgenital plates without constriction, tapered; apices widely separated. Aedeagus (Figs 145-146) with 2 longitudinal rows of preapical denticuli dorsally; apex narrow with pair of short slender processes extending laterally; gonopore apical. Connective (Fig. 146) acute posteriorly. Style (Figs 145-146) with lateral denticuli; in lateral view, with shank slender, enlarged and footlike apically; in dorsal view with distinct basolateral lobe, shank strongly curved laterally, broad apically. Female. Second valvulae (Fig. 166) width more or less uniform throughout; irregularly dentate dorsally.

Measurements (mm). Male/female. Body length 5.6/6.56.6; head width 2.1/2.3-2.4; width across pronotal humeri 2.0/ 2.2-2.3; width across tips of horns 2.4/3.1-3.3; forewing length 4.6/5.5-5.6.

Material examined. Holotype male: “VENEZUELA: Aragua/ Rancho Grande,/ 10-V-1973 1100m.; Albertson Research/ TOL-0029 ơ, Holotype/ Tolania/ cactina/ Albertson" [USNM ]. Paratypes: 1 female, samelocality; 1 female, "MEXICO Tabasco/ La Chontalpa" [USNM].

Distribution. Mexico: Tabasco; Venezuela: Aragua. Collection dates: April to May.

Notes. The name 'cactina' refers to the resemblance of the aedeagus and styles to a cactus.

\section{Tolania curvata Albertson, sp. nov.}

Figs 123-124, 138, 147-148, 159-160

Type locality. Estación Biológica Las Alturas, Coto Brus, Puntarenas, Costa Rica [INBio].

Diagnosis. This species differs from others in the group in having the pronotum mottled black, yellow, and reddish brown; suprahumeral horns tuberclelike; the lateral plate oriented posterodorsally; and the aedeagus sinuate.

Description. Color. Head, pronotum, and forewing basal sclerotization mottled yellow, black, and reddish brown; scutellum pale yellow with basolateral margins black; thoracic venter 
black; legs yellow. Forewing membrane hyaline; with dark or pale brown maculae: transverse macula basally, extending from costal margin to commisural margin; surrounding m-cu crossvein and extending across vein $\mathrm{Cu}_{1}$; surrounding s crossvein and extending across r-m crossvein. Head. Vertex (Fig. 138) with fine, sparse pubescence; dorsomedial surface concave. Frontoclypeus with dorsal plate depressed, concave; ventral lobe compressed, lateral margins slightly converging ventrally. Thorax. Pronotum punctation sparse; appearing highly polished; metopidium high, nearly vertical; median longitudinal carina well developed, keeled middorsally, strongly arcuate in lateral view (Fig. 123); suprahumeral horns weakly developed, tuberclelike. Scutellum with base slightly inflated, evenly convex; apex without punctures. Legs: mesothoracic tibia with cucullate setal row I well developed; metathoracic tibia with 0-5 supranumerary cucullate setae between rows II and III. Male. Pygofer (Figs 159-160), in lateral view, strongly convex dorsally. Lateral plate (Figs 159160) more than half length of subgenital plate; slender and tapered, with lightly sclerotized digitiform process apically; extending posterodorsally, weakly curved apically. Subgenital plates without constriction, lateral margins paral lel. Aedeagus (Figs 147148) with shaft, in lateral view, sinuate, broad basally, constricted and abruptly bent dorsad medially, apical half extending posteriorly; in dorsal view, compressed; with pair of slender elongate processes apically; gonopore apical. Connective (Fig. 148) truncate posteriorly. Style (Figs 147-148), in dorsal view, with shank broad; apex bent laterally, bladelike. Female. Unknown.

Measurements (mm). Male. Body length 6.0; head width 2.4, width across pronotal humeri 2.3; forewing length 5.0.

Material examined. Holotype male: “Est. Biol. Las Alturas,/ 1500m, Coto Brus. Prov./ Puntarenas, Costa Rica,/ F. Araya, 23 mar a 2 may/ 1992, L-S 322500,591300; Albertson Research/ TOL-0875 o", Holotype/ Tolania/ curvata/ Albertson" [INBio]. Paratype: "Sector Carro Cocori, Fca./ deE. Rojas, 150m, Prov,/ Limon, COSTA RICA, E./ Rojas, May 1991,/ L-N286000,567500; Albertson Research/ TOL-0876 ơ" [INBio].

Distribution. Costa RicA: Limon; Puntarenas. Collection dates: March to May.

Notes. This species closely resembles Tolania grallator, especially in the shape of the male genitalia. However, T. curvata differs in size, coloration, the lack of a collarlike pygofer posterior margin, and the more slender lateral plates oriented posterodorsally with the medial margins widely separated in dorsal view.

The name 'curvata' is Latin meaning "curved or bent" and refers to the shape of the aedeagus.

\section{Tolania grallator Albertson, sp. nov. Figs 125-126, 139, 149-150, 161-162}

Type locality. San Vito, Jardín Botánico Las Cruces, Puntarenas, Costa Rica [USNM].

Diagnosis. This species is very similar to T. curvata, especially in the shape of the aedeagus, but differs in its larger size, reddish brown coloration, collarlike posterior pygofer margin, and more robust lateral plates oriented posteriorly with medial margins not widely separated in dorsal view.

Description. Color. Coloration dark reddish brown overall with variable dark and pale markings; head, pronotum, and forewing basal sclerotization mottled with dark brown and yellow; scutellum white with basolateral margins brown; thoracic venter dark brown, legs yellow. Forewing membrane hyaline; with dark brown maculaesurrounding r-m crossvein, surrounding vein $\mathrm{Cu}_{1}$ and extending across $\mathrm{m}$-cu crossvein. Head. Vertex (Fig. 139) with fine, sparse pubescence; dorsomedial surface concave. Frontoclypeus with dorsal plate depressed, concave; ventral lobe compressed, lateral margins slightly converging ventrally. Thorax. Pronotum punctation sparse; appearing highly polished; metopidium high, nearly vertical; median Iongitudinal carina well developed, keeled middorsally, strongly arcuate in lateral view (Fig. 125); suprahumeral horns weakly developed, tuberclelike. Scutellum with base slightly inflated, evenly convex; apex without punctures. Legs: mesothoracic tibia with cucullate setal row I well developed; metathoracic tibia with 5 supranumerary cucullate setae between rows II and III. Male. Pygofer (Figs 161-162), in lateral view, strongly convex dorsally, collarlike posteriorly. Lateral plate (Figs 161-162) more than half length of subgenital plate; slender and tapered, with lightly sclerotized or membranous bilobed process apically; extending posteriorly. Subgenital plates without constriction, lateral margins parallel. Aedeagus (Figs 149-150) with shaft, in lateral view, sinuate, broad basally, constricted and abruptly bent dorsad medially, apical half extending posteriorly; in dorsal view, compressed; with pair of slender elongate processes apically; gonopore apical. Connective (Fig. 150) broadly rounded posteriorly. Style (Figs 149-150), in dorsal view, with shank broad; apex bent laterally, blade-like. Female. Unknown.

Measurements (mm). Male. Body length 7.2; width of head 2.5; width across pronotal humeri 2.5; forewing length 6.0.

Material examined. Holotype male: "COSTA RICA, Puntarenas/ San Vito, Jardia Bot./ Las Cruces, VII-VIII/88/ 1200m, Col. P. Hanson; gen. n. nr./ Tolania/ CH Dietrich 1992; Albertson Research/ TOL-0121 ơ, Holotype/ Tolania/ grallator/ Albertson" [USNM].

Distribution. Costa RıcA: Puntarenas. Collection dates: July to August.

Notes. The specific name 'grallator' translates from Latin as "one on stilts," referring to the species' long-legged appearance.

\section{Tolania jocosa Albertson, sp. nov. Figs 127-128, 140, 167}

Type locality. Cerro Campana, Panama, Panama [BM NH].

Diagnosis. This species differs from others in the group in having the pronotum with the median Iongitudinal carina weakly keeled and acute dorsally and the forewing membrane with basal transverse macula.

Revista Brasileira de Zoologia 23 (4): 915-993, dezembro 2006 

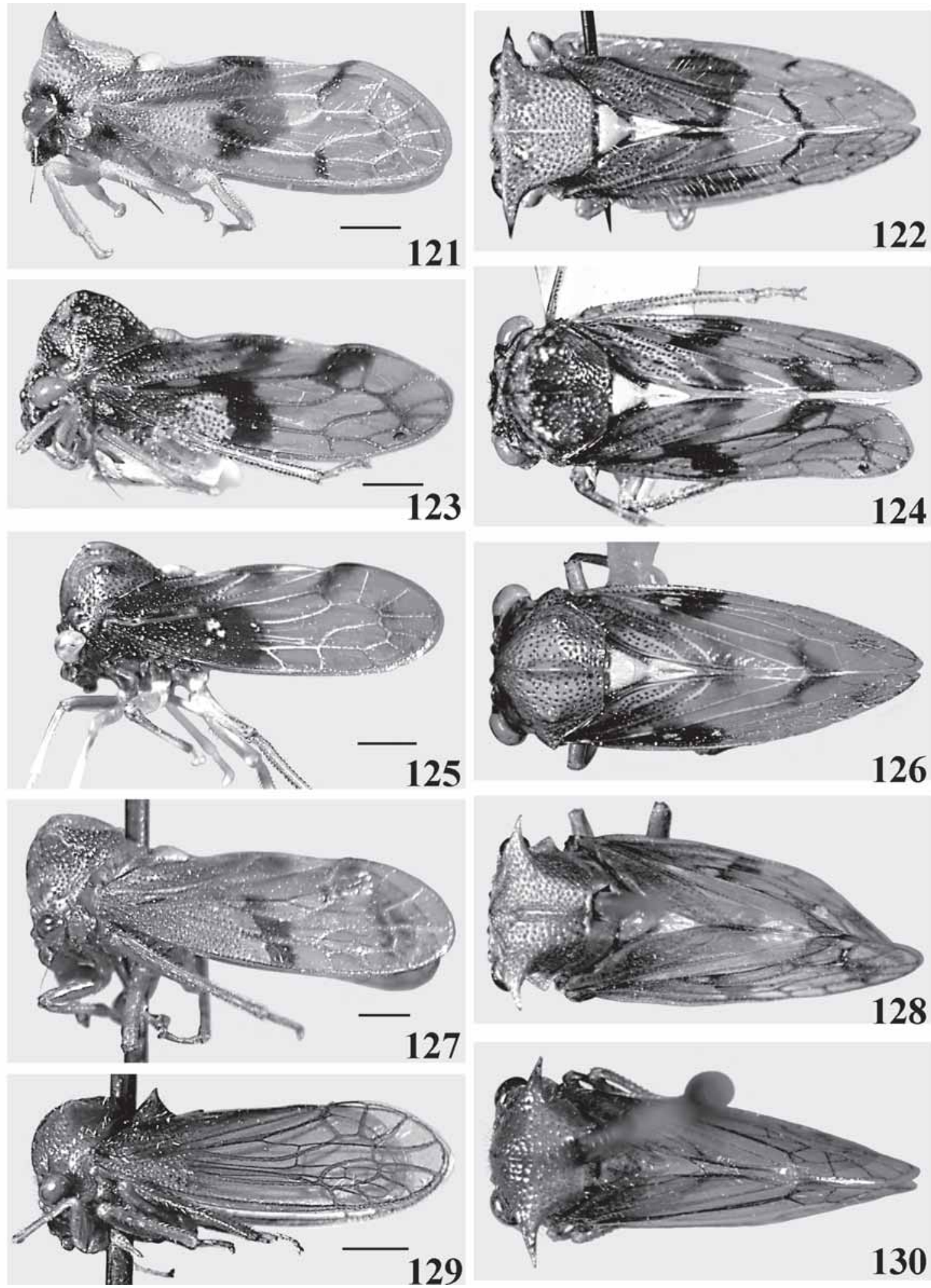

Figures 121-130. Malefica group adult lateral and dorsal habitus. (121-122) Tolania cactina paratype female; (123-124) T. curvata holotype male; (125-126) T. grallator holotype male; (127-128) T. jocosa holotype female; (129-130) T. mackameyi holotype male.

Revista Brasileira de Zoologia 23 (4): 915-993, dezembro 2006 
Description. Color. Head and pronotum yellow overall; pronotum with reddish brown macula extending from ventral suprahumeral horn to posterior margin; scutellum yellow with basolateral margins red; thoracic venter reddish brown; legs yellow. Forewing basal sclerotization brown basally, yellow apically; membrane hyaline, with brown maculae: transverse macula basally, extending from costal margin to vein $\mathrm{Cu}$; surrounding $\mathrm{s}$ crossvein and extending across $r-m$ crossvein; surrounding $m-\mathrm{cu}$ crossvein and extending across vein $\mathrm{Cu}_{1}$. Head. Vertex (Fig. 140) with dorsomedial surface concave. Frontoclypeus with dorsal plate depressed, concave; ventral lobe compressed, lateral margins slightly converging ventrally. Thorax. Pronotum appearing unpolished; punctation dense; metopidium high, nearly vertical; median longitudinal carina weakly keeled and acute dorsally (Fig. 127); suprahumeral horns well developed, erect; in dorsal view acuminate, extending laterally (Fig. 128), with posterior carina. Scutellum with base slightly inflated, evenly convex; apex without punctures. Legs: mesothoracic tibia with cucullate setal row I well developed; metathoracic tibia without supranumerary cucullate setae between rows II and III. Female. Second valvulae (Fig. 167) broadened near midlength, dorsal margin distinctly angulate; uniformly dentate dorsally. Male. Unknown.

Measurements $(\mathrm{mm})$. Female. Body length 8.1; head width 2.9; width across pronotal humeri 2.9; width across tips of horns 3.6; forewing length 6.8 .

Material examined. Holotype female: "PANAMA/ Cerro Campana/ VII-5-1974 C.W. \& L./ O’Brien \& Marshall; Tolania sp.; Brit. Mus./ 1982-424; Albertson Research/ TOL-0601 ㅇ ; Holotype/ Tolania/ jocosa/ Albertson" [BMNH].

Distribution. Panama: Panama. Collection date: July.

Notes. The name 'jocosa' is from the Latin word jocosus meaning "playful, jest".

\section{Tolania mackameyi Albertson, sp. nov. Figs 129-130, 141, 151-152, 168} [SHMC].

Type locality. Fortuna Dam area, Chiriqui, Panama

Diagnosis. This species differs from others in the group in the reddish brown coloration, the suprahumeral horns not elevated, thescutellum acutely produced dorsally, and the aedeagus with two pairs of processes, one pair truncate distally.

Description. Color. Head, pronotum, and forewing basal sclerotization reddish brown to brown overall with variable yellow markings; pronotum yellow dorsally; scutellum yellow; thoracic venter orange to brown; femora yellow with black longitudinal stripe dorsally; tibiae and tarsi yellow. Forewing membrane orange hyaline. Head. Vertex (Fig. 141) with dorsomedial surface distinctly concave. Frontoclypeus with ventral lobe compressed. Thorax. Pronotum punctation sparse; appearing highly polished; metopidium high, nearly vertical; median Iongitudinal carina weakly keeled and acute dorsally; suprahumeral horns well developed, dorsal surface of horn lower than dorsal midline, in dorsal view slender, acuminate, extending laterally (Fig.
130). Scutellum with base slightly inflated, acutely produced dorsally (Fig. 129); apex without punctures. Legs: mesothoracic tibia with cucullate setal row I well developed; metathoracic tibia with 2-5 supranumerary cucullate setae between rows II and III. Male. Lateral plate more than half length of subgenital plate; slender, tapered. Subgenital plate without constriction, tapered. Aedeagus (Figs 151-152) with pair of dorsal processes preapically, truncate distally, medial margins divergent; with pair of small triangular processes apically; gonopore on ventral preapical surface. Connective truncate posteriorly. Style (Figs 151-152), in lateral view, with preapical hump dorsally; broad in dorsal view; apex curved laterally, acute. Female. Second valvulae (Fig. 168) broadened near midlength, dorsal margin distinctly angulate; uniformly dentate dorsally.

Measurements (mm). Male/female. Body length 6.3-7.0/ 6.8-7.9; head width 2.3-2.5/2.5-2.7; width across pronotal humeri 2.2-2.4/2.4-2.7; width across tips of horns 2.9-3.4/3.4-4.1; forewing length 5.4-6.0/5.9-6.8.

Material examined. Holotype male: "PNMA: Chiriqui/ Prov., Fortuna Dam/ area, elev 1100m/ 22-28 May 1984/ S. McKamey, Coll.; 379; Albertson Research/ TOL-0131 o; Holotype/ Tolania/ mackameyi/ Albertson" [SHMC]. Paratypes: 8 males, 18 females, samelocality [SHMC]. Other material: 1 male, 2 females [GMNH, UMOC, USNM].

Distribution. Panama: Chiriqui; Cocle. Collection dates: May, August.

Notes. This species is named for S.H. McKamey, collector of the holotype and author of the recent supplement to the treehopper fascicle of the Metcalf Catalogue (MCKAMEY 1998).

\section{Tolania malefica Albertson, sp. nov. Figs 131-132, 142, 153-154, 165}

Type locality. Alto Rio Opon, Rio Carare, Santander, CoIombia [ZIMH].

Diagnosis. This species differs from others in the group by the yellow and black coloration, the median longitudinal carina weakly keeled and acute dorsally, the mesothoracic tibia with cucullate setal rows I and II, and the aedeagus with two pairs of preapical processes.

Description. Color. Head and pronotum yellow overall with variable black markings; scutellum yellow with basolateral margins black; thoracic venter black; femora black, tibiae yellow to reddish with black basally, tarsi yellow. Forewing basal sclerotization black, first anal vein yellow basally; membrane brown hyaline. Head. Vertex (Fig. 142) with dorsomedial surface distinctly concave. Frontoclypeus with dorsal lobe depressed, concave; ventral lobe with lateral margins parallel, slightly converging ventrally. Thorax. Pronotum punctation sparse; appearing highly polished; metopidium high, nearly vertical; median longitudinal carina weakly keeled and acute dorsally; suprahumeral horns well developed, erect, in dorsal view slender, acuminate, extending posterolaterally (Fig. 132). Scutellum with base slightly inflated, acutely produced dorsally 

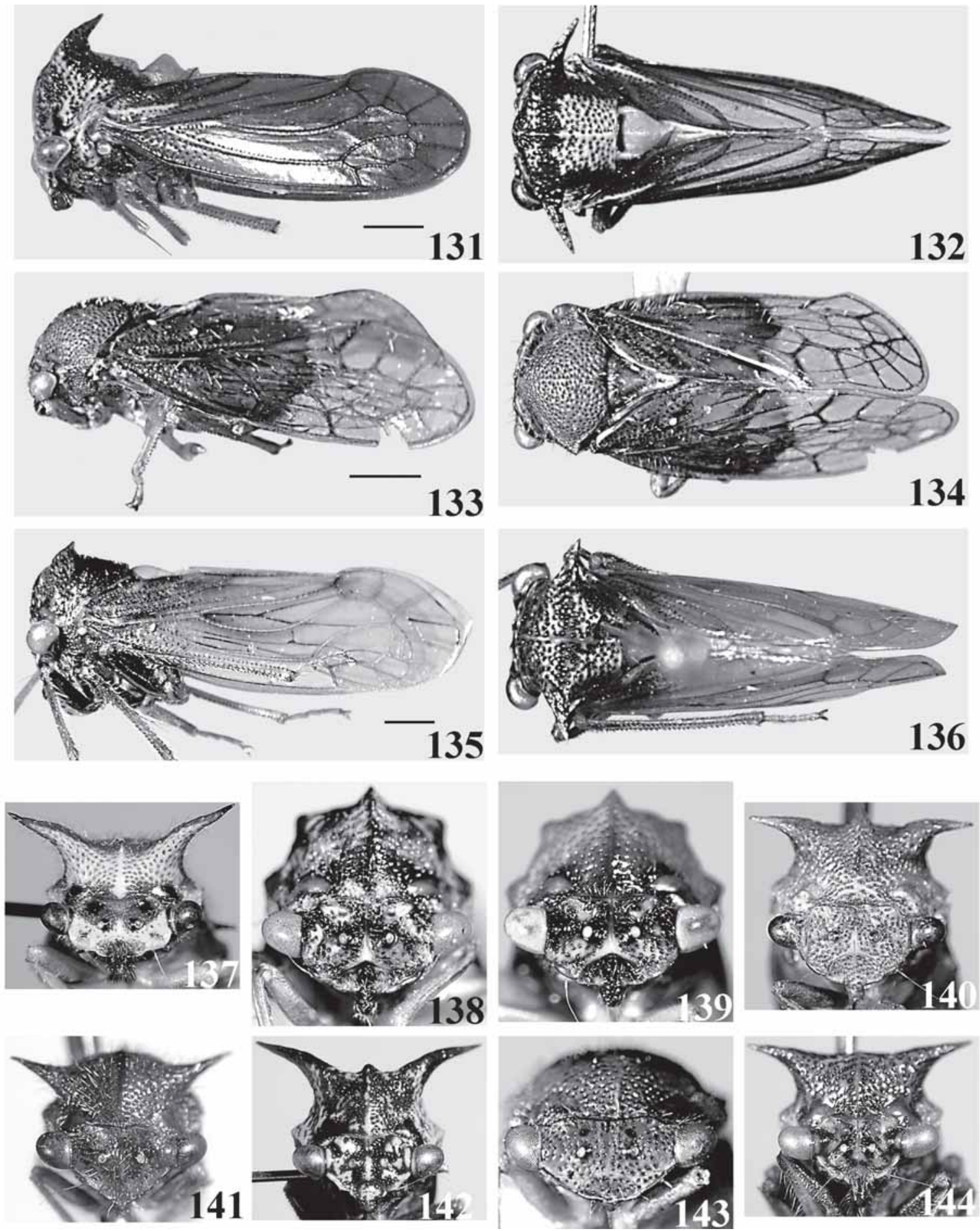

Figures 131-144. Malefica group adult habitus. (131-132) Tolania malefica holotype male: (131) lateral view; (132) dorsal view; (133134) T. obliqua (Walker) male: (133) lateral view; (134) dorsal view; (135-136) T. terencia holotype male: (135) lateral view; (136) dorsal view; (137-144) anterior view: (137) T. cactina paratype female; (138) T. curvata holotype male; (139) T. grallator holotype male; (140) T. jocosa holotype female; (141) T. mackameyi holotype male; (142) T. malefica holotype male; (143) T. obliqua (Walker) male; (144) T. terencia holotype male.

Revista Brasileira de Zoologia 23 (4): 915-993, dezembro 2006 


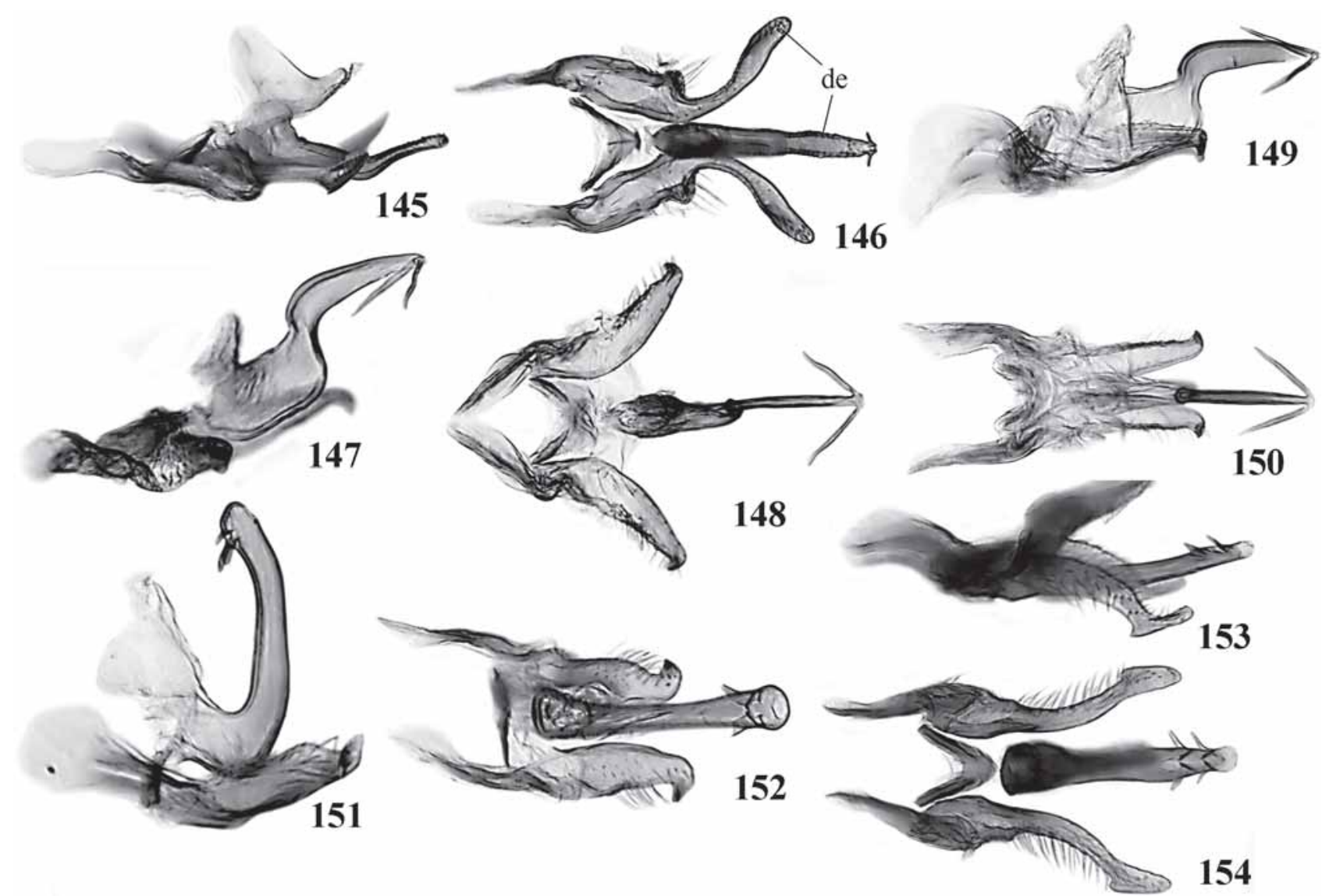

Figures 145-154. Malefica group males. (145-146) Tolania cactina holotype: (145) genitalia, lateral view; (146) same, dorsal view; (147148) T. curvata holotype: (147) genitalia, lateral view; (148) same, dorsal view; (149-150, T. grallator holotype: (149) genitalia, lateral view; (150) same, dorsal view; (151-152) T. mackameyi paratype: (151) genitalia, lateral view; (152) same, dorsal view; (153-154) T. malefica: (153) genitalia, lateral view; (154) same, dorsal view. de: Denticuli.

(Fig. 131); apex without punctures. Legs: mesothoracic tibia with cucullate setal rows I and II well developed, row I with distal half biseriate, row II uniseriate; metathoracic tibia with row I biseriate in distal two-thirds. Male. Lateral plate less than half length of subgenital plate; robust, with lightly sclerotized or membranous digitiform process apically. Subgenital plates (Fig. 165) without constriction, lateral margins parallel. Aedeagus (Figs 153-154) with 2 pairs of short slender lateral processes preapically; gonopore apical. Connective (Fig. 154) acuminate posteriorly. Style (Figs 153-154), in lateral view, with shank strongly curved dorsad basally and gradually descending toward apex; apex strongly compressed, footlike in lateral view, curved laterally. Female. Second valvulae broadened near midlength, width uniform in apical half; uniformly dentate dorsally.

Measurements (mm). Male/female. Body length 6.1-7.3/ 6.9-8.1; head width 2.3-2.8/2.6-3.1; width across pronotal humeri 2.3-2.8/2.6-3.1; width across tips of horns 3.5-4.0/3.6-4.6; forewing length 5.3-6.6/5.9-7.1.

Material examined. Holotype male: “Columbien/ Alto Rio
Opon/ Rio Carare/ 500m/ 8.5.1939; leg. L Richter/ Eing.-Nr 18/ 1958/ 11607; Albertson Research/ TOL-0533 o; Holotype/ Tolania/ malefica/ Albertson" [ZIMH]. Paratypes: 3 males, 5 females, "Columbien/ Alto Rio Opon" [ZIMH]. Other material: 3 males, 1 female [USNM, ZIHM].

Distribution. Colombia: Santander. Collection dates: May, July, and October to December.

Notes. The coloration may vary from brown to reddish brown in place of the black in the above description. The specific name 'malefica' is from the Latin word maleficus meaning "evil, wicked" and refers to the species' appearance, especially that of the suprahumeral horns.

\section{Tolania obliqua (Walker, 1858) \\ Figs 133-134, 143, 155-156}

Aethalion [sic] obliquum Walker, 1858b: 341.

Nicomia obliquum [sic]; Goding, 1927: 187.

Tolania obliqua; Albertson and Dietrich, 2005: 266.

Revista Brasileira de Zoologia 23 (4): 915-993, dezembro 2006 
Type locality. Venezuela [BMNH].

Diagnosis. This species differs from other species in this group in having the frontoclypeus with a carinate transverse fold, lacking suprahumeral horns or tubercles, the forewing bicolorous, and the aedeagus constricted medially and expanded preapically, with a pair of elongate processes.

Description. Color. Head and pronotum orange brown overall with black punctures; scutellum base orange brown, pale medially, apex yellow; thoracic venter brown; legsyellow. Forewing basal sclerotization brown; membrane bicolorous, basal half dark brown, distal half hyaline; with brown maculae surrounding vein $R_{1}$, surrounding $\mathrm{m}$-cu crossvein and extending across vein $\mathrm{Cu}_{1}$. Head. Vertex (Fig. 143) with dorsomedial surface flat. Frontoclypeus with transverse fold, carinate; apex directed posteriorly in lateral view. Thorax. Pronotum appearing polished; punctation sparse; metopidium sloping, low; suprahumeral horns absent and without tubercles (Figs 133-134). Scutellum with base slightly inflated, evenly convex; apex punctate basally. Legs: mesothoracic tibia with cucullate setal row I well developed; metathoracic tibia with 9-10 supranumerary cucullate setae between rows II and III. Male. Lateral plate more than half length of subgenital plate; slender, tapered, with lightly sclerotized or membranous recurved digitiform process apically. Subgenital plates without constriction, lateral margins parallel. Aedeagus (Figs 155-156) constricted medially and expanded preapically in dorsal view; with two small toothlike dorsal processes near midlength; with pair of slender elongate processes apically; gonoporeapical. Connective (Fig. 156) broadly rounded posteriorly. Style (Figs 155-156), in lateral view, with shank broad basally, narrowing preapically; apex curved laterally, acuminate, directed ventrally. Female. Unknown.

Measurements (mm). Male. Body length 6.7; width of head 2.0-2.2; width across pronotal humeri 2.0-2.2; forewing length 5.3 .

Material examined. Holotype: “Type; Veneza./ 55.89.; AETHALION ? [sic] OBLIQUUM.; Albertson Research/ TOL-1011 [sex unknown]" [BMNH]. Other material: 2 males [SHMC, USNM].

Distribution. Venezuela: Aragua. Collection date: May.

Notes. The type specimen is missing the abdomen and the sex is unknown.

\section{Tolania terencia Albertson, sp. nov. Figs 135-136, 144, 157-158, 164}

Type locality. La Culata, Mérida, Venezuela [SHMC].

Diagnosis. This species differs from others in the group by the reddish brown coloration, the mesothoracic tibia with cucullate setal rows I and II, the forewing membrane with macula surrounding the $\mathrm{m}$-cu crossvein and extending across vein $\mathrm{Cu}_{1}$, and the aedeagus with 2 pairs of preapical processes.

Description. Color. Head, pronotum, and forewing basal sclerotization reddish brown with black punctures and variable yellow and black markings; pronotum yellow dorsally; scutellum yellow with basolateral margins brown; thoracic ven- ter black; femora brown, tibiae orange with brown basally, tarsi yellow to orange. Forewing membrane brown hyaline, with brown macula surrounding $\mathrm{m}$-cu crossvein and extending across vein $\mathrm{Cu}_{1}$. Head. Vertex (Fig. 144) with dorsomedial surface distinctly concave. Frontoclypeus with dorsal lobe de pressed, concave; ventral lobe with lateral margins parallel, slightly converging ventrally. Thorax. Pronotum punctation sparse; appearing highly polished; metopidium high, nearly vertical; suprahumeral horns well developed, dorsal surface of horn even with dorsal midline, in dorsal view slender, acuminate, extending laterally (Fig. 136). Scutellum with base slightly inflated, evenly convex; apex without punctures. Legs: mesothoracic tibia with cucullate setal rows I and II well developed; metathoracic tibia with row I biseriate in distal two-thirds. Male. Lateral plate (Fig. 164) morethan half length of subgenital plate; tapered, apex with lightly sclerotized or membranous digitiform process, twisted dorsally. Subgenital plates without constriction, lateral margins parallel. Aedeagus (Figs 157-158) with 2 pairs of elongate lateral processes preapically; gonopore on ventral preapical surface. Connective (Fig. 158) broadly rounded posteriorly. Style (Figs 157-158), in lateral view, with shank strongly curved dorsad subbasally and gradually descending toward apex; apex strongly compressed, curved laterad, acuminate, oriented ventrally. Female. Unknown.

Measurements (mm). Male. Body length 8.6; head width 2.9; width across pronotal humeri 2.9; width across tips of horns 4.0; forewing length 7.6.

Material examined. Holotype male: “VENEZ: Merida/ La Culata, 3000m/ 25.IV-2.V.1988/ S.A. Marshall; Tolania sp./ det. S. McKamey 1991; Retained by S. McK. in/ exchange for identif.; Albertson Research/ TOL-0117 o; Holotype/ Tolania/ terencia/ Albertson" [SHMC].

Distribution. Venezuela: Mérida. Collection dates: May.

Notes. The male genitalia of Tolania terencia closely resembles that of T. malefica, however the coloration and features of the head and pronotum are distinctly different. The specific name 'terencia' is Greek for "smooth and polished" and refers to the appearance of the adult pronotum.

\section{obtusa group \\ Figs 4, 170-191}

Diagnosis. This species group differs from other Tolania in having the following combination of features: vertex width more than twice height; mesothoracic tibia with cucullate setal row I present; abdomen in dorsal view with lateral margins roundly tapered between segments III-VI, segments VII and VIII attenuate; aedeagus broad in lateral view, compressed in ventral view; and style notched apically.

Description. Head. Vertex (Figs 178-180) width between eyes more than twice height; dorsomedial surface flat; ventrolateral margin carinate; ocelli sessile. Frontoclypeus ventral lobe with lateral margins parallel, slightly converging ventrally, with median longitudinal carina present; apex directed posteriorly 

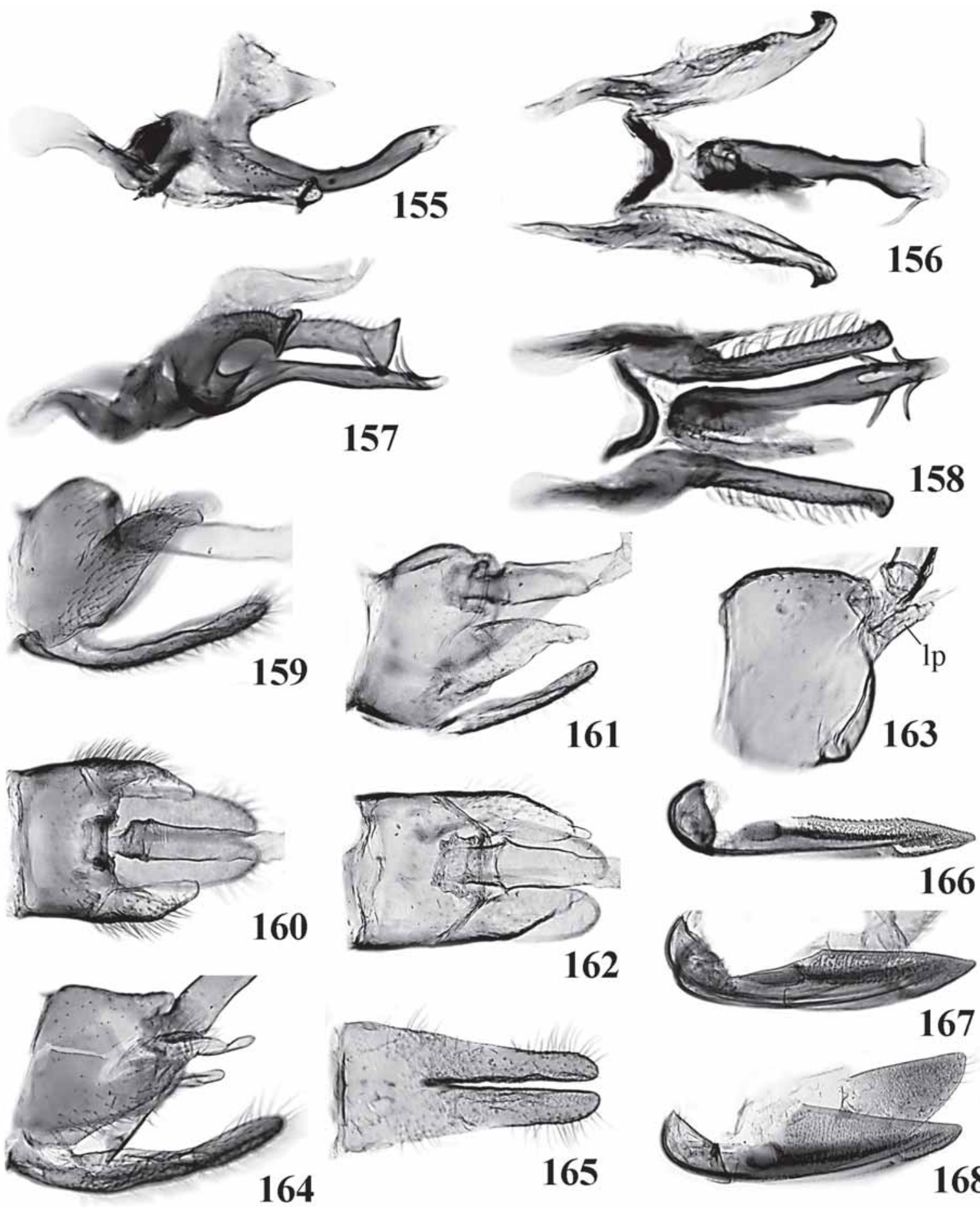

Figures 155-168. Malefica group. (155-165) Males: (155-156) Tolania obliqua (Walker): (155) genitalia, lateral view; (156) same, dorsal view; (157-158) T. terencia holotype: (157) genitalia, lateral view; (158) same, dorsal view; (159-160) T. curvata holotype: (159) pygofer, lateral view; (160) same, dorsal view; (161-162) T. grallator holotype: (161) pygofer, lateral view; (162) same, dorsal view; (163) T. cactina holotype, pygofer, right lateral view, inverted; (164) T. terencia holotype, pygofer, lateral view; (165) T. malefica, subgenital plate; (166-168) females: (166) T. cactina paratype, second valvulae; (167) T. jocosa holotype, second valvulae; (168) T. mackameyi paratype, second and third valvulae. Ip: Lateral plate. 


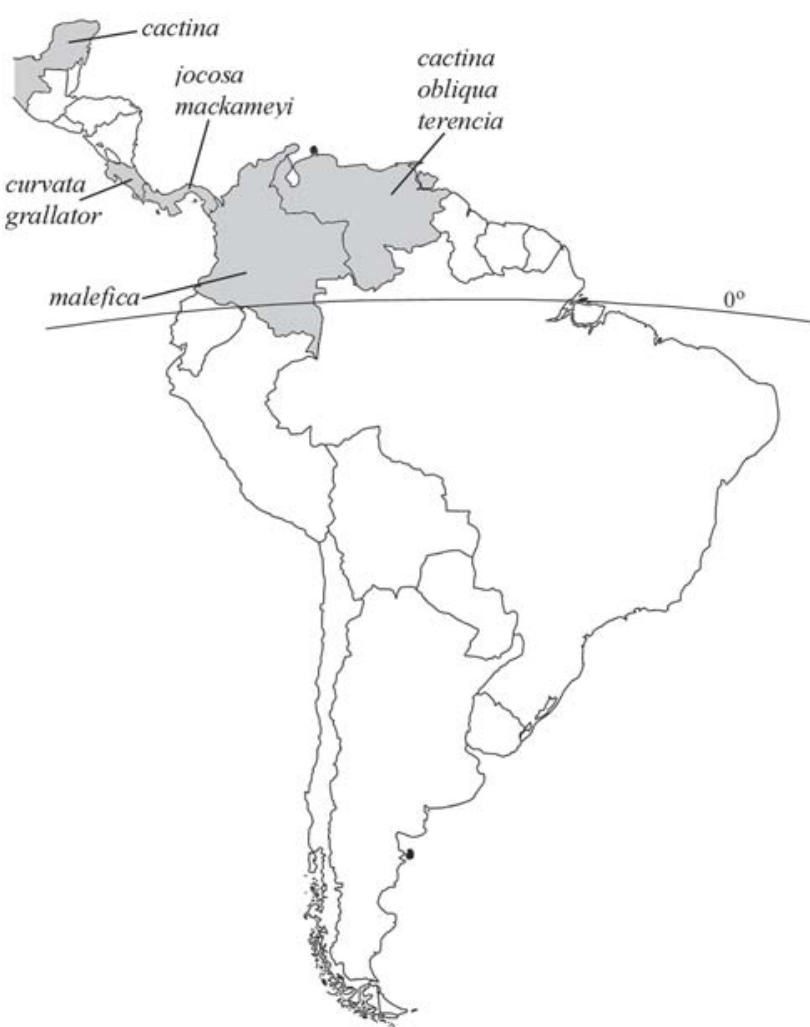

Figure 169. Known distributions of the malefica group species.

in lateral view. Thorax. Pronotum punctation dense; densely covered with short setae; metopidium sloping, low; suprahumeral horn development polymorphic (absent, weakly developed and tuberclelike, or well developed); elevation and shape in dorsal view polymorphic; with anterior and posterior carinae. Scutellum with base slightly inflated, evenly convex; apex punctate, midline carinate. Legs: mesothoracic tibia with cucullate setal row I well developed; metathoracic tibia with supranumerary cucullate setae absent. Tymbals large and conspicuous, extending beyond posterior margin of metathorax. Forewing with $1 \mathrm{~s}$ crossvein present; $1 \mathrm{r}$-m crossvein present; $\mathrm{m}$ crossvein absent; $\mathrm{m}-\mathrm{cu}$ crossvein connected between first and second vein $M$ fork. Male. Abdomen in dorsal view with lateral margins roundly tapered between segments III-VI, segments VII and VIII attenuate (Fig. 4); sternite VII with lateral Iongitudinal carina and medial depression; sternite VIII (Fig. 187) anterior margin distinctly narrow and rounded. Lateral plate (Fig. 188) more than half length of subgenital plate; tapered. Subgenital plate (Figs 188-189) with subbasal constriction, apex broad and rounded; folded dorsad in apical onethird; with densely sclerotized lateral ridge (with setae) and median basal fenestra (glabrous). Aedeagus (Figs 181-186) broad in lateral view, compressed in ventral view; gonopore apical. Connective with anterior margin strongly emarginate, apices divergent; truncate or broadly rounded posteriorly. Style (Figs
181-186), in lateral view, with shank broad; apex compressed and notched, with scales. Female. Second valvulae (Fig. 190) broadened near midlength, dorsal margin weakly arcuate; uniformly dentate dorsally.

Notes. The females in this group can only be determined to species by association with males.

In the phylogenetic analysis (AlBeRTSOn \& DIETRICH 2005), these species formed a monophyletic group with moderate support ( $\mathrm{DI}=4)$, characterized by the sternite VI width more than twice the width of sternites VII and VIII, the aedeagus broad in lateral view and compressed in ventral view, and the style apex notched.

The species in this group have been collected throughout Central America and northern South America, including the following countries: Brazil, Colombia, Costa Rica, Ecuador, El Salvador, Guatemala, Panama, Peru, Suriname, and Venezuela (Fig. 191).

\section{Tolania obtusa Fowler, 1896 \\ Figs 4, 170-173, 178, 181-182, 187, 189}

Tolania obtusa Fowler, 1896: 166.

Type locality. Tolé, Chiriqui, Panama [BMNH].

Diagnosis. This species differs from others in the group in having the apex of the aedeagus with two or more pairs of short processes laterally and ventrally.

Description. Color. Head, pronotum, and forewing basal sclerotization yellow overall with variable black, brown, or red markings; scutellum base reddish brown with yellow basolateral margins, apex yellow; thoracic venter black; femora black with yellow apically, tibiae and tarsi reddish to yellow. Forewing membrane hyaline. Male. Aedeagus (Figs 181-182), in lateral view, curved dorsad or sinuate; with pair of triangular dorsal processes preapically or dorsal keel present or absent; apex variable, with two or more pairs of processes laterally and ventrally.

Measurements (mm). Male/female. Body length 5.6-6.4/ 6.4-7.9; width of head 2.7-3.1/3.0-3.7; width across pronotal humeri 2.3-2.6/2.5-3.1; width across tips of horns 1.7-3.3/2.14.6; forewing length 4.5-5.6/5.6-6.5.

Material examined. Holotype female: "Tolé,/ Panama./ Champion.; Brit. Mus./ 1904-55.; B.C.A. Homopt. II./ Tolania/ obtusa,/ Fowl.; Tolania/ obtusa Fowler/ TYPE; Albertson Research/ TOL-1021 ㅇ " [BM NH]. Paratypes: “Para-/ type; Cubilguitz,/ Vera Paz. [sic]/ Champion.; Brit. Mus./ 1904-55.; B.C.A. Homopt. II./ Tolania/ obtusa,/ Fowl.; Albertson Research/ TOL-1023 \% "; “Para/ type; Bugaba./ Panama./ Champion.; Brit. Mus./ 1904-55.; B.C.A. Homopt. II./ Tolania/ obtusa,/ Fowl.; Albertson Research/ TOL-1025 o" [BMNH]. Other material: 4 males, 14 females [CAS, BMNH, FSCA, INBio, MNHN, SHMC, UFPC, USNM, ZIMH].

Distribution. BrazlL: Mato Grosso; Pará; Rondônia; CoLombia: Meta; Santander; Costa Rıca: Cartago; Guanacaste; Heredia; Puntarenas; Ecuador: Pichincha; El Salvador: La Libertad; Guatemala: Alta Verapaz; Panama: Chiriqui; Colon; 

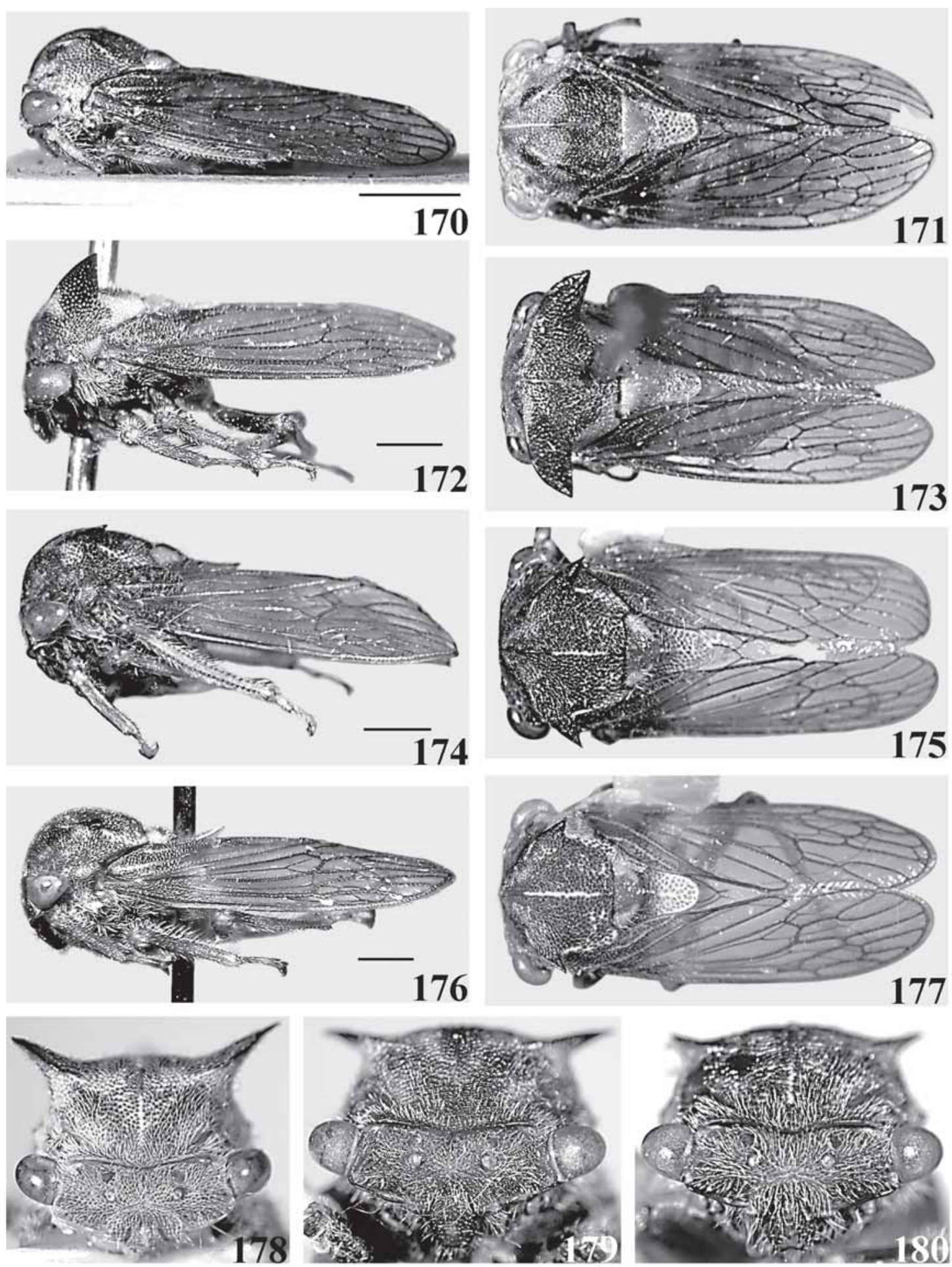

Figures 170-180. Obtusa group adult habitus. (170-171) Tolania obtusa Fowler holotype female: (170) lateral view; (171) dorsal view; (172-173) T. obtusa Fowler male: (172) lateral view; (173) dorsal view; (174-175) T. obunca holotype male: (174) lateral view; (175) dorsal view; (176-177) T. torosa holotype male: (176) lateral view; (177) dorsal view; (178-180) anterior view: (178) T. obtusa Fowler male; (179) T. obunca holotype male; (180) T. torosa holotype male.

Revista Brasileira de Zoologia 23 (4): 915-993, dezembro 2006 
Darien; Panama; Vereguas; Peru: Amazonas; Madre de Dios; Suriname: Sipaliwini; Venezuela: Amazonas; Zulia. Collection dates: January to December.

Notes. Several specimens were collected on Luhea seemanni (Tiliaceae).

\section{Tolania obunca Albertson, sp. nov. Figs 174-175, 179, 183-184, 188}

Typelocality. 62 km SW Ariquemes, near Fazenda Rancho Grande, Rondônia, Brazil [USNM].

Diagnosis. This species can be distinguished from others in the group by the aedeagus with a pair of short, recurved ventral processes apically.

Description. Color. Head, pronotum, and forewing basal sclerotization yellow, brownish red, and black, variable; scutellum base orange to red with basolateral margins yellow, apex yellow; thoracic venter black; femora black, tibiae yellow with red basally, tarsi yellow. Forewing membrane hyaline. Male. Aedeagus (Figs 183-184) with pair of triangular dorsal processes preapically present or absent; with pair of short, recurved ventral processes apically.

Measurements (mm). Male. Body length 6.5-6.8; head width 2.9-3.0; width across pronotal humeri 2.5-2.7; width across tips of horns 2.0-3.0; forewing length 5.5-5.7.

Material examined. Holotype male: "BRAZIL: Rondonia. 62/ km SW Ariquemes, nr./ Fzda. Rancho Grande/ 20-IX-1992/ U. Schmitz, BL Trap; Albertson Research/ TOL-0114 o; Holotype/ Tolania/ obunca/ Albertson" [USNM]. Paratypes: "PERU: Madre de Dios/ Rio Tambopata Res./ 30km (air) SW Pto./ Maldonado. 290m./ 12으'S, 069017'W; Smithsonian Institution/ Canopy Fogging Project/ T.L. Erwin, et al., colls./ 07 Nov 1983 01/03117; Albertson Research/ TOL-0113 $\sigma^{\prime \prime}$; “VENEZUELA: T.F. Amaz./ Cerro de la Neblina/ Basecamp, 050’N/ 669'44"W, 140 m./ 2129 Feb. 1984/ D. Davis \& T. McCabe; CHD Research/ \#98-0009; Albertson Research/ TOL-0115 ơ" [USNM].

Distribution. BrazıL: Rondônia; Peru: Madre de Dios; Venezuela: Amazonas. Collection dates: February, September, and November.

Notes. The name 'obunca' translates from Latin as "hooked," referring to the shape of the aedeagus apical processes.

\section{Tolania torosa Albertson, sp. nov. Figs 176-177, 180, 185-186}

Type locality. 62 km SW Ariquemes, near Fazenda Rancho Grande, Rondônia, Brazil [FSCA].

Diagnosis. This species differs from others in the group in having the aedeagus with a pair of elongate convexly curved processes apically, with the dorsal margin serrate.

Description. Color. Head, pronotum, and forewing basal sclerotization red to orange overall with variable black and yellow markings; scutellum base red to orange with yellow basolateral margins, apex yellow; thoracic venter black; femora black, tibiae yellow with red basally, tarsi yellow. Forewing membrane hyaline. Male. Aedeagus (Figs 185-186) with preapical dorsal keel present or absent; with pair of elongate convexly curved processes apically, dorsal margin serrate.

Measurements (mm). Male. Body length 7.0-7.3; head width 3.1-3.2; width across pronotal humeri 2.7-2.8; width across tips of horns 2.6; forewing length 6.0-6.1.

Material examined. Holotype male: “BRAZIL: Rondonia. 62/ km SW Ariquemes, nr./ Fzda. Rancho Grande/ 6-15-XII1990. DA/ Rider \& JE Eger; Albertson Research/ TOL-0119 ऽ;, Holotype/ Tolania/ torosa/ Albertson" [FSCA]. Paratype: 1 male, same locality [USNM].

Distribution. BrazıL: Rondônia. Collection date: December.

Notes. The specific name 'torosa' is Latin for "muscular, brawny" and refers to the species' robust appearance.

\section{opponens group}

Figs 192-292

Diagnosis. This species group differs from other Tolania in having the following combination of features: vertex width less than twice height, suprahumeral horns extended laterad of humeral angles (except T. tumida), mesothoracic tibia lacking cucullate setal rows, and forewing without supranumerary crossveins.

Description. Head. Vertex width between eyes less than twice height; ventrolateral margin foliaceous; ocelli sessile. Frontoclypeus with apex directed ventrally in lateral view; lateral lobes indistinct (except T. opponens); median Iongitudinal carina absent (except T. tumida). Thorax. Pronotum densely punctate; densely covered with short setae; metopidium high, nearly vertical (except T. reflexa); suprahumeral horns well developed (except T. tumida). Scutellum with base slightly inflated, evenly convex; apex with distinct median longitudinal groove. Legs: mesothoracic tibia without cucullate setal rows; metathoracic tibia with supranumerary cucullate setae present between rows II and III. Forewing with $1 \mathrm{~s}$ crossvein present; $1 \mathrm{r}-\mathrm{m}$ crossvein present; $\mathrm{m}$ crossvein absent (except $\mathrm{T}$. xantha); $\mathrm{m}-\mathrm{cu}$ crossvein connected between first and second vein $M$ fork. Male. Abdomen in dorsal view with lateral margins roundly tapered between segments III-VI, segments VII and VIII attenuate. Lateral plate length more than half length of subgenital plate. Subgenital plate uniformly sclerotized without distinct fenestra. Aedeagus variable. Connective with anterior margin strongly emarginate, apices divergent; posterior apex variable. Style with shank and apex variable. Female. Second valvulae uniformly dentate dorsally.

Notes. The females can only be determined by association with males for many species within this group.

This group was not consistently monophyletic in the phylogenetic analysis (AlBERTSON \& DIETRICH 2005) but is recognized based on the relatively narrow vertex and the absence of cucullate setal rows on the mesothoracic tibia. The coloration of all the included species is yellow overall. 

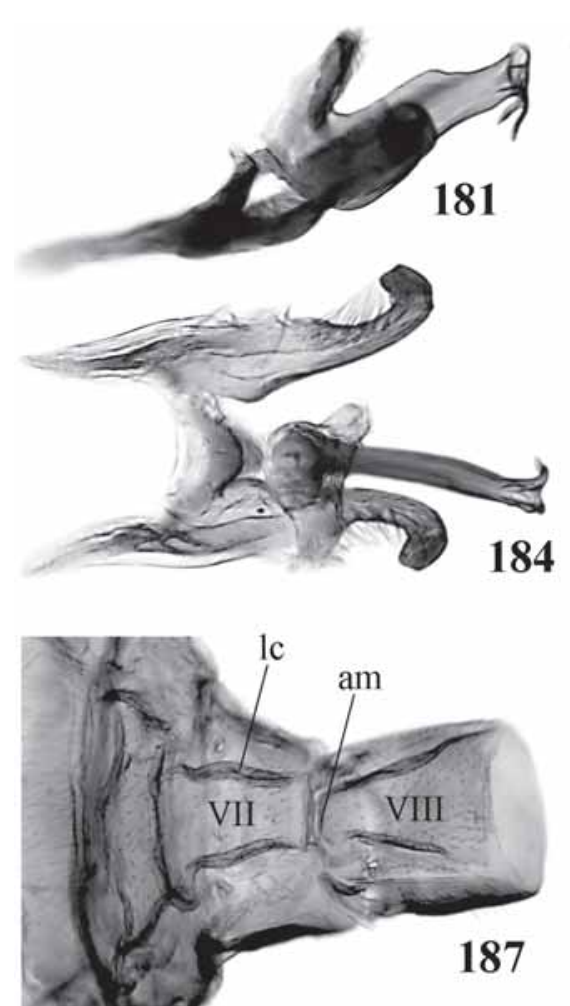
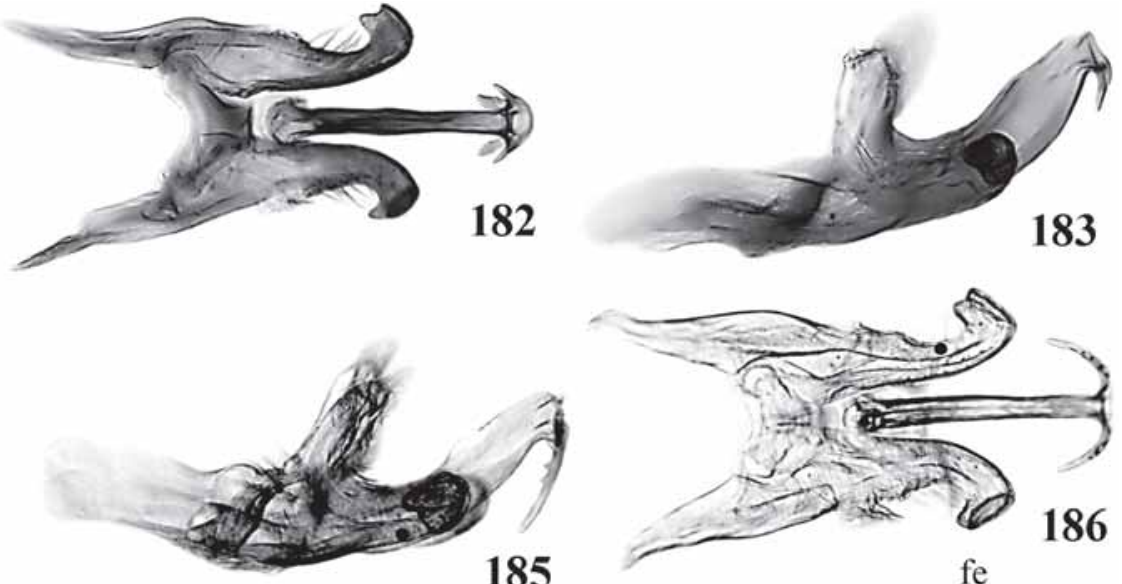

185

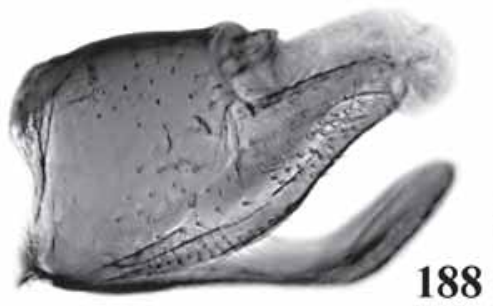

188

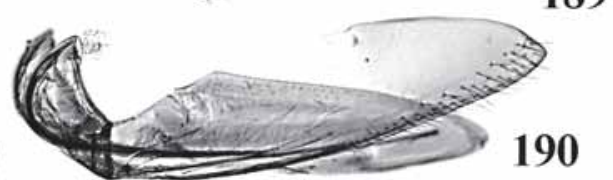

Figures 181-190. Obtusa group. (181-189) Males: (181-182) Tolania obtusa Fowler: (181) genitalia, lateral view; (182) same, ventral view; (183-184) T. obunca holotype: (183) genitalia, lateral view; (184) same, dorsal view; (185-186) T. torosa paratype: (185) genitalia, lateral view; (186) same, ventral view; (187) T. obtusa Fowler, abdomen, ventral view; (188) T. obunca holotype, pygofer, lateral view; (189) T. obtusa Fowler, subgenital plate; (190) Obtusa group female, second and third valvulae. am: Anterior margin; fe: fenestra; Ic: longitudinal carina.

The species within the opponens group have been collected in Bolivia, Brazil, Colombia, Costa Rica, Ecuador, Guatemala, Mexico, Panama, Peru, Suriname, and Venezuela (Fig. 292).

\section{Tolania alvira Albertson, sp. nov. Figs 192-193, 226, 243-244}

Type locality. Costa Rica [USNM].

Diagnosis. This species differs from others in the group in having the aedeagus with 1 triangular ventral process preapically and a pair of short lateral processes apically.

Description. Color. Coloration yellow overall; suprahumeral horns reddish dorsally; scutellum yellow. Forewing membranehyaline. Head. Vertex (Fig. 226) with dorsomedial surface flat. Frontoclypeus ventral lobe with lateral margins parallel, slightly converging ventrally. Thorax. Pronotum with suprahumeral horns well developed, erect; in dorsal view acuminate, extending posterolaterally (Fig. 193); with anterior and posterior carinae. Scutellum with apex punctate. Legs: metathoracic tibia with 10 supranumerary cucullate setae between rows II and III. Tymbals large and conspicuous, extending beyond posterior margin of metathorax. Male. Lateral plate, in dorsal view, with lateral margin concave basally, tapered in lateral view; with lightly sclerotized or membranous digitiform process apically. Subgenital plate with subbasal constriction, apical twothirds tapered. Aedeagus (Figs 243-244) with ventral process preapically, more or less triangular in shape; with pair of short slender lateral processes apically; gonopore on ventral preapical surface. Connective (Fig. 244) acuminate posteriorly. Style (Figs 243-244), in dorsal view, with shank distinctly angled laterad basally; apex abruptly bent laterally, acute. Female. Unknown.

Measurements (mm). Male. Body length 6.1-6.2; head width 2.5-2.8; width across pronotal humeri 2.3-2.4; width across tips of horns 2.9-3.2; forewing length 4.9-5.0.

Material examined. Holotype male: "Costa Rica; Albertson Research/ TOL-0012 o;, o; Holotype/ Tolania/ alvira/ Albertson" [USNM]. Paratype: "PANAMA: San Blas/ 2km. S. Nusagandi/ 3 March 1985/ Flint \& Louton; Albertson Research/ TOL-0009" [USNM].

Distribution. Costa Rica; Panama: San Blas. Collection date: March.

Notes. The specific name 'alvira' is from the Latin word albus and translates as "fair one", referring to the species' light coloration.

Revista Brasileira de Zoologia 23 (4): 915-993, dezembro 2006 


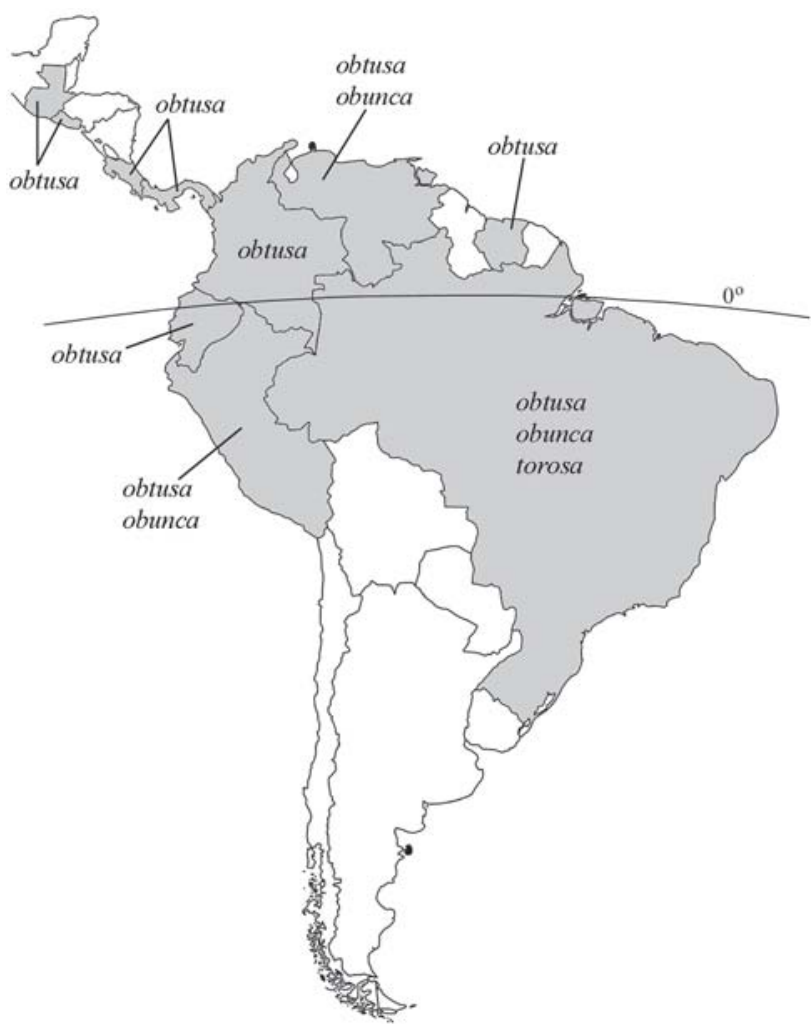

Figure 191. Known distributions of the obtusa group species.

\section{Tolania arcuata Albertson, sp. nov. Figs 194-195, 227, 245-246}

Type locality. 1 km S Onkonegare Camp, Reserva Etnica Waorani, Napo, Ecuador [USNM].

Diagnosis. This species differs from others in the group in having the aedeagus with a pair of short lateral processes preapically and a pair of elongate, convexly curved processes apically, each with a toothlike projection subbasally.

Description. Color. Coloration yellow overall; pronotum with reddish brown markings dorsally. Forewing membrane hyaline to brown hyaline. Head. Vertex (Fig. 227) with dorsomedial surface distinctly concave. Frontoclypeus ventral lobe with lateral margins parallel, slightly converging ventrally. Thorax. Pronotum with suprahumeral horns well developed, dorsal surface of horn even with dorsal midline; in dorsal view acuminate, extending posterolaterally (Fig. 195); with anterior and posterior carinae. Scutellum with apex punctate. Legs: metathoracic tibia with 4-6 supranumerary cucullate setae between rows II and III. Tymbals large and conspicuous, extending beyond posterior margin of metathorax. Male. Lateral plate, in lateral view, constricted basally, robust. Subgenital plate without constriction, tapered. Aedeagus (Figs 245-246) with pair of short lateral processes preapically; with pair of elongate convexly curved processes apically, each with a toothlike projec- tion subbasally; gonopore on ventral preapical surface. Connective (Fig. 246) truncate posteriorly. Style (Figs 245-246) with apex bent laterally, roundly tapered. Female. Unknown.

Measurements (mm). Male. Body length 5.6-6.0; head width 2.3-2.7; width across pronotal humeri 2.2-2.4; width across tips of horns 2.8-3.7; forewing length 4.5-5.1.

Material examined. Holotype male: “ECUADOR: Napo, Tran-/ sect Ent. 1km S Onkonegare/ Camp. Reserva Etnica Waorani/ 0039'10"S, 07626'00"W/ 9 Oct 1994, T.L. Erwin,/ et al., fogging terre [sic] firme/ forest, lot \#927; Albertson Research/ TOL-0030 ơ, Holotype/ Tolania/ arcuata/ Albertson" [USNM ]. Paratypes: 4 males, same locality [USNM]. Other material: 3 males [USNM].

Distribution. Ecuador: Napo. Collection dates: June to July, October.

Notes. The aedeagus of Tolania arcuata is similar to that of $\mathrm{T}$. damia, $\mathrm{T}$. lunata, and $\mathrm{T}$. umbella. However, $\mathrm{T}$. arcuata can be differentiated from the other species by the convexly curved aedeagus apical processes, each with a toothlike projection.

The name 'arcuata' translates from Latin as "bent like a bow" and refers to the shape of the apical processes of the aedeagus.

\section{Tolania damia Albertson, sp. nov.} Figs 196-197, 228, 247-248, 280-281, 285

Type locality. $30 \mathrm{~km}$ SW Puerto Maldonado, Río Tambopata Reserve, Madre de Dios, Peru [USNM].

Diagnosis. This species differs from others in the group in having the aedeagus with a pair of short recurved lateral processes preapically and with a pair of elongate apical processes, each with an acute projection on the dorsal margin subbasally.

Description. Color. Head, pronotum, and forewing basal sclerotization yellow overall with black punctures and variable black and brown markings; suprahumeral horns black dorsally; scutellum yellow; thoracic venter yellow; legs yellow. Forewing membrane brown hyaline. Head. Vertex (Fig. 228) with dorsomedial surface flat. Frontoclypeus ventral lobe with lateral margins parallel, slightly converging ventrally. Thorax. Pronotum with suprahumeral horns well developed, dorsal surface of horn even with dorsal midline or erect; in dorsal view acuminate, extending laterally (Fig. 197); with anterior carina. Scutellum with apex punctate. Legs: metathoracic tibia with 6-8 supranumerary cucullate setae between rows II and III. Tymbals large and conspicuous, extending beyond posterior margin of metathorax. Male. Lateral plate (Figs 280-281), in lateral view, constricted basally, tapered. Subgenital plate without constriction, tapered. Aedeagus (Figs 247-248) with pair of short recurved lateral processes preapically; with pair of elongate apical processes, each with acute projection on dorsal margin subbasally, apices recurved; gonopore apical. Connective (Fig. 248) truncate posteriorly. Style (Figs 247-248) with shank straight in lateral view; apex abruptly bent laterally, ta- 

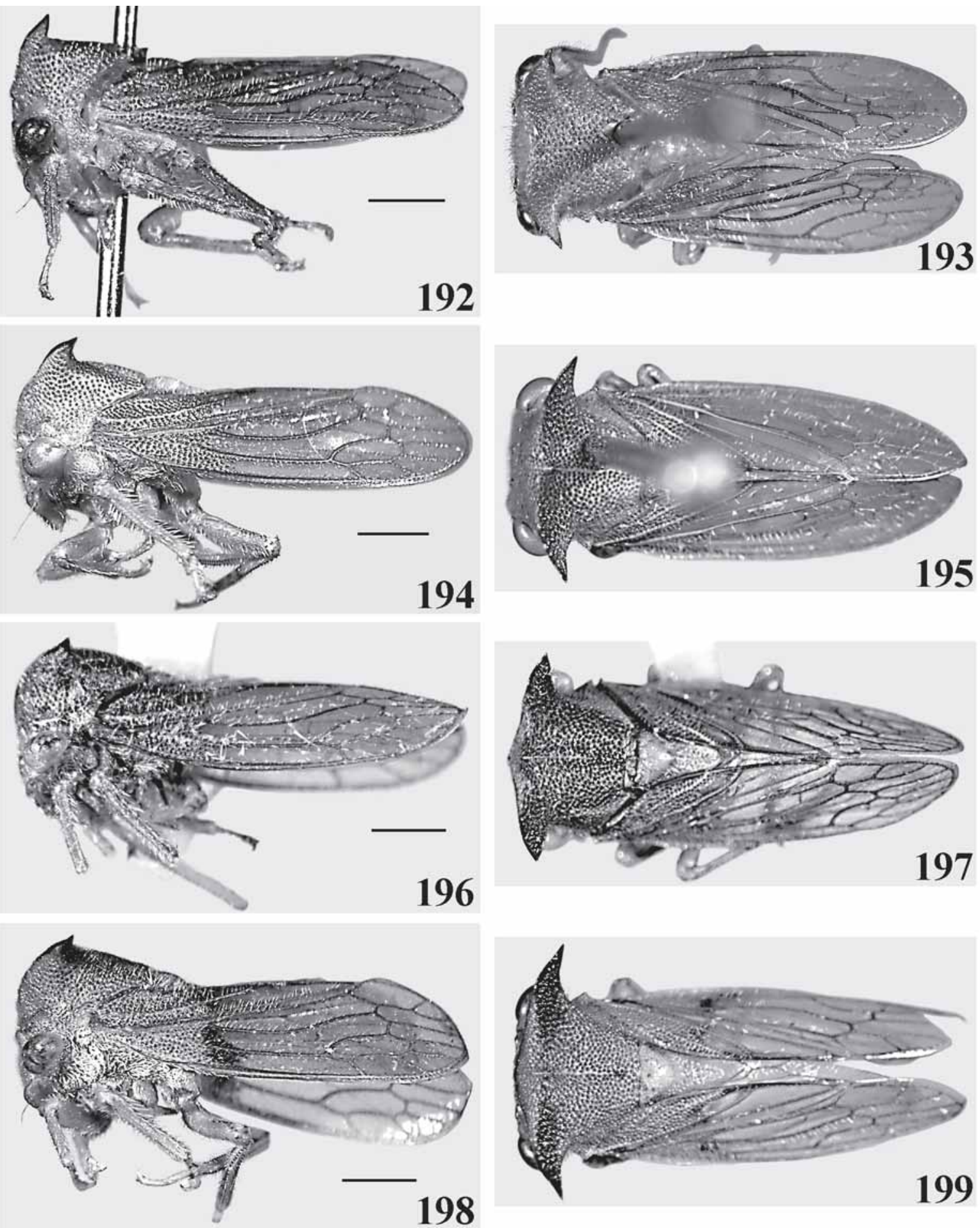

Figures 192-199. Opponens group adult lateral and dorsal habitus. (192-193) Tolania alvira holotype male; (194-195) T. arcuata holotype male; (196-197) T. damia holotype male; (198-199) T. insolita paratype male. 
pered or bladelike in lateral view. Female. Second valvulae (Fig. 285) width more or less uniform throughout; uniformly dentate dorsally.

Measurements (mm). Male/female. Body length 6.3-6.4/ 6.4; head width 2.5-2.6/3.0; width across pronotal humeri 2.32.4/2.7; width across tips of horns 2.9-3.0/3.4; forewing length 5.4-5.5/6.2.

Material examined. Holotypemale: "PERU: MadredeDios/ Rio Tambopata Res./ 30km (air) SW Pto./ Maldanado, 290m./ 1250'S, 06917'W; Smithsonian Institution/ Canopy Fogging Project/ T.L. Erwin, et al., colls./ 04 M ay 1984 01/02017; Albertson Research/ TOL-0024 o"; Holotype/ Tolania/ damia/ Albertson" [USNM ]. Paratypes: 1 male, 1 female, same locality [USNM].

Distribution. Peru: Madre de Dios. Collection dates: May and November.

Notes. The aedeagus of Tolania damia closely resembles that of $\mathrm{T}$. arcuata, T. lunata, and T. umbella and can be differentiated by the small projection on the dorsal margin of the aedeagus apical processes.

The specific name 'damia' is that of the Greek goddess of the forces of nature.

\section{Tolania insolita Albertson, sp. nov. Figs 198-199, 229, 249-250}

Type locality. 1 km S Onkonegare Camp, Reserva Etnica Waorani, Napo, Ecuador [USNM].

Diagnosis. This species differs from others in the group in having the aedeagus with a pair of elongate dorsal processes preapically and with a pair of apical processes, each with 3-4 fingerlike distal projections.

Description. Color. Coloration dark yellow to orange overall; pronotum and suprahumeral horns black dorsally. Forewing membranehyaline, with black transverse macula basally, extending from costal margin to vein M. Head. Vertex (Fig. 229) with dorsomedial surface flat. Frontoclypeus ventral lobe with lateral margins convex. Thorax. Pronotum with suprahumeral horns well developed, dorsal surface of horn even with dorsal midline or erect; in dorsal view acuminate, extending posterolaterally (Fig. 199); with anterior carina. Scutellum with apex punctate. Legs: metathoracic tibia with 2-12 supranumerary cucullate setae between rows II and III. Tymbals large and conspicuous, extending beyond posterior margin of metathorax. Male. Lateral plate robust; strongly curved mesad apically. Subgenital plate with slight subbasal constriction, apical two-thirds tapered. Aedeagus (Figs 249-250) with pair of slender dorsal processes preapically; apex acutely produced laterally, with pair of apical processes, each with 3-4 fingerlike distal projections; gonopore on ventral preapical surface. Connective (Fig. 250) truncate posteriorly. Style (Figs 249-250) with apex abruptly bent laterally, rounded or blade-like. Female. Second valvulae width more or less uniform throughout; uniformly dentate dorsally.

Measurements (mm). Male/female. Body length 6.2-6.3/ 6.5; head width 2.8-3.0/3.0; width across pronotal humeri 2.5-
2.6/2.7; width across tips of horns 3.6-3.7/4.0; forewing length 5.2-5.3/5.5.

Material examined. Holotype male: “ECUADOR: Napo, Tran-/ sect Ent. 1km S Onkonegare/ Camp. Reserva Etnica Waorani/ 0039'10"S, 07626'00"W/ 21-Jun-1994, T.L. Erwin,/ et al., fogging terre [sic] firme/ forest, lot \#702; Albertson Research/ TOL-0004 o; Holotype/ Tolania/ insolita/ Albertson" [USNM ]. Paratypes: 1 male, 1 female, same locality [USNM].

Distribution. Ecuador: Napo. Collection dates: Juneto July.

Notes. The name 'insolita' is Latin for "strange or unusual" and refers to the appearance of the aedeagus apical processes.

\section{Tolania lunata Albertson, sp. nov. Figs 200-201, 230, 251-252}

Type locality. 1 km S Onkonegare Camp, Reserva Etnica Waorani, Napo, Ecuador [USNM].

Diagnosis. This species differs from others in the group in having the aedeagus with a pair of short lateral processes preapically and a pair of elongate convexly curved processes apically.

Description. Color. Coloration dark yellow to orange overall; suprahumeral horns black dorsally. Forewing membrane brown hyaline, with transverse brown macula basally, extending from costal margin to vein $\mathrm{M}+\mathrm{Cu}$ and from claval suture to commisural margin; commisural margin brown. Head. Vertex (Fig. 230) with dorsomedial surface flat. Frontoclypeus ventral lobe with lateral margins parallel, slightly converging ventrally. Thorax. Pronotum with suprahumeral horns well developed, dorsal surface of horn even with dorsal midline; in dorsal view broad, acuminate (Fig. 201); with anterior carina, ventral carina present distally. Scutellum with apex punctate. Legs: metathoracic tibia with 5-7 supranumerary cucullate setae between rows II and III. Tymbals large and conspicuous, extending beyond posterior margin of metathorax. Male. Lateral plate weakly constricted basally; robust, tapered. Subgenital plate without constriction, tapered. Aedeagus (Figs 251-252) with pair of short lateral processes preapically; with pair of elongate convexly curved processes apically; gonopore on ventral preapical surface. Connective (Fig. 250) truncate posteriorly. Style (Figs 251-252) with apex abruptly bent laterally, bladelike. Female. Second valvulae width more or less uniform throughout; uniformly dentate dorsally.

Measurements (mm). Male/female. Body length 6.1-6.2/ 6.6-6.9; head width 2.5-2.6/2.7-2.8; width across pronotal humeri 2.2-2.3/2.4-2.5; width across tips of horns 2.9-3.2/3.1-3.4; forewing length 5.0-5.1/5.6-6.1.

Material examined. Holotype male: “ECUADOR: Napo, Tran-/ sect Ent. 1km S Onkonegare/ Camp. Reserva Etnica Waorani/ 0039'10"S, 07626'00"W/ 21-Jun-1994, T.L. Erwin,/ et al., fogging terre [sic] firme/ forest, lot \#715; Albertson Research/ TOL-0023 o;" Holotype/ Tolania/ Iunata/ Albertson" [USNM ]. Paratypes: 1 male, 2 females, same locality [USNM].

Distribution. Ecuador: Napo. Collection dates: June and October.

Revista Brasileira de Zoologia 23 (4): 915-993, dezembro 2006 
Notes. The aedeagus of Tolania lunata closely resembles that of T. arcuata, T. damia, and T. umbella. This species can be differentiated by the forewing macula and the absence of a projection on the aedeagus apical processes.

The specific name 'lunata' translates from Latin as "shaped like a crescent moon", referring to the convex shape of the aedeagus apical processes.

\section{Tolania Iurida Albertson, sp. nov.}

Figs 202-203, 231, 253-254, 277, 286 [BMNH].

Type locality. Chirun Valley, Auyántepui, Venezuela

Diagnosis. This species differs from others in the group in having the aedeagus with a pair of broad processes preapically, acute laterally with slender anterior recurved projections.

Description. Color. Coloration yellow overall with black punctures; pronotum faintly brown dorsally; tibiae with brown markings present or absent. Forewing membrane hyaline. Head. Vertex (Fig. 231) with dorsomedial surface flat. Frontoclypeus ventral lobe with lateral margins parallel, slightly converging ventrally. Thorax. Pronotum with suprahumeral horns well developed, elevation polymorphic (dorsal surface of horn even with or lower than dorsal midline); in dorsal view slender, acuminate, extending posterolaterally (Fig. 203); with anterior carina. Scutellum with apex punctate. Legs: metathoracic tibia with 710 supranumerary cucullate setae between rows II and III. Tymbals large and conspicuous, extending beyond posterior margin of metathorax. Male. Lateral plate tapered, with lightly sclerotized or membranous digitiform process apically. Subgenital plate with subbasal constriction, apical two-thirds tapered. Aedeagus (Figs 253-254, 277) with pair of processes preapically, process broad and acute laterally with slender anterior recurved projection; gonoporeon ventral preapical surface. Connective (Fig. 254) broadly rounded posteriorly. Style (Figs 253-254) with acute projection subbasally in dorsal view; apex strongly hooked laterally, acuminate. Female. Second valvulae (Fig. 286) broadened near midlength, dorsal margin angulate; uniformly dentate dorsally.

Measurements (mm). Male/female. Body length 5.5-5.9/ 6.2-7.1; head width 2.3-2.7/2.6-3.1; width across pronotal humeri 2.1-2.3/2.3-2.7; width across tips of horns 2.5-3.4/3.1-3.3; forewing length 4.7-5.0/5.3-6.0.

Material examined. Holotype male: “VENEZUELA:/ Auyántepui/ Chirun Valley/ 24-28.VIII.1924; B.B. Ridout/ B.R. 1974-650; Albertson Research/ TOL-0550 o; Holotype/ Tolania/ lurida/ Albertson" [BM NH]. Paratypes: 1 male, 2 females, Parque Nac. Yacambu, Lara, Venezuela [USNM ]; 1 male, Guanoco, Venezuela, Tolania opponens [misidentification] [AMNH]. Other material: 2 females [USNM].

Distribution. Venezuela: Aragua; Caracas; Lara; Mérida; Sucre. Collection dates: April and October.

Notes. This species has been collected on Annona muricata (Annonaceae). The specific name 'lurida' is Latin for "pale yellow" and refers to the coloration of the adults.

\section{Tolania opponens (Walker, 1858) \\ Figs 204-205, 232, 255-256, 278, 287}

Centrotus opponens Walker, 1858a: 159.

[Tolania opponens]; Stål, 1862a: 491.

Type locality. Mexico [BMNH].

Diagnosis. This species differs from others in the group in having the aedeagus with the shaft slender basally and abruptly enlarged and bulbous apically, with a pair of bifurcate apical processes.

Description. Color. Coloration yellow overall with black punctures; pronotum with dark brown to black markings dorsally; scutellum with basolateral margins black. Forewing membrane hyaline. Head. Vertex (Fig. 232) with dorsomedial surface flat to concave. Frontoclypeus lateral lobes distinct with sutures; ventral lobe with lateral margins parallel, slightly converging ventrally. Thorax. Pronotum with suprahumeral horns well developed, erect; in dorsal view broad basally, acuminate, extending posterolaterally (Fig. 205); with anterior carina. Scutellum apex without punctures. Legs: metathoracic tibia with 6-7 supranumerary cucullate setae between rows II and III. Tymbals small, not extending beyond posterior margin of metathorax. Male. Lateral plate slender, tapered, with lightly sclerotized or membranous digitiform process apically. Subgenital plate with subbasal constriction, apical two-thirds tapered. Aedeagus (Figs 255-256, 278) with shaft slender basally, abruptly enlarged and bulbous apically; with pair of bifurcate apical processes, each process with slender convexly curved projection anteriorly and acute projection posteriorly; gonopore apical. Connective (Fig. 256) truncate posteriorly. Style (Figs 255-256), in dorsal view, with shank abruptly narrowed subbasally; apex broadly hooked laterally, acute. Female. Second valvulae (Fig. 287) broadened near midlength, dorsal margin distinctly angulate; uniformly dentate dorsally.

Measurements (mm). Male/female. Body length 6.6-7.3/ 7.7; head width 2.5-2.6/2.7; width across pronotal humeri 2.22.4/2.6; width across tips of horns 2.1-3.3/3.7; forewing length 5.8-6.3/6.6.

Material examined. Holotype male: “Type; CENTROTUS OPPONENS.; Mex; Albertson Research/ TOL-1018 o" [BMNH]. Other material: 2 males, 1 female [CNC, USNM].

Distribution. Costa Rica: Guanacaste; Guatemala: Suchitepéquez; Mexico. Collection date: May.

Notes. The male genitalia of Tolania opponens closely resemblethose of T. tumida but can bedistinguished by theangulate appearance of the bulbous apex of the aedeagus in lateral view (appears rounded in T. tumida) and the smaller apical processes.

\section{Tolania oriana Albertson, sp. nov. Figs 206-207, 233, 257-258}

Type locality. Leon Pampa, Arequipa, Peru [USNM].

Diagnosis. This species differs from others in the group in having the aedeagus with a pair of slender recurved ventral 

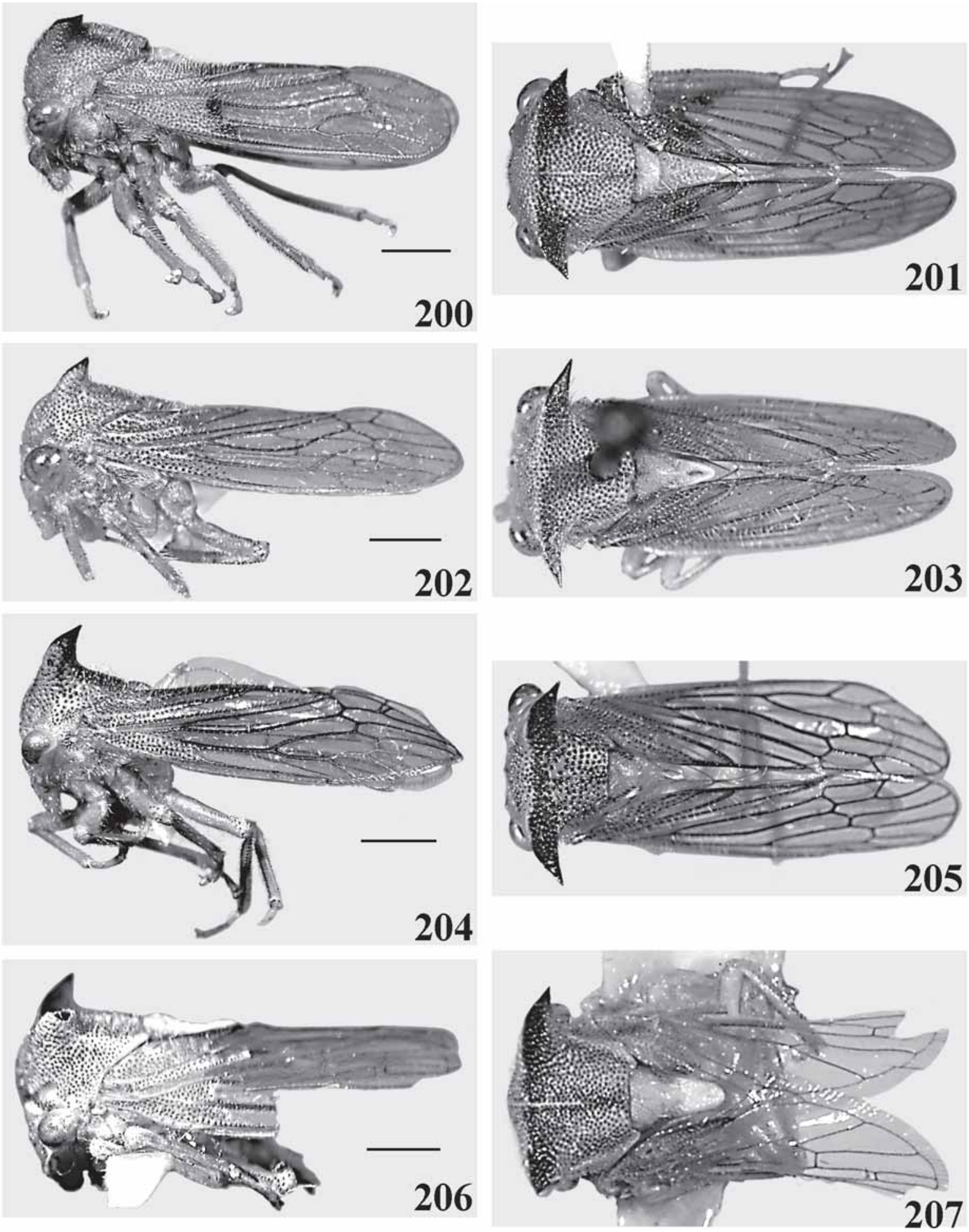

Figures 200-207. Opponens group adult lateral and dorsal habitus. (200-201) Tolania lunata paratype male; (202-203) T. lurida holotype male; (204-205) T. opponens (Walker) male; (206-207) T. oriana holotype male.

Revista Brasileira de Zoologia 23 (4): 915-993, dezembro 2006 
processes medially and a pair of slender lateral processes apically.

Description. Color. Coloration yellow overall with black punctures; pronotum faintly mottled with brown dorsally. Forewing membranehyaline. Head. Vertex (Fig. 233) with dorsomedial surface flat. Frontoclypeus ventral lobe with lateral margins parallel, slightly converging ventrally. Thorax. Pronotum with me dian longitudinal carina weakly keeled and acute dorsally; suprahumeral horns well developed, erect, in dorsal view broad, acuminate, extending laterally (Fig. 207), with anterior and posterior carinae. Scutellum with apex punctate. Legs: metathoracic tibia with 7 supranumerary cucullate setae between rows II and III. Tymbals large and conspicuous, extending beyond posterior margin of metathorax. Male. Lateral plate with dorsal margin convex in lateral view; tapered, with lightly sclerotized or membranous digitiform process apically. Subgenital plate without constriction, tapered. Aedeagus (Figs 257-258) with pair of slender recurved ventral processes medially; with pair of slender lateral processes apically; gonopore apical. Connective (Fig. 258) broadly rounded posteriorly. Style (Figs 257-258), in dorsal view, with shank broad, abruptly narrowing preapically; apex bent laterally, acuminate. Female. Unknown.

Measurements ( $\mathrm{mm}$ ). Male. Body length [unknown, forewing missing]; head width 2.6; width across pronotal humeri 2.5; width across tips of horns 3.4; forewing length [missing].

Material examined. Holotype male: "Leonpampa [sic],/ Peru/ Dec. 1937; opponens [misidentification]; WD Funkhouser/ Collection/ 1962; Albertson Research/ TOL-0010 ơ, Holotype/ Tolania/ oriana/ Albertson" [USNM].

Distribution. Peru: Arequipa. Collection date: December.

Notes. The holotype is missing the fore and hind wings. The specific name 'oriana' is Greek for "golden one" and refers to the species' overall coloration.

\section{Tolania reflexa Albertson, sp. nov. Figs 208-209, 234, 259-260, 288}

Type locality. 1 km S Onkonegare Camp, Reserva Etnica Waorani, Napo, Ecuador [USNM].

Diagnosis. This species differs from other species in this group in having the aedeagus compressed in ventral view with a single distal process, recurved dorsally over apex.

Description. Color. Coloration yellow overall with brown punctures; suprahumeral horns brown dorsally; tibiae with pale brown band medially and apically. Forewing basal sclerotization yellow with dark brown transverse macula distally; membrane brown hyaline; commisural margin brown. Head. Vertex (Fig. 234) with dorsomedial surface flat. Frontoclypeus ventral lobe with lateral margins parallel. Thorax. Pronotum with metopidium sloping, low; suprahumeral horns well developed, erect, in dorsal view acuminate, extending posterolaterally (Fig. 209), with anterior and posterior carinae, dorsal carina present distally. Scutellum with apex punctate. Legs: metathoracic tibia with 4-6 supranumerary cucullate setae between rows II and
III. Tymbals small, not extending beyond posterior margin of metathorax. Male. Lateral plate weakly convex in lateral view; tapered, with lightly sclerotized or membranous digitiform process apically. Subgenital plate without constriction, tapered. Aedeagus (Figs 259-260) with shaft strongly compressed in ventral view; with single distal process recurved dorsally over apex; gonopore apical. Connective (Fig. 260) truncate posteriorly. Style (Figs 259-260) with shank slender throughout; apex hooked laterally, acute. Female. Second valvulae (Fig. 288) broadened near midlength; uniformly dentate dorsally.

Measurements (mm). Male/female. Body length 6.1/6.26.6; head width 2.6/2.7-2.8; width across pronotal humeri 2.1/ 2.2-2.3; width across tips of horns 3.0/3.3-3.8; forewing length 5.2/5.5-5.7.

Material examined. Holotype male: “ECUADOR: Napo, Tran-/ sect Ent. 1km S Onkonegare/ Camp. Reserva Etnica Waorani/ 0039'10"S, 07626'00"W/ 3-Jul-1994, T.L. Erwin,/ et al., fogging terre [sic] firme/ forest, lot \#761; Albertson Research/ TOL-0142 o", Holotype/ Tolania/ reflexa/ Albertson". Paratype: 1 female, same locality [USNM ]. Other material: 1 female [USNM].

Distribution. EcuAdor: Napo. Collection dates: Juneto July.

Notes. Thename 'reflexa' is Latin for "turned or bent back" and refers to the shape of the aedeagus distal process.

\section{Tolania risa Albertson, sp. nov. Figs 210-211, 235, 261-262, 279, 289}

Type locality. 1 km S Onkonegare Camp, Reserva Etnica Waorani, Napo, Ecuador [USNM].

Diagnosis. This species differs from others in the group in having the aedeagus with a pair of slender, flattened dorsal processes preapically, 2 pairs of short hooked processes preapically, and the dorsoapical margin produced into a small recurved projection.

Description. Color. Coloration yellow overall with black punctures; suprahumeral horns brown dorsally; scutellum with basolateral margins black. Forewing basal sclerotization yellow; membrane hyaline with brown macula basally, extending from costal margin to vein $\mathrm{M}+\mathrm{Cu}$. Head. Vertex (Fig. 235) with dorsomedial surface flat. Frontoclypeus ventral lobe with lateral margins parallel, slightly converging ventrally. Thorax. Pronotum with suprahumeral horns well developed, erect; in dorsal view slender, acuminate, extending posterolaterally (Fig. 211); with anterior carina. Scutellum with apex punctate. Legs: metathoracic tibia with 4-10 supranumerary cucullate setae between rows II and III. Tymbals large and conspicuous, extending beyond posterior margin of metathorax. Male. Lateral plate evenly tapered; in dorsal view, strongly curved mesad apically. Subgenital plate without constriction, tapered. Aedeagus (Figs 261-262, 279) with pair of slender, flattened dorsal processes preapically; with 2 pairs of short hooked processes preapically; dorsal margin produced into small recurved projection; gonopore apical. Connective (Fig. 262) broadly rounded posteriorly. Style (Figs 261-262) with shank slender; apex abruptly bent laterally and bladelike.

Revista Brasileira de Zoologia 23 (4): 915-993, dezembro 2006 

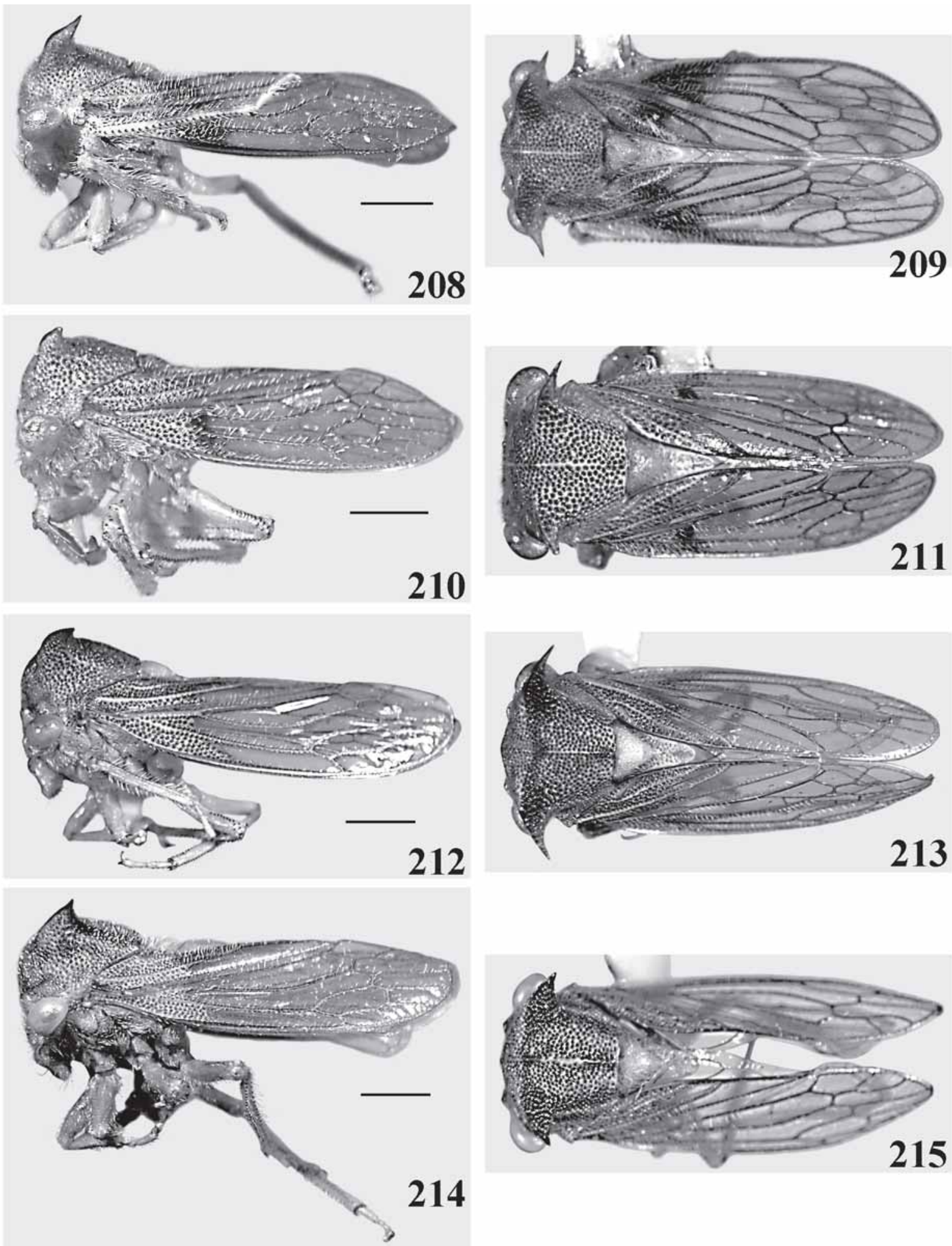

Figures 208-215. Opponens group adult lateral and dorsal habitus. (208-209) Tolania reflexa holotype male; (210-211) T. risa holotype male; (212-213) T. sinuata holotype male; (214-215) T. trilobata holotype male.

Revista Brasileira de Zoologia 23 (4): 915-993, dezembro 2006 
Female. Second valvulae (Fig. 289) broadened near midlength, dorsal margin distinctly angulate; uniformly dentate dorsally.

Measurements (mm). Male/female. Body length 5.0/5.76.1; head width 2.2/2.3-2.5; width across pronotal humeri 1.9/ 2.1-2.2; width across tips of horns 2.4/2.3-2.9; forewing length 4.2/4.6-5.1.

Material examined. Holotype male: “ECUADOR: Napo, Tran-/ sect Ent. 1km S Onkonegare/ Camp. Reserva Etnica Waorani/ 0039'10"S, 07626'00"W/ 25 Jun 1994, T.L. Erwin,/ et al., fogging terre [sic] firme/ forest, lot \#722; Albertson Research/ TOL-0014 o; Holotype/ Tolania/ risa/ Albertson" [USNM]. Paratypes: 3 females, same locality [USNM]. Other material: 1 female [USNM]. October.

Distribution. Ecuador: Napo. Collection dates: June and

Notes. The specific name 'risa' is Latin for "laughter".

\section{Tolania sinuata Albertson, sp. nov. Figs 212-213, 236, 263-264}

Type locality. Villa Tunari, Cochabamba, Bolivia [INHS].

Diagnosis. This species differs from others in the group in having the aedeagus, in lateral view, enlarged basally, slender and weakly curved distally, without distal processes, but with a pair of acute dorsal projections subbasally.

Description. Color. Coloration yellow overall with black punctures and variable red and brown markings; suprahumeral horns brown dorsally; scutellum with red medial longitudinal stripe basally. Forewing membrane hyaline to brown hyaline. Head. Vertex (Fig. 236) with dorsomedial surface flat. Frontoclypeus ventral lobe with lateral margins weakly convex. Thorax. Pronotum with suprahumeral horns well developed, erect; in dorsal view polymorphic (triangular or slender and acuminate, Fig. 213); with anterior carina. Scutellum with apex punctate. Legs: metathoracic tibia with 6-9 supranumerary cucullate setae between rows II and III. Tymbals large and conspicuous, extending beyond posterior margin of metathorax. Male. Lateral plate tapered. Aedeagus (Figs 263-264), in lateral view, enlarged basally and narrowing, apical half slender and weakly curved; with pair of acute dorsal projections subbasally; gonopore apical. Connective (Fig. 264) acuminate posteriorly. Style (Figs 263-264), in dorsal view, with shank abruptly narrowed preapically; apex recurved in lateral view. Female. Second valvulae broadened near midlength, dorsal margin distinctly angulate; uniformly dentate dorsally.

Measurements (mm). Male/female. Body length 5.8-6.4/ 6.6; head width 2.6-2.7/2.8; width across pronotal humeri 2.32.5/2.5; width across tips of horns 1.6-3.1/3.1; forewing length 4.9-5.3/5.5.

Material examined. Holotype male: "BOLIVIA: Cochabamba Prov./ Villa Tunari 06.X.2001/ tropical forest, malaisetrap/ 1654'55"S, 65²2'06"W/ leg. Helmut Heider; Albertson Research/ TOL-1004 o; Holotype/ Tolania/ sinuata/ Albertson" [INHS]. Paratypes: 1 female, same locality [INHS]; 1 male, Villa Bella,
Bolivia [ICCM]; 1 male, Cusca, Peru [NCSU]. Other material: 1 female, 1 male [ICCM ].

Distribution. Bolivia: Cochabamba; Pando; Potosi; BrazIL: Piauí; Peru: Ancash. Collection dates: June to August, October.

Notes. The aedeagus and styles of Tolania sinuata resemble those of T. vitocensis; however the aedeagus of T. sinuata in dorsal view abruptly narrows from the enlarged base (that of $\mathrm{T}$. vitocensis is uniformly slender). The subgenital plates were missing or broken in all male specimens examined.

The name 'sinuata' is Latin for "bend or curve" and refers to the shape of the aedeagus.

\section{Tolania trilobata Albertson, sp. nov. Figs 214-215, 237, 265-266, 290}

Type locality. 30 km SW Puerto Maldonado, Río Tambopata Reserva, Madre de Dios, Peru [USNM].

Diagnosis. This species differs from others in the group in having the aedeagus with 2 pairs of short dorsal processes medially and with a pair of slender lateral processes apically.

Description. Color. Coloration yellow to dark orange overall with black punctures and variable black markings; pronotum with suprahumeral horns black dorsally, black macula extending from posterior suprahumeral horn to posterolateral projection; scutellum with basolateral margins reddish brown. Forewing membrane hyaline to brown hyaline. Head. Vertex (Fig. 237) with dorsomedial surface distinctly concave. Frontoclypeus ventral lobe with lateral margins parallel, slightly converging ventrally. Thorax. Pronotum with suprahumeral horns well developed, erect; in dorsal view short, acuminate, extending posterolaterally (Fig. 215); with anterior carina. Scutellum with apex punctate. Legs: metathoracic tibia with 6-10 supranumerary cucullate setae between rows II and III. Tymbals large and conspicuous, extending beyond posterior margin of metathorax. Male. Lateral plate in lateral view weakly convex; tapered. Subgenital plate without constriction, tapered. Aedeagus (Figs 265-266) with 2 pairs of short dorsal processes medially; apex with pair of slender processes extending laterally; gonopore apical. Connective (Fig. 266) truncate posteriorly. Style (Figs 265-266) hooked laterad preapically, apex acuminate or bladelike and oriented ventrally. Female. Second valvulae (Fig. 290) width more or less uniform throughout; uniformly dentate dorsally.

Measurements (mm). Male/female. Body length 6.2-6.5/ 7.1; head width 2.8-2.9/3.0; width across pronotal humeri 2.42.6/2.7; width across tips of horns 2.8-3.5/3.8; forewing length 5.2-5.5/6.0.

Material examined. Holotype male: “PERU: Madre de Dios/ Rio Tambopata Res./ 30km (air) SW Pto./ Maldonado, 290m./ 1250'S, 06917'W; Smithsonian Institution/ Canopy Fogging Project/ T.L. Erwin, et al., colls./ 12 Nov 1983 02/03090; Albertson Research/ TOL-0020 o; Holotype/ Tolania/ trilobata/ Albertson" [USNM]. Paratypes: 1 female same locality [USNM ]; 1 male, same locality [CAS]. Other material: 1 male [BMNH].

Revista Brasileira de Zoologia 23 (4): 915-993, dezembro 2006 
Distribution. Peru: Madre de Dios; Suriname: Sipaliwini. Collection dates: March, August to November.

Notes. The name 'trilobata' is derived from the Latin words tres translating as "three" and lobus meaning "projection" and refers to the 3 pairs of processes on the aedeagus.

\section{Tolania tumida Albertson, sp. nov. Figs 216-217, 238, 267-268}

Type locality. Río San Lorenzo, Tierras Morenas, RF Cord., Guanacaste, Costa Rica [INBio].

Diagnosis. This species differs from others in the group in having weakly developed, carinate suprahumeral horns and the aedeagus with the shaft slender, abruptly enlarged and bulbous apically, with a pair of bifurcate apical processes.

Description. Color. Coloration yellow overall with variable brown markings; pronotum brown with median longitudinal carina yellow dorsally; scutellum with basolateral margins brown. Forewing membrane hyaline, with brown transverse macula basally, extending from costal margin to vein $\mathrm{M}+\mathrm{Cu}$ and from claval suture to commisural margin; commisural margin brown. Head. Vertex (Fig. 238) with dorsomedial surface flat. Frontoclypeus ventral lobe with lateral margins parallel, slightly converging ventrally; with median Iongitudinal carina present. Thorax. Pronotum with suprahumeral horns weakly developed, carinate (Fig. 217). Scutellum with apex punctate. Legs: metathoracic tibia with 10 supranumerary cucullate setae between rows II and III. Tymbals small, not extending beyond posterior margin of metathorax. Male. Lateral plate slender, tapered. Subgenital plate with subbasal constriction, apical two-thirds tapered. Aedeagus (Figs 267-268) with shaft slender, abruptly enlarged and bulbous apically; with pair of bifurcate apical processes, each process with convexly curved elongate projection anteriorly and acute projection posteriorly; gonopore apical. Connective (Fig. 268) truncate posteriorly. Style (Figs 267-268), in dorsal view, with shank abruptly narrowed subbasally; apex broadly hooked laterally, acute. Female. Second valvulae broadened near midlength, dorsal margin distinctly angulate; uniformly dentate dorsally.

Measurements (mm). Male/female. Body length 6.1/7.2; head width 2.4/2.9; width across pronotal humeri 2.0/2.5; width across tips of horns 1.2/1.9; forewing length 5.1/6.1.

Material examined. Holotype male: “R. Sn Lorenzo, 1050m./ Tierras Morenas, RF/ Cord. Guanacaste, Prov/ Guan. COSTA RICA./ C. Alvarado, Ene 1992,/ L-N-287800,427600; Tolania/ sp. 2; Albertson Research/ TOL-0874 o; Holotype/ Tolania/ tumida/ Albertson" [INBio]. Paratype: "COSTA RICA Guana./ Volcan Cacao, 1100m/ Est. Cacao forest/ Mar. 20, 1990/ R.W. Flowers; Tolania sp. 2; Albertson Research/ TOL-0885 o " [INBio]. Other material: 2 female [BMNH].

Distribution. Costa Rica: Guanacaste; Panama: Chiriqui. Collection dates: January and March.

Notes. The vertex varies in coloration, with some specimens having the vertex mottled red and yellow with black punctures. The genitalia of this species closely resemble those of Tolania opponens but differ in the rounded appearance of the bulbous apex of the aedeagus in lateral view (angulate in $\mathrm{T}$. opponens) and the larger apical processes.

The specific name 'tumida' translates from Latin as "swollen", referring to the apex of aedeagus.

\section{Tolania umbella Albertson, sp. nov. Figs 218-219, 239, 269-270}

Type locality. 30 km SW Puerto Maldonado, Río Tambopata Reserve, Madre de Dios, Peru [USNM].

Diagnosis. This species differs from others in the group in having the aedeagal apex with a pair of convexly curved flat processes with weakly serrate margins.

Description. Color. Coloration yellow to orange overall with black punctures and variable brown markings; suprahumeral horns black dorsally; femora with brown band subapically, tibiae with brown markings. Forewing membrane hyaline; commisural margin brown. Head. Vertex (Fig. 239) with dorsomedial surface flat. Frontoclypeus ventral lobe with lateral margins parallel, slightly converging ventrally. Thorax. Pronotum with suprahumeral horns well developed, erect; in dorsal view short, acuminate, extending posterolaterally (Fig. 219); with anterior carina. Scutellum with apex punctate. Legs: metathoracic tibia with 6-10 supranumerary cucullate setae between rows II and III. Tymbals large and conspicuous, extending beyond posterior margin of metathorax. Male. Lateral platetapered, with lightly sclerotized or membranous digitiform process apically. Subgenital plate without constriction, tapered. Aedeagus (Figs 269-270) with apex produced laterally into pair of convexly curved flat processes with weakly serrate margins dorsally; gonopore apical. Connective (Fig. 270) truncate posteriorly. Style (Figs 269-270) with shank abruptly bent laterad preapically, apex acuminate or blade-like. Female. Second valvulae broadened near midlength, dorsal margin angulate; uniformly dentate dorsally.

Measurements (mm). Male/female. Body length 5.1-5.4/ 6.0-6.4; head width 2.2-2.3/2.4-2.6; width across pronotal humeri 2.0-2.1/2.2-2.3; width across tips of horns 2.3-2.6/2.9-3.3; forewing length 4.3-4.6/5.0-5.4.

Material examined. Holotype male: "PERU: Madre de Dios/ Rio Tambopata Res./ 30km (air) SW Pto./ Maldonado, 290m./ 12050'S, 069017'W; Smithsonian Institution/ Canopy Fogging Project/ T.L. Erwin, et al., colls./ 6 Sep 1984 05/02; Albertson Research/ TOL-0001 o; Holotype/ Tolania/ umbella/ Albertson" [USNM]. Paratypes: 2 males, 1 female same data [USNM]. Other material: 1 male, 1 female [USNM].

Distribution. Peru: Madre de Dios. Collection dates: March, September, and November.

Notes. The aedeagus of Tolania umbella is similar to that of $\mathrm{T}$. arcuata, T. damia, and T. Iunata but can be differentiated by the broader, serrate apical processes.

The name 'umbella' is Latin for "umbrella" and refers to the shape of aedeagus apical processes.

Revista Brasileira de Zoologia 23 (4): 915-993, dezembro 2006 

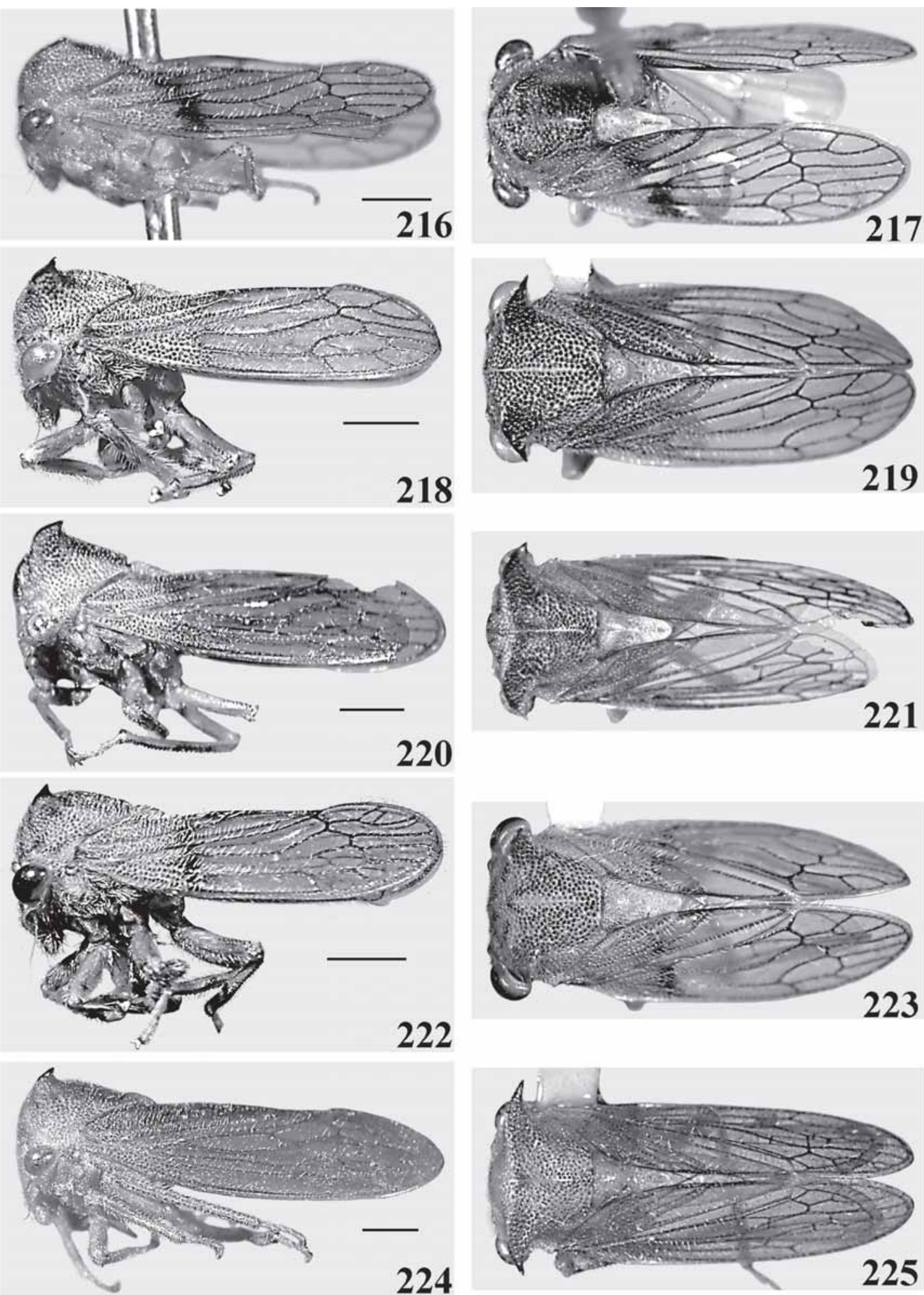

Figures 216-225. Opponens group adult lateral and dorsal habitus. (216-217) Tolania tumida holotype male; (218-219) T. umbella male; (220-221) T. vitocensis holotype male; (222-223) T. woodi holotype male; (224-225) T. xantha holotype male. 


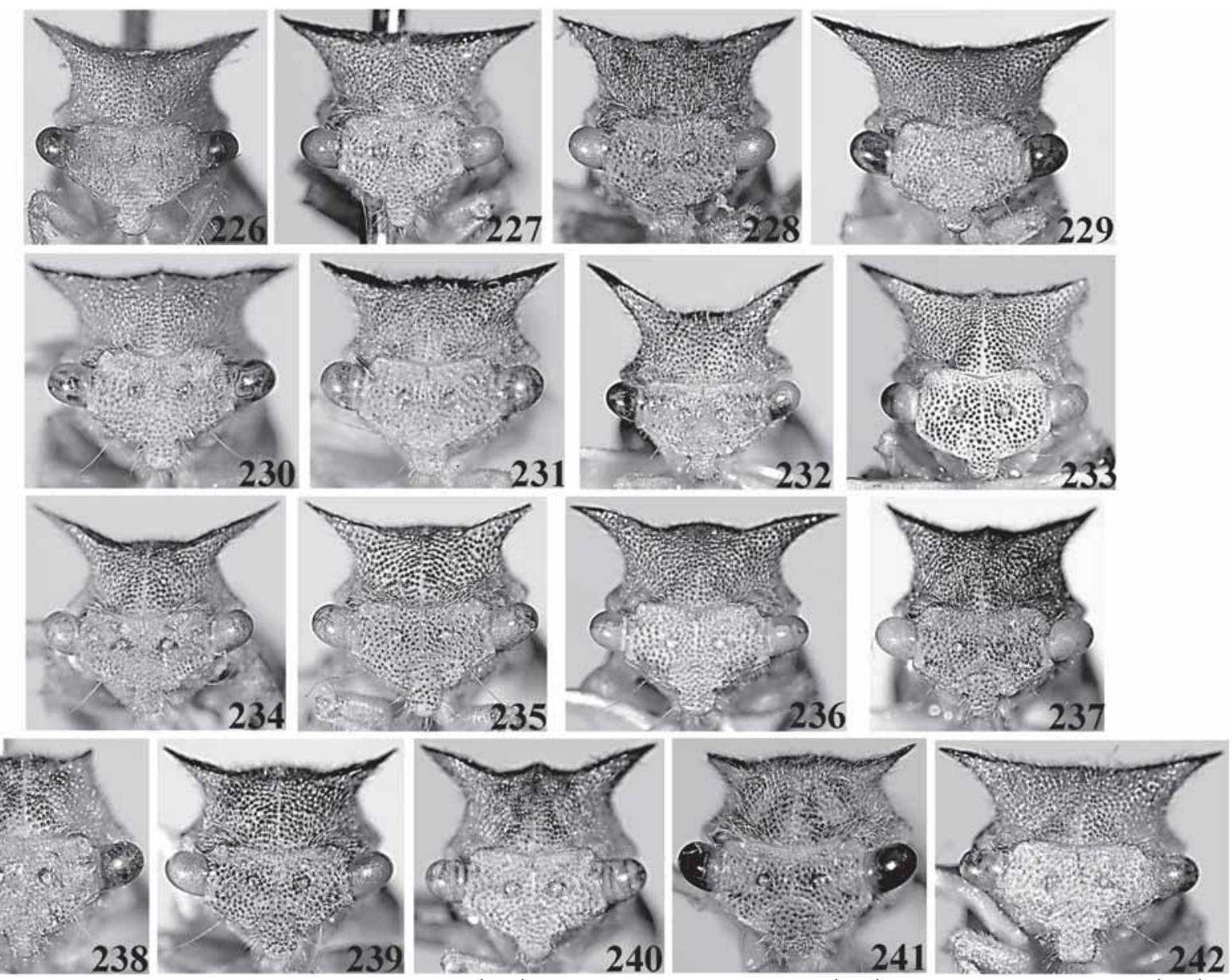

Figures 226-242. Opponens group adult anterior habitus. (226) Tolania alvira holotype male; (227) T. arcuata holotype male; (228) T. damia holotype male; (229) T. insolita paratype male; (230) T. lunata paratype male; (231) T. lurida holotype male; (232) T. opponens (Walker) male; (233) T. oriana holotype male; (234) T. reflexa holotype male; (235) T. risa holotype male; (236) T. sinuata holotype male; (237) T. trilobata holotype male; (238) T. tumida holotype male; (239) T. umbella male; (240) T. vitocensis holotype male; (241) T. woodi holotype male; (242) T. xantha holotype male.

\section{Tolania vitocensis Albertson, sp. nov.}

Figs 220-221, 240, 271-272, 291

Type locality. Vitoc, Junin, Peru [USNM].

Diagnosis. This species differs from others in the group in having the aedeagus, in lateral view, enlarged basally and tubular distally, in ventral view uniformly slender with distinct angles medially, and lacking apical processes.

Description. Color. Coloration yellow overall with variable red and brown markings; suprahumeral horns dark brown dorsally. Forewing membrane hyaline. Head. Vertex (Fig. 240) with dorsomedial surface flat. Frontoclypeus ventral lobe with lateral margins parallel, slightly converging ventrally. Thorax. Pronotum with suprahumeral horns well developed, erect; in dorsal view short, acuminate, extending posterolaterally (Fig. 221); with anterior and posterior carinae. Scutellum with apex punctate. Legs: metathoracic tibia with 12 supranumerary cucullate setae between rows II and III. Tymbals large and conspicuous, extending beyond posterior margin of metathorax. Male. Lateral plate evenly tapered, strongly curved mesad apically. Subgenital plate without constriction, tapered. Aedeagus (Figs 271-272), in lateral view, enlarged basally and abruptly narrowing near midlength; in ventral view, slightly narrowed with distinct angles near midlength; apical processes absent; gonopore apical. Connective (Fig. 272) acuminate posteriorly. Style(Figs 271-272), in dorsal view, with shank abruptly narrowed preapically; apex recurved in lateral view. Female. Second valvulae (Fig. 291) broadened near midlength, dorsal margin distinctly angulate; uniformly dentate dorsally.

Measurements $(\mathrm{mm})$. Male/female. Body length 6.6/6.7; head width 2.7/2.8; width across pronotal humeri 2.5/2.5; width across tips of horns 3.0/3.4; forewing length 5.5/5.5.

Revista Brasileira de Zoologia 23 (4): 915-993, dezembro 2006 


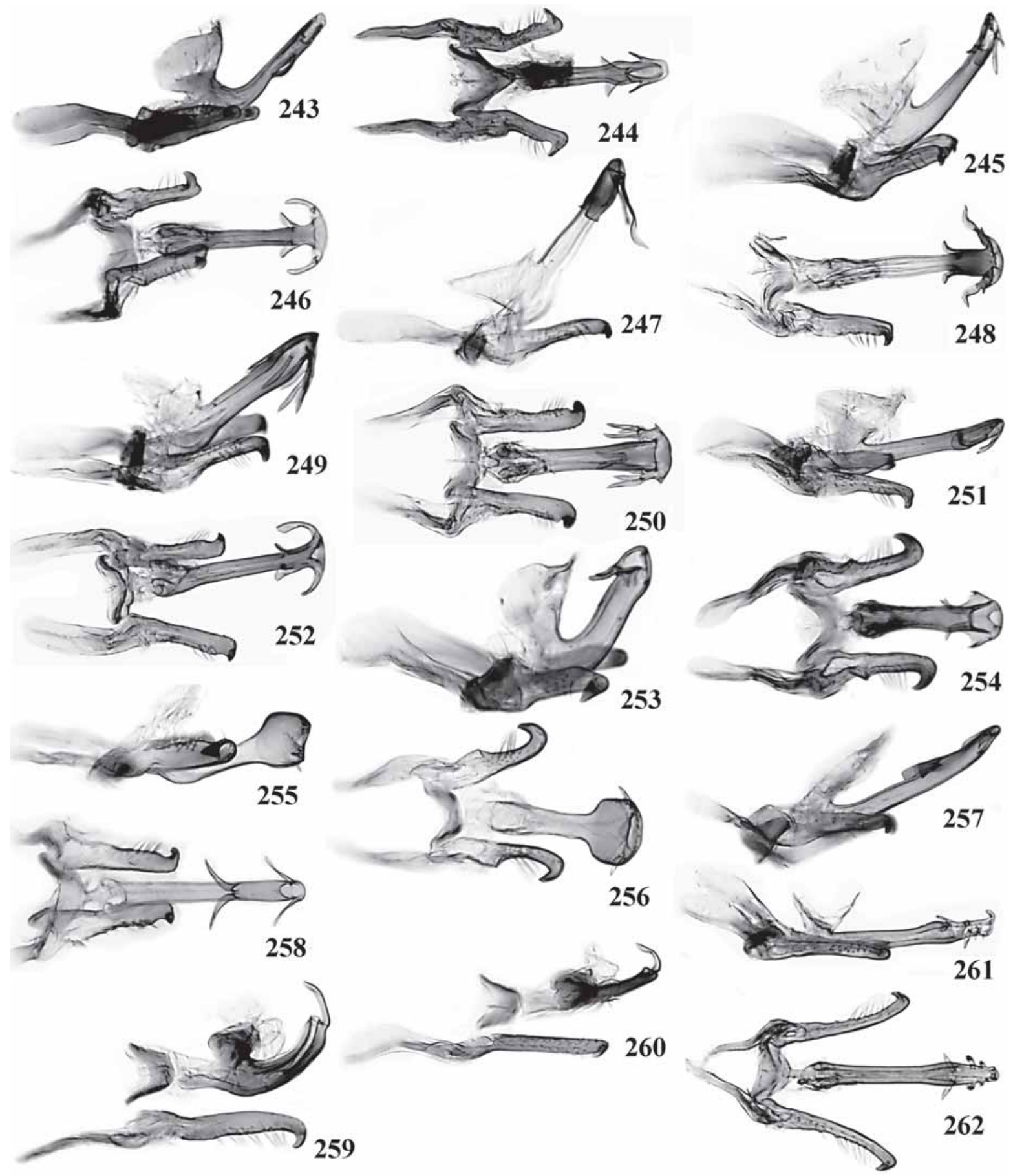

Figures 243-262. Opponens group males. (243-244) Tolania alvira holotype: (243) genitalia, lateral view; (244) same, ventral view; (245246) T. arcuata holotype: (245) genitalia, lateral view; (246) same, ventral view; (247-248) T. damia holotype: (247) genitalia, right lateral view, inverted; (248) same, ventral view; (249-250) T. insolita holotype: (249) genitalia, lateral view; (250) same, ventral view; (251-252) T. lunata holotype: (251) genitalia, lateral view; (252) same, dorsal view; (253-254) Tolania lurida paratype: (253) genitalia, lateral view; (254) same, ventral view; (255-256) T. opponens (Walker): (255) genitalia, lateral view; (256) same, ventral view; (257-258) T. oriana holotype: (257) genitalia, lateral view; (258) same, ventral view; (259-260) T. reflexa holotype: (259) genitalia, lateral view; (260) same, dorsal view; (261-262) T. risa holotype: (261) genitalia, lateral view; (262) same, dorsal view. 
Material examined. Holotype male: “Vitoc/ Peru/ Aug. 1940; opponens; WD Funkhouser/ Collection/ 1962; Albertson Research/ TOL-0015 o; Holotype/ Tolania/ vitocensis/ Albertson" [USNM ]. Paratype: 1 female, same data [USNM ].

Distribution. Peru: Junin. Collection date: August.

Notes. The aedeagus and styles of Tolania vitocensis resemble those of T. sinuata; however, the aedeagus of $\mathrm{T}$. vitocensis abruptly narrows from theenlarged base in lateral view (T. sinuata gradually narrows) and is uniformly slender in dorsal view.

The name 'vitocensis' refers to the location in which the type specimens were collected.

\section{Tolania woodi Albertson, sp. nov. Figs 222-223, 241, 273-274, 282}

Type locality. 1 km S Onkonegare Camp, Reserva Etnica Waorani, Napo, Ecuador [USNM].

Diagnosis. This species differs from others in the group in having the aedeagus with the apex bent posteriorly at a nearly right angle in lateral view and bearing a pair of short, bifurcate apical processes and 2 pairs of short preapical processes.

Description. Color. Coloration yellow overall with concentrations of black punctures; suprahumeral horns brown dorsally. Forewing membrane hyaline, with narrow transverse black macula basally, extending from costal margin to vein $\mathrm{M}+\mathrm{Cu}$ and for short distance on clavus; commisural margin black. Head. Vertex (Fig. 241) with dorsomedial surface distinctly concave. Frontoclypeus ventral lobe with lateral margins convex. Thorax. Pronotum with suprahumeral horns well developed, erect; in dorsal view short, acuminate, extending laterally (Fig. 223); with anterior carina. Scutellum with apex punctate. Legs: metathoracic tibia with 8 supranumerary cucullate setae between rows II and III. Tymbals large and conspicuous, extending beyond posterior margin of metathorax. Male. Lateral plate (Fig. 282) robust, roundly tapered, with lightly sclerotized or membranous digitiform process apically. Subgenital platewithout constriction, tapered. Aedeagus (Figs 273-274) with apex bent posteriorly at a nearly right angle in lateral view, with pair of short, bifurcate apical processes and 2 pairs of short preapical processes; gonopore apical. Connective (Fig. 274) broadly rounded posteriorly. Style (Figs 273-274) with shank abruptly narrowed preapically, apex hooked laterally, notched. Female. Unknown.

Measurements (mm). Male. Body length 5.4; head width 2.2; width across pronotal humeri 2.1; width across tips of horns 2.5; forewing length 4.6.

Material examined. Holotype male: “ECUADOR: Napo, Tran-/ sect Ent. 1km S Onkonegare/ Camp. Reserva Etnica Waorani/ 0039'10"S, 076026'00"W/ 21-Jun-1994, T.L. Erwin,/ et al., fogging terre [sic] firme/ forest, lot \#12; Albertson Research/ TOL-0013 o; Holotype/ Tolania/ woodi/ Albertson" [USNM].

Distribution. EcuAdor: Napo. Collection date: June.

Notes. This species is named in honor of the late Thomas K. Wood, a well known treehopper ecologist and evolutionary biologist.

Revista Brasileira de Zoologia 23 (4): 915-993, dezembro 2006

\section{Tolania xantha Albertson, sp. nov.}

Figs 224-225, 242, 275-276, 283-284

Typelocality. 3 mi. W. Villavicencio, Meta, Colombia [CAS].

Diagnosis. This species differs from others in the group in having the forewing with $1 \mathrm{~m}$ crossvein and the aedeagus with 2 humps and a pair of acute projections on the dorsal margin preapically, and the apex with a distinct anterodorsal lobe.

Description. Color. Coloration yellow overall with variable red markings; suprahumeral horns reddish brown dorsally. Forewing membrane hyaline to yellow hyaline. Head. Vertex (Fig. 424) with dorsomedial surface flat. Frontoclypeus ventral lobe with lateral margins parallel. Thorax. Pronotum with suprahumeral hornswell developed, dorsal surface of horn even with dorsal midline; in dorsal view acuminate, extending posterolaterally (Fig. 225); with anterior carina, dorsal carina present distally. Scutellum with apex punctate. Legs: metathoracic tibia with 5-11 supranumerary cucullate setae between rows II and III. Tymbals small, not extending beyond posterior margin of metathorax. Forewing with $1 \mathrm{~m}$ crossvein present. Male. Lateral plate (Fig. 283) robust; apex truncate in lateral view, strongly curved mesad in dorsal view. Subgenital plate (Fig. 284) broadly rounded basally, apical two-thirds tapered. Aedeagus (Figs 275-276) with 2 humps and pair of acute projections on dorsal margin preapically, apex with distinct anterodorsal lobe; gonopore apical. Connective (Fig. 276) acuminate posteriorly. Style (Figs 275-276) with shank abruptly narrowed preapically; apex curved laterally, bladelike. Female. Second valvulae broadened near midlength, dorsal margin distinctly angulate; uniformly dentate dorsally.

Measurements (mm). Male/female. Body length 6.1-7.2/ 6.5-7.2; head width 2.3-2.7/2.6-2.8; width across pronotal humeri 2.1-2.3/2.2-2.5; width across tips of horns 2.7-3.4/2.9-3.7; forewing length 5.3-6.3/5.4-6.3.

Material examined. Holotype male: “COLOMBIA: 3 mi./ W. Villavicencio/ Meta. 920 m./ III-11-1955; E.I. Schlinger/ \& E.S. Ross/ collectors; Albertson Research/ TOL-0138 ơ; Holotype/ Tolania/ xantha/ Albertson" [CAS]. Paratypes: 1 male, same locality [ZIMH]; 2 females, same locality [USNM ]. Other material: 5 males, 6 females [ZIMH].

Distribution. Colom BiA: Meta; Santander. Collection dates: March, May, and September.

Notes. Tolania xantha is uniqueamong species in thisgroup in having theforewing with crossvein $m$ present. The name 'xantha' is Greek for "yellow" and refers to the coloration of the adult.

\section{peltacauda group \\ Figs 293-335}

Diagnosis. This species group differs from other Tolania in having the following combination of features: vertex width more than twice height; pygofer with dorsal median posterior process; lateral plate with more than one posterior lobe or process; aedeagus with two pairs of processes, preapical pair usually with multiple fingerlike projections. 


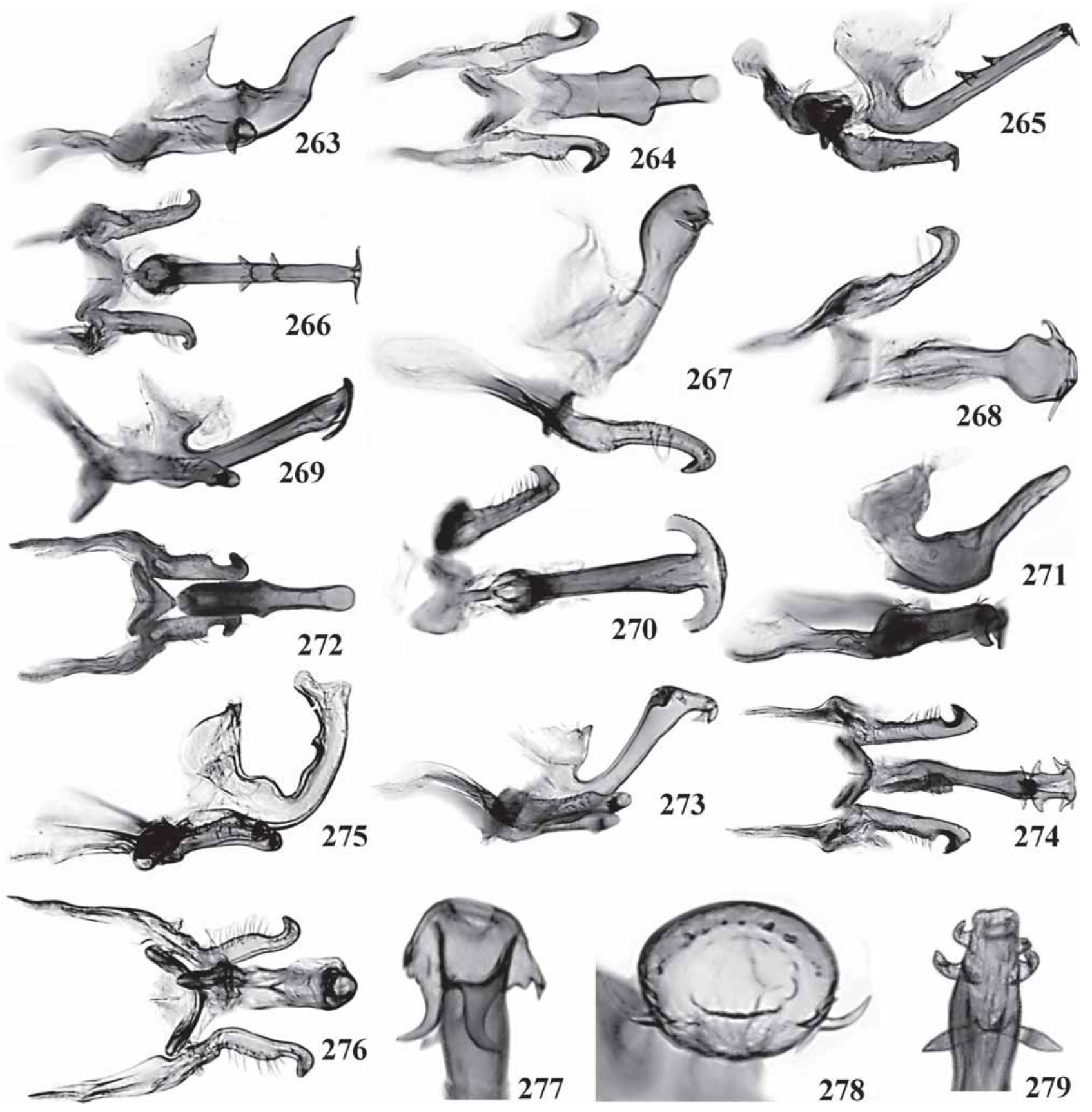

Figures 263-279. Opponens group males. (263-264) Tolania sinuata paratype: (263) genitalia, lateral view; (264) same, dorsal view; (265-266) T. trilobata holotype: (265) genitalia, lateral view; (266) same, ventral view; (267-268) T. tumida holotype: (267) genitalia, right lateral view) inverted; (268) same, ventral view; (269-270) T. umbella: (269) genitalia, lateral view; (270) same, ventral view; (271-272) Tolania vitocensis holotype: (271) genitalia, lateral view; (272) same, ventral view; (273-274) T. woodi holotype: (273) genitalia, lateral view; (274) same, dorsal view; (275-276) T. xantha holotype: (275) genitalia, lateral view; (276) same, dorsal view; (277) T. lurida paratype, aedeagus apex, dorsal view; (278) T. opponens, aedeagus apex, posterior view; (279) T. risa holotype, aedeagus apex, dorsal view.

Revista Brasileira de Zoologia 23 (4): 915-993, dezembro 2006 


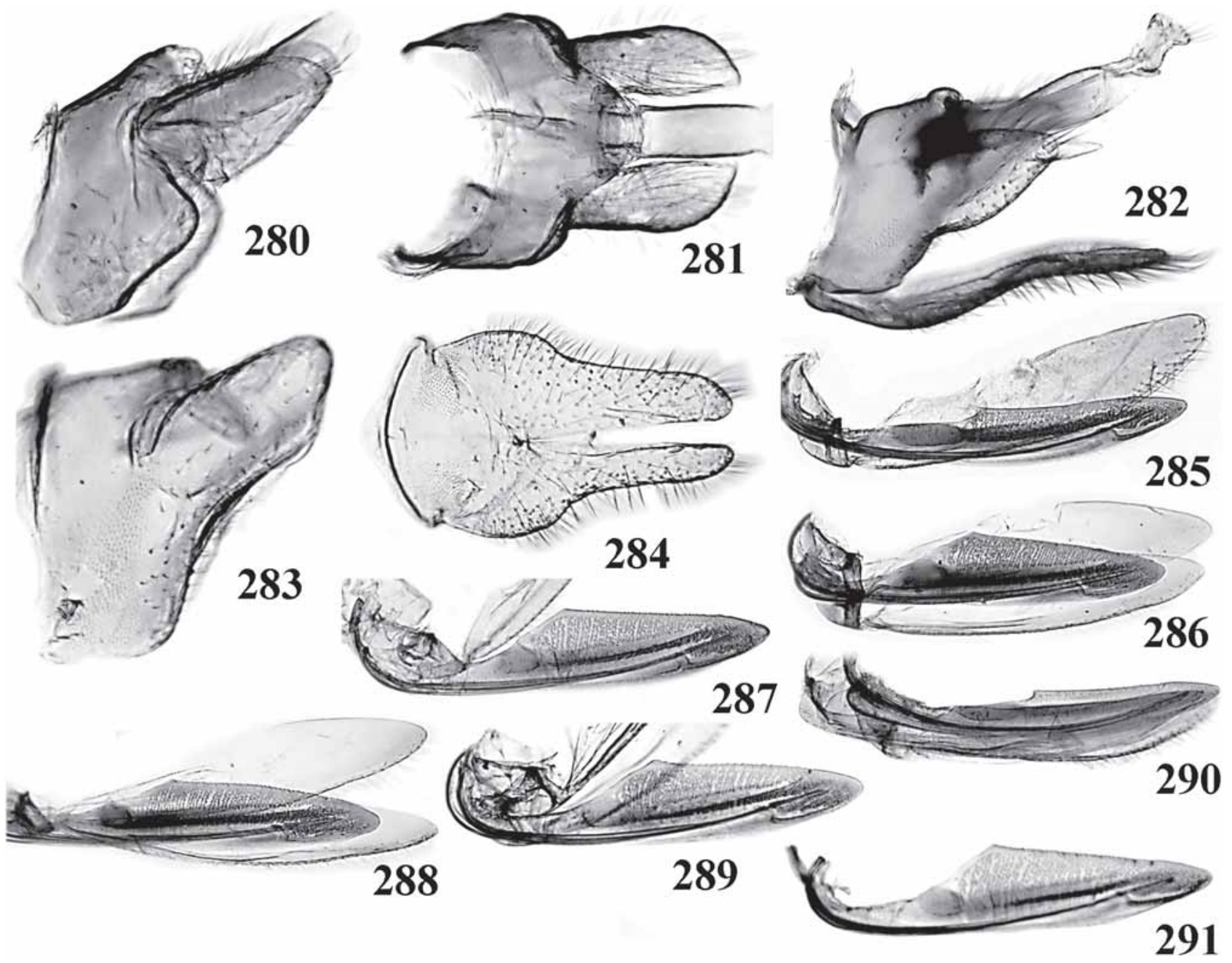

Figures 280-291. Opponens group. (280-284) Males: (280-281) Tolania damia holotype: (280) pygofer, lateral view; (281) same, dorsal view; (282) T. woodi holotype, pygofer, lateral view; (283-284) T. xantha holotype: (283) pygofer, lateral view; (284) subgenital plate; (285-291) females: (285) T. damia paratype, second and third valvulae; (286) T. lurida, second and third valvulae; (287, T. opponens (Walker)) second valvulae; (288) T. reflexa paratype, second and third valvulae; (289) T. risa paratype, second valvulae; (290) T. trilobata paratype, second valvulae; (291) T. vitocensis paratype, second valvulae.

Description. Head. Vertex width between eyes more than twice height; dorsomedial surface flat; ventrolateral margin carinate; ocelli sessile. Frontoclypeus with lateral lobes distinct; ventral lobe with median Iongitudinal carina present; apex directed posteriorly in lateral view. Thorax. Pronotum densely punctate; densely covered with setae; metopidium sloping, low; suprahumeral horn development variable. Scutellum with base slightly inflated, evenly convex; apex punctate, with distinct median longitudinal groove. Legs: mesothoracic tibia with cucullate setal row I well developed. Tymbals large and conspicuous, extending beyond posterior margin of metathorax. Forewing with $1 \mathrm{~s}$ crossvein present; $1 \mathrm{r}$-m crossvein present (exception: T. modesta with 2 r-m crossveins); m crossvein absent; m- cu crossvein connected between first and second vein $M$ fork. Male. Abdomen in dorsal view with lateral margins roundly tapered between segments III-VI, segments VII and VIII attenuate. Pygofer (Figs 329-331) with well developed dorsal median posterior process (except T. thyrea, Fig. 332). Lateral plate (Figs 329-331), in lateral view, slender with posteroventral lobe recurved (except T. thyrea, Fig. 332); auriculate in dorsal view; extending laterally with medial margins divergent; with lightly to densely sclerotized posterodorsal process (except T. thyrea). Subgenital plate (Fig. 333) with lateral margin rounded basally, apical two-thirds tapered; with densely sclerotized lateral ridge (with setae) and median fenestra (glabrous). Aedeagus slender; with pair of preapical processes with multiple fingerlike pro-

Revista Brasileira de Zoologia 23 (4): 915-993, dezembro 2006 


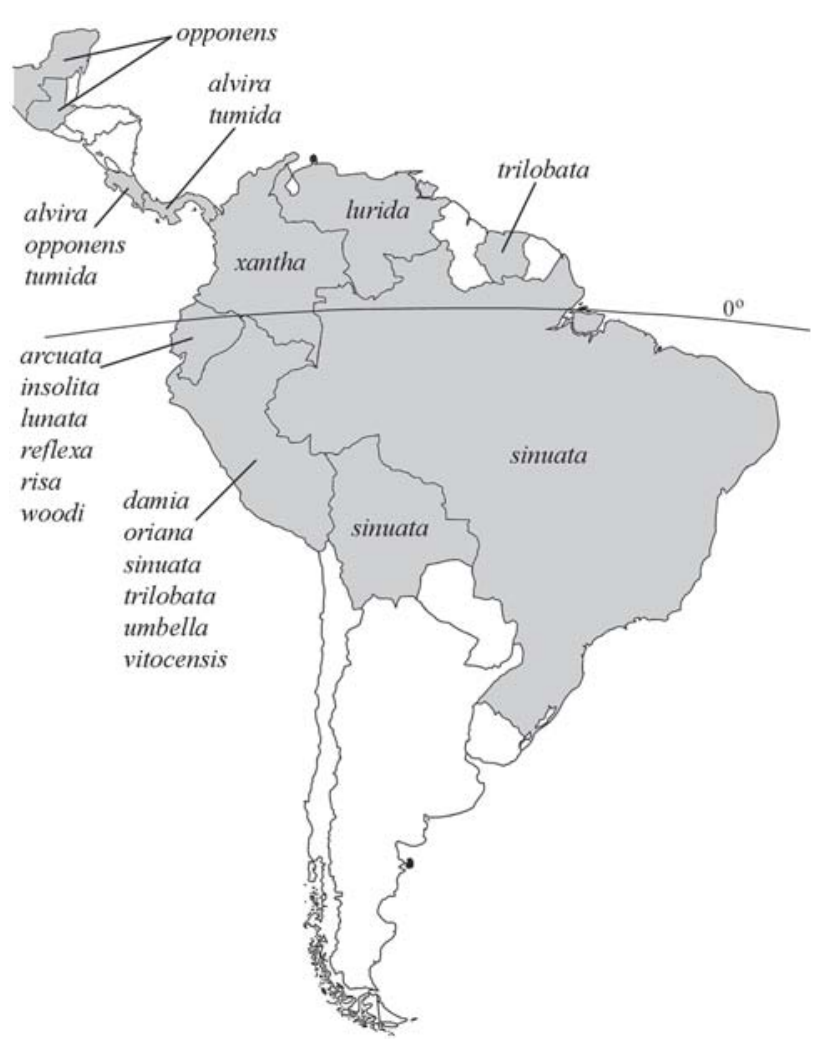

Figure 292. Known distributions of the opponens group species.

jections (Figs 323-324, 326-328) (except T. modesta, Fig. 325) and pair of elongate processes apically. Connective (Figs. 312, 320) with anterior margin strongly emarginate, horseshoeshaped, with distinct posterior stem. Style with apical scales.

Notes. In the phylogenetic analysis (AlberTson \& Dietrich 2005), the peltacauda group was monophyletic with moderate support (DI $=4$ ) and was supported by the presence of a dorsal median posterior process on the male pygofer and the presence of two pairs of apical processes on the aedeagus, one with multiple fingerlike projections.

The species in this group have been collected in Brazil and French Guiana (Fig. 335).

\section{Tolania brasiliensis Albertson, sp. nov.}

Figs 293-294, 305, 311-312, 323, 329-330

Type locality. Petropolis, Rio de Janeiro, Brazil [USNM].

Diagnosis. This species differs from others in the group in having the vertex coloration black; the lateral plate, in lateral view, with the posteroventral lobe bifid; and the aedeagus with the preapical pair of processes with multiple fingerlike projections, and the apical pair of processes bifurcate.

Description. Color. Vertex black, ventral margin yellow; frontoclypeus black; pronotum yellow overall, metopidium with median black macula ventrally, suprahumeral horns red- dish brown, broad reddish brown macula extending from suprahumeral horn to posterior margin; scutellum base dark orange with reddish brown anterior margin, apex yellow; thoracic venter black; femora black with yellow apically, tibiae yellow with red basally, tarsi yellow. Forewing basal sclerotization yellow to red with black punctures; membrane hyaline. Head. Frontoclypeus ventral lobe with lateral margins broadly expanding ventrally. Thorax. Pronotum with suprahumeral horns well developed, dorsal surface even with dorsal midline; in dorsal view short, acuminate, extending posterolaterally (Fig. 294); with anterior and posterior carinae. Legs: metathoracic tibia with 1 supranumerary cucullate seta present between rows II and III. Male. Lateral plate (Figs 329-330), in lateral view, with posteroventral lobe bifid; posterodorsal process long and slender, lightly sclerotized. Aedeagus (Figs 311-312, 323) with pair of flattened processes preapically, each with multiple fingerlike projections; with pair of bifurcate processes apically; gonopore on ventral preapical surface. Style (Figs 311-312), in lateral view, with shank arcuate; apex abruptly bent laterally, bladelike. Female. Unknown.

Measurements (mm). Male. Body length 5.8; head width 2.5; width across pronotal humeri 2.2; width across tips of horns 2.9; forewing length 5.0.

Material examined. Holotype male: "BRAZIL: Rio Jan./ Petropolis, 650m/ 20 October 1985/ Scott E. Miller; Albertson Research/ TOL-0088 o; Holotype/ Tolania/ brasiliensis/ Albertson" [USNM].

Distribution. BrazıL: Rio de Janeiro. Collection date: October.

Notes. The name 'brasiliensis' refers to the country in which the holotype was collected.

\section{Tolania iratafelis Albertson, sp. nov. Figs 295-296, 306, 313-314, 324, 334}

Type locality. Chapada dos Guimarães, Mato Grosso, Brazil [UFPC].

Diagnosis. This species differs from other species in this group in having the presence of suprahumeral horns polymorphic; and the aedeagus with multiple fingerlike projections on the dorsal margin of the preapical processes, and the apical pair of processes with a subbasal acute projection.

Description. Color. Head, pronotum, and forewing basal sclerotization red overall with variable yellow and black markings; scutellum base orange, apex yellow; thoracic venter red; legs red to orange, tibiae with transverse yellow band subbasally. Forewing membrane hyaline. Head. Frontoclypeus ventral lobe with lateral margins broadly expanding ventrally or parallel. Thorax. Pronotum with suprahumeral horn development polymorphic (absent, weakly developed and tuberclelike, or well developed), dorsal surface of horn lower than dorsal midline; well developed horns in dorsal view slender, acuminate, extending posteriorly (Fig. 296); with anterior and posterior cari- 
nae. Legs: metathoracic tibia with 4-5 supranumerary cucullate setae between rows II and III. Male. Lateral plate with basal process lightly sclerotized, inconspicuous. Aedeagus (Figs 313314,324 ) with pair of flattened processes preapically, each with multiple fingerlike projections on dorsal margin; with pair of convexly curved processes apically, each with subbasal acute projection; gonopore apical. Style (Figs 313-314), in lateral view, with shank arcuate; apex abruptly bent laterally, bladelike in lateral view. Female. Second valvulae (Fig. 334) broadened near midlength, dorsal margin distinctly angulate; uniformly dentate dorsally.

Measurements (mm). Male/female. Body length 5.0-6.4/ 5.9-6.5; head width 2.2-2.7/2.6-2.7; width across pronotal humeri 1.8-2.3/2.2-2.3; width across tips of horns 2.2-2.4/2.2-2.6; forewing length 4.5-5.3/4.9-5.5.

Material examined. Holotype male: “DPTo ZOOL/ UF PARANA; Chap. Guimarães-MT/ 27-29.XI.1983/ Exc. Dep. Zool - UFPR/ (Polonoroeste)/ Malaise; Albertson Research/ TOL-0847 o; Holotype/ Tolania/ iratafelis/ Albertson" [UFPC]. Paratypes: 2 males, "Morretes - PR Brasil" [UFPC]; 2 males, "FÊNIX PARANÁ/ Reserva Est. - ITCF/ BRASIL" [UFPC]; 1 male, "Curitiba, Paraná" [UFPC]. Other material: 18 males, 7 females [BMNH, ICCM, MNHN, MZSP, NCSU, UCB, UFPC, USNM].

Distribution. Brazıl: Bahia; Distrito Federal; Mato Grosso; Minas Gerais; Paraná; Piaui; Rio de Janeiro; Rio Grande do Sul; Santa Catarina; São Paulo. Collection dates: April to August and October to December.

Notes. The specific name 'iratafelis' is a combination of the Latin words iratus ("to be angry") and felis ("cat"), referring to the position of the suprahumeral horns resembling the laid back ears of an angry cat.

\section{Tolania modesta Albertson, sp. nov.} Figs 297-298, 307, 315-316, 325, 331

Type locality. Serra da Bocaina, São Paulo, Brazil [UFPC].

Diagnosis. This species differs from others in the group in lacking suprahumeral horns and the aedeagus with the preapical pair of processes bifurcate, the apical pair long and slender.

Description. Color. Head, pronotum, and forewing basal sclerotization mottled black, orange, and yellow overall; scutellum base orange, apex yellow; thoracic venter black; femora black with yellow apically, tibiae yellow with brown to black transverse bands, tarsi brown. Forewing membrane hyaline. Head. Frontoclypeus ventral lobe with lateral margins parallel. Thorax. Pronotum with suprahumeral horns absent and without tubercles (Fig. 297). Legs: metathoracic tibia with supranumerary cucullate setae absent. Forewing with $2 \mathrm{r}-\mathrm{m}$ crossveins present, both distad of vein $\mathrm{R}_{1}$. Male. Lateral plate (Fig. 331) with basal process prominent, densely sclerotized. Aedeagus (Figs 315-316, 325) with pair of long slender bifurcate processes preapically (may be asymmetrical); with pair of long slender processes apically; gonopore on ventral preapical surface. Style (Figs 315-316), in lateral view, with shank arcuate; apex abruptly bent laterally, bladelike. Female. Unknown.

Measurements (mm). Male. Body length 4.8; head width 2.2; width across pronotal humeri 1.9; forewing length 4.0.

Material examined. Holotype male: "S. BOCAINA/ Brasil - I-1969/ Alvarenga-leg.; Albertson Research/ TOL-0803 o; Holotype/ Tolania/ modesta/ Albertson" [UFPC]. Paratype: "S. Bocaina - 1,680m/ S.J. Barreiro - SP/ III- 1973/ F.M. Oliveira leg.; Albertson Research/ TOL-0821 ơ" [UFPC].

Distribution. Brazıl: São Paulo. Collection dates: January, March.

Notes. The name "modesta' is Latin for "modest" and re fers to the lack of suprahumeral horns.

\section{Tolania peltacauda Albertson, sp. nov. Figs 299-300, 308, 317-318, 326, 333}

Typelocality. Jussaral Angra, Rio de Janeiro, Brazil [MZSP]. Diagnosis. This species differs from others in the group in coloration; and in having the preapical pair of aedeagal processes with multiple fingerlike projections on the dorsal margin and small submarginal projections, and the apical pair of processes with a subbasal acute projection.

Description. Color. Head and pronotum mottled brown, black, and yellow overall; scutellum base reddish brown, apex yellow; thoracic venter black; femora black with yellow apically, tibiae yellow with variable black markings, tarsi brown to black. Forewing basal sclerotization black and yellow; membrane hyaline. Head. Frontoclypeus ventral lobe with lateral margins broadly expanding ventrally. Thorax. Pronotum with suprahumeral horns well developed, erect; in dorsal view acuminate, extending laterally (Fig. 300); with anterior, posterior, and dorsal carinae. Legs: metathoracic tibia with 4 supranumerary cucullate setae between rows II and III. Male. Lateral plate with basal processlong and slender, densely sclerotized. Aedeagus (Figs 317-318, 326) with pair of flattened processes preapically, each with multiple fingerlike projections on dorsal margin and small submarginal projections; with pair of convexly curved processes apically, each with subbasal acute projection; gonopore apical. Style (Figs 317-318), in lateral view, with shank arcuate; apex abruptly bent laterally, blade-like. Female. Unknown.

Measurements (mm). Male. Body length 6.5; head width 2.7; width across pronotal humeri 2.3; width across tips of horns 3.0; forewing length 5.3.

Material examined. Holotype male: "BRASI L/ JUSSARAL/ ANGRA- E. DO RIO/ L.TRAV. ET LOPES/ X-934; Colecao/ PINTO DA/ FONSECA; Tolania sp. nov.; Albertson Research/ TOL-0538 o", Holotype/ Tolania/ peltacauda/ Albertson" [MZSP].

Distribution. BrazIL: Rio de Janeiro. Collection date: October.

Notes. The specific name 'peltacauda' is derived from the Latin words pelta ("small shield") and cauda ("tail") and refers to the dorsal median posterior process of the pygofer. 

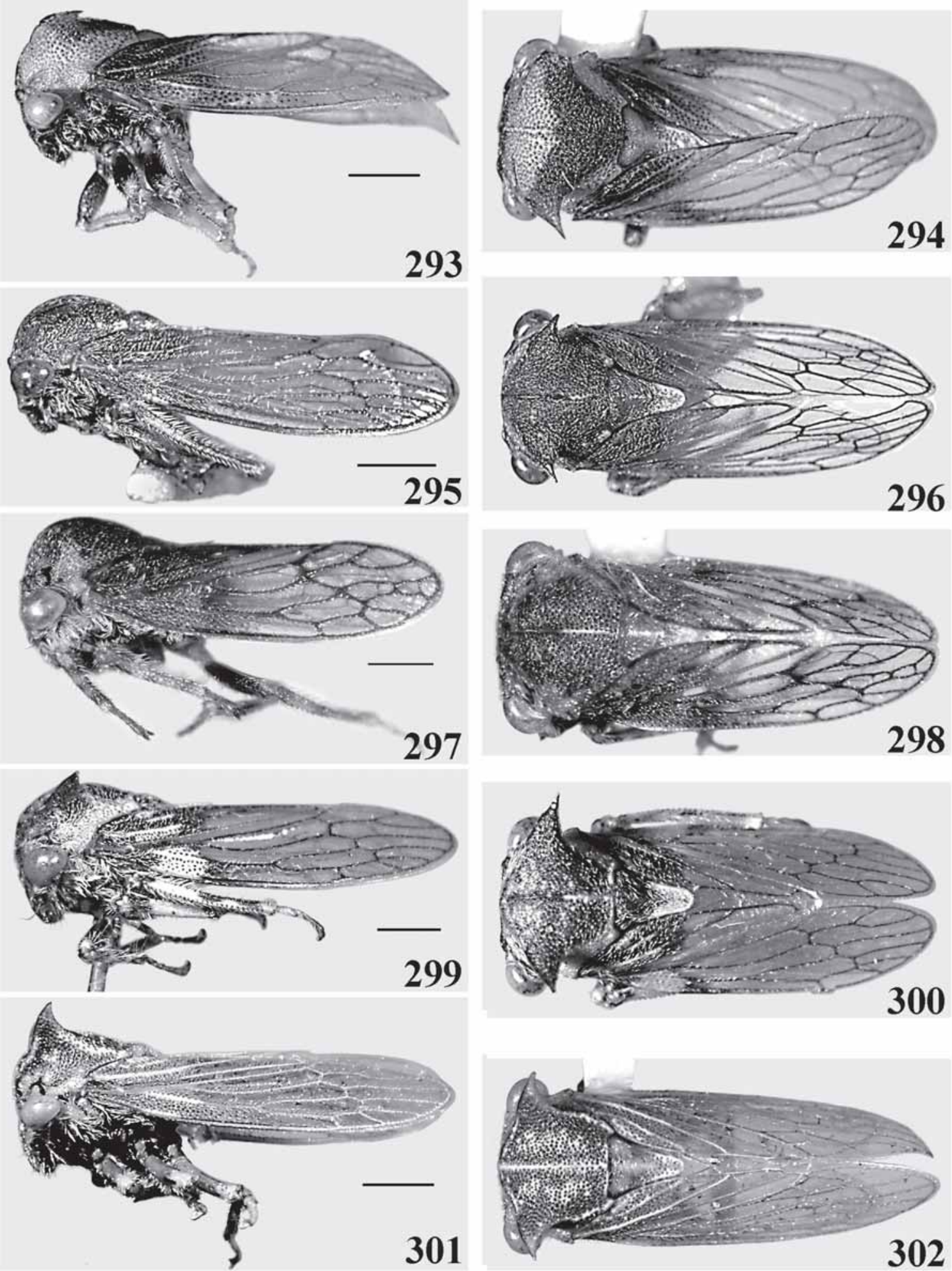

Figures 293-302. Peltacauda group adult lateral and dorsal habitus. (293-294) Tolania brasiliensis holotype male; (295-296) T. iratafelis male; (297-298) T. modesta paratype male; (299-300) T. peltacauda holotype male; (301-302) T. picta holotype male. 


\section{Tolania picta Albertson, sp. nov.}

Figs 301-302, 309, 319-320, 327

Type locality. Cachoeiras de Macacu, Rio de Janeiro, Brazil [USNM].

Diagnosis. This species is distinguished from others in the group by the striped pronotum; and the aedeagus with the preapical pair of processes convexly curved with multiple fingerlike projections on the dorsal margin, and the apical pair of processes convexly curved and elongate.

Description. Color. Head yellow with variable pale brown markings; pronotum pinkish brown, with yellow macula or stripes dorsally and laterally, supraocular callosity black, median Iongitudinal carina yellow; scutellum yellow with basolateral margins brown; thoracic venter black; femora orange with yellow apically, longitudinal black macula anteriorly, tibiae and tarsi yellow to orange. Forewing basal sclerotization orange with yellow veins, membrane brown hyaline. Head. Frontoclypeus ventral lobe with lateral margins parallel. Thorax. Pronotum with suprahumeral horns well developed, erect; in dorsal view short, acuminate apically, extending posterolaterally (Fig. 302); with anterior carina. Legs: metathoracic tibia with 2 supranumerary cucullate setae between rows II and III. Male. Lateral plate with basal process short and blunt, densely sclerotized. Aedeagus (Figs 319-320, 327) with pair of convexly curved processes preapically, each with multiple fingerlike projections on dorsal margin; with pair of slender convexly curved processes apically; gonopore on ventral preapical surface. Style (Figs 319-320), in lateral view, with shank arcuate; apex abruptly bent laterally, bladelike. Female. Unknown.

Measurements $(\mathrm{mm})$. Male. Body length 6.3; head width 2.6; width across pronotal humeri 2.2; width across tips of horns 2.7; forewing length 5.3.

Material examined. Holotype male: “BRAZIL: Rio Jan./ Cachoeiras de/ Macacu, 400m./ 13 October 1985/ Scott E. Miller; Albertson Research/ TOL-0092 ơ; Holotype/ Tolania/ picta/ Albertson" [USNM].

Distribution. Brazıl: Rio de Janeiro. Collection date: October.

Notes. The name 'picta' is Latin for "decorated" and refers to the coloration of the adult.

\section{Tolania thyrea Albertson, sp. nov.}

Figs 303-304, 310, 321-322, 328, 332

Type locality. Carbet Lavaud (Rive Surinamienne), Itani, French Guiana [MNHN].

Diagnosis. This species differs from others in the group in having the posteromedian dorsal lobe of the pygofer weakly produced, the lateral plate auriculate in lateral view, and the aedeagus with a dorsal acuminate projection near the midlength.

Description. Color. Head and pronotum yellow overall with variable brown markings; scutellum base orange, apex yel- low; thoracic venter red and black; femora yellow with black apically, tibiae and tarsi yellow. Forewing basal sclerotization dark yellow; membrane hyaline. Head. Frontoclypeus ventral lobe with lateral margins more or less parallel. Thorax. Pronotum with suprahumeral horns weakly developed, tuberclelike (Fig. 304). Legs: metathoracic tibia with supranumerary cucullate setae absent. Forewing vein $\mathrm{R}$ with 5 branches; $1 \mathrm{r}$-m crossvein present. Male. Pygofer (Fig. 332) with posteromedian dorsal lobe weakly developed. Lateral plate (Fig. 332), in lateral view, auriculate; with basal process absent. Aedeagus (Figs 321-322, 328) with median acuminate projection dorsally near midlength; with pair of elongate processes preapically, each with multiple fingerlike distal projections; with pair of slender convexly curved processes apically; gonopore on ventral preapical surface. Style (Figs 321-322), in lateral view, with shank broad, abruptly narrowed preapically; slender and curved laterally in dorsal view; apex abruptly bent laterally, rounded. Female. Unknown.

Measurements (mm). Male. Body length 5.9; head width 2.6; width across pronotal humeri 2.2; forewing length 4.7.

Material examined. Holotype male: "CARBET LAVAUD/ (RIVE SURINAMIENNE)/ 3-4-XII-1975; ITANI (GUYANES)/ Mission M. Boulard,/ P. Jauffret et P. Pompanon/ Muséum PARIS; Albertson Research/ TOL-0909 o; Holotype/ Tolania/ thyrea/ Albertson" [MNHN].

Distribution. French Guiana. Collection date: December.

Notes. The name 'thyrea' is derived from the Greek word thyreos, translating as "shield-bearer" and referring to the posteriorly produced pygofer.

\section{semipellucida group \\ Figs 336-361}

Diagnosis. This species group differs from other Tolania in having the following combination of features: vertex width less than twice height, mesothoracic tibia with cucullate setal row I present, and aedeagus with broad flanged apex.

Description. Head. Vertex width between eyes less than twice height; dorsomedial surface flat; ventrolateral margin carinate; ocelli sessile. Frontoclypeus with apex directed ventrally in lateral view. Thorax. Pronotum densely punctate; densely covered with setae; metopidium high, nearly vertical; suprahumeral horns variable. Scutellum with base slightly inflated, evenly convex; apex without punctures, with distinct median longitudinal groove. Legs: mesothoracic tibia with cucullate setal row I well developed. Tymbals large and conspicuous, extending beyond posterior margin of metathorax. Forewing with $1 \mathrm{~s}$ crossvein present; $1 \mathrm{r}$-m crossvein present; $\mathrm{m}$ crossvein absent; $\mathrm{m}$-cu crossvein connected between first and second vein $M$ fork (except T. nicia). Male. Lateral plate (Figs 356-357) more than half length of subgenital plate, with compressed lobe ventrally. Subgenital plate (Fig. 358) with subbasal constriction, apical two-thirds broad and rounded; in lateral view, curved dorsad apically; uniformly sclerotized without distinct fenestra. Aedeagus, in lateral view, with shaft short and 

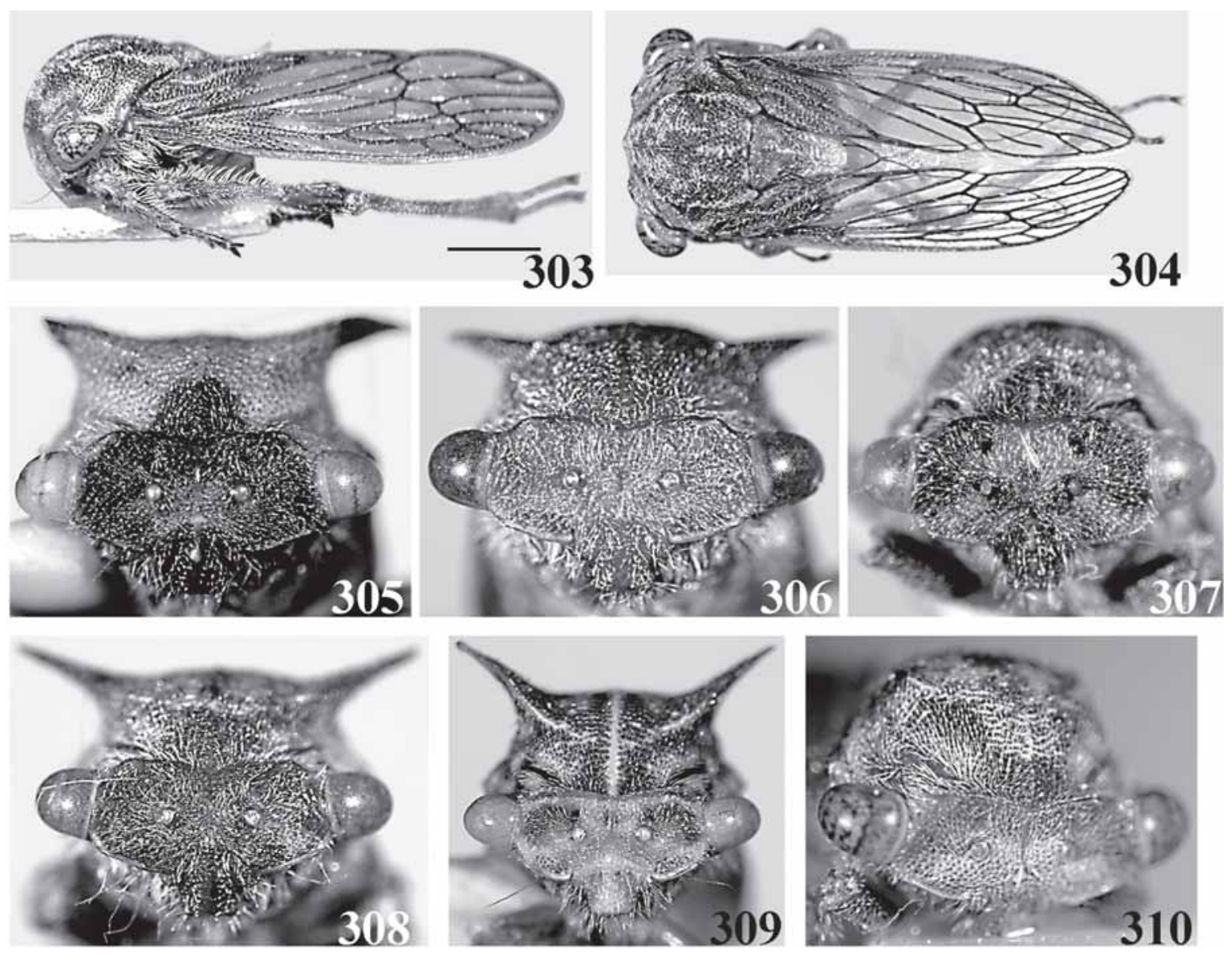

Figures 303-310. Peltacauda group adult habitus. (303-304) Tolania thyrea holotype male: (303) lateral view; (304) dorsal view; (305310) anterior view: (305) T. brasiliensis holotype male; (306) T. iratafelis male; (307) T. modesta paratype male; (308) T. peltacauda holotype male; (309) T. picta holotype male; (310) T. thyrea holotype male.

broad; apex greatly enlarged with serrate flange (Figs 348-355); gonopore apical. Connective (Figs 355) with median keel extending anterad of lateral arms, arms divergent; truncate posteriorly. Style (Figs 348-355), in lateral view, with shank arcuate; apex curved laterally, rounded or bladelike. Female. Second valvulae (Figs 359-360) broadened near midlength; uniformly dentate dorsally.

Notes. In the phylogenetic analysis (AlBertson \& DietrICH 2005), these species formed a monophyletic group with low support ( $\mathrm{DI}=1$ ) and were united by features of the male genitalia.

Species in the semipellucida group have been collected in Brazil, Ecuador, Guyana, Peru, and Venezuela (Fig. 361).

\section{Tolania atrata Albertson, sp. nov. \\ Figs 336-337, 344, 348-349, 356}

Type locality. Chapada, Piaui, Brazil [ICCM].

Diagnosis. This species differs from others in the group in the black coloration, the small size, and the aedeagus with the apex, in dorsal view, broadly and shallowly concave.

Description. Color. Head, pronotum, thoracic venter, and forewing basal sclerotization black overall; scutellum base black with yellow medially, apex yellow; femora black, tibiae yellow with black basally, tarsi yellow. Forewing membrane hyaline. Head. Vertex (Fig. 344) densely covered with long white setae. Frontoclypeus ventral lobe with lateral margins broadly expanding ventrally. Thorax. Pronotum with suprahumeral horns polymorphic (absent and without tubercles, Fig. 336, to well developed); elevation and shape in dorsal view polymorphic; with anterior and posterior carinae, dorsal carina present on distal half. Legs: metathoracic tibia with 3-5 supranumerary cucullate setae between rows II and III. Forewing with $\mathrm{m}-\mathrm{cu}$ crossvein connected between first and second vein $M$ fork. Male. Sternite VIII anterior margin distinctly narrowed and rounded. Lateral plate (Fig. 356) with ventral lobe prominent, margin truncate. Aedeagus (Figs 348-349), in lateral view, broad basally, dorsal margin with distinct preapical concavity; apex, in

Revista Brasileira de Zoologia 23 (4): 915-993, dezembro 2006 


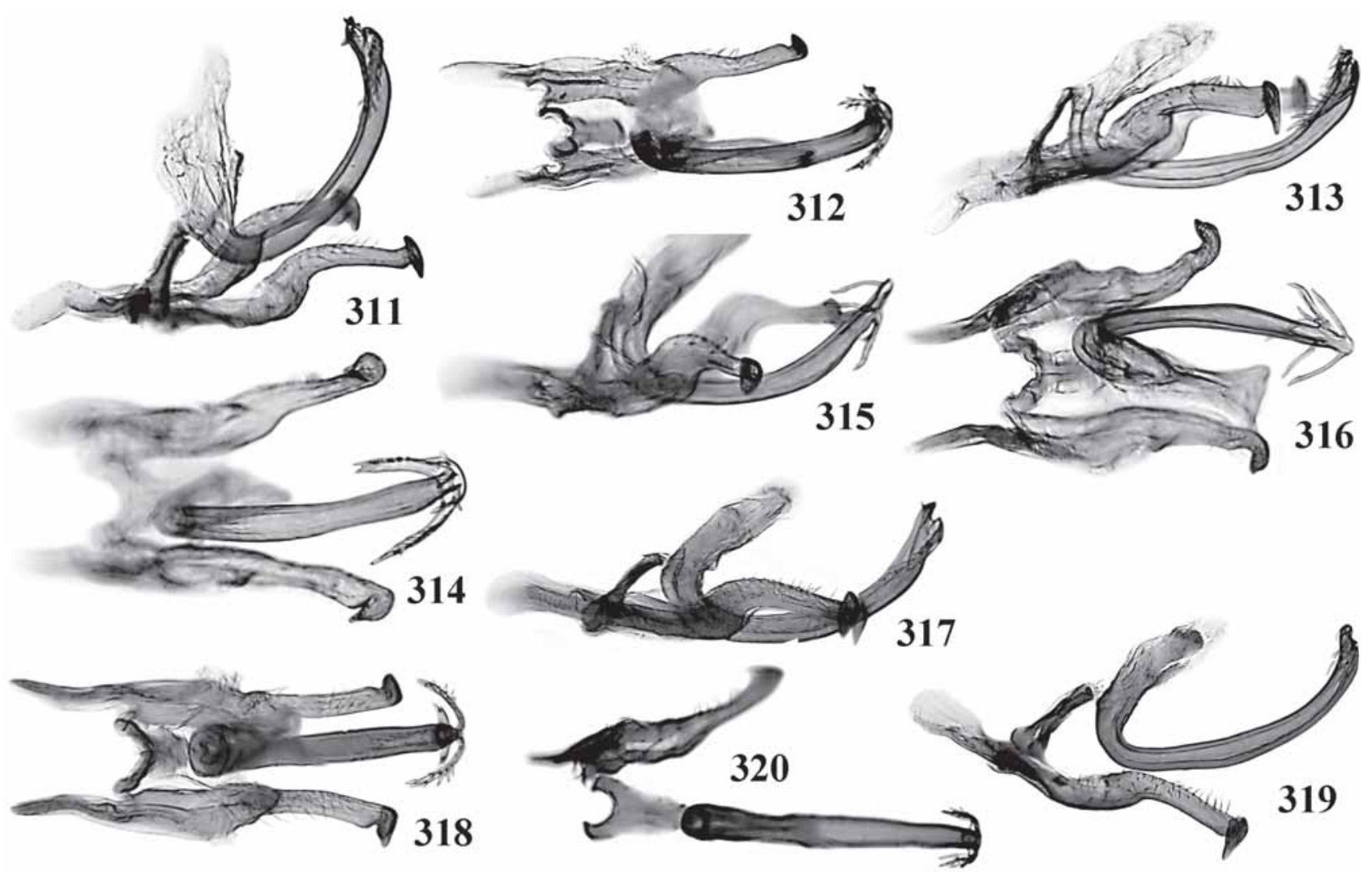

Figures 311-320. Peltacauda group males. (311-312) Tolania brasiliensis holotype: (311) genitalia, lateral view; (312) same, dorsal view; (313-314) T. iratafelis paratype: (313) genitalia, lateral view; (314) same, ventral view; (315-316) T. modesta paratype: (315) genitalia, lateral view; (316) same, ventral view; (317-318) T. peltacauda holotype: (317) genitalia, lateral view; (318) same, dorsal view; (319320) T. picta holotype: (319) genitalia, right lateral view, inverted; (320) same, ventral view.

dorsal view, broadly concave, flange serrate ventrally. Female. Second valvulae broadened near midlength, dorsal margin distinctly angulate.

Measurements (mm). Male/female. Body length 4.6-5.4/ 5.6-5.8; head width 2.3-2.7/2.6-2.9; width across pronotal humeri 2.0-2.3/2.3-2.5; width across tips of horns 2.9/1.9-2.2; forewing length 3.9-4.5/4.7-5.0.

Material examined. Holotype male: "Chapada/ Brazil/ Acc. No 2966; Sept.; Albertson Research/ TOL-0468 o; Holotype/ Tolania/ atrata/ Albertson" [ICCM ]. Paratypes: 1 male, 6 females, same locality [AMNH, ICCM]. Other material: 1 male [USNM].

Distribution. Brazil: Piauí; Ecuador: Napo. Collection dates: April and September to November.

Notes. The name 'atrata' is Latin for "clothed in black" and refers to the coloration of the adult.

\section{Tolania fimbriata Albertson, sp. nov.}

Figs 338-339, 345, 350-351, 360

Type locality. 1 km S Onkonegare Camp, Reserva Etnica Waorani, Napo, Ecuador [USNM].

Revista Brasileira de Zoologia 23 (4): 915-993, dezembro 2006
Diagnosis. This species differs from others in the group in having the pronotum with distinct stripes dorsally and laterally and the aedeagus with the apex, in dorsal view, deeply concave.

Description. Color. Head and pronotum bright yellow to orange overall with variable black markings; pronotum with distinct stripes dorsally and laterally; scutellum yellow with basolateral margins reddish; thoracic venter black; femora yellow with black apically, tibiae and tarsi yellow. Forewing basal sclerotization brown to black with yellow veins; membrane hyaline; commisural margin black. Head. Vertex (Fig. 345) densely covered with long white setae. Frontoclypeus ventral lobe with lateral margins parallel, slightly broadened ventrally. Thorax. Pronotum with suprahumeral horns well developed, erect; in dorsal view slender, acuminate, extending posterolaterally (Fig. 339); with anterior, posterior, and dorsal carinae. Legs: metathoracic tibia with 2-7 supranumerary cucullate setae between rows II and III. Forewing with m-cu crossvein connected between first and second vein $M$ fork. Male. Lateral plate with ventral lobe narrow anteriorly and broadened posteriorly. Aedeagus (Figs $350-$ 351), in lateral view, broad basally, dorsal margin more or less 


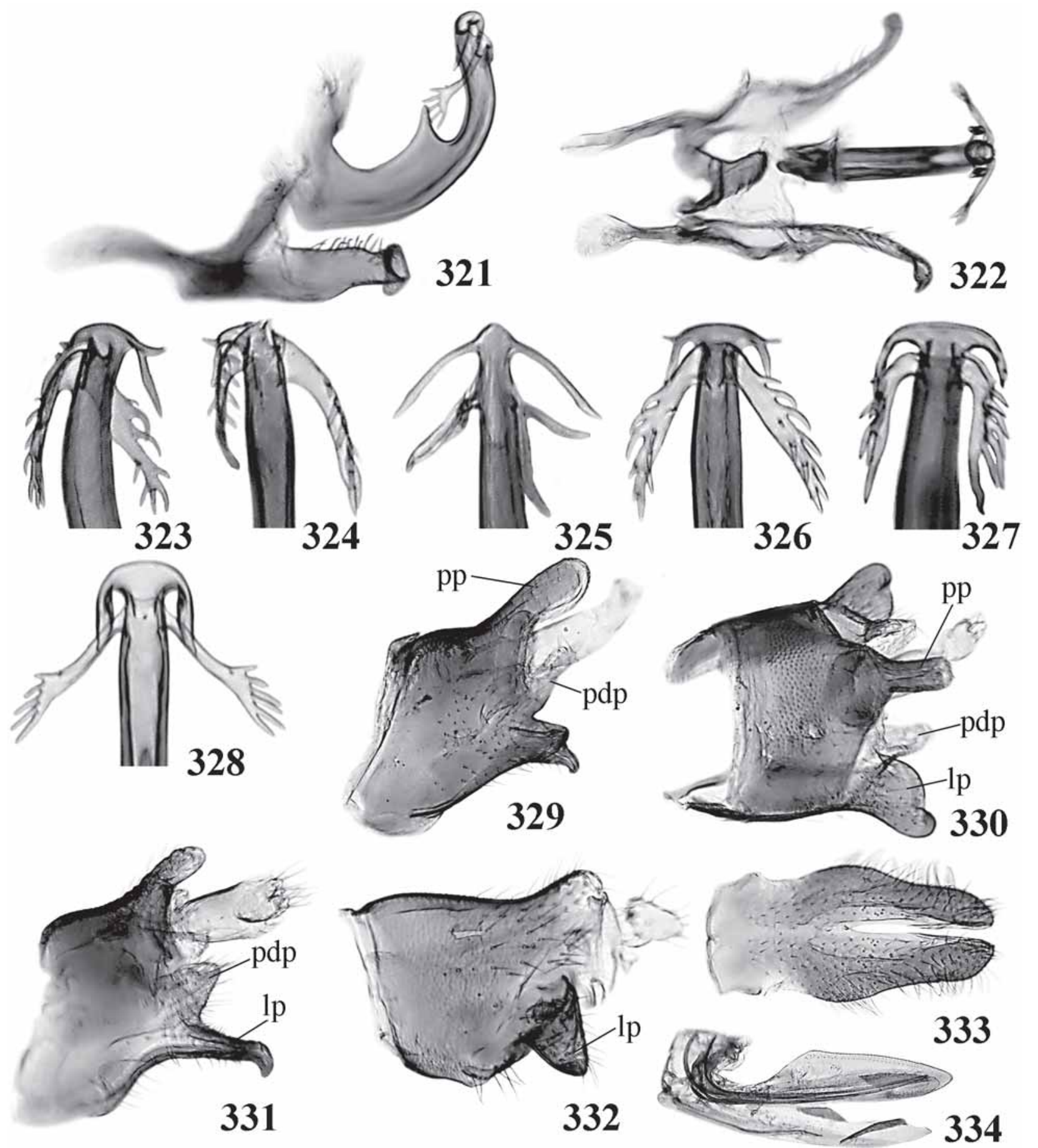

Figures 321-334. Peltacauda group. (321-333) Males: (321-322) Tolania thyrea holotype: (321) genitalia, lateral view; (322) same, dorsal view; (323-328) aedeagus apex, posterior view: (323) T. brasiliensis holotype; (324) T. iratafelis; (325) T. modesta paratype; (326) T. peltacauda holotype; (327) T. picta holotype; (328) T. thyrea holotype; (329-330) T. brasiliensis holotype: (329) pygofer, lateral view; (330) same, dorsal view; (331) T. modesta paratype, pygofer, lateral view; (332) T. thyrea holotype, pygofer, lateral view; (333) T. peltacauda holotype, subgenital plate; (334) T. iratafelis female, first and second valvulae. Ip: Lateral plate; pdp: posterodorsal process; pp: posterior process. 


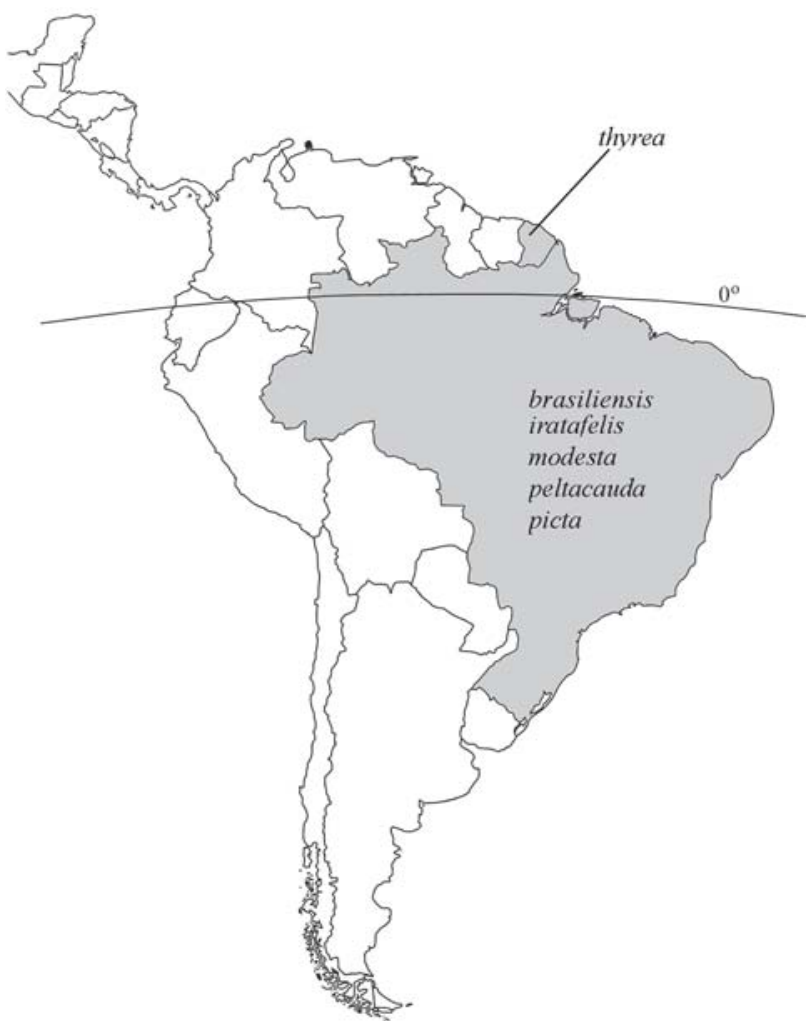

Figure 335. Known distributions of the peltacauda group species.

straight; apex, in dorsal view, deeply concave, flange serrate ventrally. Female. Second valvulae (Fig. 360) broadened near midlength, dorsal margin distinctly angulate.

Measurements (mm). Male/female. Body length 6.0-6.6/ 6.4-7.4; head width 2.4-2.6/2.6-3.0; width across pronotal humeri 2.1-2.2/2.3-2.6; width across tips of horns 2.8-3.6/3.3-4.1; forewing length 5.0-5.2/5.4-6.0.

Material examined. Holotype male: “ECUADOR: Napo, Tran-/ sect Ent. 1km S Onkonegare/ Camp. Reserva Etnica Waorani/ 00³9'10"S, 076²6'00"W; 21-Jun-1994, T.L. Erwin,/ et al., fogging terre [sic] firme/ forest, lot\#708; Albertson Research/ TOL-0045 o; Holotype/ Tolania/ fimbriata/ Albertson" [USNM ]. Paratypes: 2 males, 4 females, same locality [USNM]. Other material: 6 males, 4 females [FSAC, SHMC, USNM].

Distribution. ECUADOR: Napo; PERU: Loreto; Madre de Dios. Collection dates: March, May to June, and October to November.

Notes. The specific name 'fimbriata' translates from Greek as "fringed", referring to the serrate flange on the aedeagus.

\section{Tolania nicia Albertson, sp. nov. \\ Figs 340-341, 346, 352-353, 359}

Type locality. Sinop, Mato Grosso, Brazil [UFPC].

Diagnosis. This species is distinguished from others in the group in having the suprahumeral horns short and broad, the forewing with crossvein m-cu connected distad of the second vein $M$ fork, and the aedeagus with the apex, in dorsal view, bulbous.

Description. Color. Head, pronotum, and thoracic venter yellow overall with reddish brown and black markings; scutellum yellow with basolateral margins reddish brown; femora brown with yellow apically, tibia and tarsi yellow. Forewing basal sclerotization reddish brown with yellow veins; membrane hyaline. Head. Vertex (Fig. 346) densely covered with long white setae. Frontoclypeus ventral lobe with lateral margins convex. Thorax. Pronotum with suprahumeral horns well developed, erect; in dorsal view short and broad, with apices acute, extending laterally (Fig. 341); with anterior and posterior carinae. Legs: metathoracic tibia with 2-6 supranumerary cucullate setae between rows II and III. Forewing with $\mathrm{m}-\mathrm{cu}$ crossvein connected distad of second vein $M$ fork, to vein $M_{4}$. Male. Lateral plate with ventral lobe narrow anteriorly and broadened posteriorly. Aedeagus (Figs 352-353), in lateral view, broad basally, dorsal margin more or less straight preapically; apex, in dorsal view, broad and massive, bulbous, flange narrow, serrate. Female. Second valvulae (Fig. 259) broadened near midlength, dorsal margin roundly angulate.

Measurements (mm). Male/female. Body length 6.2-6.5/ 7.1-7.4; head width 2.8-2.9/3.1-3.2; width across pronotal humeri 2.5-2.6/2.6-2.8; width across tips of horns 2.4-2.7/3.4-3.7; forewing length 5.2-5.4/6.0-6.3.

Material examined. Holotype male: “SINOP - M. Grosso/ Brasil - X/1975/ M. Alvarenga; Albertson Research/ TOL-0809; Holotype/ Tolania/ nicia/ Albertson" [UFPC]. Paratypes: 2 males, 5 females, same data [UFPC].

Distribution. BrazlL: Mato Grosso. Collection date: December.

Notes. The name 'nicia' is derived from the Greek word nike, meaning "victorious army".

\section{Tolania semipellucida Stål, 1858}

Figs 342-343, 347, 354-355, 357-358

T [olania] semipellucida Stål, 1858: 249.

[Tolania] semipellucida; Funkhouser, 1927: 494.

Type locality. Minas Gerais, Brazil [NRS].

Diagnosis. This species differs from others in the group in having the forewing with crossvein $\mathrm{m}$-cu connected between first and second vein $M$ fork and the aedeagus with the apex, in dorsal view, broad and flat.

Description. Color. Head, pronotum, and forewing basal sclerotization varying from reddish brown with black and yellow markings to black overall; scutellum yellow with basolateral margins reddish brown, apical groove reddish; thoracic venter black; femora black with yellow basally and apically, tibiae and tarsi yellow. Forewing membrane hyaline to orange hyaline. Head. Vertex (Fig. 347) densely covered with long white setae; dorsomedial surface flat to concave. Frontoclypeus ventral lobe 

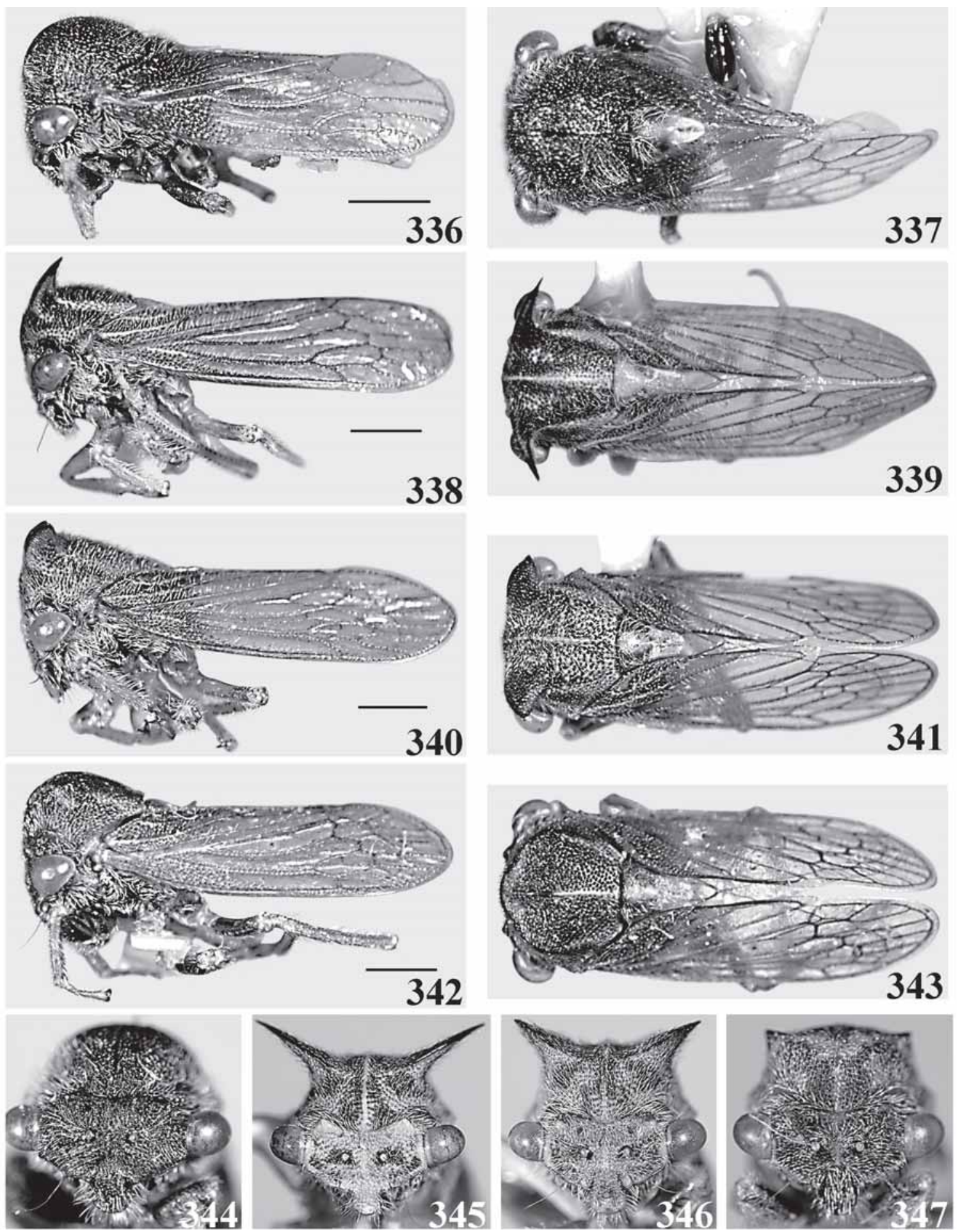

Figures 336-347. Semipellucida group adult habitus. (336-337) Tolania atrata holotype male: (336) lateral view; (337) dorsal view; (338339) T. fimbriata paratype male: (338) lateral view; (339) dorsal view; (340-341) T. nicia holotype male: (340) lateral view; (341) dorsal view; (342-343) T. semipellucida (Stål) male: (342) lateral view; (343) dorsal view; (344-347) anterior view: (344) T. atrata holotype male; (345) T. fimbriata paratype male; (346) T. nicia holotype male; (347) T. semipellucida (Stål) male.

Revista Brasileira de Zoologia 23 (4): 915-993, dezembro 2006 


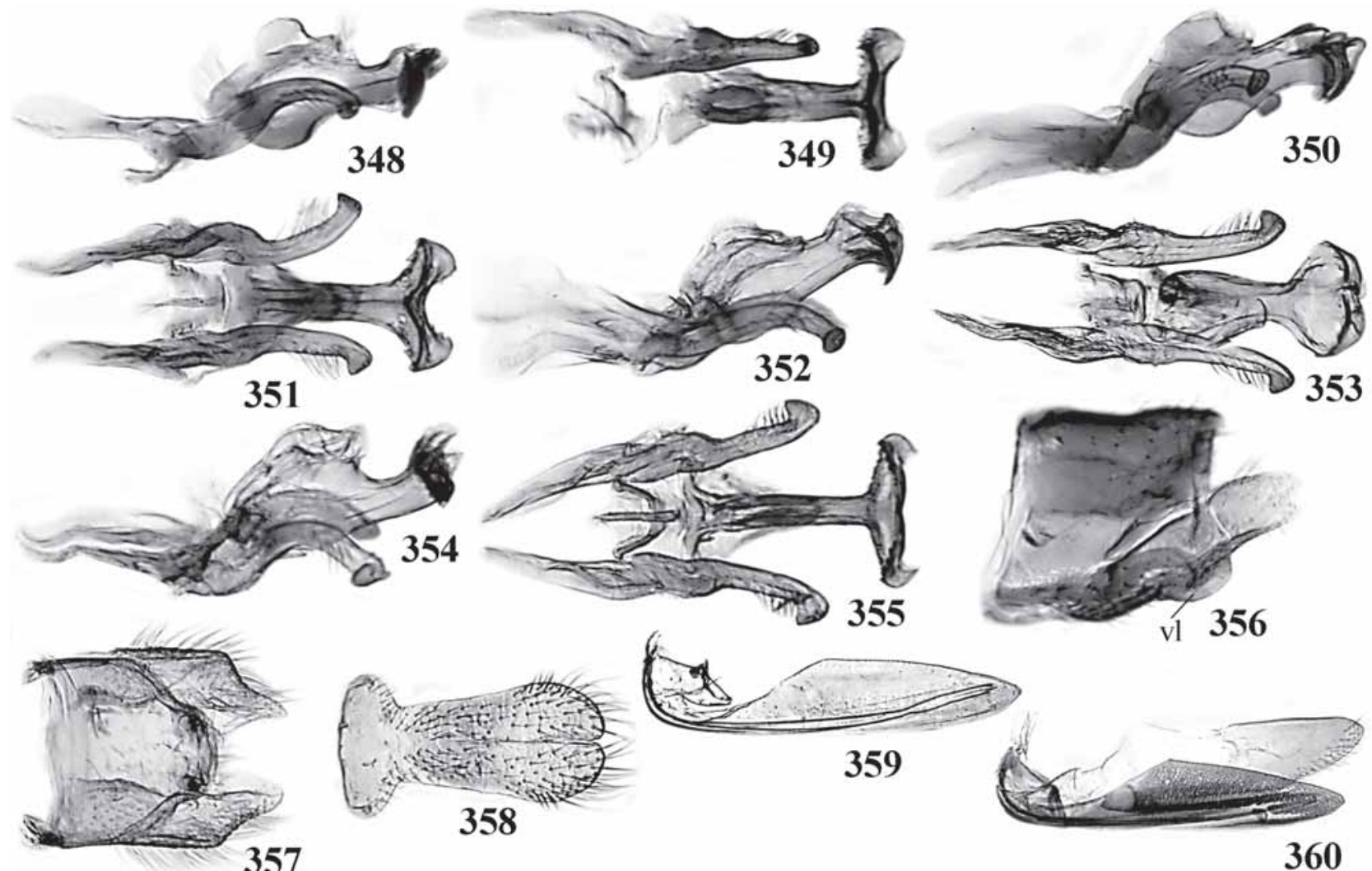

Figures 348-360. Semipellucida group. (348-358) Males: (348-349) Tolania atrata holotype: (348) genitalia, lateral view; (349) same, ventral view; (350-351) T. fimbriata: (350) genitalia, lateral view; (351) same, ventral view; (352-353) T. nicia paratype: (352) genitalia, lateral view; (353) same, ventral view; (354-355) T. semipellucida (Stål): (354) genitalia, lateral view; (355) same, ventral view; (356) T. atrata holotype, pygofer, lateral view; (357-358) T. semipellucida (Stål): (357) pygofer, dorsal view; (358) subgenital plate; (359-360) females: (359) T. nicia paratype, second valvulae; (360) T. fimbriata, second and third valvulae. vl: Ventral lobe.

with lateral margins more or less convex. Thorax. Pronotum with suprahumeral horn development polymorphic (absent and without tubercles to well developed); elevation and shape in dorsal view polymorphic; with anterior and posterior carinae, dorsal carina present on distal half in some specimens. Legs: metathoracic tibia with 2-6 supranumerary cucullate setae between rows II and III. Forewing with $\mathrm{m}$-cu crossvein connected between first and second vein $M$ fork. Male. Lateral plate with ventral lobe rounded, narrow posteriorly. Aedeagus (Figs 354355), in lateral view, broad basally, dorsal margin concave; apex, in dorsal view, broad and flat, with lateral margins produced posteriorly, flange serrate ventrally. Female. Second valvulae broadened near midlength, dorsal margin distinctly angulate.

Measurements. Male/female. Body length 5.3-6.0/5.9-6.5; head width 2.4-2.7/2.4-2.6; width across pronotal humeri 2.02.4/2.2-2.4; width across tips of horns 1.6-3.3/1.6-2.7; forewing length 4.5-4.7/5.2-5.5.

Material examined. Lectotypefemale: “Minas Geraes [sic]; [illegible]; Tolania semipellucida; Typus; Albertson Research/ TOL-0986 ㅇ" [NRS]. Paralectotype: "Brasil; Signt; Paratypus;
Albertson Research/ TOL-0985" [NRS]. Other material: 19 males [BMNH, CAS, ICCM, SHMC, UFPC, USNM, ZMNH].

Distribution. Brazil: Mato Grosso, Minas Gerais, Pará, Piauí, Rondônia; GuYana: Cuyuni-Mazaruni; East BerbiceCorentyne; Panama: Darien; Paraguay; Peru: Amazonas; Loreto; Venezuela: Amazonas. Collection dates: January to April, June to August, and October to November.

Notes. The two female specimens in NRS are apparently syntypes, despite being labeled "Typus" and "Paratypus", respectively (see notes under T. femoral is and T. fasciata). In accordance with ICZN Articles 72.4.7 and 74.7, we designate the specimen labeled "Typus" as lectotype to fix the identity of the species.

\section{UNPLACED SPECIES}

\section{Tolania anomala Albertson, sp. nov.}

Figs 362-363, 388, 401-402, 427

Type locality. La Cangreja, Cartago, Costa Rica [USNM].

Diagnosis. This species differs from other Tolania in having the vertex width less than twice the height; thefrontoclypeus

Revista Brasileira de Zoologia 23 (4): 915-993, dezembro 2006 


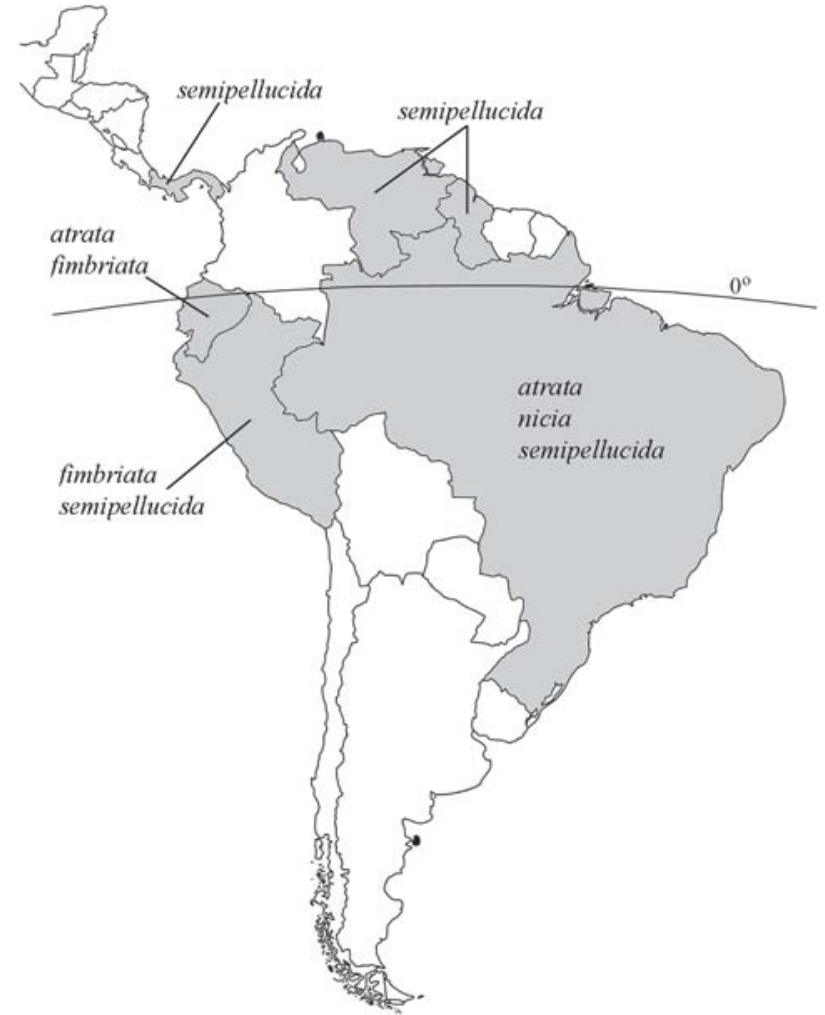

Fig. 361. Known distributions of the semipellucida group species.

with a transverse fold; the forewing with supranumerary crossveins distally; and the aedeagus broad and tubular, without processes.

Description. Color. Head, pronotum, and forewing basal sclerotization pale yellow overall with variable orange or black markings; thoracic venter dark yellow; femora and tibiae reddish brown with yellow markings. Forewing membrane hyaline. Head. Vertex (Fig. 388) width between eyes less than twice height; dorsomedial surface flat; ventrolateral margin carinate; ocelli sessile. Frontoclypeus with transverse fold present, carinate; ventral lobe with lateral margins parallel; apex directed posteriorly in lateral view. Thorax. Pronotum densely punctate; densely covered with short white setae; metopidium high, nearly vertical; median longitudinal carina weakly keeled and acute dorsally; suprahumeral horns well developed, dorsal surface of horn even with dorsal midline, in dorsal view short, acuminate, extending posterolaterally (Fig. 363), dorsal margin convex in anterior view (Fig. 388), with anterior carina. Scutellum with base slightly inflated; apex punctate, with distinct median Iongitudinal groove. Legs: mesothoracic tibia without cucullate setal rows; metathoracic tibia with cucullate setal row I weakly developed. Forewing (Figs 362-363) with sclerotized punctate area in basal two-thirds, reaching vein $\mathrm{R}_{1}$; supranumerary crossveins present; $\mathrm{m}$-cu crossvein connected between first and second vein $\mathrm{M}$ fork.
Male. Abdomen in dorsal view evenly tapered. Lateral plate (Fig. 427) more than half length of subgenital plate; broad, evenly tapered. Subgenital plate without constriction, tapered, uniformly sclerotized without distinct fenestra. Aedeagus (Figs 401402), in lateral view, with dorsal margin weakly convex preapically; broad and tubular; apex slightly narrowed, collarlike; processes absent; gonopore apical. Connective (Fig. 402) with anterior margin strongly emarginate, apices divergent; broadly rounded posteriorly. Style (Figs 401-402) with shank weakly arcuate in lateral view; curved laterad apically, apex flattened, blade-like. Female. Unknown.

Measurements (mm). Male. Body length 7.7; head width 2.5; width across pronotal humeri 2.4; width across tips of horns 2.7; forewing length 6.5.

Material examined. Holotypemale: "COSTA RICA, Cartago/ La Cangreja/ VII-1991/ Col. P. Hanson; Albertson Research/ TOL0003 o; Holotype/ Tolania/ anomala/ Albertson" [USNM].

Distribution. Costa RıCA: Cartago; Collection date: July. Notes. In the phylogenetic analysis (AlberTson \& DietrICH 2005), Tolania anomala (CCC) was consistently sister to all other species of Tolania. This species is unique among Tolania in having the forewing with supranumerary crossveins and placement of this species in a separate genus may eventually be justifiable. T. anomala was included in Tolania here based on a number of shared characteristics, including: the frontoclypeus produced ventrally, the pronotum posterior margin angulate with posterolateral projections, and 3 rows of cucullate setae on the metathoracic tibia.

The specific name 'anomala' translates from Greek as “abnormal, unusual", referring to the reticulate venation unusual in the genus Tolania.

\section{Tolania corcula Albertson, sp. nov. Figs 364-365, 389, 403-404}

Type locality. 62 km SW Ariquemes, near Fazenda Rancho Grande, Rondônia, Brazil [USNM].

Diagnosis. This species differs from other Tolania in having the vertex width less than twice the height; the mesothoracic tibia with cucullate setal row I present; the forewing with 1 m crossvein; and the aedeagus broadened apically, with a pair of preapical processes dorsally and a pair of processes apically.

Description. Color. Head, pronotum, and forewing basal sclerotization yellow overall with red to brown punctures and markings; scutellum reddish basally, apex yellow; thoracic venter red and black; femora brown to black with yellow basally and apically, tibiae and tarsi yellow. Forewing membrane hyaline. Head. Vertex (Fig. 389) width between eyes less than twice height; dorsomedial surfaceflat; ventrolateral margin foliaceous; ocelli sessile. Frontoclypeus ventral lobe with lateral margins broadly expanding ventrally; apex directed posteriorly in lateral view. Thorax. Pronotum densely punctate; densely covered with short white setae; metopidium high, nearly vertical; suprahumeral horns well developed, erect, in dorsal view acumi- 
nate, extending posterolaterally (Fig. 365), with anterior and posterior carinae. Scutellum with base slightly inflated, evenly convex; apex punctate, with distinct median longitudinal groove. Legs: mesothoracic tibia with cucullate setal row I well developed; metathoracic tibia with 11-12 supranumerary cucullate setae between rows II and III. Tymbals large and conspicuous, extending beyond posterior margin of metathorax. Forewing with 1 scrossvein present; 1 r-m crossvein present; $1 \mathrm{~m}$ crossvein present; $\mathrm{m}$-cu crossvein connected between first and second vein $M$ fork. Male. Abdomen in dorsal view evenly tapered. Lateral plate more than half length of subgenital plate; slender and tapered, with membranous digitiform process apically. Subgenital plate with weak subbasal constriction, apical two-thirds tapered; uniformly sclerotized without distinct fenestra. Aedeagus (Figs 403-404) with pair of slender dorsal processes preapically; apex slightly enlarged with pair of slender, convexly curved processes laterally; gonopore apical. Connective (Fig. 404) with anterior margin strongly emarginate, apices divergent; posteriorly produced into short arm. Style (Figs 403-404) with shank straight in lateral view; strongly hooked laterad apically, apex acute. Female. Unknown.

Measurements (mm). Male. Body length 7.2; head width 2.8; width across pronotal humeri 2.5; width across tips of horns 3.2; forewing length 5.8 .

Material examined. Holotype male: “BRAZIL: Rondonia. 62/ km SW Ariquemes, nr./ Fzda. Rancho Grande/ 5-17-X-1993 JE Eger/ MV \& Black Lights; Albertson Research/ TOL-0036 ๙; Holotype/ Tolania/ corcula/ Albertson" [USNM].

Distribution. Brazil: Rondônia. Collection date: October.

Notes. This species resembles members of the opponens group but differs in having a row of cucullate setae on the mesothoracic tibia. The name 'corcula' is from the Latin corculum for "little heart".

\section{Tolania cristata Lethierry, 1890 sp. rev. Figs 366-367, 390}

Tolania cristata Lethierry, 1890: 155. Reinstated from synonymy with T. femoralis Stål.

Type locality. Mérida, Venezuela [MNHN].

Diagnosis. This species differs from other Tolania in having the vertex width more than twice the height, the frontoclypeus with a transverse fold, the mesothoracic tibia with cucullate setal row I weakly developed, and the forewing with $3 \mathrm{r}$-m crossveins.

Description. Color. Head, pronotum, and forewing basal sclerotization yellow overall with variable orange markings; thoracic venter yellow; legs yellow, tibiae with red transverse bands. Forewing membrane hyaline. Head. Vertex (Fig. 390) width between eyes more than twice height; dorsomedial surface flat; ventrolateral margin carinate; ocelli sessile. Frontoclypeus with transverse fold present; ventral lobe with lateral margins parallel; apex directed posteriorly in lateral view. Thorax. Pronotum densely punctate; densely covered with short pale setae; metopidium sloping, low; suprahumeral horns weakly developed, tuberclelike (Figs 366-367). Scutellum with base slightly inflated, evenly convex; apex punctate, with distinct median longitudinal groove. Legs: mesothoracic tibia with cucullate setal row I weakly developed, with 3-4 cucullate setae; metathoracic tibia with supranumerary cucullate setae between rows II and III. Forewing veins with long, pale setae basally and long, black setae on distal half; 1 s crossvein present, basad of distal r-m crossvein; 3 r-m crossveins present; m-cu crossvein connected between first and second vein $M$ fork. Female. [not dissected]. Male. Unknown.

Measurements (mm). Female. Body length 7.5; head width 2.6; width across pronotal humeri 2.2; forewing length 6.3.

Material examined. Lectotype female: "Colonia Tovar/ E. Simon 1.II.88; Venezuela; Tolania/ cristata/ Leth.; type; Holotype/ Tolania/ cristata/ Lethierry/ Michel Boulard det. 1980; Albertson Research/ TOL-0960 o " [MNHN].

Distribution. Venezuela: Mérida. Collection date: February.

Notes. LethieRry (1890) did not designate a holotype for Tolania cristata but in his description noted that 5 specimens were examined. Boulard (pers. comm.) labeled a specimen from Lethierry's collection in the MNHN as "Holotype"; this specimen is here designated lectotype to avoid possible confusion over the identity of the species.

Goding (1927) considered Tolania cristata a synonym of Tolania femoralis Stål, but our examination of the types of both species indicates that both are valid.

Tolania cristata was not included in ALBERTSON \& DIETRICH'S (2005) phylogenetic analysis because only the female is known.

The $\mathrm{m}$ crossvein is fully developed on one forewing of the lectotype and incomplete on the other.

\section{Tolania hamulata Albertson, sp. nov. Figs 368-369, 391, 405-406, 424-425}

Type locality. Encruzilhada, Bahia, Brazil [UFPC].

Diagnosis. This species may be distinguished from other Tolania by the reddish brown coloration, pronotum with bright yellow median longitudinal carina; the vertex width less than twice the height; the mesothoracic tibia with cucullate setal row I present; and the lateral plate with a barblike process apically.

Description. Color. Head, pronotum, and forewing basal sclerotization reddish brown overall with black, red, and yellow markings; pronotum with median Iongitudinal carina bright yellow dorsally, yellow macula extending from posterior suprahumeral horn to lateral margin; scutellum bright yellow with basolateral margins red; thoracic venter reddish brown; femora black with yellow apically, tibiae and tarsi yellow. Forewing membrane brown hyaline, commisural margin black. Head. Vertex (Fig. 391) width between eyes less than twice height; dorsomedial surface flat; ventrolateral margin foliaceous; ocelli stalked. Frontoclypeus ventral lobe with lateral margins parallel; apex directed ventrally in lateral view. Thorax. Pronotum sparsely punctate; dorsal pubescence sparse,

Revista Brasileira de Zoologia 23 (4): 915-993, dezembro 2006 
setae long and erect; metopidium high, nearly vertical; suprahumeral horns well developed, erect, in dorsal view short, triangular, extending laterally (Fig. 369), with anterior and posterior carinae. Scutellum with base slightly inflated, evenly convex; apex without punctures, with distinct median longitudinal groove. Legs: mesothoracic tibia with cucullate setal row I well developed; metathoracic tibia with 5-10 supranumerary cucullate setae between rows II and III. Tymbals Iarge and conspicuous, extending beyond posterior margin of metathorax. Forewing with $1 \mathrm{~s}$ crossvein present; $1 \mathrm{r}$-m crossvein present; $\mathrm{m}-\mathrm{cu}$ crossvein connected between first and second vein $M$ fork. Male. Abdomen in dorsal view with lateral margins roundly tapered between segments III-VI, segments VII and VIII attenuate. Lateral plate (Fig. 424) length more than half length of subgenital plate; in lateral view, abruptly bent dorsad near midlength; apex with process strongly produced and elongate dorsally, barblike ventrally. Subgenital plate (Fig. 425) with abruptly narrowing subbasally, apical two-thirdstapered, apex acute; uniformly sclerotized without distinct fenestra. Aedeagus (Figs 405-406) with apex expanded laterally into pair of large flattened acute processes, convexly curved; gonopore apical. Connective (Fig. 406) with anterior margin strongly emarginate, apices divergent; truncate posteriorly. Style (Figs 405-406) with shank straight in lateral view; strongly hooked laterad preapically; apex long and narrow, with ventral tooth. Female. Unknown.

Measurements (mm). Male. Body length 6.0-6.3; head width 2.2-2.3; width across pronotal humeri 2.0-2.1; width across tips of horns 2.0-2.1; forewing length 5.1-5.4.

Material examined. Holotype male: "Encruzilhada-BA/ Brasil - XI/1972/ Seabra/Alvarenga; Albertson Research/ TOL0812 o"; Holotype/ Tolania/ hamulata/ Albertson" [UFPC]. Paratypes: 4 males, same data [UFPC].

Distribution. BrazlL: Bahia. Collection date: November.

Notes. This species resembles members of the femoralis group in having the vertex relatively narrow and the mesothoracic tibia with a row of cucullate setae, but differs in its relatively slender aedeagus and highly modified lateral plate. The specific name 'hamulata' is from the Latin word hamulus meaning "hook, barb" and refers to the shape of the lateral plate apical process.

\section{Tolania histria Albertson, sp. nov. Figs 370-371, 392, 407-408}

Type locality. $30 \mathrm{~km}$ SW Puerto Maldonado, Río Tambopata Reserve, Madre de Dios, Peru [USNM].

Diagnosis. This species differs from other Tolania in having the vertex width less than twice the height; the mesothoracic tibia with cucullate setal row I present; the forewing with $2 \mathrm{r}$-m crossveins, both distad of vein $\mathrm{R}_{1}$; and the aedeagus, in ventral view, distinctly compressed medially with a pair of flattened acuminate processes apically.

Description. Color. Head, pronotum, and forewing basal sclerotization yellow overall with variable black markings; scutel- lum yellow with basolateral margins red; thoracic venter black; femora black, tibiae and tarsi yellow. Forewing membrane hyaline. Head. Vertex (Fig. 392) width between eyes less than twice height; dorsomedial surface flat; ventrolateral margin foliaceous; ocelli sessile. Frontoclypeus ventral lobe with lateral margins broadly expanding ventrally; apex directed ventrally in lateral view. Thorax. Pronotum densely punctate; densely covered with whitesetae; metopidium high, nearly vertical; suprahumeral horns well developed, erect, in dorsal view long, broad basally, acuminate, extending posterolaterally (Fig. 371), with anterior and posterior carinae. Scutellum with base slightly inflated, evenly convex; apex punctate, median longitudinal groove indistinct. Legs: mesothoracic tibia with cucullate setal row I well developed; metathoracic tibia with 7 supranumerary cucullate setae between rows II and III. Tymbals small, not extending beyond posterior margin of metathorax. Forewing with $1 \mathrm{~s}$ crossvein present; $2 \mathrm{r}$ $m$ crossveins present, both distad of vein $R_{1} ; 1$ m crossvein present; $m$-cu crossvein connected between first and second vein $M$ fork. Male. Abdomen in dorsal view tapered. Lateral plate more than half length of subgenital plate; evenly tapered. Subgenital plates without constriction, lateral margins parallel; uniformly sclerotized without distinct fenestra. Aedeagus (Figs 407-408) distinctly compressed medially in ventral view; apex slightly enlarged, with pair of flattened acuminate processes laterally. Style (Figs 407408), in lateral view, with shank weakly arcuate; apex abruptly bent laterally, acuminate. Female. Unknown.

Measurements $(\mathrm{mm})$. Male. Body length 7.0; head width 2.8; width across pronotal humeri 2.6; width across tips of horns 3.6; forewing length 5.9.

Material examined. Holotype male: "PERU: Madre de Dios/ Rio Tambopata Res./ 30km (air) SW Pto./ Maldonado, 290m./ 12 $50^{\prime} \mathrm{S}, 069^{\circ} 17^{\prime} \mathrm{W}$; Smithsonian Institution/ Canopy Fogging Project/ T.L. Erwin, et al., colls./ 10 Nov 1983 03/03; Albertson Research/ TOL-0513 o; Holotype/ Tolania/ histria/ Albertson" [USNM].

Distribution. Peru: Madre de Dios. Collection date: November.

Notes. The number of crossveins differs between the two forewings in the holotype. The minimum numbers for each crossvein were given in the description. This species was not included in the phylogenetic analysis (AlberTSON \& DIETRICH 2005).

The specific name 'histria' is Latin for "actor".

\section{Tolania humilis (Walker, 1858) \\ Figs 372-373, 393, 409-410, 435}

Centrotus humilis Walker, 1858a: 161.

[Tolania humilis]; Stål, 1862a: 491.

Tolania scutata Stål, 1862b: 36. Syn. nov.

Type locality. Petropolis, Rio de Janeiro, Brazil [BMNH].

Diagnosis. This species differs from other Tolania in having the coloration red-brown to black with a bright yellow median stripe on the scutellum; the vertex width less than twice the height; the mesothoracic tibia with cucullate setal row I 

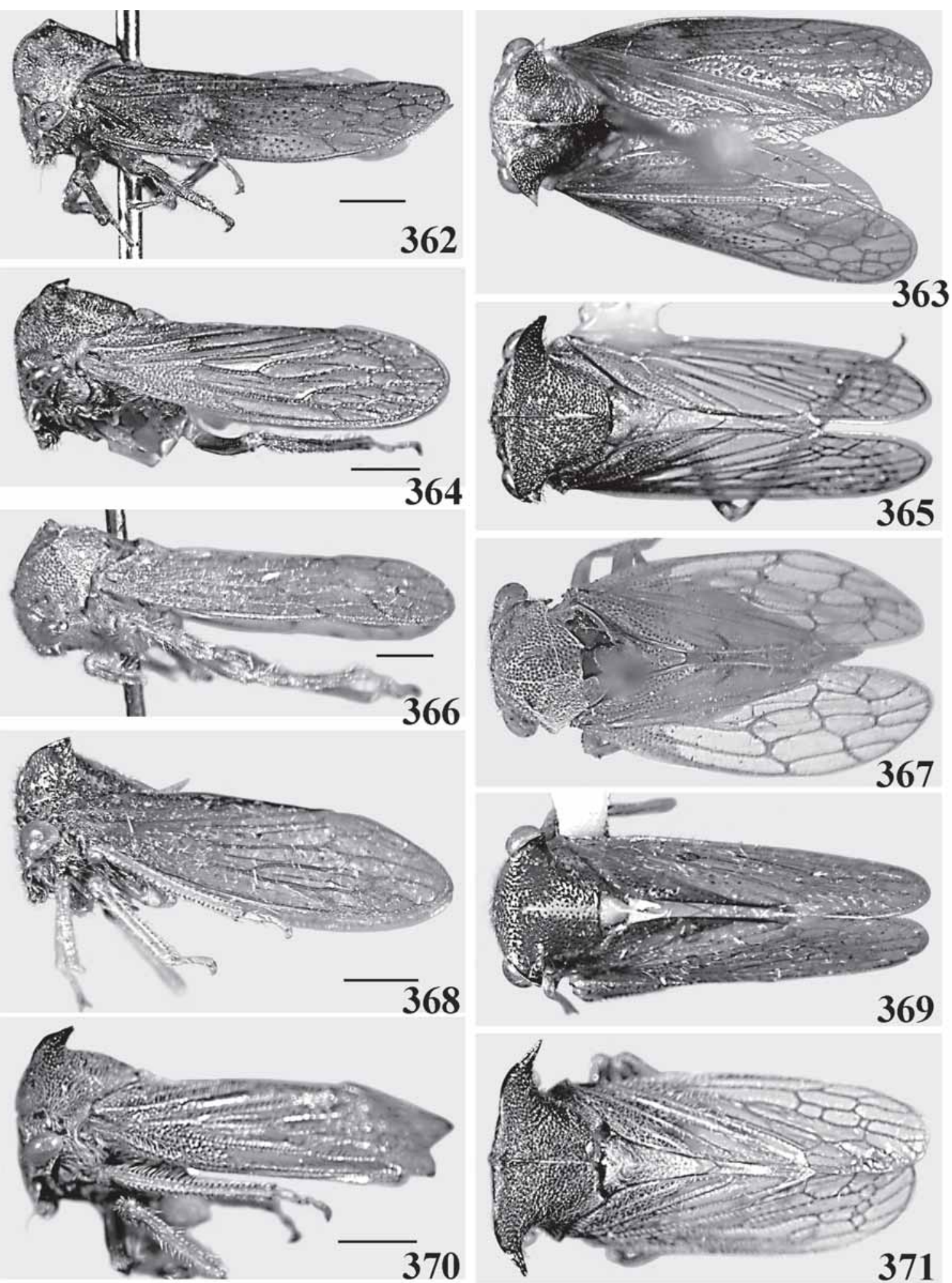

370

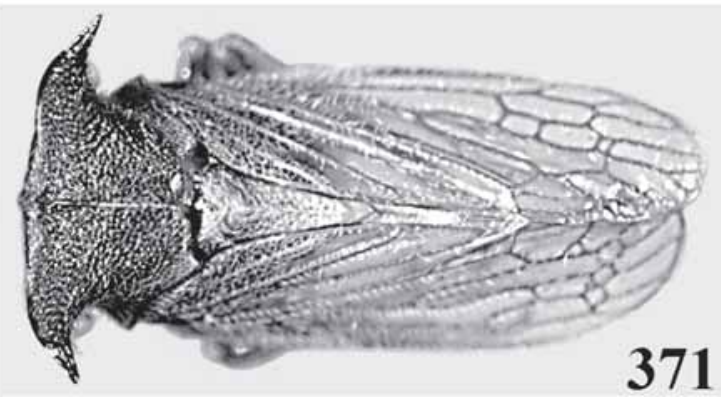

Figures 362-371. Unplaced species adult lateral and dorsal habitus. (362-363) Tolania anomala holotype male; (364-365) T. corcula holotype male; (366-367) T. cristata Lethierry holotype female; (368-369) T. hamulata holotype male; (370-371) T. histria holotype male.

Revista Brasileira de Zoologia 23 (4): 915-993, dezembro 2006 
present and 1-5 cucullate setae in row II; and the aedeagus strongly compressed, broad in lateral view.

Description. Color. Head, pronotum, and forewing basal sclerotization mottled reddish brown and black overall; scutellum bright yellow with reddish brown basolateral margins; thoracic venter black; femora black with apex pale, tibiae orange, tarsi yellow. Forewing membrane orange hyaline. Head. Vertex (Fig. 393) width between eyes less than twiceheight; dorsomedial surface flat; ventrolateral margin foliaceous; ocelli sessile. Frontoclypeus ventral lobe with lateral margins parallel, with median longitudinal carina present; apex directed ventrally in lateral view. Thorax. Pronotum densely punctate; metopidium high, nearly vertical, densely covered with long, white setae; dorsal pubescence sparse; median Iongitudinal carina with or without acute dorsal projection; suprahumeral horns well developed, erect, in dorsal view acuminate, extending laterally (Fig. 373), with anterior and posterior carinae. Scutellum with base slightly inflated, evenly convex; apex without punctures, with distinct median longitudinal groove. Legs: mesothoracic tibia with cucullate setal row I well developed and cucullate setal row II weakly developed, 1-5 cucullate setae; metathoracic tibia with 6-12 supranumerary cucullate setae between rows II and III. Tymbals large and conspicuous, extending beyond posterior margin of metathorax. Forewing basal sclerotization with white setae, veins with dark setae; $1 \mathrm{~s}$ crossvein present; $1 \mathrm{r}$-m crossvein present; $m$-cu crossvein connected between first and second vein M fork. Male. Abdomen in dorsal view tapered. Lateral plate more than half length of subgenital plate, tapered. Subgenital plate with subbasal constriction, apical two-thirds tapered; uniformly sclerotized without distinct fenestra. Aedeagus (Figs 409410) strongly compressed, broad in lateral view; with pair of dorsal toothlike processes preapically; apex with serrate flange laterally; gonopore on ventral preapical surface. Connective(Fig. 410) with anterior margin strongly emarginate, apices divergent; posteriorly produced into short arm. Style (Figs 409-410) with shank straight in lateral view, in dorsal view, distinctly narrowed preapically; apex bent laterally, bladelike. Female. Second valvulae (Fig. 435) broadened near midlength, dorsal margin distinctly angulate; uniformly dentate dorsally.

Measurements. Male/female. Body length 7.1/7.6-8.9; head width 2.7/2.9-3.4; width across pronotal humeri 2.6/2.6-3.2; width across tips of horns 3.4/4.2-5.0; forewing length 6.2/6.5-7.5.

Material examined. Holotype female, Centrotus humilis Walker: "Type; PETROPOLIS/ Feb. 1857./ J. Gray; CENTROTUS HUM ILIS; Albertson Research/ TOL-1013 क " [BM NH]. Lectotype male, Tolania scutata Stål: "Rio Jan; F. Sahlb.; Typus; Albertson Research/ TOL-0995 $\sigma^{\prime \prime}$ [NRS]. Paralectotype female, Tolania scutata Stål: "Rio Jan; Stål; Paratypus; Albertson Research/ TOL0991 \%" [NRS]. Other material: 9 females [BM NH, MZSP, UFPC].

Distribution. Brazıl: Paraná; Rio de Janeiro; São Paulo. Collection dates: January to February and November to De cember.

Notes. Tolania scutata Stål is here considered a junior syn- onym of Tolania humilis (Walker) based on comparison of the type specimens. The holotype of $\mathrm{T}$. humilis is a female. The two specimens of T. scutata in NRS apparently examined by Stål, although labeled "Typus" and "Paratypus", should be treated as syntypes (see notes under T. femoralis and T. fraterna). To fix the identity of T. scutata, we designate the specimen label ed "Typus" as lectotype. The phylogenetic position of this species was poorly resolved by the analysis of ALBERTSON \& Dietrich (2005). The male genitalia most closely resemble those of the femoralis group.

\section{Tolania inornata Albertson, sp. nov. \\ Figs 374-375, 394, 411-412, 429-430, 436}

Type locality. Vila Vera, Mato Grosso, Brazil [UFPC].

Diagnosis. This species differs from other Tolania in having the vertex width more than twice the height; the pronotum without suprahumeral horns or tubercles; the mesothoracic tibia with cucullate setal row I present; the lateral plate auriculate with a large, densely sclerotized process basally; and the style abruptly enlarged, compressed and rounded preapically.

Description. Color. Coloration variable. Head yellow or mottled yellow and red-brown; pronotum mottled yellow, black, and brown, or entirely black; scutellum yellow with basolateral margins orange, or entirely yellow; thoracic venter black and red; femora orange with black longitudinal stripe anteriorly; tibiae and tarsi yellow, tibiae often with 3 transverse red bands. Forewing basal sclerotization brown with pale yellow veins; membrane hyaline. Head. Vertex (Fig. 394) width between eyes more than twice height; dorsomedial surface flat; ventrolateral margin carinate; ocelli sessile. Frontoclypeus lateral lobes distinct; ventral lobe with lateral margins parallel, with median longitudinal carina; apex directed posteriorly in lateral view. Thorax. Pronotum densely punctate; densely covered with short white setae; metopidium sloping, low; suprahumeral horns or tubercles absent (Fig. 375). Scutellum with base slightly inflated, evenly convex; apex punctate, with distinct median longitudinal groove. Legs: mesothoracic tibia with cucullate setal row I well developed; metathoracic tibia with 3-4 supranumerary cucullate setae between rows II and III. Tymbals large and conspicuous, extending beyond posterior margin of metathorax. Forewing with 1 s crossvein present; 1 r-m crossvein present; $m$ cu crossvein connected between first and second vein $M$ fork. Male. Abdomen in dorsal view with lateral margins roundly tapered between segments III - VI, segments VII and VIII attenuate. Lateral plate (Figs 429-430) length more than half length of subgenital plate; divided distally into pair of large strongly divergent lobes, posteroventral margin densely sclerotized. Subgenital plate (Fig.429) with weak subbasal constriction, apical two-thirds tapered; uniformly sclerotized without distinct fenestra; bent dorsally in distal third. Aedeagus (Figs 411-412) slender, tapered; apex slightly enlarged with small lateral processes present or absent; gonopore apical. Connective (Fig. 412) with anterior margin strongly emarginate, horseshoe-shaped; posteriorly produced into distinct stem. Style (Figs 411-412) with

Revista Brasileira de Zoologia 23 (4): 915-993, dezembro 2006 

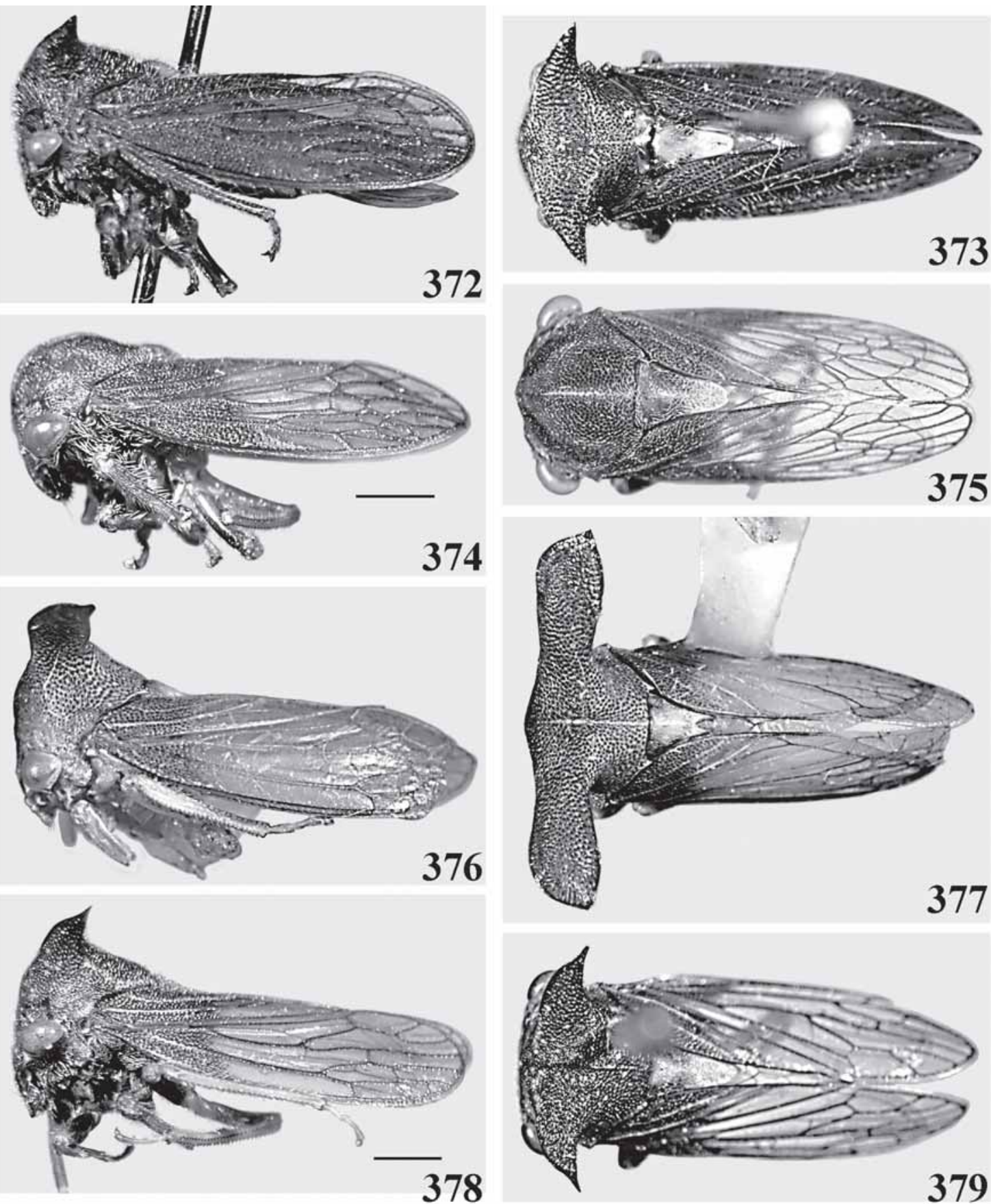

Figures 372-379. Unplaced species adult lateral and dorsal habitus. (372-373) Tolania humilis (Walker) female; (374-375) T. inornata holotype male; (376-377) T. laticornis holotype male; (378-379) T. melantha holotype male.

shank straight in lateral view, abruptly enlarged and compressed preapically, apex round, scaly, with distal constriction, produced dorsoventrally into acute processes. Female. Second valvulae (Fig. 436) broadened near midlength, dorsal margin distinctly angulate; uniformly dentate dorsally.

Measurements (mm). Male/female. Body length 4.5-5.4/ 5.1-6.4; head width 2.2-2.4/2.2-2.6; width across pronotal humeri 1.8-2.1/2.0-2.3; forewing length 3.7-4.6/4.3-5.6.

Revista Brasileira de Zoologia 23 (4): 915-993, dezembro 2006 
Material examined. Holotype male: “VILA VERA-MT/ Brasil- X/1974/ M. Alvarenga; Albertson Research/ TOL-0820 o; Holotype/ Tolania/ inornata/ Albertson" [UFPC]. Paratypes: 1 female, 1 female same data; 1 male, 1 female, "SI NOP_M.Grosso/ Brasil- X/1975/ M. Alvarenga”; 3 females, "RIO BRILHANTEMT/ Brasil-25/I/1971/ À lus-V.O. Becker" [UFPC]. Other material: 14 males, 43 females [CAS, ICCM, MNHN, SHMC, UFPC, USNM, ZIMH].

Distribution. Argentina: Tucuman; Brazil: Mato Grosso, Minas Gerais, Pará, Piauí; Rondônia; EcuAdor: Morona-Santiago; Napo; French Guiana: Cayenne, Paraguay: Cordillera; Peru: Amazonas; Madre de Dios. Collection dates: January to July and October to December.

Notes. In the phylogenetic analysis (AlberTson \& Dietrich 2005), this species was consistently sister to a clade comprising the peltacauda group, and shares with that group the bilobed lateral plates and well developed connective stem. Tolania inornata lacks the paired, often multi-branched aedeagal processes characteristic of the peltacauda group.

The name 'inornata' is Latin for "unadorned" and refers to the absence of suprahumeral horns.

\section{Tolania laticornis Albertson, sp. nov. Figs 376-377, 400, 413-414, 428}

Type locality. $30 \mathrm{~km}$ SW Puerto Maldonado, Río Tambopata Reserve, Madre de Dios, Peru [USNM].

Diagnosis. This species differs from other Tolania in having the vertex width less than twice the height, the suprahumeral horns distinctly spatulate, the mesothoracic tibia with cucullate setal rows I and II present, and the aedeagus with two pairs of processes dorsally.

Description. Color. Head and pronotum orange brown overall with variable yellow markings; scutellum pale yellow; thoracic venter yellow; legs yellow. Forewing basal sclerotization yellow with black punctures; membrane hyaline, costal margin black. Head. Vertex (Fig. 400) width between eyes less than twice height; dorsomedial surface flat; ventrolateral margin foliaceous; ocelli sessile. Frontoclypeus lateral lobes distinct; ventral lobe with lateral margins broadly rounded; apex directed posteriorly in lateral view. Thorax. Pronotum densely punctate; dorsal pubescence sparse, setae short; metopidium high, nearly vertical; dorsum with pit bearing small tubercle; suprahumeral horns well developed, in dorsal view spatulate, concave ventrally, apex acute, extending laterally (Fig. 377), with anterior, posterior, and posteroventral carinae. Scutellum with base slightly inflated, evenly convex; apex without punctures, with distinct depression (Fig. 377). Legs: pro- and mesothoracic tibiae slightly expanded and flattened; mesothoracic tibia with cucullate setal rows I and II well developed; metathoracic tibia with 9 supranumerary cucullate setae between rows II and III. Tymbals small, not extending beyond posterior margin of metathorax. Forewing with $1 \mathrm{~s}$ crossvein present; $1 \mathrm{r}$-m crossvein present; 1 $\mathrm{m}$ crossvein present; $\mathrm{m}$-cu crossvein connected between first and second vein $M$ fork. Male. Abdomen in dorsal view tapered. Lateral plate (Fig. 428) less than half length of subgenital plate; short and robust. Subgenital plate without constriction, tapered; uniformly sclerotized without distinct fenestra. Aedeagus (Figs 413-414) with pair of slender dorsal processes preapically; apex narrow, with short slender processes laterally; gonopore on ventral preapical surface. Connective (Fig. 414) with anterior margin strongly emarginate, apices divergent; broadly rounded posteriorly. Style (Figs 413-414), in lateral view, with shank arcuate basally and gradually descending toward apex; apex footlike, oriented ventrally. Female. Unknown.

Measurements (mm). Male. Body length 6.1; head width 2.3; width across pronotal humeri 2.3; width across tips of horns 5.1; forewing length 4.7.

Material examined. Holotype male: “PERU: Madre de Dios;/ Rio Tambopata Res; 30 air/ km. SW Pto. Maldonado, 290m./ 11-15 XI 1979 J.B. Heppner/ subtropical moist forest; CHD Research/ \#98-0007; Tolania/ sp./ det. C.H. Dietrich, 1998; Albertson Research/ TOL-0123 o; Holotype/ Tolania/ laticornis/ Albertson" [USNM].

Distribution. Peru: Madre de Dios. Collection date: November.

Notes. In the phylogenetic analysis (AlberTSOn \& DIETRICH 2005) this species (BBB) was usually placed as sister to all other Tolania except T. anomala. The specific name 'laticornis' is a combination of the Latin words latus and cornus translating as "broad" and "horn" respectively and refers to the spatulate suprahumeral horns.

\section{Tolania melantha Albertson, sp. nov. Figs 378-379, 395, 415-416}

Type locality. Cerro de la Neblina Basecamp, Amazonas, Venezuela [USNM].

Diagnosis. This species differs from other Tolania in having the vertex width less than twice the height, the mesothoracic tibia with cucullate setal row I present, and the aedeagus with a pair of forked processes apically.

Description. Color. Head, pronotum, and forewing basal sclerotization reddish brown overall with variable yellow and black markings; scutellum yellow with basolateral margins reddish brown; thoracic venter black; femora black, tibiae entirely yellow or yellow with red transverse bands, tarsi yellow. Forewing membrane brown hyaline. Head. Vertex (Fig. 395) width between eyes less than twice height; dorsomedial surface flat; ventrolateral margin carinate; ocelli sessile. Frontoclypeus ventral lobe with lateral margins broadly rounded; apex directed ventrally in lateral view. Thorax. Pronotum densely punctate; densely covered with short white setae; metopidium high, nearly vertical; suprahumeral horns well developed, erect, in dorsal view broad, acuminate apically, extending posterolaterally (Fig. 379), with anterior and posterior carinae. Scutellum with base slightly inflated, evenly convex; apex punctate, with distinct median longitudinal groove. Legs: mesotho- 
racic tibia with cucullate setal row I well developed; metathoracic tibia with 5-9 supranumerary cucullate setae between rows II and III. Tymbals large and conspicuous, extending beyond posterior margin of metathorax. Forewing with $1 \mathrm{~s}$ crossvein present; $1 \mathrm{r}-\mathrm{m}$ crossvein present; $\mathrm{m}$-cu crossvein connected between first and second vein $M$ fork. Male. Abdomen in dorsal view with lateral margins roundly tapered between segments III - VI, segments VII and VIII attenuate. Lateral plate more than half length of subgenital plate; slender, evenly tapered; lightly sclerotized or membranous apically. Subgenital plate with subbasal constriction, apical two-thirdstapered; uniformly sclerotized without distinct fenestra. Aedeagus (Figs 415-416) with pair of lateral processes apically, each divided distally into 2 close-set spines; gonopore on ventral preapical surface. Connective (Fig. 416) with anterior margin strongly emarginate, apices divergent; truncate posteriorly. Style (Figs 415-416) with shank straight in lateral view; apex curved laterally, acute. Female. Second valvulae broadened near midlength, dorsal margin distinctly angulate; uniformly dentate dorsally.

Measurements (mm). Male/female. Body length 7.2-7.3/ 7.9; head width 2.7-3.0/3.2; width across pronotal humeri 2.52.8/2.8; width across tips of horns 3.5-4.1/4.3; forewing length 5.8-6.0/6.8.

Material examined. Holotype male: “VENEZUELA. T.F. Amaz./ Cerro de la Neblina/ Basecamp, 140m./ 050'N, 66¹0'W/ 21-28 February 1985; P.J. \& P.M. Spangler/ R.A. Faitoute/ W.E. Steiner/ collectors; Albertson Research/ TOL-0065 o"; Holotype/ Tolania/ melantha/ Albertson" [USNM]. Paratypes: 2 males, 1 female, same locality [USNM].

Distribution. Venezuela: Amazonas. Collection dates: February to March.

Notes. The relationships of this species were poorly resolved by the phylogenetic analysis of Albertson \& Dietrich (2005). The specific name 'melantha' translates from Greek as "dark", referring to the species' coloration.

\section{Tolania pogonia Albertson, sp. nov. Figs 380-381, 396, 417-418, 431-432}

Type locality. Bogotá, Distrito Capital de Santa Fe de Bogotá, Colombia [BMNH].

Diagnosis. This species differs from other species of Tolania in having the vertex width less than twice the height; the forewing with $2 \mathrm{r}$-m crossveins, both distad of vein $R_{1}$; the subgenital plate with a dense brush of elongate setae; and the aedeagus with a pair of slender processes apically.

Description. Color. Head and pronotum yellow overall with black punctures and black and brown markings; scutellum yellow with basolateral margins brown; thoracic venter yellow and brown; femora black with venter yellow, tibiae yellow to orange with brown markings basally, tarsi yellow to orange. Forewing basal sclerotization yellow to brown; membrane hyaline; commisural margin brown. Head. Vertex (Fig. 396) width between eyes less than twice height; dorsomedial surface dis- tinctly concave; ventrolateral margin foliaceous; ocelli sessile. Frontoclypeus ventral lobe with lateral margins parallel, slightly converging ventrally; apex directed ventrally in lateral view. Thorax. Pronotum deeply punctate; densely covered with short setae; metopidium high, nearly vertical; suprahumeral hornswell developed, dorsal surface of horn even with dorsal midline, in dorsal view short, triangular (Fig. 381), with anterior carina. Scutellum with base slightly inflated, evenly convex; apex punctate, with distinct median longitudinal groove. Legs: mesothoracic tibia without cucullate setal rows; metathoracic tibia with supranumerary cucullate setae present between rows II and III. Forewing with $1 \mathrm{~s}$ crossvein present; 2 r-m crossveins present, both distad of vein $R_{1}$; $m$-cu crossvein connected between first and second vein $M$ fork. Male. Abdomen in dorsal view with lateral margins roundly tapered between segments III - VI, segments VII and VIII attenuate. Lateral plate (Fig. 431) length more than half length of subgenital plate; tapered, with lightly sclerotized or membranous digitiform process apically. Subgenital plate (Figs 431-432) with subbasal constriction, apical two-thirds tapered; uniformly sclerotized without distinct fenestra; with dense brush of elongate setae near midlength of lateral margin. Aedeagus (Figs 417-418), in ventral view, tapered, apex with pair of slender processes laterally; gonopore on ventral preapical surface. Connective (Fig. 418) with anterior margin strongly emarginate, apices divergent; acute posteriorly. Style (Figs 417-418), in dorsal view, with distinct lateral lobesubbasally; apex strongly hooked laterally, acute. Female. Unknown.

Measurements $(\mathrm{mm})$. Male. Body length 6.8; head width 2.5; width across pronotal humeri 2.2; width across tips of horns 2.0; forewing length 5.6.

Material examined. Holotype male: “Bogota; Lindig; Albertson Research/ TOL-0546 ơ, Holotype/ Tolania/ pogonia/ Albertson" [BMNH].

Distribution. Colombia: Distrito Capital de Santa Fe de Bogotá.

Notes. The position of this species was poorly resolved by the phylogenetic analysis of AlberTson \& DieTRICH (2005). The specific name 'pogonia' translates from Greek as "bearded", referring to the long setae on the subgenital plate.

\section{Tolania rideri Albertson, sp. nov.} Figs 382-383, 397, 419-420, 426

Type locality. 62 km SW Ariquemes, near Fazenda Rancho Grande, Rondônia, Brazil [FSCA].

Diagnosis. This species is distinguished from other Tolania in having the vertex width more than twice the height; the mesothoracic tibia with cucullate setal row I present; the forewing with $2 \mathrm{r}-\mathrm{m}$ crossveins present, both distad of vein $\mathrm{R}_{1}$; the lateral plate with a ventral process; and the apex of the aedeagus distinctly flattened with a pair of processes.

Description. Color. Head, pronotum, and forewing basal sclerotization black overall with variable red and yellow markings; scutellum yellow with basolateral margins black; thoracic 

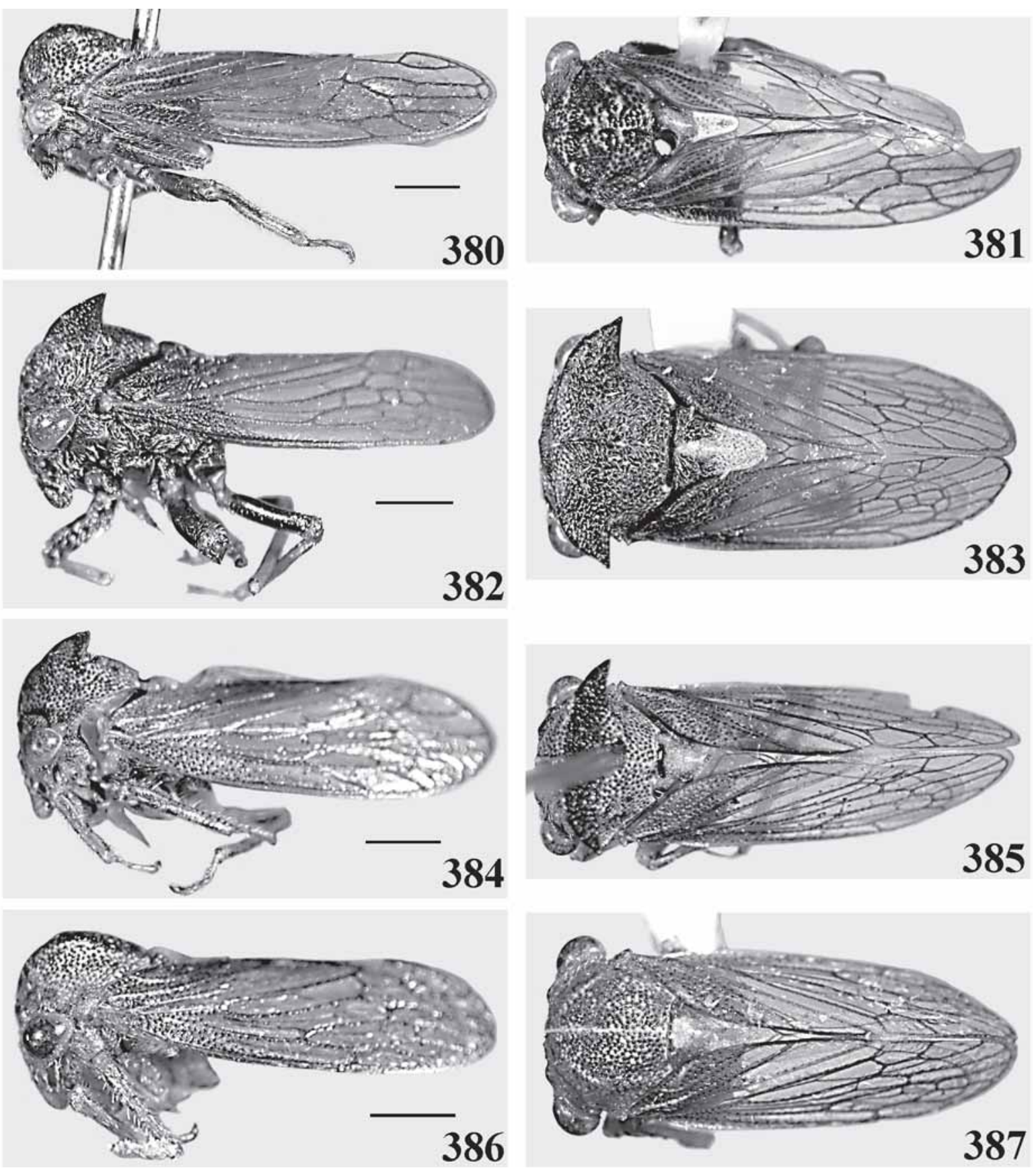

Figures 380-387. Unplaced species adult lateral and dorsal habitus. (380-381) Tolania pogonia holotype male; (382-383) T. rideri holotype male; (384-385) T. taura holotype male; (386-387) T. taura male.

venter black; femora black with yellow apically, tibiae and tarsi yellow. Forewing membrane hyaline. Head. Vertex (Fig. 397) width between eyes more than twice height; dorsomedial surface flat; ventrolateral margin carinate; ocelli sessile. Frontoclypeus ventral lobe with lateral margins parallel, with median
Iongitudinal carina present; apex directed ventrally in lateral view. Thorax. Pronotum densely punctate; densely covered with short setae; metopidium sloping, low; suprahumeral horns well developed, erect, in dorsal view short and broad, apex acute (Fig. 383), with anterior and posterior carinae. Scutellum with base

Revista Brasileira de Zoologia 23 (4): 915-993, dezembro 2006 
slightly inflated, evenly convex; apex punctate, with distinct median longitudinal groove. Legs: mesothoracic tibia with $\mathrm{cu}-$ cullate setal row I well developed; metathoracic tibia with 10 supranumerary cucullate setae between rows II and III. Tymbals large and conspicuous, extending beyond posterior margin of metathorax. Forewing with 1 scrossvein present; 2 r-m crossveins present, both distad of vein $\mathrm{R}_{1}$; $\mathrm{m}$-cu crossvein connected between first and second vein $M$ fork. Male. Abdomen in dorsal view with lateral margins roundly tapered between segments III - VI, segments VII and VIII attenuate; sternite VII with lateral Iongitudinal carina and medial depression; sternite VIII anterior margin distinctly narrow and rounded. Lateral plate (Fig. 426) more than half length of subgenital plate; rectangular, truncate apically; with toothlike process ventrally. Subgenital plate with subbasal constriction, apex broad and rounded bent dorsally in apical third, with distinct preapical process in lateral view; uniformly sclerotized without distinct fenestra. Aedeagus (Figs 419420) with shaft slender, tubular, flattened distad of gonopore; apex, in dorsal view, expanded and round, with pair of slender anteriorly directed lateral processes; gonopore on posterior preapical surface. Connective (Fig. 420) with anterior margin strongly emarginate, horseshoe-shaped; with posterior stem. Style (Figs 419-420) with shank straight in lateral view; apex abruptly bent laterally, flattened and recurved, scaly. Female. Unknown.

Measurements (mm). Male. Body length 6.3; head width 3.0; width across pronotal humeri 2.7; width across tips of horns 3.4; forewing length 4.8 .

Material examined. Holotype male: “BrazIL: Rondônia. 62/ km SW Ariquemes, nr./ Fzda. Rancho Grande/ 6-15-XII1990. DA/ Rider \& JE Eger; collected at light; Albertson Research/ TOL-0093 o; Holotype/ Tolania/ rideri/ Albertson" [FSCA].

Distribution. BRAzIL: Rondônia. Collection date: December.

Notes. The phylogenetic analysis (Albertson \& Dietrich 2005) consistently placed this species within a clade comprising the peltacauda and obtusa groups, but its relationships to other members of the clade were poorly resolved. Tolania rideri resembles the peltacauda group in the shape of the connective and the obtusa group in features of abdominal sternites VII and VIII.

The species is named for Dr. D.A. Rider of North Dakota State University, collector of the holotype and mentor of the first author.

\section{Tolania stria (Cryan and Deitz, 2002)}

Holdgatiella stria Cryan and Deitz, 2002: 876.

Tolania stria; Albertson and Dietrich, 2005: 266.

Type locality. 20 km SE of Azulita, Mérida, Venezuela. [SHMC, deposited on indefinite loan to USNM]

Distribution. Venezuela. Merida. Collection dates: July to August.

Notes. This species was described by Cryan and Deitz (2002) from a singlefemalespecimen and placed in thegenus Holdgatiella based on the absence of suprahumeral horns. The species was transferred to Tolania (Albertson \& Dietrich 2005) based on the illustrations and description of the pronotum, the forewing venation, and the leg chaetotaxy. The holotype was not examined.

\section{Tolania taura Albertson, sp. nov. Figs 384-387, 398-399, 421-423, 433-434}

Type locality. Serra da Bocaina, São Paulo, Brazil [UFPC]. Diagnosis. This species differs from other Tolania in having the vertex width less than twice the height, the mesothoracic tibia with cucullate setal row I weakly developed, the subgenital plate distinctly folded, and the aedeagus with irregularly serrate lateral preapical flange.

Description. Color. Head, pronotum, and forewing basal sclerotization yellow overall with black markings; scutellum yellow; thoracic venter black with yellow markings; femora and tibiae yellow with variable black markings. Forewing membrane hyaline, commisural margin black. Head. Vertex (Figs 398-399) width between eyes less than twice height; dorsomedial surface flat; ventrolateral margin carinate; ocelli sessile. Frontoclypeus ventral lobe with lateral margins parallel; apex directed ventrally in lateral view. Thorax. Pronotum densely punctate; dorsal pubescence sparse; metopidium sloping, low; suprahumeral horn development polymorphic (weakly developed and tuberclelike, Fig. 387, or well developed, Fig. 385); elevation and shape in dorsal view polymorphic. Scutellum with base slightly inflated, evenly convex; apex with few punctures, with distinct median Iongitudinal groove. Legs: mesothoracic tibia with cucullate setal row I weakly developed, 5 or more cucullate setae; metathoracic tibia with 8-10 supranumerary cucullate setae between rows II and III. Tymbals large and conspicuous, extending beyond posterior margin of metathorax. Forewing with 1 scrossvein present; $1 \mathrm{r}$-m crossvein present; $\mathrm{m}$-cu crossvein connected between first and second vein $\mathrm{M}$ fork. Male. Abdomen in dorsal view with lateral margins roundly tapered between segments III-VI, segments VII and VIII attenuate; sternite VII with lateral Iongitudinal carina and medial depression; sternite VIII anterior margin distinctly narrow and rounded. Lateral plate (Fig. 433) morethan half length of subgenital plate; slender, weakly tapered, apex truncate with sclerotized posteroventral projection. Subgenital plate (Figs 433-434) with subbasal constriction, apex in ventral view broad and rounded; with densely sclerotized lateral ridge (with setae) and median basal fenestra (glabrous); bent dorsally in apical third with densely sclerotized ventral projection. Aedeagus (Figs 421-423) slender with irregularly serrate lateral preapical flange; gonopore on ventral preapical surface. Connective (Fig. 422) with anterior margin weakly emarginate, apices acuminate; broadly rounded posteriorly. Style (Figs 421-422) with shank straight in lateral view; apex abruptly bent laterally, bladelike. Female. Unknown.

Measurements (mm). Male. Body length 5.6-6.3; head width 2.3-2.8; width across pronotal humeri 2.0-2.4; width across tips of horns 2.3-2.9; forewing length 4.6-5.5. 

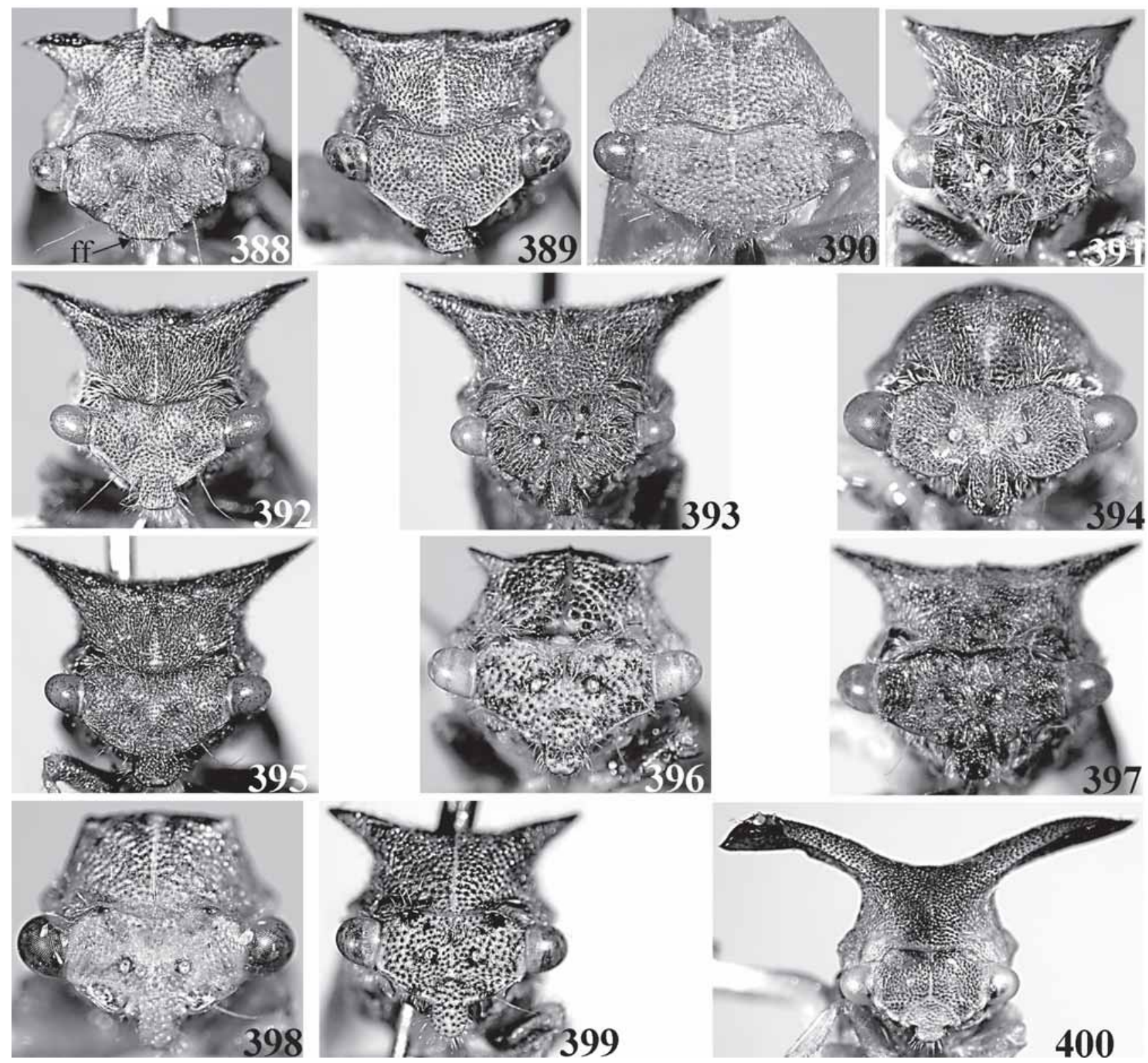

Figures 388-400. Unplaced species adult anterior habitus. (388) Tolania anomala holotype male; (389) T. corcula holotype male; (390) T. cristata Lethierry holotype female; (391) T. hamulata holotype male; (392) T. histria holotype male; (393) T. humilis (Walker) female; (394) T. inornata holo

Material examined. Holotype male: "Sa. BOCAINA-SP./ Brasil - XI-1970/ M. Alvarenga leg.; Albertson Research/ TOL-0831 o; Holotype/ Tolania/ taura/ Albertson” [UFPC]. Paratypes: “BRAZIL/ Guanabara,/ Rio de Janeiro/ X: 1963; M. Alvarenga,/ coll.; Albertson Research/ TOL-0034 ơ" [USNM]; “ENCRUZILHADABA/ Brasil - XI/1972/ Seabra/Alvarenga; Albertson Research/ TOL0819 o" [UFPC]. Other material: 1 male [UFPC].

Distribution. Brazıl: Bahia; Rio deJaneiro; São Paulo. Col- lection dates: October to November.

Notes. The phylogenetic analysis (Albertson \& Dietrich 2005) consistently placed this species within a clade comprising the peltacauda and obtusa groups, but its relationships to other members of the clade were poorly resolved. Tolania taura resembles the obtusa group in features of abdominal sternites VII and VIII.

The name 'taura' is Greek for "bull".

Revista Brasileira de Zoologia 23 (4): 915-993, dezembro 2006 


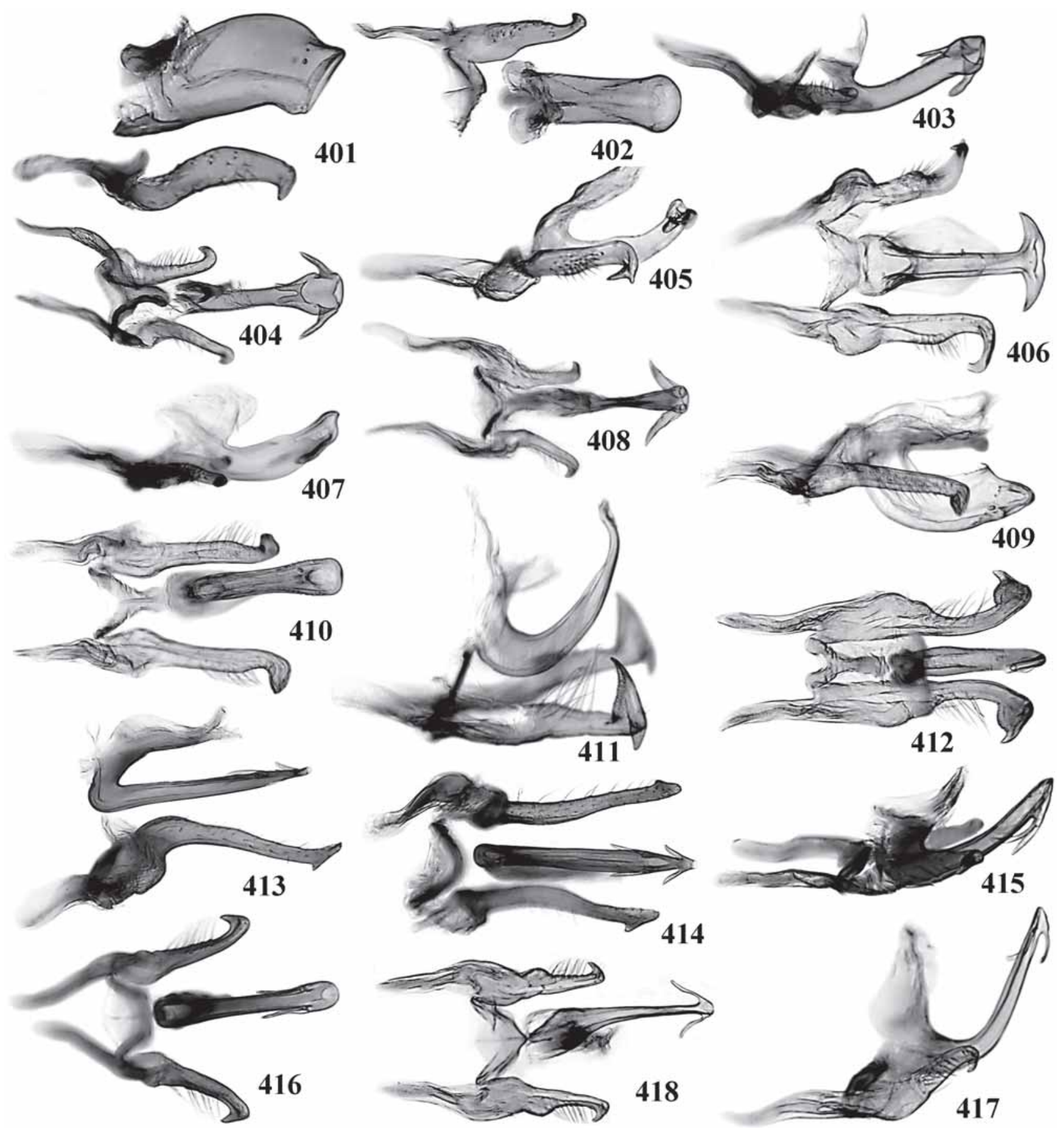

Figures 401-410. Unplaced species males. (401-402) T. anomala holotype: (401) genitalia, lateral view; (402) same, dorsal view; (403404) T. corcula holotype: (403) genitalia, lateral view; (404) same, dorsal view; (405-406) T. hamulata holotype: (405) genitalia, lateral view; (406) same, ventral view; (407-408) T. histria holotype: (407) genitalia, lateral view; (408) same, dorsal view; (409-410) T. scutata Stål holotype (equals T. humilis): (409) genitalia, lateral view; (410) same, ventral view; (411-412) Tolania inornata holotype: (411) genitalia, lateral view; (412) same, dorsal view; (413-414) T. laticornis holotype: (413) genitalia, lateral view; (414) same, ventral view; (415-416) T. melantha paratype: (415) genitalia, lateral view; (416) same, ventral view; (417-418) T. pogonia holotype: (417) genitalia, lateral view; (418) same, ventral view.

Revista Brasileira de Zoologia 23 (4): 915-993, dezembro 2006 


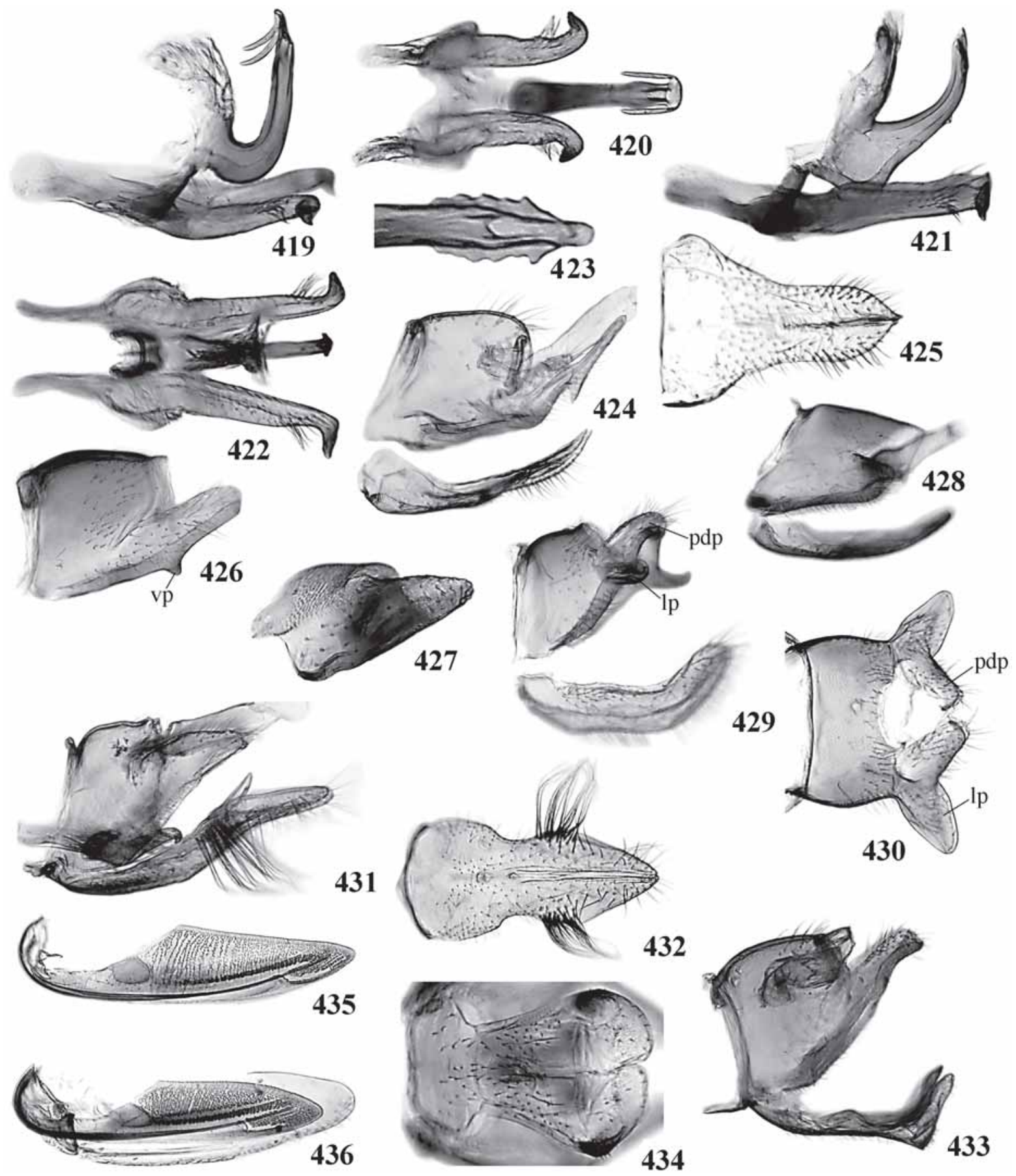

Figures 419-428. Unplaced species. (419-434). Males: (419-420) Tolania rideri holotype: (419) genitalia, lateral view; (420) same, ventral view; (421-423) T. taura paratype: (421) genitalia, lateral view; (422) same, dorsal view; (423) aedeagus apex, posterior view; (424-425) T. hamulata holotype: (424) pygofer, lateral view; (425) subgenital plate; (426) T. rideri holotype, pygofer, lateral view; (427) T. anomala holotype, pygofer, lateral view; (428) T. laticornis holotype, pygofer, lateral view. vp: Ventral process; (429-430) Tolania inornata holotype: (429) pygofer, dorsal view; (430) same, lateral view; (431-432) T. pogonia holotype: (431) pygofer, lateral view; (432) subgenital plate; (433-434) T. taura paratype: (433) pygofer, lateral view; (434) subgenital plate; (435-436) females: (435) T. humilis (Walker), second valvulae; (436) T. inornata, second and third valvulae. Ip: Lateral plate; pdp: posterodorsal process. 


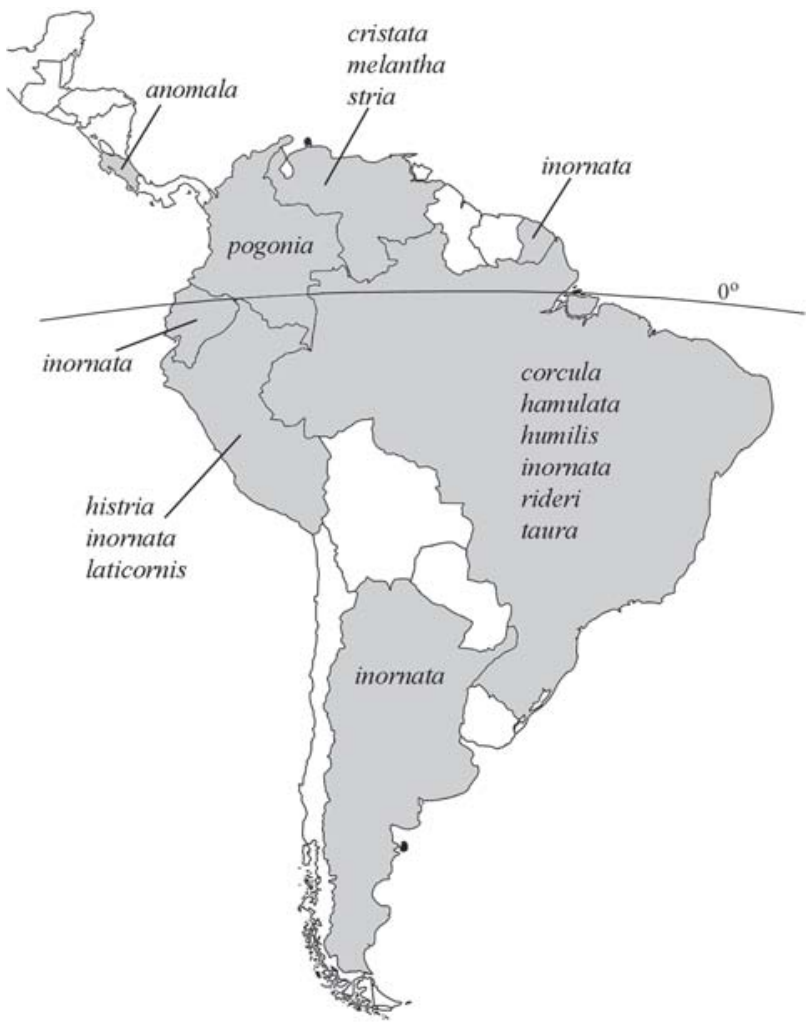

Figure 437. Known distributions of the unplaced species.

\section{SPECIES OF UNCERTAIN POSITION}

Tolania armata Goding, 1927a: 71. Based on illustrations by Stoll (1788).

Centrotus felinus Germar, 1835: 259. Type specimens not located.

Centrotus obscurus Germar, 1835: 258. Type specimens not located.

Centrotus fasciatus Walker, 1858: 161 (=Tolania walkeri Goding, 1931). Type apparently lost.

\section{CONCLUDING REMARKS}

With 69 valid species, Tolania currently ranks as the most speciose New World genus of Membracidae. Given that many species are known from few or single individuals and that vast areas of Neotropical rainforest have yet to be sampled, the number of extant species of Tolania is likely to be much higher. Recent sampling by insecticidal fogging of lowland rainforest canopies has proven especially effectivein the discovery of new Tolania species. Fogging at three localities Peru and Ecuador yielded 21 species, 14 of which (nine in Ecuador, five in Peru) were either not collected previously, or only collected in those countries by fogging. Fogging of rainforest canopies in other parts of the Neotropical region might be expected to yield similar results.
A few interesting biogeographic patterns become apparent when viewing the known distributions within a phylogenetic context (cf. cladogram of AlberTSON \& DietRICH 2005). The genus is most diverse in Brazil, with 24 species, and species of the fasciata and femoralis groups are known only from Brazil. The malefica group and its sister, the hispida group, are recorded from Central America and northwestern South America. Both the obtusa group and the semipellucida group are widespread throughout most of northern South America and range into Central America. The peltacauda group is apparently restricted to Brazil except for the most unusual member of the group, $\mathrm{T}$. thyrea, recorded from French Guiana. The opponens group is widespread but is most diverse in Ecuador and Peru (12 of 17 species found in these two countries). The dira group is most diverse in Ecuador and Peru, but T. macaria is only recorded from Colombia and Venezuela; and T. dira, sister to the rest of the group, is found in the Guianas.

This apparent tendency for monophyletic groups of Tolania species to be associated with particular regions suggests that large-scale vicariance may have driven some early divergences within the genus, and that processes operating on more local scales were responsible for more recent speciation. These observations must be regarded as preliminary, given the sparse material available for most species and, consequently, the very incomplete knowledge of species distributions.

Some Tolania species, such as T. obtusa and T. periculosa, for which specimens are available from multiple localities, exhibit a high degree of polymorphism in coloration and in the aedeagal processes. Some of the populations represented by these specimens may eventually be found to be distinct species. More collecting is needed to improve knowledge of the diversity of the genus, to document host plants, and to elucidate more completely the geographic ranges of species.

\section{ACKNOWLEDGMENTS}

We thank L.L. Deitz, S.H. McKamey, J.R. Cryan, and R. Rakitov and two anonymous referees for their insights and suggestions. We are also indebted to the following people for the loan of specimens in their care: C.B. Barr (Essig Museum of Entomology), M. Boulard (Museum National d'Histoire Naturelle), E. Cancello (Museu deZoologia), L. L. Deitz and R. L. Blinn (North Carolina State University), M. Dorn (Martin-Luther-Universität), P.H. Freytag (University of Kentucky), K.G.A. Hamilton (Canadian National Collection of Insects), S.H. McKamey and D.G. Furth (National Museum of Natural History), F.W. Mead and S. Halbert (Florida State Collection of Arthropods), N.D. Penny (California Academy of Sciences), A.M. Sakakibara (Universidade Federal do Paraná), R.T. Schuh (American Museum of Natural History), C. Smith (Georgia Museum of Natural History), $\mathrm{H}$. Strümpel (Zoölogisches Institut und Zoölogisches), B. Viklund (Naturhistorisches Riksmuseet), M.D. Webb (Natural History Museum, London), Thomas K. Wood, C.W. Young (Carnegie Museum of Natural History), and M. Zumbado (Instituto 
Nacional de Biodiversidad). D. M. Takiya translated the abstract into Portuguese. The research was supported in part by National Science Foundation Partnerships for Enhancing Expertise in Taxonomy (PEET) Grants DEB-9978026 and 0529679.

\section{REFERENCES}

AlberTson, J.L. \& C.H. DietriCh. 2005. Systematics and phylogeny of the Neotropical treehopper subfamily Nicomiinae (Hemiptera, Membracidae). Revista Brasileira de Zoologia, Curitiba, 22 (1): 231-283.

CRYAN, J.R. \& L.L. DeitZ. 2002. Enigmatic treehopper genera (Hemiptera: Membracidae): Deiroderes Ramos, Holdgatiella Evans, and Togotolania, new genus. Proceedings of the Entomological Society of Washington, Washington, 104: 868-883.

DeITZ, L.L. 1975. Classification of the higher categories of the New World treehoppers (Homoptera: Membracidae). North Carolina Agricultural Experiment Station Technical Bulletin, Raleigh, 225: 1-177.

DietRich, C.H. \& L.L. Deitz. 1993. Superfamily Membracoidea (Homoptera: Auchenorrhyncha). II. Cladistic analysis and conclusions. Systematic Entomology, London, 18: 297-311.

Dietrich, C.H.; S.H. McKamey \& L.L. Deitz. 2001. Morphologybased phylogeny of the treehopper family Membracidae (Hemiptera: Cicadomorpha: Membracoidea). Systematic Entomology, London, 26: 213-239.

Fowler, W.W. 1896. Order Rhynchota. Suborder HemipteraHomoptera. (Continued). Biologia Centrali-Americana, London, 2: 161-168.

FunkHouser, W.D. 1927. Membracidae. General Catalogue of the Hemiptera, Northampton, 1: 1-581.

Germar, E.F. 1835. Species Membracidum Musae. E.F. Germari. Silbermann Revue Entomologique, Strasbourg, 3: 223-262.

Goding, F.W. 1927. Revision of the Membracidae of South America and Antilles. Journal of the New York Entomological Society, New York, 35: 183-191.

Goding, F.W. 1931. Synonymical notes on Membracidae. II.
Annals of the Entomological Society of America, College Park, 24: 935-936.

LethieRRY, L.F. 1890. VoyagedeM.E. Simon au Venezuela (Decembre 1887 - Avril 1888) 9e memoire Hemipteres Homopteres. Annales de la Société Entomologique de France, Paris, 10: 147-160.

McKameY, S.H. 1998. Taxonomic catalogue of the Membracoidea (exclusive of leafhoppers); second supplement to Fascicle 1-Membracidae of the General Catal ogue of the Hemiptera. Memoirs of the American Entomological Institute, Gainesville, 60: 1-377.

Metcalf, Z.P. \& V. WADE. 1965. General Catalogue of the Homoptera. A Supplement to Fascicle I - Membracidae of the General Catalogue of the Hemiptera. Membracoidea. Raleigh, North Carolina State University. I-VI: 1-1552.

STÅL, C. 1858. Nagra nya genera och arter bland Hemiptera. Öfversigt af Kongliga Vetenskaps-Akademiens Förhandlingar, Stockholm, 15: 248-450.

STÅL, C. 1862a. Synonymiska och systematiska anteckningar öfver Hemiptera. Öfversigt af Kongliga Svenska VetenskapsAkademiens Förhandlingar, Stockholm, 19: 479-504.

STÅL, C. 1862b. Bidrag till Rio Janeiro-Traktens Hemipter-Fauna. II. Kongliga Vetenskaps- Akademiens Handlingar, Stockholm, 3(6): 1-75.

StolL, C. 1788. Cigales. Amsterdam, [1788]: 1-124.

WALKER, F. 1852. List of the Specimens of Homopterous Insects in the Collection of the British Museum. Part 4, London, 1852: 908-1188.

W ALKER, F. 1858a. Supplement. List of the Specimens of Homopterous Insects in the Collection of the British Museum. London, British Museum, 307p.

W ALKER, F. 1858b. Addenda. List of the specimens of Homopterous insects in the collection of the British Museum, London, [1858]: 308-369.

Wood, T.K. 1984. Life history patterns of tropical membracids (Homoptera: Membracidae). Sociobiology, Chico, 8: 299344.

Received in 20.III.2006; accepted in 17.XI.2006. 